\title{
Effect of Initial Shear Stress Direction and Stress History on the Undrained Behaviour of Sands under Triaxial Loading
}

\author{
Submitted by \\ Mohammad Shahsavari Goughari \\ B. Sc., Shahid Bahonar University of Kerman, Iran (2008)
}

A thesis submitted to the Faculty of Graduate and Postdoctoral Affairs in partial fulfillment of the requirements for the degree of

Master of Applied Science

in

Civil Engineering

Department of Civil and Environmental Engineering

Carleton University

Ottawa, Ontario

(C) 2012, Mohammad Shahsavari Goughari

The Master of Applied Science in Civil Engineering Program is a joint program with University of Ottawa, administrated by the Ottawa-Carleton Institute of Civil Engineering 
Library and Archives

Canada

Published Heritage

Branch

395 Wellington Street

Ottawa ON K1A ON4

Canada
Bibliothèque et

Archives Canada

Direction du

Patrimoine de l'édition

395 , rue Wellington

Ottawa ON K1A ON4

Canada
Your file Votre référence

ISBN: 978-0-494-93495-1

Our file Notre référence

ISBN: 978-0-494-93495-1
NOTICE:

The author has granted a nonexclusive license allowing Library and Archives Canada to reproduce, publish, archive, preserve, conserve, communicate to the public by telecommunication or on the Internet, loan, distrbute and sell theses worldwide, for commercial or noncommercial purposes, in microform, paper, electronic and/or any other formats.

The author retains copyright ownership and moral rights in this thesis. Neither the thesis nor substantial extracts from it may be printed or otherwise reproduced without the author's permission.
AVIS:

L'auteur a accordé une licence non exclusive permettant à la Bibliothèque et Archives Canada de reproduire, publier, archiver, sauvegarder, conserver, transmettre au public par télécommunication ou par l'Internet, prêter, distribuer et vendre des thèses partout dans le monde, à des fins commerciales ou autres, sur support microforme, papier, électronique et/ou autres formats.

L'auteur conserve la propriété du droit d'auteur et des droits moraux qui protege cette thèse. $\mathrm{Ni}$ la thèse ni des extraits substantiels de celle-ci ne doivent être imprimés ou autrement reproduits sans son autorisation.
In compliance with the Canadian Privacy Act some supporting forms may have been removed from this thesis.

While these forms may be included in the document page count, their removal does not represent any loss of content from the thesis.
Conformément à la loi canadienne sur la protection de la vie privée, quelques formulaires secondaires ont été enlevés de cette thèse.

Bien que ces formulaires aient inclus dans la pagination, il n'y aura aucun contenu manquant. 


\begin{abstract}
An experimental study of the monotonic and cyclic response of Fraser River sand under triaxial loading has been conducted. Effects of a wide range of initial states characterized by the magnitude and the direction of the initial static shear stress level, loading mode, relative density, and stress history are covered. The main objective of the cyclic tests was to assess the effect of initial state, especially the direction of the initial static shear stress and OCR on correction factor $K_{\alpha}$.

Undrained monotonic response of Fraser River sand is highly dependent on both the direction and the magnitude of the initial static shear. It has been shown that ignoring this factor would lead to unsafe designs when the monotonic load is of extension type. On the other hand, higher OCR values lead to a more dilative response, and cyclic resistance increases significantly with OCR. A 'negative' initial static shear stress significantly reduces the cyclic resistance. The $K_{\alpha}$ correction factor is influenced by the direction of the initial static shear stress and OCR level. The results indicate that, ignoring the effect of the direction of the initial static shear stress and OCR in $K_{\alpha}$ could lead to unsafe designs.
\end{abstract}




\section{ACKNOWLEDGEMENTS}

First and foremost I offer my sincerest gratitude to my supervisor, Dr. Siva Sivathayalan, who has supported me throughout my thesis with his patience and knowledge. I attribute the level of my Masters degree to his encouragement and effort and without him this thesis, too, would not have been completed or written.

Friends are always a huge part of any endeavor in life, and I have been truly blessed throughout my years at Carleton University. The many hours spent on working, talking, playing and laughing with my friends and colleagues got me through many rocky patches and truly made both life and studies much richer. I would like to express my sincere thanks to Kourosh Khosravi for his supports and encouragements from the very first days of my studies at Carleton University.

During my master's studies, I have earned the knowledge and experience in the advanced geotechnical laboratory in Carleton University. I would like to acknowledge the laboratory technicians, Stanley, Pierre, Jason, and Kenneth for their great support to do my lab experiments.

Most importantly, I would like to express my deepest gratitude to my parents and my lovely wife Parnia for their continuous support, patience and encouragement throughout my studies and life. 


\section{TABLE OF CONTENTS}

ABSTRACT

ACKNOWLEDGEMENTS .............................................................................................................. iii

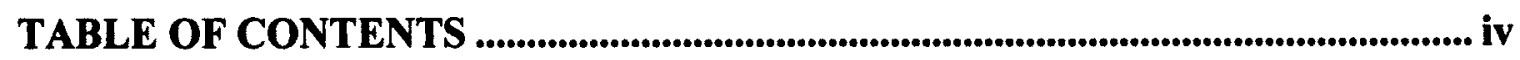

LIST OF FIGURES ...................................................................................................... viii

LIST OF TABLES ......................................................................................................... xvi

LIST OF SYMBOLS ................................................................................................................... xvii

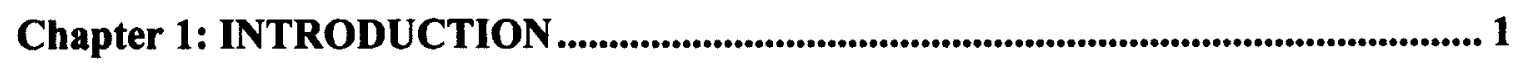

1.1 LIQUEFACTION PHENOMENON .......................................................... 1

1.2 LIQUEFACTION SUSCEPTIBILITY ....................................................... 3

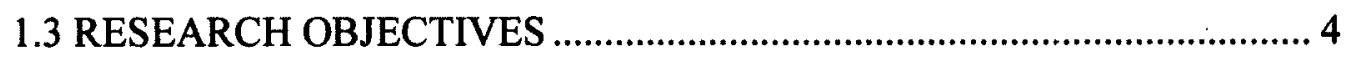

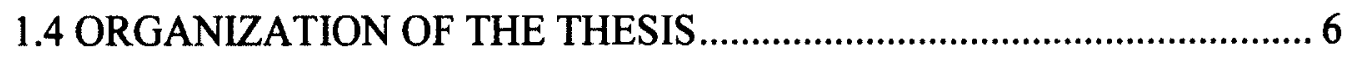

Chapter 2: LITERATURE REVIEW ............................................................................................ 7

2.1 LIQUEFACTION PHENOMENON ......................................................

2.2 UNDRAINED MONOTONIC LOADING BEHAVIOUR ......................... 8

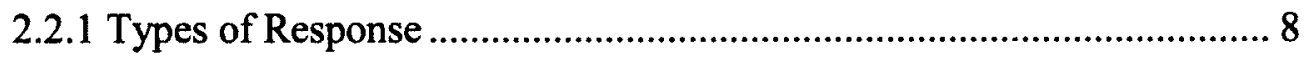

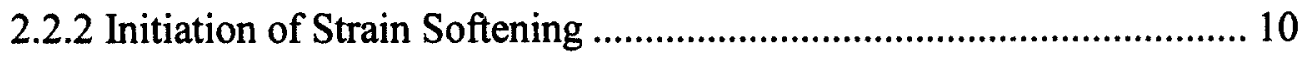

2.2.3 Phase Transformation and Steady State................................................ 11

2.2.4 Ultimate Failure Line ...................................................................... 12 
2.2.5 Factors of Influence

2.2.6 Effect of Overconsolidation ................................................................. 15

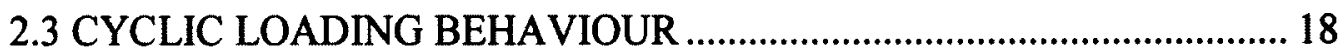

2.3.1 Mechanisms of Strain Development..................................................... 18

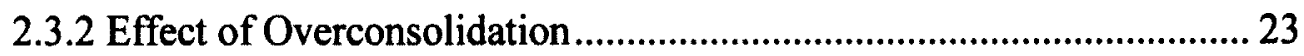

2.3.3 Effect of Confining Stress Level........................................................ 25

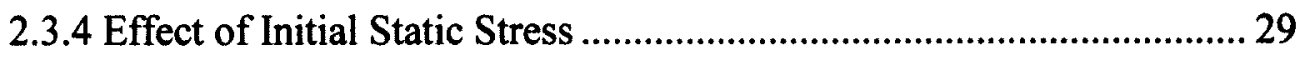

2.4. POST LIQUEFACTION RESPONSE ..................................................... 32

2.5. REVIEW OF TRIAXIAL APPARATUS................................................. 34

Chapter 3: EXPERIMENTAL WORK .......................................................................... 38

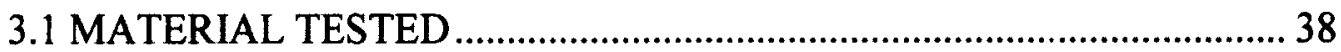

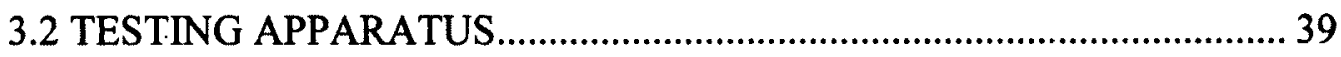

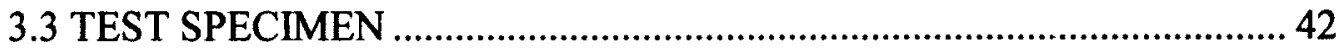

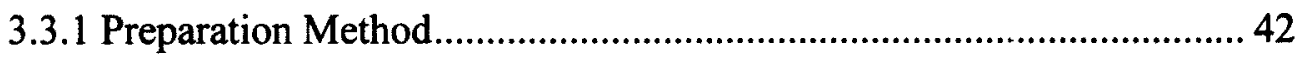

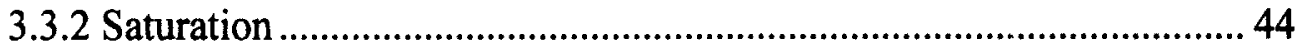

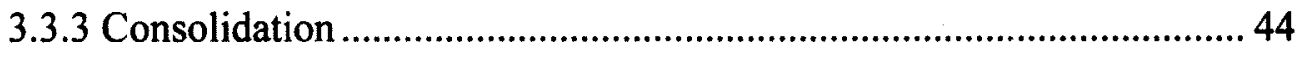

3.3.4 Monotonic Loading............................................................................ 50

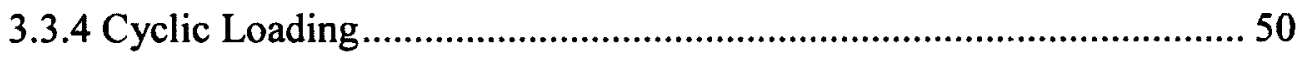

3.3.5 Post Cyclic Loading ........................................................................... 51 


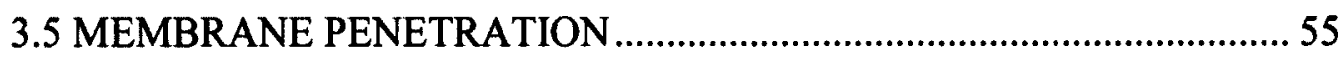

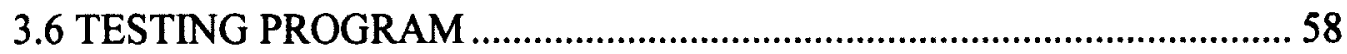

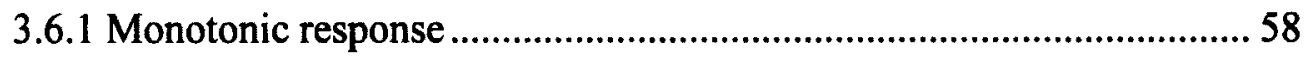

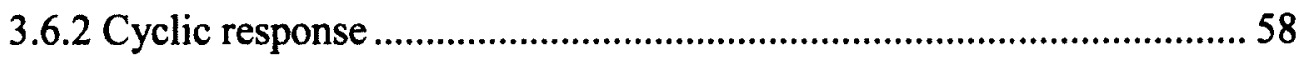

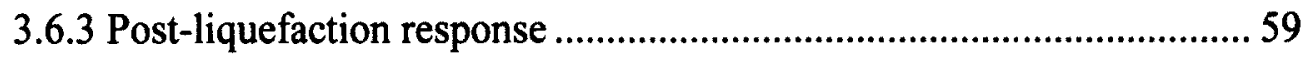

Chapter 4: EFFECT OF STRESS HISTORY AND INITIAL STRESS
CONDITIONS ON LIQUEFACTION POTENTIAL ..........................................................60

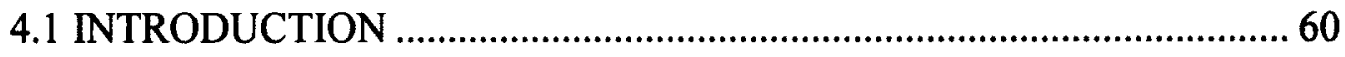

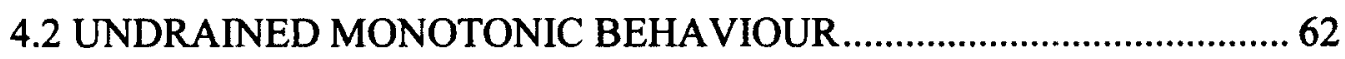

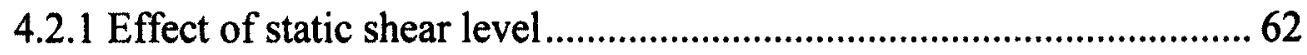

4.2.2 Effect of overconsolidation.................................................................. 73

4.2.3 Triggering of contractive deformation................................................... 79

4.2.4 Phase transformation and steady state ................................................ 83

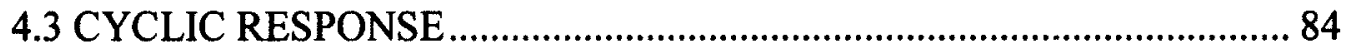

4.3.1 Behaviour dependency on Overconsolidation ..................................... 85

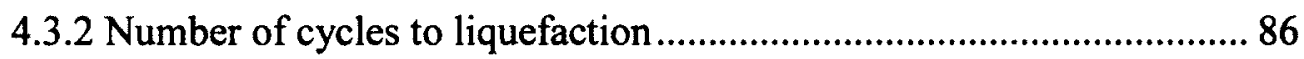

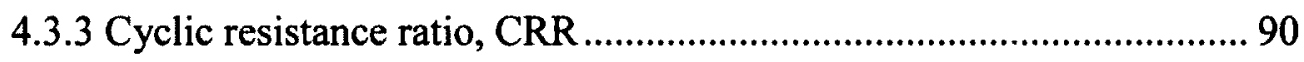

4.3.4 Effect of initial static shear stress level................................................ 95

4.3.4.1 Effect of static shear level on cyclic resistance ratio (CRR) ........ 97 
5.1 MONOTONIC TRIAXIAL TESTS

5.2 CYCLIC RESPONSE 125

5.3 POST LIQUEFACTION BEHAVIOUR 126 


\section{LIST OF FIGURES}

Figure 2.1 Undrained simple shear response of reconstituted and undisturbed samples of two sands (After Vaid and Chern, 1985) ............................................... 9

Figure 2.2 Undrained static behaviour at different confining stress levels and a constant relative density (After Thomas, 1992)...................................... 13

Figure 2.3 Effect of different sample preparation methods on the undrained simple shear response (After Vaid et al. 1999) 15

Figure 2.4 Undrained simple shear response of reconstituted and undisturbed samples of two sands (After Vaid et al. 1999) 16

Figure 2.5 Effect of overconsolidation on the stress path in triaxial (a) compression (b) extension (After Ishihara and Okada, 1978) 17

Figure 2.6 True liquefaction and type of response under cyclic loading (After Vaid and Chern 1985) 20

Figure 2.7 Limited liquefaction type of response under cyclic loading (After Vaid and Chern 1985) 21

Figure 2.8 Cyclic mobility type of response under cyclic loading (After Vaid and Chern 1985) 22

Figure 2.9 Effect of OCR on cyclic resistance of sand at fixed $K_{0}$ values(After Ishihara and Takatsu, 1979) 24

Figure 2.10 Relationship between cyclic resistance and OCR (After Ishihara and Takatsu, 1979) 24 
Figure 2.11 Relationship between effective confining pressure and $K_{\sigma}$ correction factor (After Seed and Harder 1990) 26

Figure 2.12 $K_{\sigma}$ correction factor recommended for engineering practice (After Youd et al., 2001) 27

Figure 2.13 $K_{\sigma}$ correction factor (After Boulanger and Idriss, 2004) 28

Figure 2.14 $K_{\sigma}$ correction factor obtained from simple shear and triaxial test results (After Vaid and Sivathayalan, 1996) 28

Figure 2.15 Effect of overconsolidation ratio (OCR) on $K_{\sigma}$ (a) Loose (b) Dense (After Manmatharajan, 2011) 29

Figure 2.16 Range of $K_{\alpha}$ correction factor at different relative density levels (After Sivathayalan and $\mathrm{Ha}, 2011$ ) 31

Figure 2.17 Stress-strain response of tailings sand (After Kuerbis, 1989)... 33

Figure 2.18 Post-cyclic stress-strain response (After Vaid and Thomas, 1995) ......... 34

Figure 2.19 Stress conditions and Mohr's circle of triaxial test (a) Isotropically consolidated (b) Anisotropically consolidated 37

Figure 3.1 Particle size distribution of Fraser River sand 39

Figure 3.2(a) Schematic diagram of the triaxial device in this study (After Logeswaran, 2005)

Figure 3.2(b) Triaxial device at the advanced geotechnical laboratory at Carleton University. 42 
Figure 3.3 Isotropic and anisotropic consolidation stress path

Figure 3.4 Isotropic loading and unloading characteristics of Fraser River sand at different initial void ratios

Figure 3.5 Effect of anisotropic consolidation on compressibility of Fraser River sand. 48

Figure 3.6 Loading and unloading strain path during isotropic and anisotropic consolidation of Fraser River sand

Figure 3.7 Particle size distribution of virgin and used Fraser River sand .52

Figure 3.8 Monotonic response of used and virgin sand under triaxial compression loading mode 53

Figure 3.9 Monotonic response of used and virgin sand under triaxial extension loading mode. 54

Figure 3.10 Unit membrane penetration $\left(\varepsilon_{m}\right)$ vs. radial effective stress $\left(\sigma_{r}^{\prime}\right)$ for loose Fraser River sand (After Logeswaran, 2005). 57

Figure 4.1 Behaviour of loosest deposited normally consolidated sand at different $K_{c}$ values 63

Figure 4.2 Behaviour of loosest deposited sand at $\mathrm{OCR}=1.25$ 66

Figure 4.3 Behaviour of loosest deposited sand at $\mathrm{OCR}=1.50$ 67

Figure 4.4 Behaviour of loosest deposited sand at $\mathrm{OCR}=2.00$ 68 
Figure 4.5 Behaviour of normally consolidated loosest deposited sand under extension loading mode 69

Figure 4.6 Behaviour of loosest deposited sand at $\mathrm{OCR}=1.25$ under extension loading mode. . .70

Figure 4.7 Behaviour of loosest deposited sand at $\mathrm{OCR}=1.50$ under extension loading mode. 71

Figure 4.8 Behaviour of loosest deposited sand at $\mathrm{OCR}=2.00$ under extension loading mode. . .72

Figure 4.9 Variation of modified brittleness index with initial static shear stress ratio. .74

Figure 4.10 Monotonic response of loose sand with $K_{c}=0.80$ at different $\mathrm{OCR}$ .75

Figure 4.11 Monotonic response of loose sand with $K_{c}=1.00$ at different $\mathrm{OCR}$ .77

Figure 4.12 Monotonic response of loose sand with $K_{c}=1.50$ at different $\mathrm{OCR}$ .78

Figure 4.13 Variation of modified brittleness index with $K_{c}$ and OCR .79

Figure 4.14 Effective stress state at the triggering of strain softening under extension loading mode at different $\mathrm{OCR}$ and $K_{c}$ levels 80

Figure 4.15 Variation of peak shear strength with OCR and $K_{c}$ in extension loading. 81

Figure 4.16 Peak shear strength normalised with respect to $\sigma_{1 c}^{\prime}$ at different OCR and $K_{c}$ levels 82

Figure 4.17 Peak shear strength normalised with respect to $\sigma_{3 c}^{\prime}$ at different OCR and $K_{c}$ levels 82 
Figure 4.18 Peak shear strength normalised with respect to $\sigma_{h c}^{\prime}$ at different OCR and $K_{c}$ levels

Figure 4.19 Effective stress states at phase transformation in compression and extension loading modes

Figure 4.20(a) Cyclic test results of loose samples at $\alpha=-0.11$ (a) normally consolidated, (b) at $\mathrm{OCR}=1.25$ with $\mathrm{CSR}=0.10$

Figure 4.20(b) Cyclic test results of loose samples at $\alpha=-0.11$ (a) OCR=1.50, (b) at $\mathrm{OCR}=2.00$ with $\mathrm{CSR}=0.10$ .88

Figure 4.21 Stress-strain and stress path response of isotropically consolidated sand at different $\mathrm{OCR}$ values with $\mathrm{CSR}=0.10$ 89

Figure 4.22 Variation of the number of cycles to liquefaction with OCR 90

Figure 4.23 Variation of number of cycles to liquefaction with CSR 91

Figure 4.24 Variation of the cyclic resistance ratio (CRR) of sand with relative density $\left(D_{r c}\right)$ and OCR 92

Figure 4.25 Dependency of $K_{O C R}$ on relative density .94

Figure 4.26 Cyclic tests (a) with stress reversal (b) without stress reversal 96

Figure 4.27(a) Variation of cyclic resistance ratio (CRR) of Fraser River sand with initial static shear stress ratio $(\alpha)$ at (a) $\mathrm{OCR}=1.00$, (b) $\mathrm{OCR}=1.25$ 98

Figure 4.27(b) Variation of cyclic resistance ratio (CRR) of Fraser River sand with initial static shear stress ratio $(\alpha)$ at (a) $\mathrm{OCR}=1.50$, (b) $\mathrm{OCR}=2.00$ 
Figure 4.28(a) Variation of cyclic resistance with OCR and $\alpha$ at (a) $D_{r c}=19 \%$ (b) $D_{r c}=40 \%$

Figure 4.28(b) Variation of cyclic resistance with OCR and $\alpha$ at $D_{r c}=65 \% \ldots \ldots \ldots \ldots \ldots \ldots . . .103$

Figure 4.29 Variation of $K_{\alpha}$ with $\alpha$ at different levels of OCR and $D_{r c}=19 \% \ldots \ldots \ldots .104$

Figure 4.30 Variation of $K_{\alpha}$ with $\alpha$ at different levels of OCR and $D_{r c}=40 \% \ldots \ldots \ldots .105$

Figure 4.31 Variation of $K_{\alpha}$ with $\alpha$ at different levels of $\mathrm{OCR}$ and $D_{r c}=65 \% \ldots \ldots \ldots .106$

Figure 4.32 Variation of $K_{\alpha}$ with $\alpha$ at different levels of relative density at $\mathrm{OCR}=1.00$ and 2.00 107

Figure 4.33 Cyclic and post cyclic response of Fraser River sand (a) stress-strain (b) stress path

Figure 4.34 Effect of relative density post liquefaction response of normally consolidated Fraser River sand

Figure 4.35 Effect of OCR on post-liquefaction response of Fraser River sand at different levels of relative density. 115

Figure 4.36 The range of deformation at zero stiffness 117

Figure 4.37 Mobilized shear strength from the end of phase one 119

Figure 4.38 Post liquefaction response of isotropically and anisotropically consolidated sand under triaxial compression loading mode 121

Figure 4.39 Post liquefaction response of isotropically and anisotropically consolidated sand under triaxial extension loading mode 122 
Figure A. 1 Variation of number of cycles to liquefaction at $K_{c}=0.80$ and $\mathrm{OCR}=1.00$.

Figure A. 2 Variation of number of cycles to liquefaction at $K_{c}=0.80$ and $\mathrm{OCR}=1.25$ 137

Figure A. 3 Variation of number of cycles to liquefaction at $K_{c}=0.80$ and $\mathrm{OCR}=1.50$ 138

Figure A. 4 Variation of number of cycles to liquefaction at $K_{c}=0.80$ and $\mathrm{OCR}=1.50$. 138

Figure A. 5 Variation of number of cycles to liquefaction at $K_{c}=1.00$ and $\mathrm{OCR}=1.00$. 139

Figure A. 6 Variation of number of cycles to liquefaction at $K_{c}=1.00$ and $\mathrm{OCR}=1.25$. 139

Figure A. 7 Variation of number of cycles to liquefaction at $K_{c}=1.00$ and $\mathrm{OCR}=1.50$ 140

Figure A. 8 Variation of number of cycles to liquefaction at $K_{c}=1.00$ and $\mathrm{OCR}=2.00$. 140

Figure A. 9 Variation of number of cycles to liquefaction at $K_{c}=1.25$ and $\mathrm{OCR}=1.00$. 141

Figure A. 10 Variation of number of cycles to liquefaction at $K_{c}=1.50$ and $\mathrm{OCR}=1.00$ 141 
Figure A. 11 Variation of number of cycles to liquefaction at $K_{c}=1.50$ and

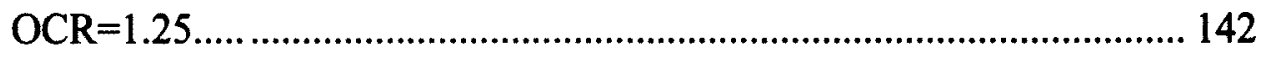

Figure A. 12 Variation of number of cycles to liquefaction at $K_{c}=1.50$ and

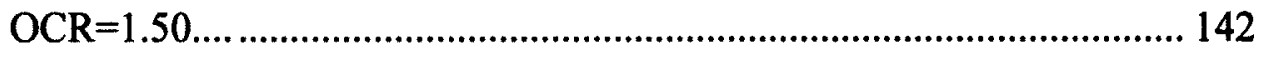

Figure A. 13 Variation of number of cycles to liquefaction at $K_{c}=1.50$ and

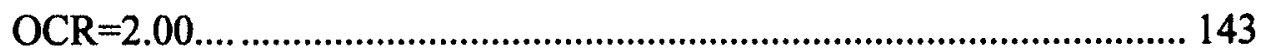




\section{LIST OF TABLES}

Table B.1 Monotonic tests on Fraser River sand............................................. 145

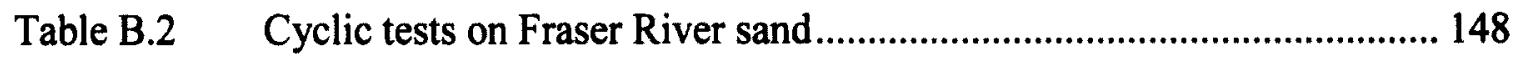




\section{LIST OF SYMBOLS}

A Total area of the sample in contact with the membrane, $\mathrm{m}^{2}$

$A_{s} \quad$ Soil skeleton area

$b \quad=\left(\sigma_{2}^{\prime}-\sigma_{3}^{\prime}\right) /\left(\sigma_{1}^{\prime}-\sigma_{3}^{\prime}\right)$, intermediate principal stress parameter

$C_{c} \quad$ Coefficient of curvature

$C_{c} \quad$ Compressibility index

$C_{r} \quad$ Rebound index

$C_{u} \quad$ Uniformity coefficient

D Displacement, $\mathrm{mm}$

$D_{50} \quad$ Average particle size, $\mathrm{mm}$

$D_{r c} \quad$ Relative density of the specimen after consolidation, (\%)

$D_{r i} \quad$ Relative density of the specimen after specimen prepared, (\%)

$e_{i} \quad$ Void ratio of the specimen after placing the top cap

$e_{\min }$ Minimum void ratio

$e_{\max }$ Maximum void ratio

$G_{s} \quad$ Secant shear stiffness, $\mathrm{MPa}$

$G_{\text {tan }}$ Tangent shear modulus, $\mathrm{MPa}$

$I_{B} \quad$ Brittleness index

$I_{\bar{B}} \quad$ Modified brittleness index 
$K_{c} \quad=\sigma^{\prime}{ }_{v} / \sigma_{h}^{\prime}$, Static shear stress ratio

$K_{0} \quad=\sigma^{\prime}{ }_{h} / \sigma_{v}^{\prime}$, At rest earth pressure coefficient

$P \quad$ Pressure, $\mathrm{kPa}$

p Applied load, $\mathrm{g}$

$s \quad=1 / 2\left(\sigma_{v}^{\prime}+\sigma_{h}^{\prime}\right)$, Normal effective stress, $\mathrm{kPa}$

$t \quad=1 / 2\left(\sigma_{v}^{\prime}-\sigma_{h}^{\prime}\right)$, Shear stress, $\mathrm{kPa}$

$S_{\min }$ Shear strength at minimum effective confining stress, $\mathrm{kPa}$

$S_{\text {peak }}$ Peak shear strength, $\mathrm{kPa}$

$S_{P T} \quad$ Shear strength at phase transformation, $\mathrm{kPa}$

$S_{s s} \quad$ Steady state shear strength, $\mathrm{kPa}$

U Pore pressure, $\mathrm{kPa}$

$V_{T} \quad$ Total volume of the sample, $\mathrm{mm}^{3}$

$\alpha=\left(\sigma_{v}^{\prime}-\sigma_{h}^{\prime}\right) /\left(\sigma_{v}^{\prime}+\sigma_{h}^{\prime}\right)$, Static shear stress ratio

$\alpha_{\sigma} \quad$ Angle of major principal stress and vertical line, deg

$\Delta U \quad$ Excess pore pressure, $\mathrm{kPa}$

$\Delta U_{\max }$ Maximum excess pore pressure, $\mathrm{kPa}$

$\Delta V_{T} \quad$ Total volume change, $\mathrm{mm}^{3}$

$\Delta V_{s} \quad$ Skelton volume change of specimen, $\mathrm{mm}^{3}$ 
$V_{\text {so }} \quad$ Initial soil volume, $\mathrm{mm}^{3}$

$\Delta V_{m} \quad$ Volume change due to the membrane penetration, $\mathrm{mm}^{3}$

$\varepsilon_{a} \quad$ Axial strain, (\%)

$\varepsilon_{m} \quad$ Membrane penetration per unit membrane surface area, (\%)

$\varepsilon_{v} \quad$ Volumetric strain, (\%)

$\varepsilon_{r} \quad$ Radial strain, (\%)

$\varphi \quad$ Angle, deg

$\varphi_{C S R} \quad$ Friction angle at critical stress, deg

$\varphi_{f} \quad$ Failure friction angle, deg

$\varphi_{P T} \quad$ Phase transformation friction angle, deg

$\varphi_{s s} \quad$ Steady state friction angle, deg

$\varphi_{\text {ult }} \quad$ Ultimate friction angle, deg

$\gamma \quad$ Shear strain, $\%$

v Poisson's ratio

$\sigma \quad$ Normal stress, $\mathrm{kPa}$

$\sigma_{d} \quad$ Deviator stress, $\mathrm{kPa}$

$\sigma_{c} \quad$ Confining stress, $\mathrm{kPa}$

$\sigma_{c}^{\prime} \quad$ Effective confining stress, $\mathrm{kPa}$

$\sigma_{h} \quad$ Total horizontal stress, $\mathrm{kPa}$ 
$\sigma_{h}^{\prime} \quad$ Effective horizontal stress, $\mathrm{kPa}$

$\sigma_{h c}^{\prime} \quad$ Effective horizontal stress during consolidation, $\mathrm{kPa}$

$\sigma_{n} \quad$ Total mean normal stress, $\mathrm{kPa}$

$\sigma_{n}^{\prime} \quad$ Effective mean confining stress, $\mathrm{kPa}$

$\sigma_{n c}^{\prime} \quad$ Effective mean confining stress during consolidation, $\mathrm{kPa}$

$\sigma_{\text {noc }}^{\prime}$ Maximum confining pressure during consolidation, $\mathrm{kPa}$

$\sigma_{v} \quad$ Total vertical stress, $\mathrm{kPa}$

$\sigma_{v}^{\prime} \quad$ Effective vertical stress, $\mathrm{kPa}$

$\sigma_{v c}^{\prime} \quad$ Effective vertical stress during consolidation, $\mathrm{kPa}$

$\sigma_{r} \quad$ Total radial stress, $\mathrm{kPa}$

$\sigma_{r}^{\prime} \quad$ Effective radial stress, $\mathrm{kPa}$

$\sigma_{1}^{\prime} \quad$ Major principal stress, $\mathrm{kPa}$

$\sigma_{1 c}^{\prime} \quad$ Major principal stress at consolidation, $\mathrm{kPa}$

$\sigma_{2}^{\prime} \quad$ Effective intermediate principal stress, $\mathrm{kPa}$

$\sigma_{3} \quad$ Minor principal stress, $\mathrm{kPa}$

$\sigma_{3 c} \quad$ Minor principal stress at consolidation, $\mathrm{kPa}$

$\delta \sigma_{d} \quad$ Change in deviator stress, $\mathrm{kPa}$

$\gamma \quad$ Shear strain (\%)

$\tau \quad$ Shear stress, $\mathrm{kPa}$ 
$\tau_{\mathrm{s}} \quad$ Initial static shear stress, $\mathrm{kPa}$

ABBREVIATIONS

CPT Cell Pressure Transducer

CRR Cyclic Resistance Ratio

CSR Critical Stress Ratio

CSR Cyclic Stress Ratio

DPT Differential Pressure Transducer

DPVC Digital Pressure/Volume Controller

FRS Fraser River Sand

LVDT Linear Variable Displacement Transducer

MO Maximum Obliquity

OCR Overconsolidation Ratio

PPT Pore Pressure Transducer

PT Phase Transformation

QSS Quasi Steady State

SS Steady State 


\section{CHAPTER 1}

\section{INTRODUCTION}

\subsection{LIQUEFACTION PHENOMENON}

Saturated granular materials when subjected to undrained loading can lose much of their shear strength and undergo excessive deformation due to "liquefaction". The main cause of liquefaction is the development of excess pore water pressure under either dynamic loads (such as earthquakes) or monotonic loads (such as the stresses caused by building a dam). Depending on the initial conditions of the soil in the field, this excess pore pressure development can cause limited or unlimited deformations. Over the past several years, liquefaction induced ground failures have caused extensive damages in different parts of the world.

Liquefaction phenomenon has been observed in many historical earthquakes with the oldest one in the 1891 Mino-Owari earthquake in Japan and the most recent one in the 2011 Christchurch earthquake in New Zealand. However, systematic research on liquefaction began after the failures in the 1964 earthquakes in Alaska, USA and Niigata, Japan. Since then, most of our understanding of liquefaction and the effect of various factors controlling this phenomenon have been derived from controlled laboratory experiments. These experiments have made it possible to study the effect of each factor individually and obtain a better insight into this phenomenon.

Although liquefaction flow failures associated with ground shaking during earthquakes are the main concern, several failures have also occurred as a result of static 
loads. Examples of such failures include the Calaveras dam (Hazen, 1918), Nerlerk underwater berms (Sladen et al., 1985), Fort Peck dam (Casagrande, 1965), Merriespruit tailings dam (Fourie et al., 2001), and Wachusett dam (Olson and Stark, 2003). Flow or limited flow deformation of slopes and embankments is the main cause of failure under static loading. Therefore, to have a safe geotechnical design on saturated granular materials, it is critical to have a good understanding of the mechanisms leading to liquefaction and factors affecting it under both static and cyclic loads.

Depending on the geometry and the nature of stresses acting on the soil prior to loading, liquefaction failures can be seen in different forms. The most common indicative of in-situ liquefaction is sand boils. Sand boils occur in the field due to the flow of pore water from the liquefied zone to the ground surface due to piezometric head difference. In sloping grounds, where the sand is subjected to initial static shear stresses, liquefaction manifests in the form of unidirectional flow deformations. On the other hand, lateral spreading is common in relatively level ground.

Liquefaction might lead to deformations that are in excess of safety and serviceability guidelines and requirements. Therefore, initial design attempts tried to avoid occurrence of soil liquefaction by undertaking appropriate hazard mitigation processes, which often tended to be some form of site densification. However, recent studies (Vaid and Thomas, 1995) on the response of the liquefied soil to both dynamic and static loads show that a proper understanding of the post-liquefaction response can help a more cost effective performance based design. These studies indicate that even if the soil liquefies under seismic loading, catastrophic failure may still be avoided. Therefore, a better understanding of the post-liquefaction response of the soil can 
improve the current design practice to deal with the consequences of soil liquefaction, and limit liquefaction induced deformations within the permitted limits instead of taking precautions against liquefaction.

\subsection{LIQUEFACTION SUSCEPTIBILITY}

The early characterization of liquefaction susceptibility was based on the empirical analysis of case histories (Seed and Idriss, 1971; Seed et al., 1985). Seed et al. (1985) provided a relationship between soil relative density (corrected SPT blow counts) and liquefaction potential for given cyclic stress. This methodology to derive the liquefaction potential of a specific soil was based on the Seed and Idriss (1971) "simplified procedure" and has been widely used since that time.

In determining the liquefaction susceptibility of a specific site, usually site specific measurements are not made. Instead, correction factors derived from the literature are used to consider the effect of various state variables. The state variables include: void ratio (relative density), confining effective stress level, soil fabric, static shear stress, strain/stress history, and stress path. Among these variables, the effect of relative density and confining stress level are well understood, and commonly considered (Vaid and Sivathayalan, 2000). On the other hand, a comprehensive study of the effects of soil fabric and strain/stress history is not available in the literature. In current design practice, the effect of prior stress history (e.g. overconsolidation) is ignored due to the belief that a normally consolidated soil generally has a more contractive response than overconsolidated soil while other variables are not changing. This practice often leads to a conservative design. On the other hand, only limited research (Manmatharajan, 2011) 
has been reported on the effect of overconsolidation on the correction factors used in determining the cyclic resistance. Therefore, further research is needed on the interaction of the state variables with each other.

Most of the previous studies (Thomas, 1992; Stedman, 1997) on the effect of static shear on the liquefaction potential of soils have been done with samples consolidated anisotropically and loaded under triaxial loading mode. During anisotropic consolidation, usually the horizontal stress is the minor principal stress and the vertical stress is the major principal stress. However, the field stress conditions are not always like this and the major principal stress direction might change with the geometry of the ground. Therefore, to consider the effect of the direction of the initial static shear, triaxial tests on anisotropically consolidated samples with the horizontal stress as the major principal stress and the vertical stress as the minor principal stress are needed.

\subsection{RESEARCH OBJECTIVES}

Most of the previous research on the initial state variables that affect the soil behaviour have been focused on the effect of the relative density, confining stress, and initial static shear (Vaid and Thomas, 1994; Vaid and Sivathayalan, 1996; Vaid et al., 2001). However, other influencing factors such as overconsolidation and the direction of the initial static shear have received little or no attention (Ishihara and Takatsu, 1979; Manmatharajan, 2011). In this research, the effect of overconsolidation ratio (OCR) on the undrained monotonic response of the sand at different initial static shear levels and void ratios under triaxial loading mode has been studied. On the other hand, to study the effect of the direction of initial static shear, undrained monotonic triaxial tests on 
anisotropically consolidated samples with different initial static shear directions have been performed. Various tests have been done at different relative density values but at a fixed level of the mean normal stress of $100 \mathrm{kPa}$. The monotonic tests were aimed to address two research objectives: 1) provide a better understanding of the effect of initial state variables on the monotonic response of saturated sands, 2) to obtain a link between cyclic and monotonic response. Due to the inherent anisotropy of granular materials, their response is highly dependent on the loading mode. Therefore, all tests have been performed under both triaxial compression and extension loading mode.

A comprehensive study has been undertaken to study the effect of overconsolidation ratio on the cyclic resistance of saturated sands. Rather than looking at the cyclic resistance alone (Ishihara and Takatsu, 1979), the role of OCR on the correction factors and its interaction with other initial state variables has been studied. All tests have been performed over a range of relative densities and at different initial static shear levels. In addition, the effect of the direction of the initial static shear on the cyclic resistance has also been studied.

To have an insight into the post-cyclic response of overconsolidated sand, samples have been loaded under triaxial monotonic loading at the end of the cyclic loading phase. Tests were conducted under both triaxial compression and extension loading modes to evaluate the effect of loading mode on the post-liquefaction response. 


\subsection{ORGANIZATION OF THE THESIS}

A comprehensive study of the monotonic and cyclic response of Fraser River sand subjected to a variety of initial conditions is covered in this thesis. The relevance and practical importance of the liquefaction research are highlighted in this first chapter. Following this chapter, a well detailed background and the current state of the art related to the behaviour of granular materials under both monotonic and cyclic loading modes is presented in chapter 2. At the end of chapter 2, a review of the stress-strain conditions under triaxial loading mode is discussed.

Chapter 3 covers the experimental aspect of this research. Characteristics of the Fraser River sand are presented in this chapter. Triaxial testing apparatus used in this research and its capabilities are also explained. At the end, the testing program and the methodology to interpret the test results are discussed.

Experimental results are presented and discussed in chapter 4. Undrained response of Fraser River sand at different initial conditions and loading modes under monotonic, cyclic, and post-cyclic loading is presented. At the end, new correction factors are introduced and compared with the ones currently available in the literature.

Finally, the findings are summarized and presented in chapter 5. Conclusions of this research and suggestions for further research are presented in this chapter. All the monotonic, cyclic and post-cyclic test results and responses used to arrive at the conclusions are summarized in the appendix. 


\section{CHAPTER 2}

\section{LITERATURE REVIEW}

\subsection{LIQUEFACTION PHENOMENON}

Loose saturated cohessionless soils lose much of their shear strength and can undergo excessive deformations under undrained loading conditions. The term liquefaction is used when considerable excess pore pressure is generated in a soil and it undergoes large deformations under either monotonic or cyclic undrained loading.

Liquefaction can be triggered by earthquakes, static loading, vibration during pile driving, train traffic, and blasting. Serious attention has been paid to liquefaction studies following 1964 Niigata and Alaska earthquakes. Over the past four decades, liquefaction phenomenon has been studied using controlled laboratory tests under both static and cyclic loading conditions (Castro, 1969; Seed and Peacock, 1971; Finn et al., 1971; Vaid and Chern, 1985; Vaid et al., 1990; Vaid and Sivathayalan, 1996). Loose granular soils tend to contract under loading, and thus saturated soils will generate excess pore pressure under undrained loading. Since the total stress in the soil mass is constant, an increase in excess pore pressure results in a reduction of effective stress between soil particles. Shear modulus of sand decreases as the effective stress decreases and thus sandy ground becomes softer with time. In the extreme case of zero effective stress, the sand particles are floating in pore water with minimal contact, and soil has lost all of its shear strength and stiffness. 
The interest in static undrained response is mainly associated with large deformations due to flow slides. On the other hand, under cyclic loading the interest is also in the accumulation of large shear strains due to progressive reduction in shear stiffness as a result of the increase in excess pore pressure.

\subsection{UNDRAINED MONOTONIC LOADING BEHAVIOUR}

\subsubsection{Types of Response}

Undrained monotonic (static) behaviour of saturated sand under triaxial loading conditions has been studied by several researchers (e.g. Castro, 1969; Lee and Seed, 1967; Chern, 1985; Vaid and Thomas, 1994). Three different types of response of granular materials under undrained loading condition have been reported (Figure 2.1). The type of response is mainly dependent on the initial state of stress and relative density prior to the initiation of undrained loading. The undrained response at a given initial stress state changes from type 1 to 3 as the relative density increases. Type 1 response is associated with very loose sand. Castro (1969), Casagrande (1975) and Seed (1979) called this strain softening type of response "liquefaction", whilst Chern (1985) named it "true liquefaction". In this type of response soil strength increases until it reaches a peak at low strains. After the peak, shear stress decreases to reach a steady state at which continuous deformations happen at a state of constant effective and shear stresses, and the corresponding shear stress has been called the "steady state strength" or "residual strength".

The response of medium dense sand is similar to loose soil (type l) in early stages, however, after initial contractive behaviour the soil transforms and begins to dilate and 
gain strength with further straining (Figure 2.1-type2). This transformation happens at the peak pore pressure state which coincides with the minimum shear strength. Ishihara et al. (1975) named this point phase transformation (PT). After PT state, negative pore pressure develops and the material strength increases. This type of behaviour has been named limited liquefaction by Castro (1969) and Chern (1985), while Lee and Seed (1967) called it partial liquefaction.
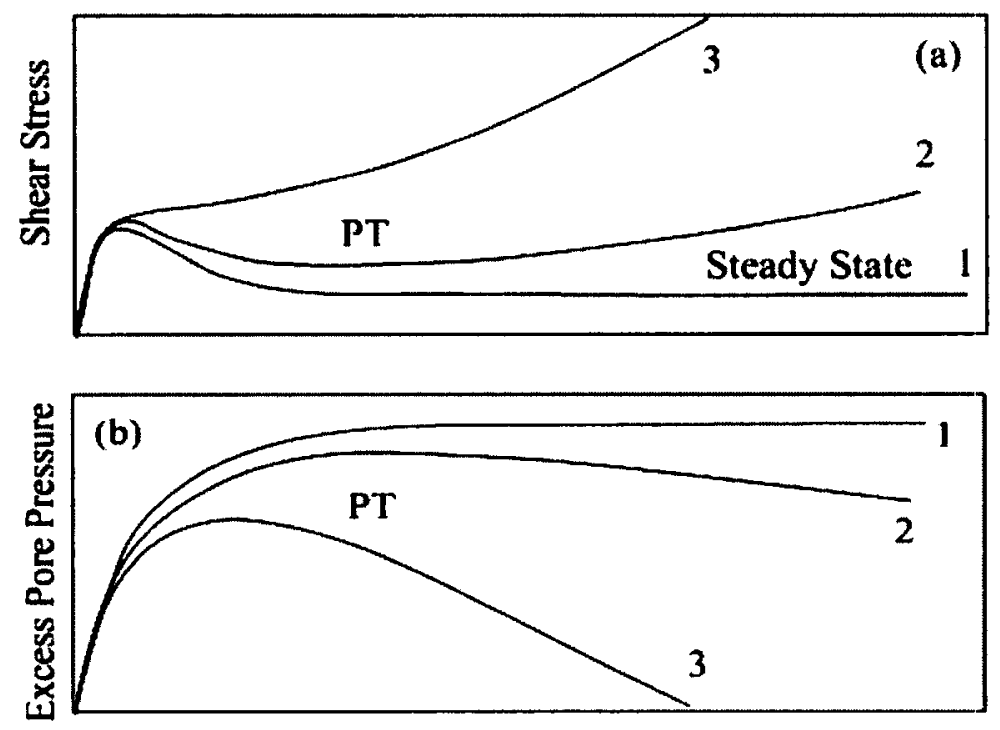

Shear Strain

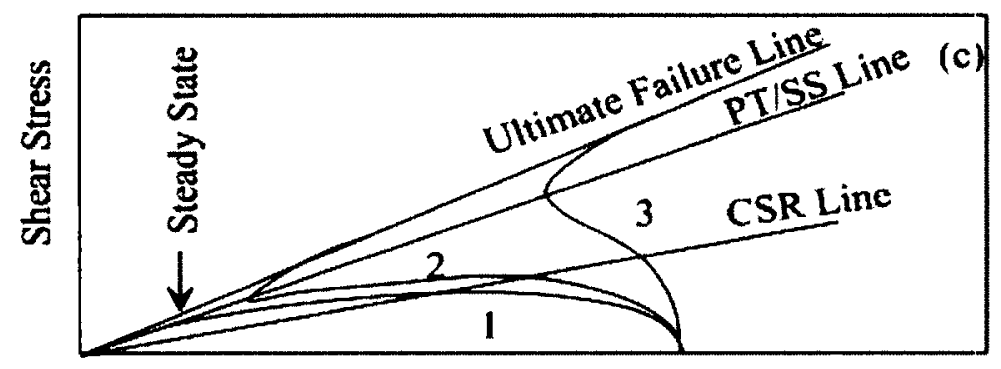

Normal Effective Stress

Figure 2.1 Undrained simple shear response of reconstituted and undisturbed samples of two sands (After Vaid and Chern, 1985)

Dense sand behaviour is of type 3 in Figure 2.1. Although some contractive behaviour is observed at very small strain range, there is no strain softening, and the 
behaviour is generally called dilative. Some positive pore pressure develops at early stages of loading but subsequent negative pore pressure development will lead to strain hardening with further straining.

The type of response that a soil may exhibit is dependent upon the initial state of the soil. The initial state consists of relative density, confining stress, shear stress prior to the loading, fabric, and loading mode. The undrained response of a specific sand under the same loading mode and initial stress state may vary from type 1 to type 3 as the relative density increases (void ratio decreases).

\subsubsection{Initiation of Strain Softening}

Upon reaching the peak deviatoric stress (type 1 and 2) the process of strain softening starts. The effective stress ratio corresponding to the peak deviatoric stress has been called Critical Stress Ratio (CSR) by Vaid and Chern (1983). Chern (1985), Kuerbis (1989) and Vaid et al. (1990) have shown that CSR is a unique value for water pluviated sand specimens under triaxial compression loading mode. However, Castro (1969) and Sladen et al. (1985) have reported that CSR varies with void ratio and confining pressure for moist tamped samples. These different conclusions show the dependency of CSR on the fabric of the soil. It has been shown that CSR values are dependent on relative density in triaxial extension and simple shear loading modes even in water pluviated sands (Vaid and Thomas, 1994; Vaid and Sivathayalan, 1996; Stedman, 1997). The CSR values in triaxial compression are higher than those obtained from the triaxial extension and the simple shear. Arthur and Menzies (1972) have shown that this difference in response is due to inherent anisotropy of granular materials. 


\subsubsection{Phase Transformation and Steady State}

Ishihara et al. (1975) called the point at which the soil behaviour changes from contractive to dilative (in types 2 and 3, Figure 2.1) as "Phase Transformation" (PT). Under undrained loading, PT corresponds to the instance of maximum pore pressure. This transition in behaviour from contractive to dilative is characterized by a sharp turnaround in the effective stress path.

Monotonic undrained response is generally characterized in terms of the undrained strength and/or the friction angle mobilized at different states. In type 1 response both peak strength $\left(S_{\text {peak }}\right)$ and minimum strength $\left(S_{s s}\right)$ can be defined. On the other hand when the response is of limited liquefaction or strain hardening the strength at phase transformation $\left(S_{P T}\right)$ would be considered as the minimum undrained shear strength. It has been shown that the friction angle mobilized at steady state $\left(\varphi_{s s}\right)$ and that of phase transformation $\left(\varphi_{P T}\right)$ are the same and it is a unique material property (Castro, 1969; Chern, 1985; Vaid and Sivathayalan, 2000). Therefore, phase transformation and steady state can be treated in the same framework in stress space despite of the fact that they may be different in the void ratio - effective stress space.

It has been shown that mobilized friction angle at PT state $\left(\varphi_{P T}\right)$ is a constant material property for a given sand regardless of void ratio, initial stress state, mode of loading, type of response, fabric (sample preparation method), intermediate principal stress level (b), or the direction of major principal stress $\left(\alpha_{\sigma}\right)$ (Chern, 1985; Vaid and Thomas, 1995; Stedman, 1997; Uthayakumar and Vaid, 1998; Vaid et al., 1999). This friction angle $\left(\varphi_{P T}\right)$ is found to be dependent on the soil mineralogy and equals to the constant volume friction angle under drained condition (Neguessy et al., 1988). 
Logeswaran (2005) extended this conclusion and have shown that friction angle mobilised at maximum pore pressure state under different drainage conditions (linear and non-linear drainage paths) is equal to that of undrained loading.

\subsubsection{Ultimate Failure Line}

Following the phase transformation stress path approaches the line of maximum obliquity and further deformation progress at constant friction angle. The friction angle corresponding to this failure state often called ultimate friction angle $\left(\varphi_{u l t}\right.$ or $\left.\varphi_{f}\right)$. Vaid and Chern (1985) and Thomas (1992) have reported that this friction angle is a unique material property in water deposited specimens and is independent of relative density, confining pressure level and loading mode. However, Miura and Toki (1982) have shown that this angle increases as the relative density increases and varies with loading mode, but the recorded changes were minor.

\subsubsection{Factors of Influence}

Different factors such as void ratio, confining stress level, stress history, loading mode, sample preparation method (fabric), and drainage conditions can affect the undrained response of saturated sand. Among these factors, void ratio is considered to be the most dominant one. As relative density increases (void ratio decreases) the response transforms from contractive to dilative at a constant initial stress state (Bishop, 1971; Been et al., 1991; Vaid and Thomas, 1995; Vaid and Sivathayalan, 1996; Uthayakumar and Vaid, 1998).

Although increasing confining pressure would densify the sand, a more contractive behaviour is observed as the level of confining stress increases under triaxial 
compression and simple shear loading modes (Figure 2.2). This occurs since in compression loading mode the increased normal stresses offsets the effect of densification at higher confining pressures and suppresses the dilation potential in the material. However, under triaxial extension loading mode, increasing confining pressure promotes a more dilative response (Vaid and Thomas, 1995; Vaid and Sivathayalan, 1996) which indicates that the effect of densification is more pronounced than the effect of stress level.
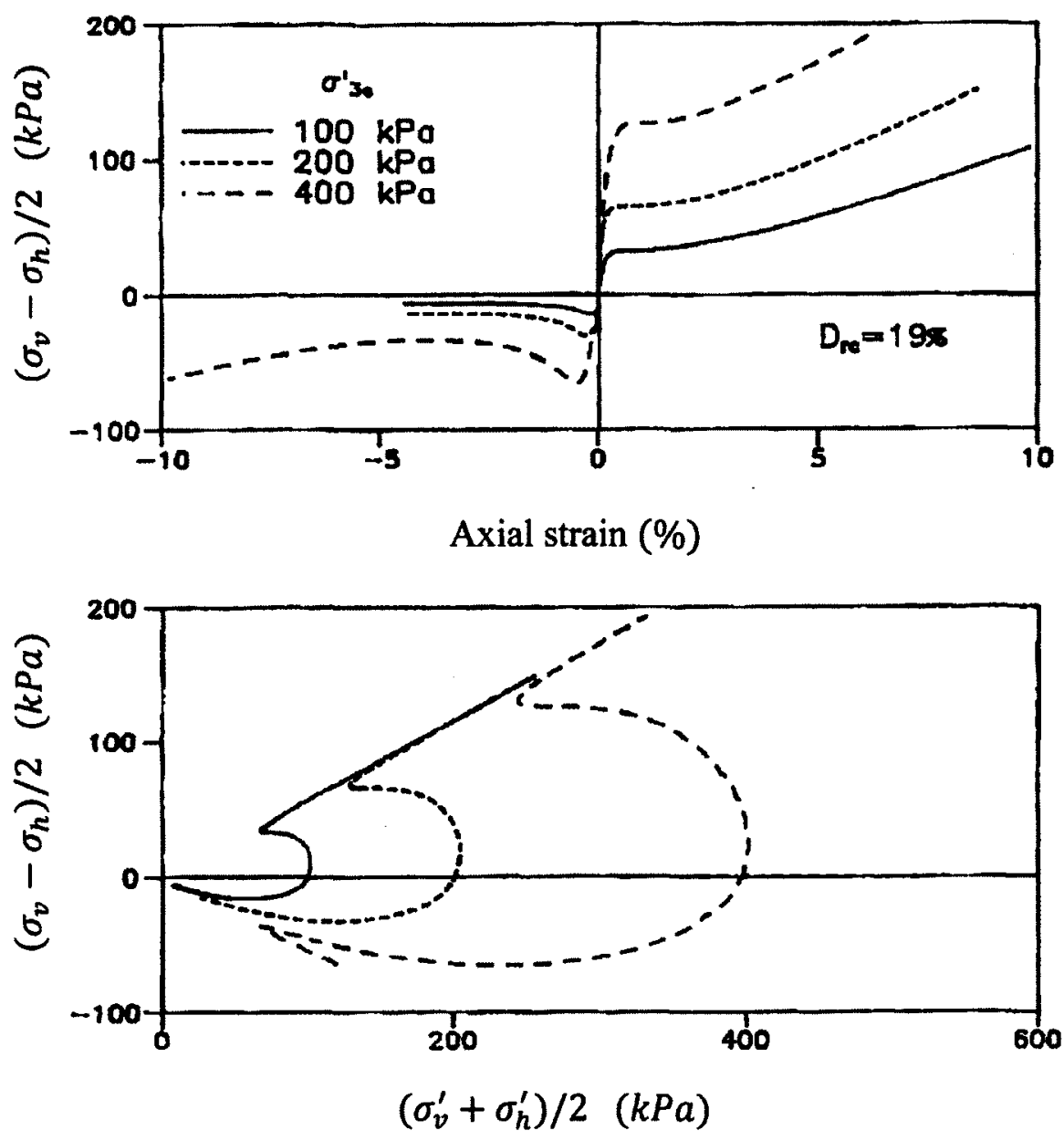

Figure 2.2 Undrained static behaviour at different confining stress levels and a constant relative density (After Thomas, 1992) 
Increasing static shear level at a constant confining pressure and fixed level of relative density promotes a more contractive response under triaxial compression loading mode (Thomas, 1992; Stedman, 1997). However, just the effect of positive static shear (major principal stress in the vertical direction) has been studied in the literature. Both Thomas (1992) and Stedman (1997) have reported that the positive static shear has almost no effect on the material response under triaxial extension loading mode (Figure 2.3).

Due to the inherent anisotropy of sands, their response is influenced by the direction of the major principal stress. Sands show a stronger response when the major principal stress is perpendicular to the bedding plane and weaker response when it is parallel to the bedding plane (Vaid et al., 1989; Thomas, 1992). Stress conditions in a triaxial compression test represent the former and triaxial extension the latter.

It has been noted that water pluviated sands strain harden under triaxial compression even at the loosest void ratio available. On the other hand, these materials strain soften over a range relative density state under triaxial extension mode of loading. These differences in response and direction dependency of the behaviour of sands have been noted by Symes et al. (1984), Hight et al. (1983), Shibuya and Hight (1988), Uthayakumar (1995), and Logeswaran (2010).

Another factor that can have a significant influence on soil response is the fabric (Mulilis et al. 1977; Ladd 1977). Vaid et al. (1999) have clearly demonstrated the effect of three different sample preparation methods (water pluviation, air pluviation, and moist tamp preparation method) on sand response (Figure 2.3). It has been shown that water pluviated sand specimens tend to be more uniform compared to moist tamped ones. As 
shown in Figure 2.4 the results of tests from undisturbed samples and water pluviated ones under simple shear loading have been found to be quite similar at identical initial states.

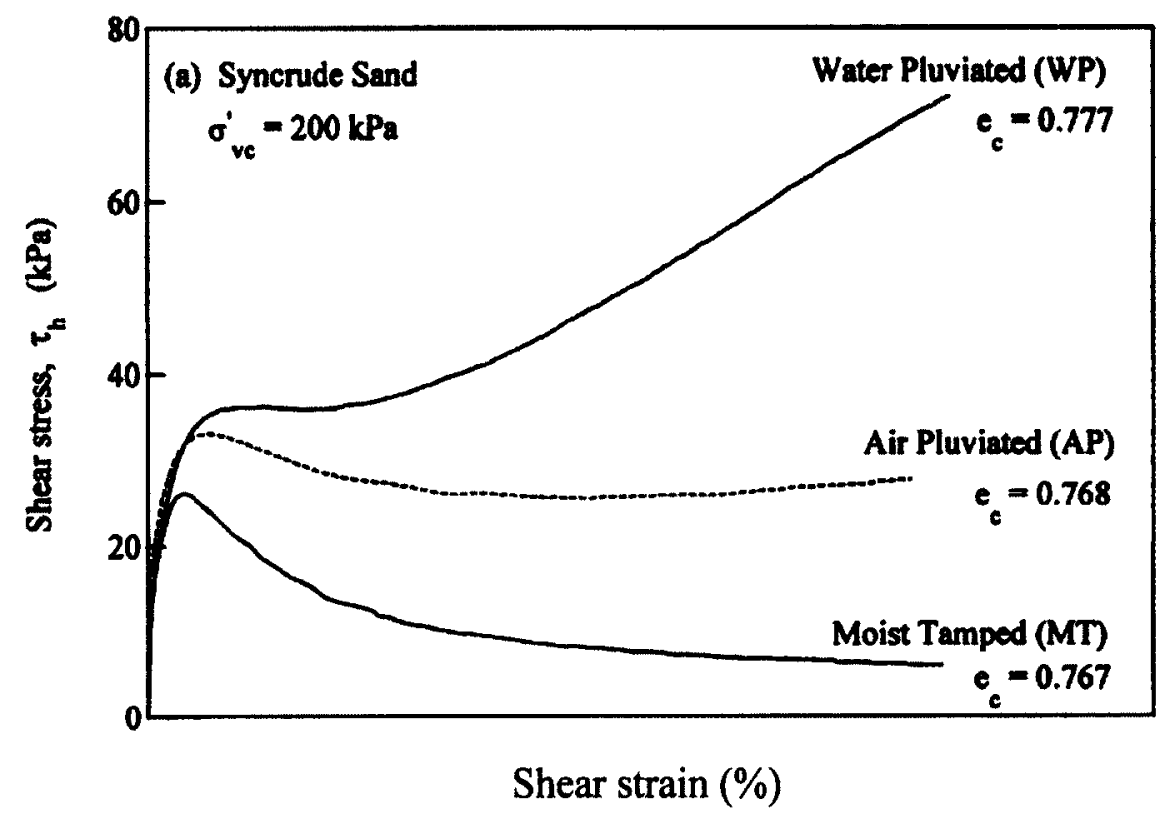

Figure 2.3 Effect of different sample preparation methods on the undrained simple shear response (After Vaid et al. 1999)

\subsubsection{Effect of Overconsolidation}

Sand can be overconsolidated due to geologic considerations such as fluctuation of ground water, removal of overburden by erosion, or due to ice advance/retreat during Glacial tides, or intentionally by man-made mechanisms such as temporary surcharge loading. Ishihara and Okada (1978) studied the effect of overconsolidation on the monotonic response of sand under triaxial compression and extension loading modes (Figure 2.5). They have reported a reduction in pore pressure generation with increasing overconsolidation ratio (OCR) and also mentioned that even a small level of 
overconsolidation can significantly change the monotonic response of given sand at a specific relative density (Ishihara et al., 1978).

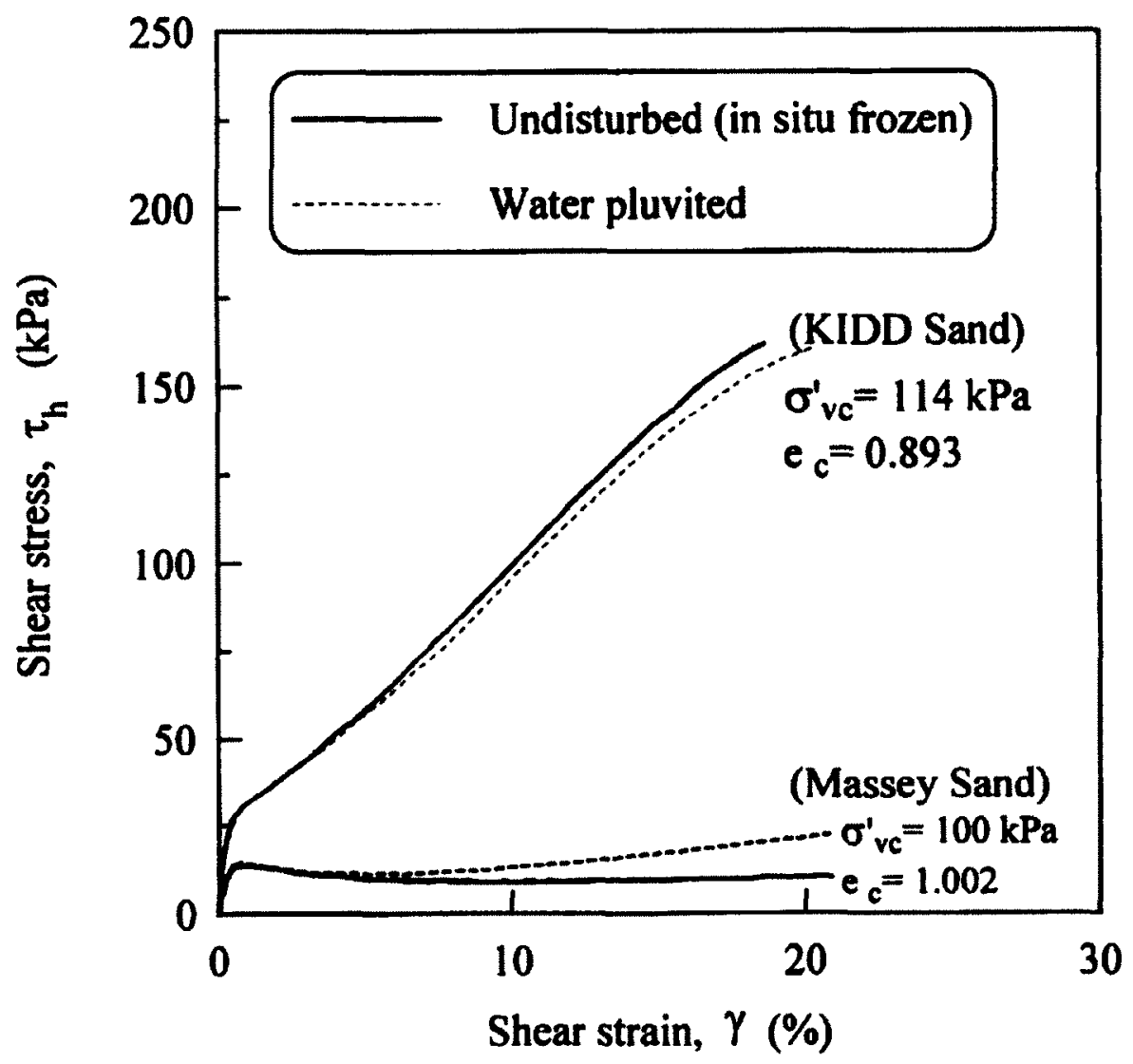

Figure 2.4 Undrained simple shear response of reconstituted and undisturbed samples of two sands (After Vaid et al. 1999) 

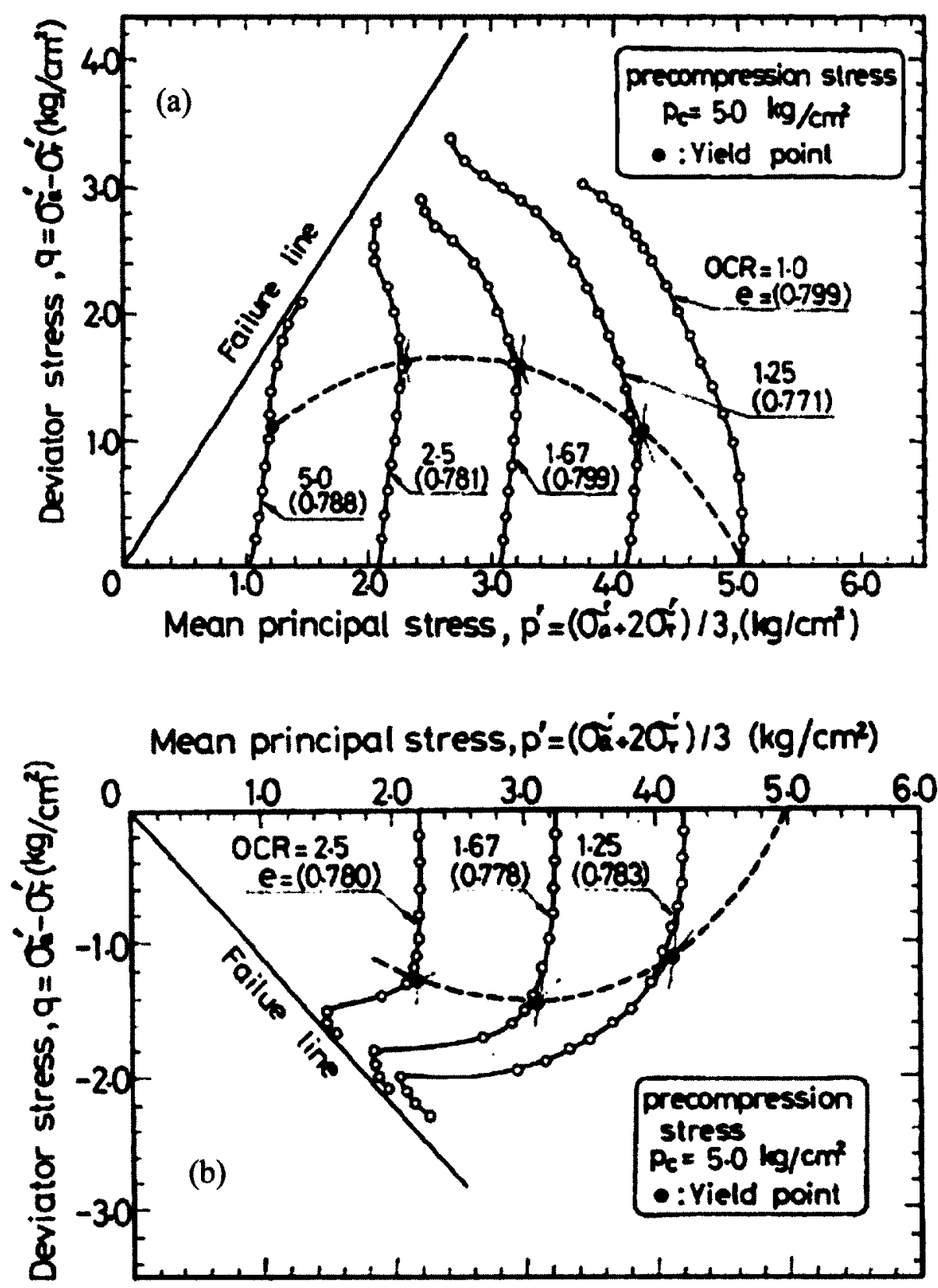

Figure 2.5 Effect of overconsolidation on the stress path in triaxial (a) compression (b) extension (After Ishihara and Okada, 1978) 


\subsection{CYCLIC LOADING BEHAVIOUR}

Cyclic loads are applied to the soil during earthquakes. Due to the rapid nature of loading and the extent of the loaded areas, drainage is quite impossible during earthquakes. Thus response during earthquake loading is studied by imposing undrained conditions on soil element. Catastrophic failures due to liquefaction and subsequent flow during Niigata and Alaska 1964 earthquakes had originally attracted researchers to the study of the behaviour of saturated sands under undrained cyclic loading.

Different factors affect the undrained response of saturated sands under cyclic loading. The most important factors are: relative density, confining stress level, static stress level, cyclic shear stress level and over consolidation ratio. While most of these factors have been studied in details, less attention has been paid to the effect of over consolidation ratio in the literature.

\subsubsection{Mechanisms of Strain Development}

Due to progressive increase of pore pressure and reduction of effective stress during cyclic loading, large deformations occur in the soil. Strain development can either be due to true liquefaction, limited liquefaction or cyclic mobility (Castro, 1969; Vaid and Chern, 1985). The type of response mainly depends on relative density (void ratio) and the stresses prior to the cyclic loading (static shear stress and confining pressure). These mechanisms are shown typically in Figure 2.6, 2.7 and 2.8 and correspond with types 1, 2, and 3 of monotonic loading response, respectively. As shown in Figure 2.6 (a), loose sand deposits that show contractive response under monotonic loading, behave in the same way under cyclic loading (i.e. flow failure). On the other hand, limited 
liquefaction followed by cyclic mobility is characteristic of medium dense sand (Figure 2.6 (b)). In contrast, strain accumulation in dense samples, as depicted in Figure 2.7, is due to cyclic mobility. Due to different mechanisms that are responsible for the accumulation of strain during cyclic loading, the cyclic resistance is defined as the cyclic stress required causing a specific level of shear strain under a fixed number of cycles regardless of the responsible mechanism for strain development. The experts' panel commissioned by NRC (1985) recommended that a soil be deemed liquefied if shear strain exceeds $3.75 \%$ (equivalent axial strain $2.5 \%$ in triaxial loading). The number of stress cycles depends on the design earthquake magnitude, and for an M 6.75 earthquake is considered to be 10 cycles. That stress ratio causing liquefaction in the given number of stress cycles is called the "cyclic resistance ratio (CRR)".

Initial deformations occur due to stiffness degradation because of excess pore pressure development due to cycles of loading and unloading. Seed (1979) has shown that strain development is small until excess pore pressure ratio $\left(\Delta u / \sigma_{3 c}^{\prime}\right)$ exceeds about $60 \%$. In contractive sand (true liquefaction and limited liquefaction type of response), large deformations may occur without large excess pore pressure built up. On the other hand, a transient state of zero effective stress due to excess pore pressure ratio of $100 \%$ is a pre-requisite for large strain development due to cyclic mobility. However, this transient state would not be achieved unless the magnitude of the cyclic stress is greater than the static shear so that stress reversal would occur. Strain development in cases without stress reversal would be limited. 

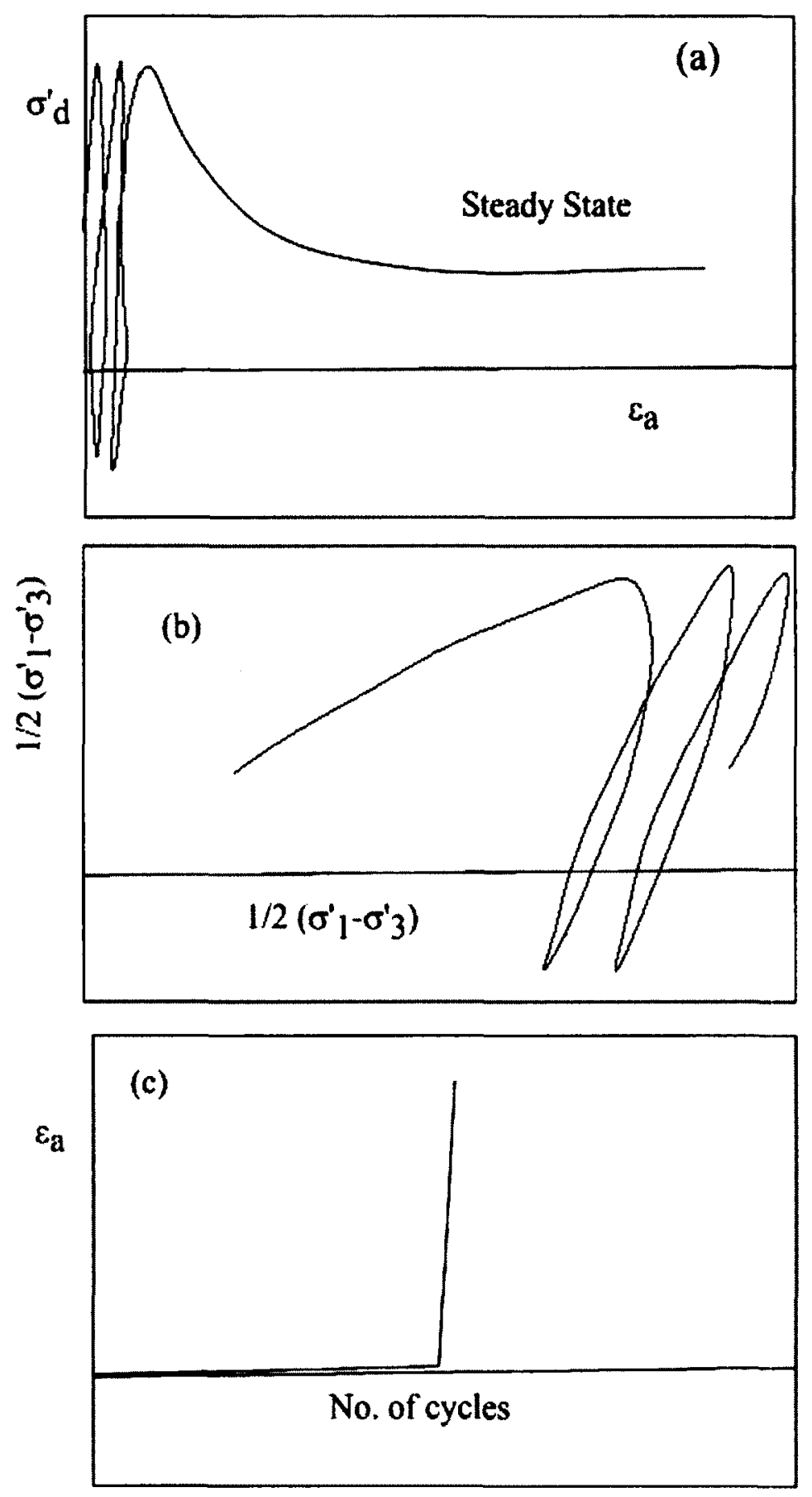

Figure 2.6 True liquefaction and type of response under cyclic loading (After Vaid and Chern 1985) 

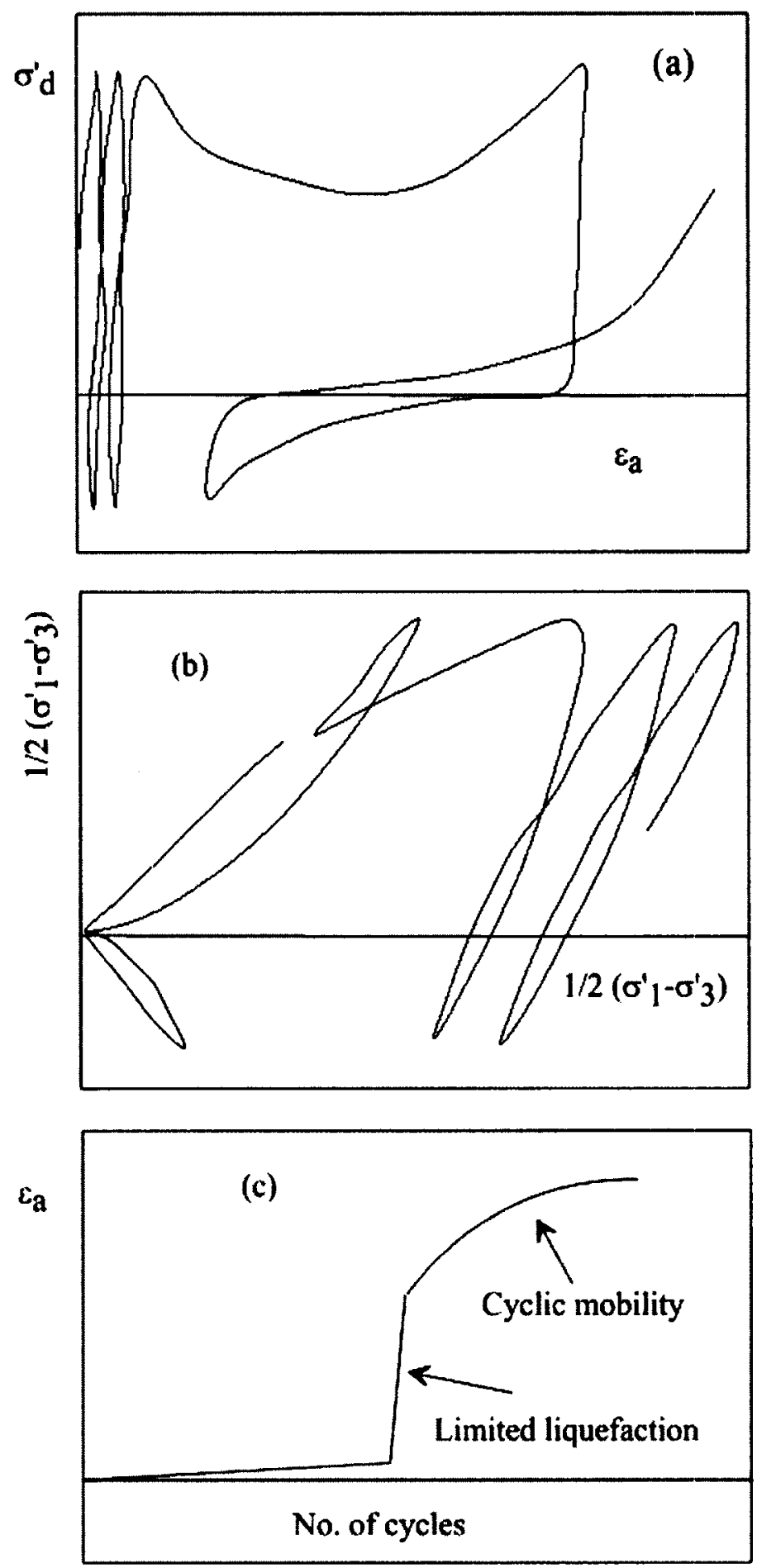

Figure 2.7 Limited liquefaction type of response under cyclic loading (After Vaid and Chern 1985) 

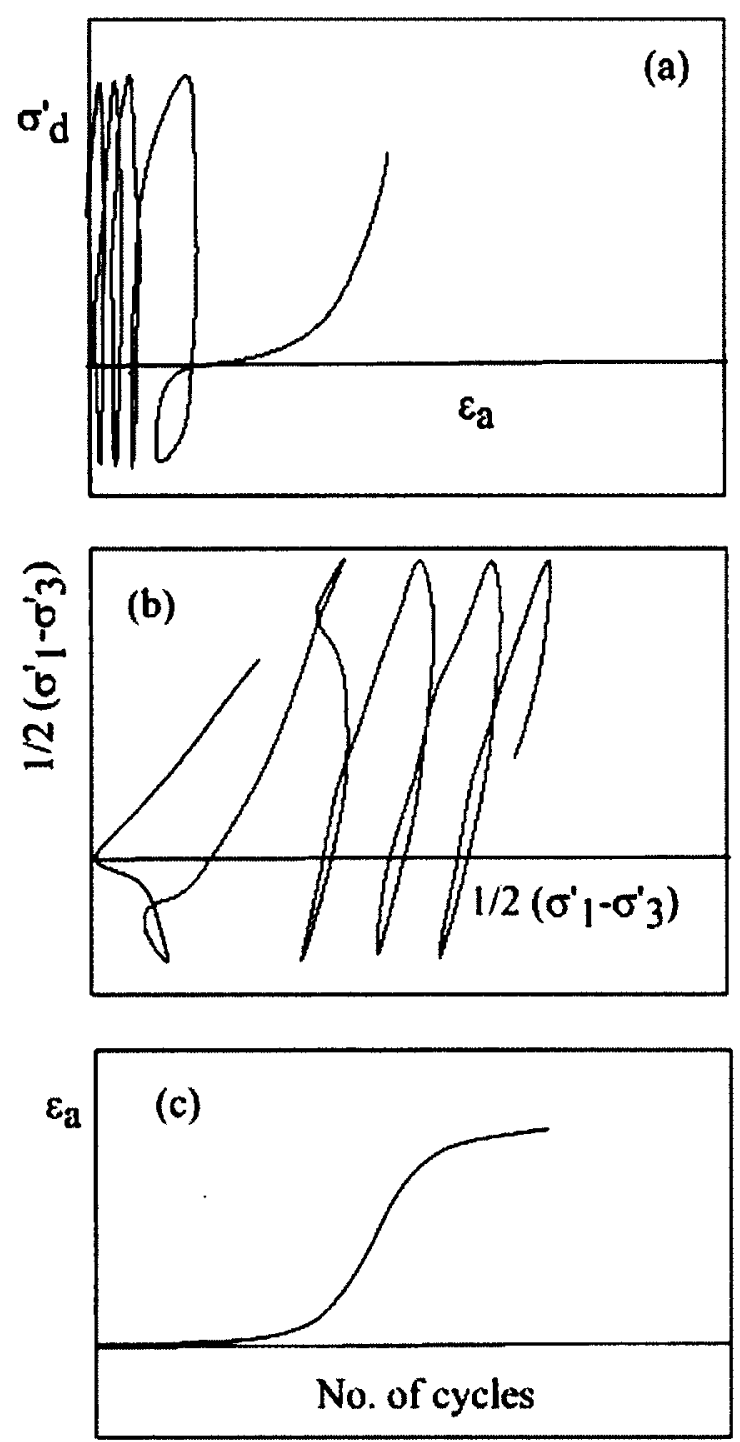

Figure 2.8 Cyclic mobility type of response under cyclic loading (After Vaid and Chern 1985)

In true liquefaction and limited liquefaction type of response, contractive deformation begins when the stress ratio reaches the critical stress value (CSR) that was observed under static loading (Vaid and Chern, 1985). At this stage, large strains at finite stress level occur in true liquefaction type of response (loose sand). In limited liquefaction type of behaviour, however, strain accumulation due to softening stops upon 
reaching the PT state and beyond this point stresses increase due to dilation. Subsequent unloading cycle brings sand to state of zero effective stress $\left(\sigma_{3 c}^{\prime}=0\right)$ and further cycles of loading and unloading take the sand through transient state of zero effective stress and cause strain accumulation.

On the other hand, in cyclic mobility type of response strain accumulation is small until the stress path reaches the PT line (Vaid and Chern, 1985). At this stage the unloading pulse generates a high pore pressure that brings sand to a state of very low effective stresses. Subsequent cycles of loading and unloading cause more stiffness degradation and take sand through a state of zero confining stress which causes further strain accumulation.

\subsubsection{Effect of Overconsolidation}

Effect of overconsolidation on the liquefaction potential of sand under cyclic loading has not received much attention and is fairly limited in the literature (Ishihara and Takatsu, 1979; Adalier and Elgamal, 2005). Ishihara and Takatsu (1979) studied the effect of overconsolidation on cyclic resistance of sand under torsional shear tests at $K_{o}$ condition. It has been shown that at a fixed value of $K_{o}$ the cyclic resistance increases with an increase in OCR (Figure 2.9). As shown in Figure 2.10, irrespective of $K_{O}$ value, there is a unique relationship between OCR and cyclic strength. On the other hand, the effect of overconsolidation on cyclic resistance of sand under triaxial loading condition needs to be addressed. In addition overconsolidation ratio affects the coefficient of earth pressure at rest. Therefore, in a sloping ground with static shear stress, both $K_{o}$ and $K_{c}$ effects are present and need to be studied separately. Such attempts have been very 
limited in the literature. Therefore, one of the goals of this study is to better understand the combined effect of overconsolidation and static shear.

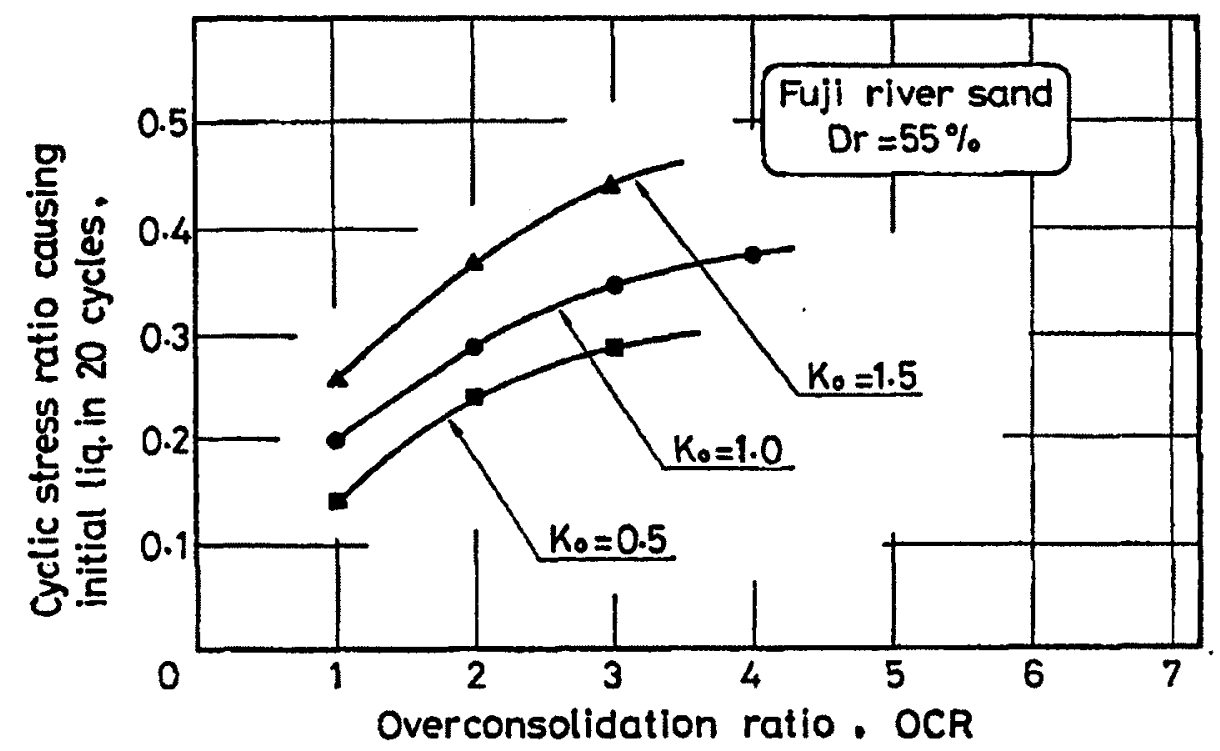

Figure 2.9 Effect of OCR on cyclic resistance of sand at fixed $K_{o}$ values(After Ishihara and Takatsu, 1979)

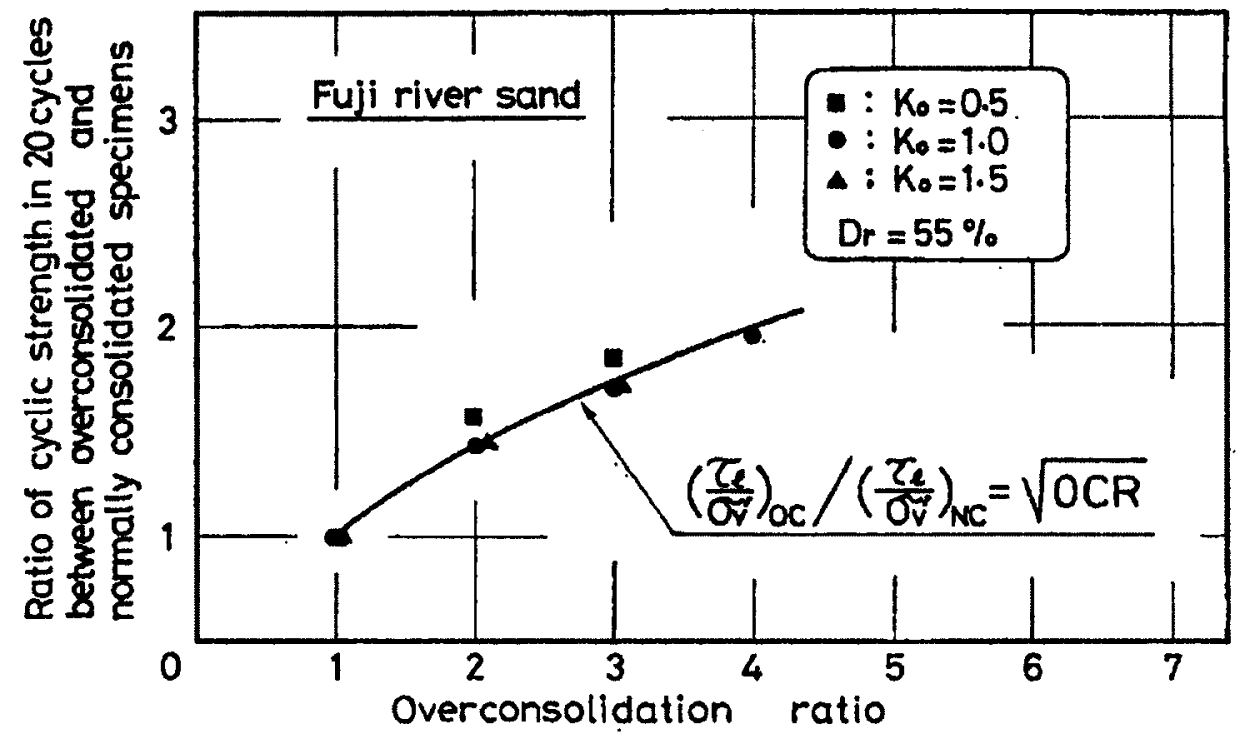

Figure 2.10 Relationship between cyclic resistance and OCR (After Ishihara and Takatsu, 1979) 


\subsubsection{Effect of Confining Stress Level}

Several researchers (Castro 1969; Chern, 1985; Vaid and Thomas, 1994; Vaid et al., 2001) have studied effects of confining pressure on cyclic resistance. It has been shown that increasing confining pressure leads to a lower cyclic resistance (represented by CRR). To take into consideration the effect of overburden pressure, Seed (1983) proposed a correction factor $K_{\sigma}$ to correct the measured cyclic resistance at a reference confining stress for various pressures in-situ. This factor is defined as the ratio between the cyclic resistance ratio at a specific confining pressure and the one at a reference confining stress of $100 \mathrm{kPa}$.

$$
K_{\sigma}=\frac{\tau / \sigma_{n}^{\prime} \text { causing liquefaction at } \sigma_{n}^{\prime}}{\tau / \sigma_{n}^{\prime} \text { causing liquefaction at } \sigma_{n}^{\prime}=100 \mathrm{kPa}}=\frac{\operatorname{CSR}_{\sigma_{n}^{\prime}}}{C S R_{100}}
$$

As depicted in Figure 2.11, there is a large scatter in Seed and Harder (1990) data. This indicates that in addition to confining pressure other factors (such as relative density and loading mod) have an influence on $K_{\sigma}$. It has been shown by Vaid and Thomas (1994) that void ratio affects $K_{\sigma}$ and the value is smaller in denser samples. On the other hand, reported data shows that cyclic triaxial tests tend to overestimate the correction factor at high densities when compared with simple shear test results (Vaid and Sivathayalan, 1996).

Participants in the 1997 and 1998 workshops on Evaluation of Liquefaction resistance of Soils held by National Center for Earthquake Engineering Research (NCEER) agreed that the values of the correction factor proposed by Seed and Harder (1990) were too conservative. Based on the results of other researchers and taking into 
consideration the effect of void ratio, they proposed a new set of graphs for engineering ractice (Figure 2.12).

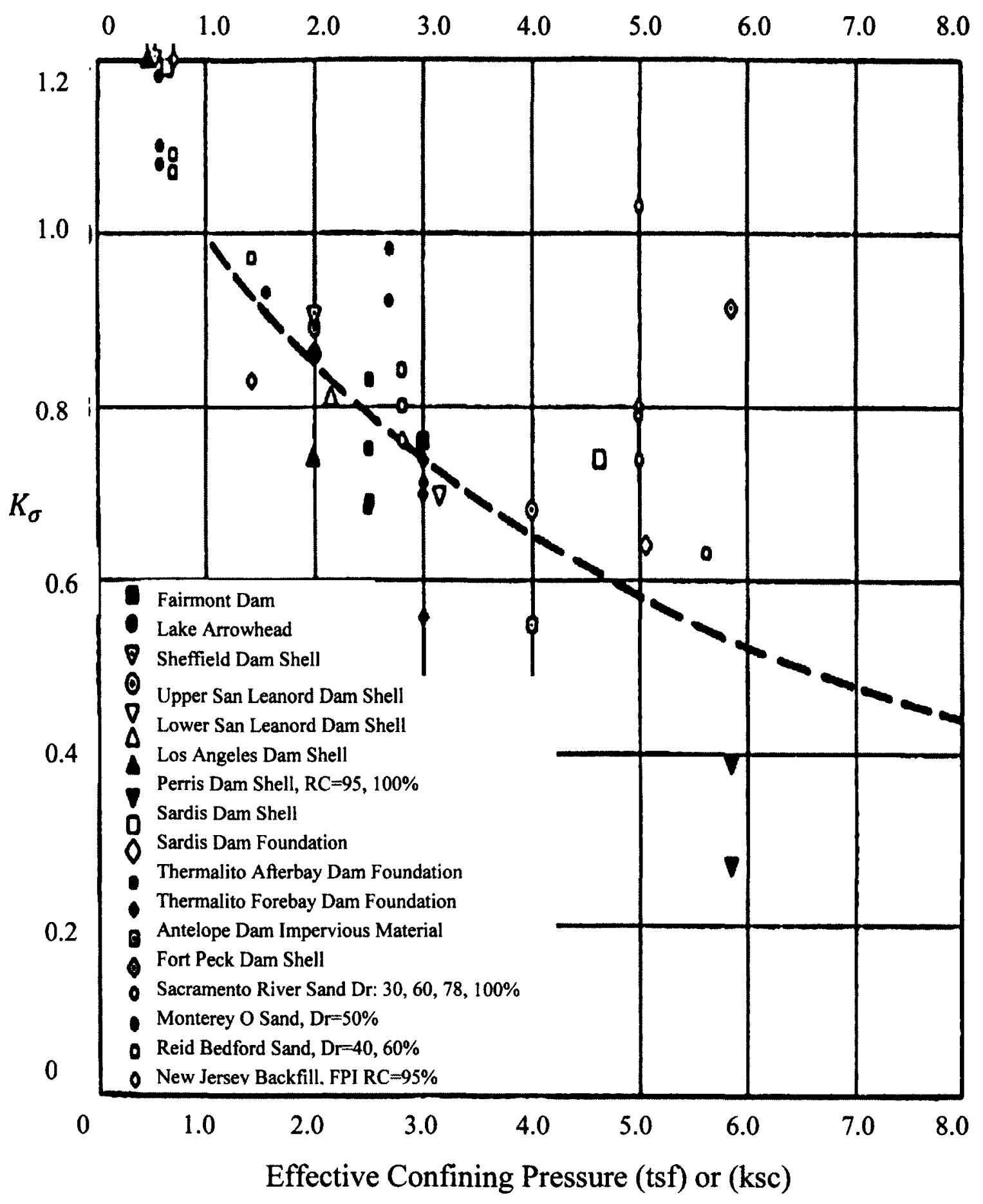

Figure 2.11 Relationship between effective confining pressure and $K_{\sigma}$ correction factor (After Seed and Harder 1990) 


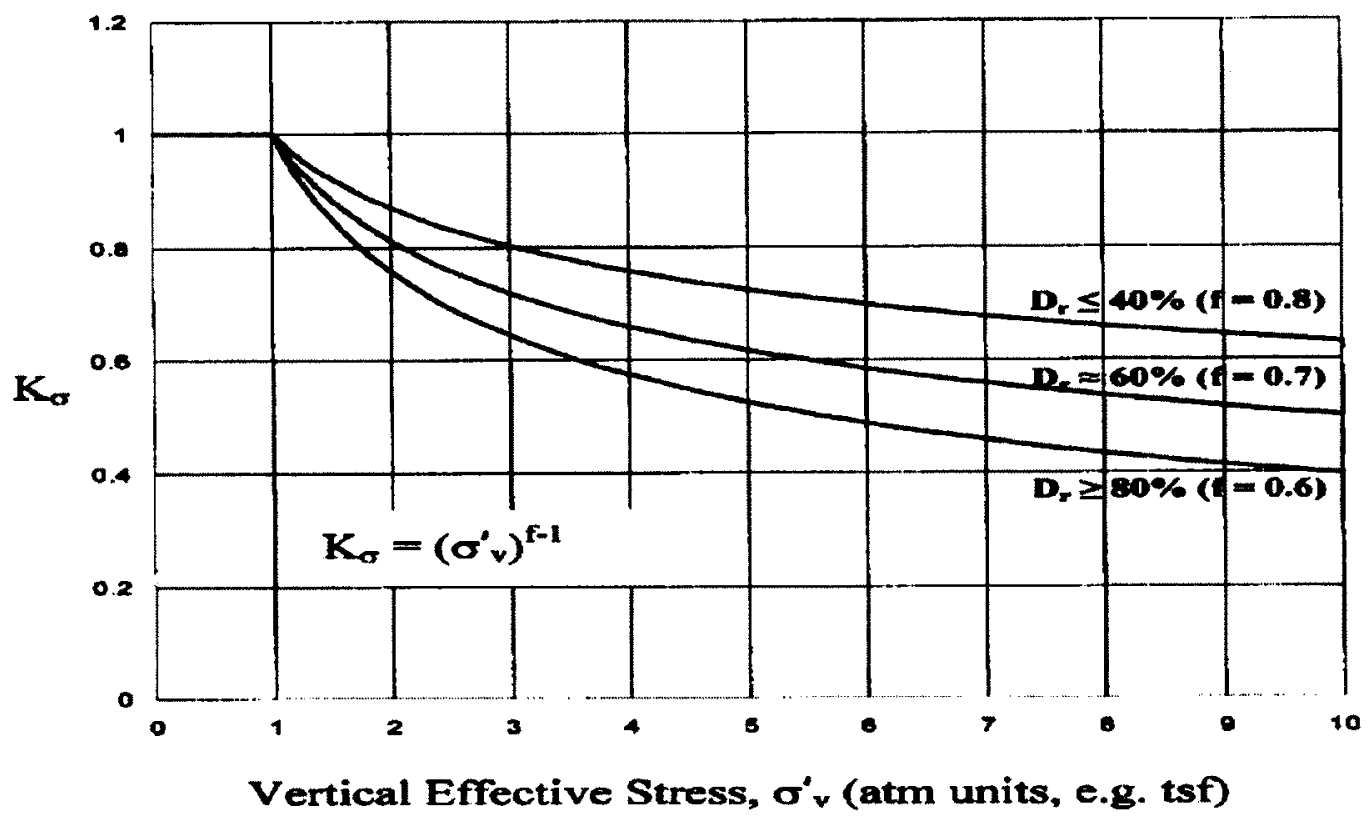

Figure 2.12 $K_{\sigma}$ correction factor recommended for engineering practice (After Youd et al., 2001)

Boulanger and Idriss (2004) proposed a new a set of curves to estimate $K_{\sigma}$ based on relative state parameter index. It has been shown that the values suggested by Haynes and Olsen (1983) and Youd et al. (2001) were too conservative (Figure 2.13). The values of the overburden correction factor proposed by Boulanger and Idriss (2004) are very close to those proposed by Vaid and Sivathayalan (1996) based on simple shear test results. The largest deviations are observed at low relative density of $40 \%$.

All the results and recommendations noted above for confining stress correction factor come from tests on normally consolidated samples. Manmatharajan (2011) investigated the effect of overconsolidation on $K_{\sigma}$ factor using simple shear tests. As shown in Figure 2.14 a systematic reduction in the correction factor can be seen as the overconsolidation ratio (OCR) increases regardless of the relative density. Finally, it can be understood from Figures 2.12 to 2.14 that the differences in the 
suggested values of the correction factors are minor and regardless of which value one adopts in the design, the outcome would be a relatively conservative design.

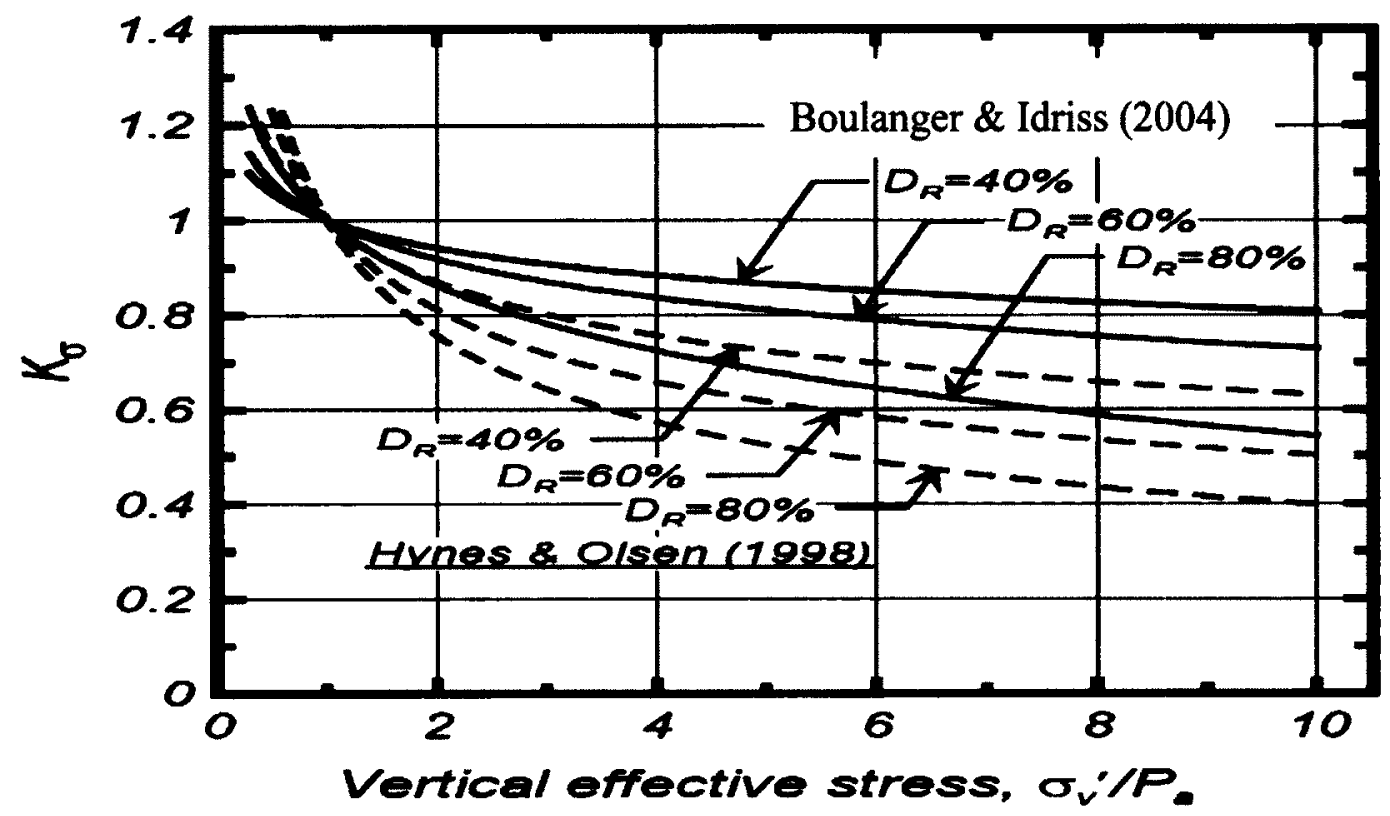

Figure 2.13 $K_{\sigma}$ correction factor (After Boulanger and Idriss, 2004)

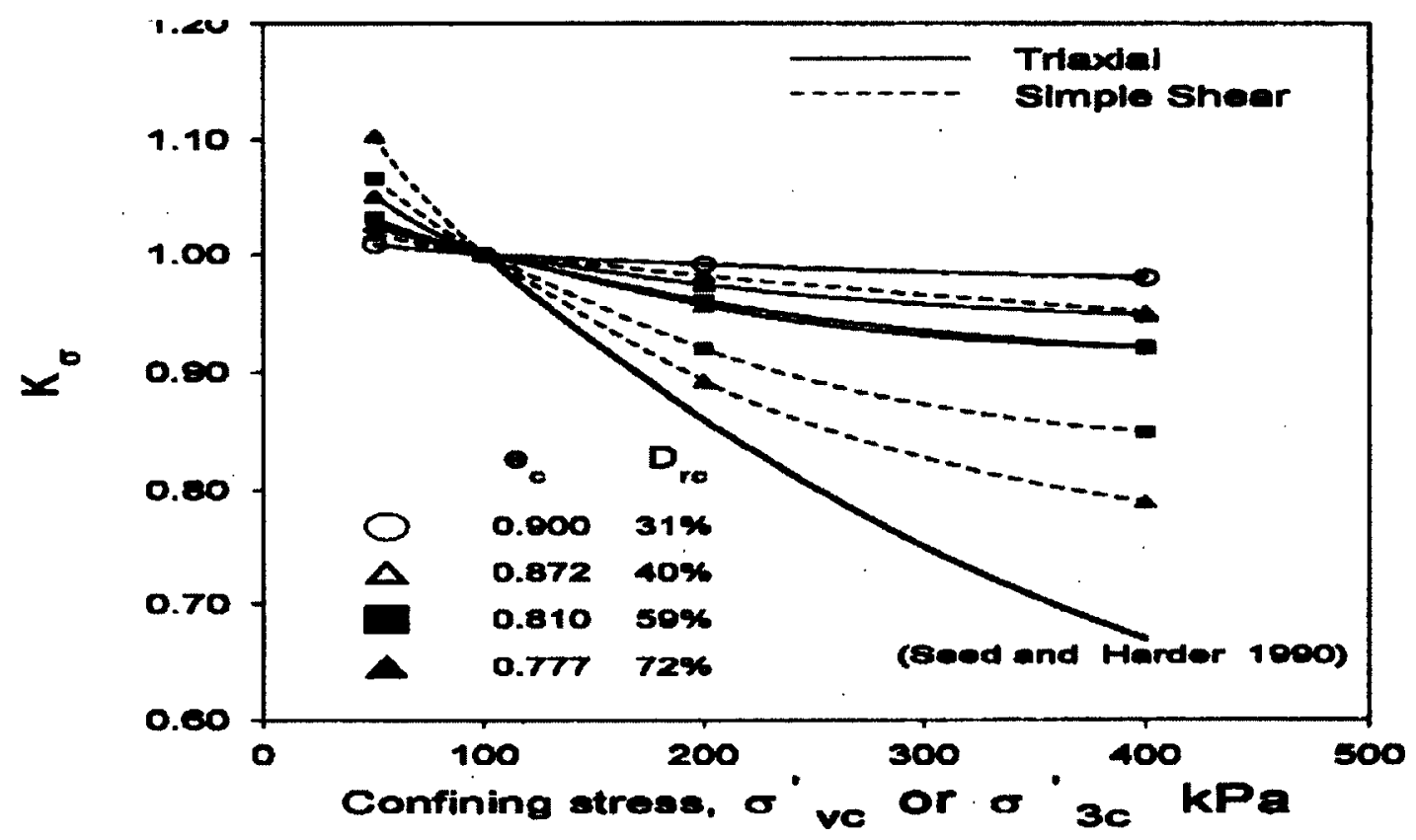

Figure 2. $14 K_{\sigma}$ correction factor obtained from simple shear and triaxial test results (After Vaid and Sivathayalan, 1996) 

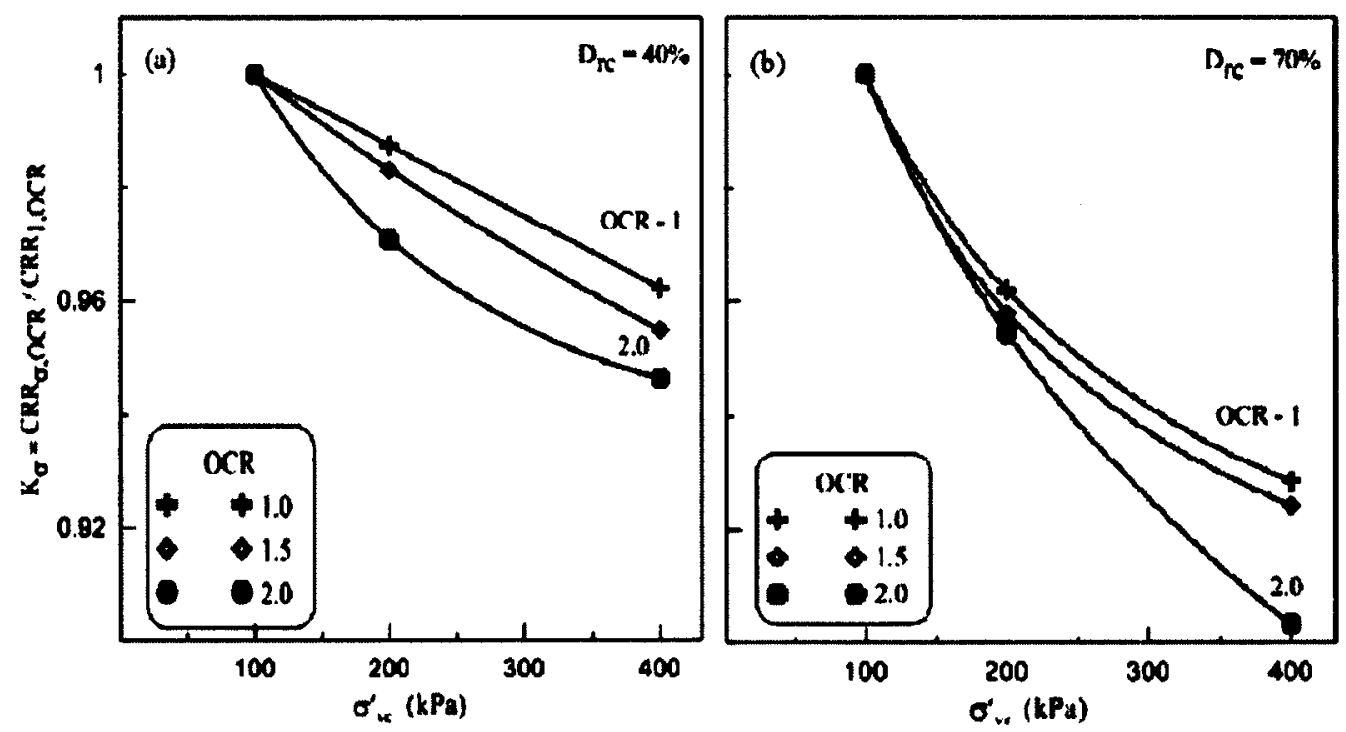

Figure 2.15 Effect of overconsolidation ratio (OCR) on $K_{\sigma}$ (a) Loose (b) Dense (After Manmatharajan, 2011)

\subsubsection{Effect of Initial Static Stress}

The presence of a static shear during consolidation can affect the cyclic response of saturated sand deposits. Lee and Seed (1967) were the first researchers to study the cyclic response of anisotropically consolidated specimens under triaxial loading. Some further studies showed that presence of a static shear would lead to a higher cyclic resistance (Lee and Seed, 1967; Lee et al., 1975; Seed, 1983; Seed et al., 1985). On the hand, Castro (1969), Casagrande (1975), Castro and Poulos (1977) and Castro et al. (1982) performed cyclic triaxial tests on anisotropically consolidated samples and came to an opposite conclusion that the static shear would decrease the cyclic resistance. Vaid and Chern (1985) have shown that these different conclusions are due to the fact that the effect of static shear is dependent on relative density, magnitude of static shear stress, and the strain criteria used to define liquefaction. 
The level of static shear is characterized by the static shear stress ratio, $\alpha$, defined as the ratio of static shear on the horizontal plane over the effective confining stress.

$$
\begin{array}{ll}
\alpha=\frac{\tau_{s}}{\sigma_{v c}^{\prime}} & \text { Simple Shear } \\
\alpha=\frac{\left(\sigma_{v c}^{\prime}-\sigma_{h c}^{\prime}\right) / 2}{\sigma_{n c}^{\prime}} & \text { Triaxial }
\end{array}
$$

Seed and Harder (1990) based on the data available at that time, introduced a correction factor of $K_{\alpha}$ as in equation (2.3) to calculate the cyclic resistance.

$$
K_{\alpha}=\frac{\operatorname{CSR}_{\alpha}}{\operatorname{CSR} R_{\alpha=0}}
$$

Unlike the $K_{\sigma}$ factor, there is not a strong agreement on the value of $K_{\alpha}$, and a wide range of values based on relative density has been proposed (Seed and Harder, 1990; Harder and Boulanger 1997; Vaid et al., 2001; Sivathayalan and Ha, 2011). However, recent studies (Boulanger and Idriss, 2004; Sivathayalan and Ha, 2004) have proven that relative density is not a proper parameter to quantify the static shear correction factor. As mentioned by Sivathayalan and $\mathrm{Ha} \mathrm{(2011),} \mathrm{the} \mathrm{mechanism} \mathrm{that} \mathrm{leads}$ to liquefaction also needs to be considered when dealing with the effect of static shear. They have shown that specific levels of static bias can decrease cyclic resistance of dense specimens that deform contractively and ignoring this based on relative density will lead to unsafe design. 

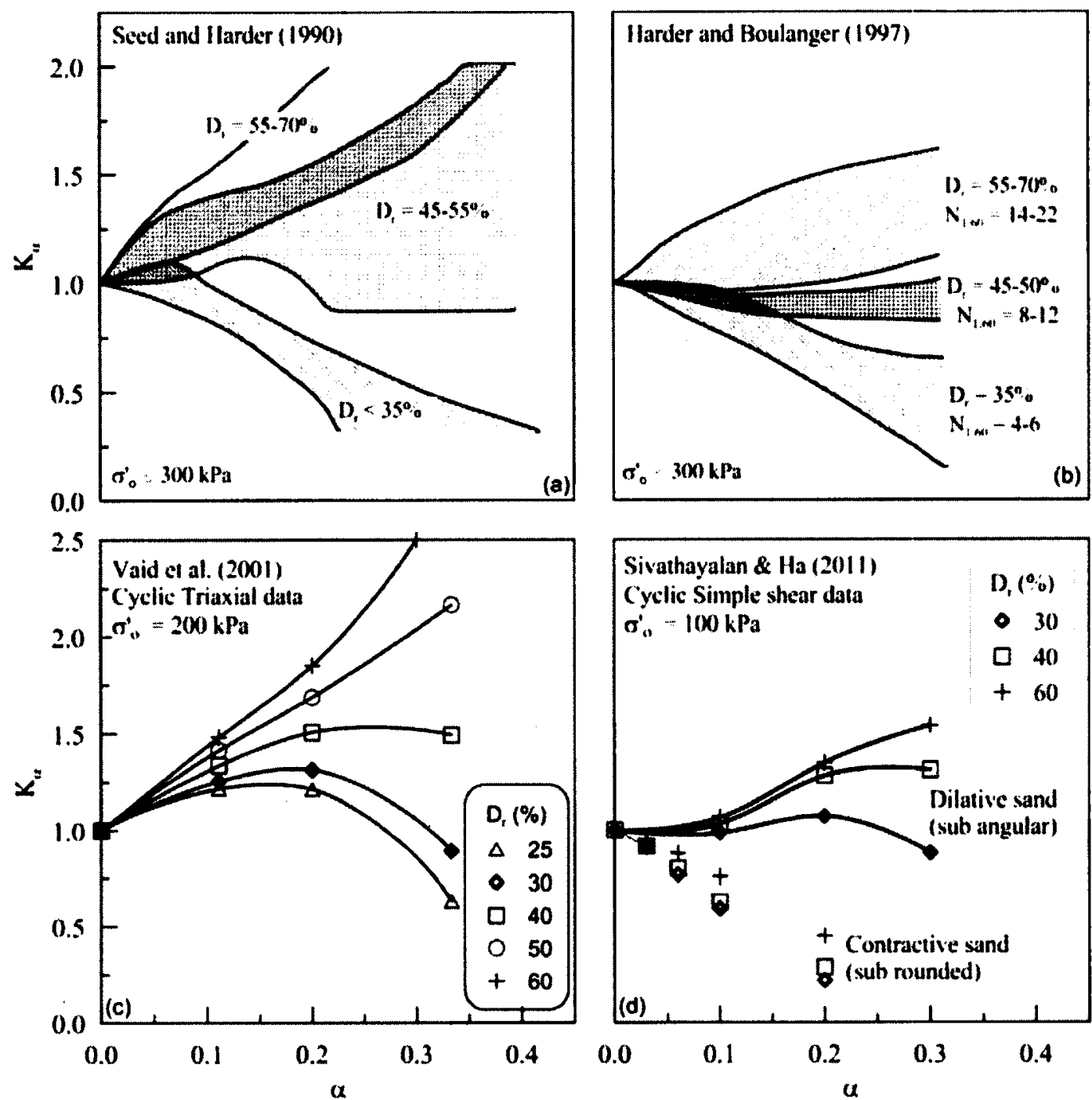

Figure 2.16 Range of $K_{\alpha}$ correction factor at different relative density levels (After Sivathayalan and $\mathrm{Ha}, 2011$ )

Finally, to determine the cyclic resistance of a ratio of a specific site (at a given level of static shear and confining stress), it is common to use a reference CRR at $\alpha=0.00$ and confining pressure of $100 \mathrm{kPa}$ and use $K_{\alpha}$ and $K_{\sigma}$ factors as in equation (2.4).

$$
C R R_{\sigma, \alpha}=C R R_{\sigma_{n}^{\prime}=100 \mathrm{kPa}, \alpha=0} * K_{\sigma} * K_{\alpha}
$$


Although in equation (2.4) the two correction factors are considered to have no effect on each other, Vaid et al. (2001) have shown that they may be inter-related.

\subsection{POST LIQUEFACTION RESPONSE}

Large deformations and flow failure can occur after the cessation of the shaking. The most notable of these deformations are the ones happened in the lower San Fernando dam (Seed et al., 1985). Vaid and Thomas (1995) have shown that the residual normal stress after the cyclic loading is the main factor that defines the type of post liquefaction behaviour. In cyclic loading with stress reversal, the excess pore pressure ratio will reach $100 \%$ following liquefaction and as result the sand would be at state of transient zero effective stress at the end of cyclic loading. On the other hand, when there is no stress reversal (i.e. the presence of static shear), the excess pore pressure development is small and there will a considerable amount of residual effective confining pressure at the end of shaking (Finn et al., 1971; Vaid and Thomas, 1994). Figure 2.17 shows the stress- strain response of a tailings material which is one of the first studies on the post cyclic response of sand (Kuerbis, 1989).

Large deformations occur during post liquefaction loading due to the void ratio redistribution, and change in stiffness and shear resistance. During an earthquake, the excess pore pressure increases and brings the sand to a state of zero effective stress ( $100 \%$ excess pore pressure generation). After the cessation of the cyclic loading, water will migrate from the regions with higher piezometric head depending on the hydraulic gradients. This would lead to the redistribution of voids and causes volume change and consequently densification of the sand. 


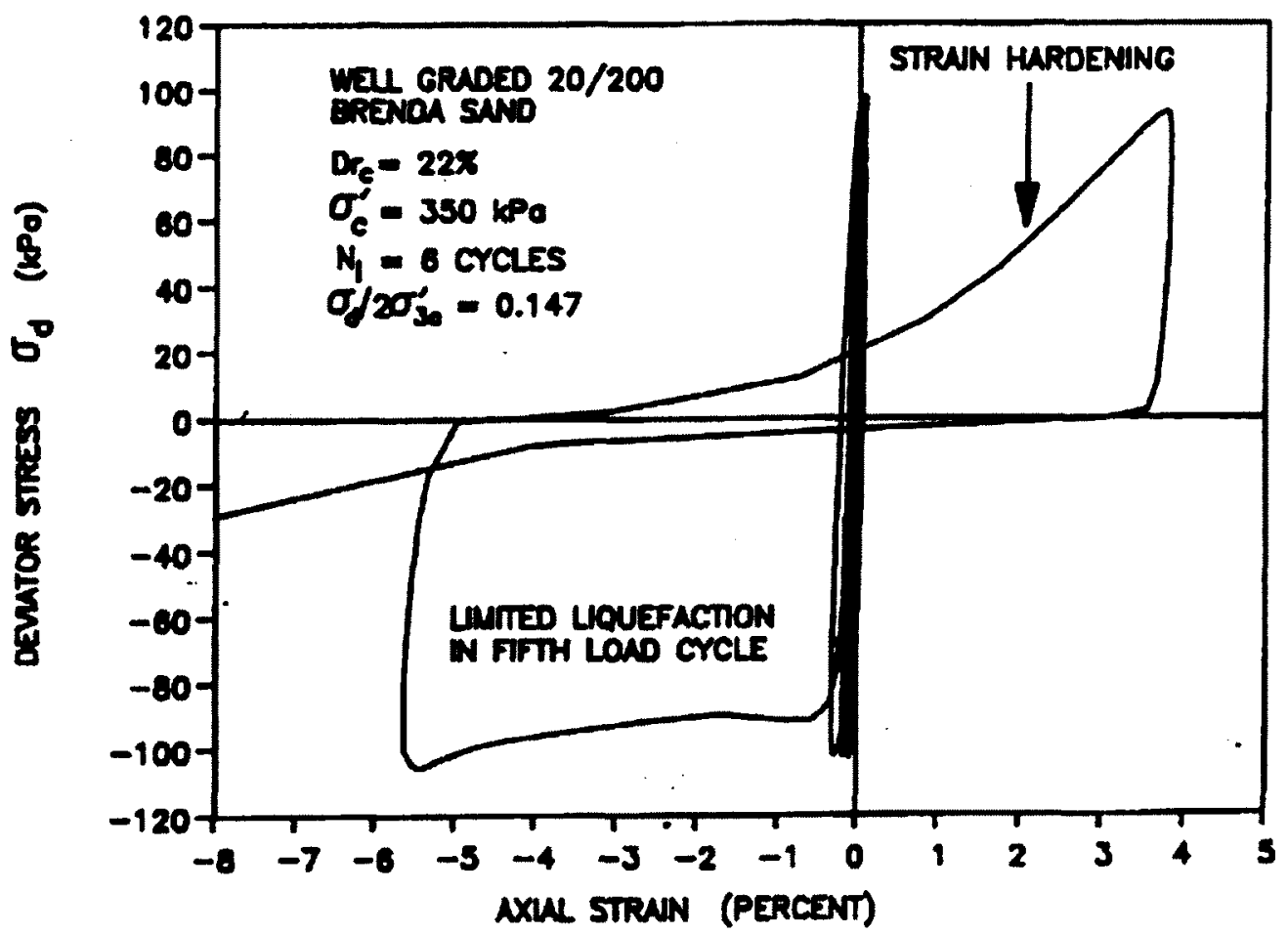

Figure 2.17 Stress-strain response of tailings sand (After Kuerbis, 1989)

Figure 2.18 shows the post liquefaction strain-strain curve. There are three distinct regions marked in the curve (Vaid and Thomas, 1995). In the first region, the soil stiffness and strength are zero. As the response enters the second region, the stiffness starts to increase gradually as strain increases. Finally, in the third region, the shear stiffness remains constant. Factors the influence the deformation characteristics of post liquefaction response are: relative density, initial confining stress, and loading mode (Vaid and Thomas, 1995; Vaid and Sivathayalan, 1996; Shamoto et al., 1997; Sivathayalan and Yazdi, 2004). 


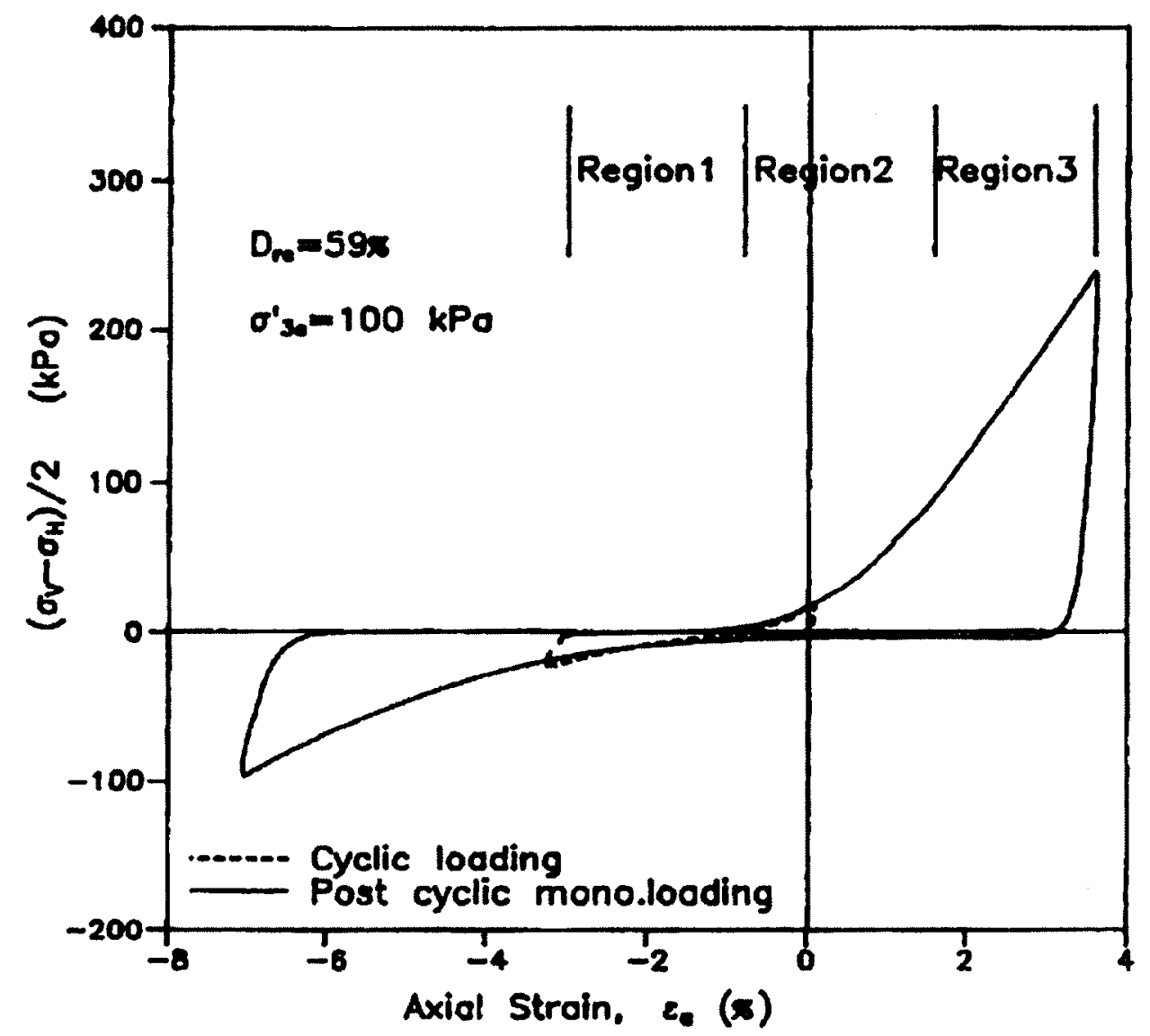

Figure 2.18 Post-cyclic stress-strain response (After Vaid and Thomas, 1995)

\subsection{REVIEW OF TRIAXIAL APPARATUS}

In order to overcome disadvantages of direct shear device, cylindrical compression tests were developed. Those attempts lead to the triaxial test which is by now the most popular device and is widely used in soil mechanics research. One of the advantages of triaxial test is the ability to control drainage conditions, i.e. drained, undrained or partially drained. Stress concentrations are much less intense in triaxial tests in comparison with direct shear. Unlike the pre-determined failure plane in direct shear tests, the failure plane in triaxial test is not fixed and can change according to the material properties. In addition, field stress paths can be simulated to some extent in the laboratory 
by triaxial test. However, it must be noted that the stress condition in triaxial test is axisymmetric and this is not exactly representative of many field conditions.

Lee and Seed (1967) performed the first liquefaction studies that used triaxial testing device. Triaxial apparatus has been in use for several decades and has been the most popular testing platform as the testing procedure in this device is simple and straightforward in comparison with the complicated three-dimensional devices. In triaxial testing, a tall cylindrical sample covered with a non-reinforced membrane is used while the confining pressure is applied all around it. During the test, vertical load is applied (cyclic or monotonic) while the confining pressure is kept constant. The specimen is supported by top and bottom platens which allow drainage of pore water. The influence of these restraints causes some stress and strain non- uniformities in the test specimen. Consequently, bulging during compression test or necking during extension tests can be seen at large strains. It has been recommended to use a length to diameter ratio (aspect ratio) of two or higher in order to reduce this effect (Taylor, 1948; Bishop and Green, 1965; Lade, 1982). On the other hand, the use of lubricated end platens has also been proposed by some researchers (Rowe and Barden, 1964; Barden and Khayatt, 1966), but, it has been shown to introduce bedding problems (Sarsby et al., 1980).

Triaxial tests can be done in two general types: compression and extension. During a compression test, vertical stress increases in comparison with the lateral stress, however, the reverse is done in an extension test. In both scenarios the applied stresses (vertical and horizontal) are principal. In compression test the major principal stress axis is the same as vertical stress and minor principal stress axis coincides with the horizontal stress axis while the reverse occurs in an extension test. The triaxial stress path can easily 
be understood by using Mohr's circle of stresses as depicted in Figure 2.19. In both isotropically and anisotropically consolidated test samples, it can be noticed that there is an instantaneous rotation of major principal stress direction by $90^{\circ}$ when the axial deviatoric stress reverses the direction. These types of $90^{\circ}$ jump rotations of the principal stresses are not expected in-situ where smooth and continue rotation of principal stress axis occurs. In addition, the axisymmetric lateral deformation that occurs in triaxial tests in not a suitable representative of the in-situ plane strain deformations. However, the failure plane is not fixed in triaxial test and varies according to the material properties (friction angle). This angle is set to be $(45+\varphi / 2)^{\circ}$ for frictional Mohr-Coulomb materials.

The lack of control on the value of intermediate principal stress $\left(\sigma_{2}^{\prime}\right)$ causes the triaxial test not to be representative field stress conditions. In a triaxial test, the intermediate principal stress takes either the value of the minor principal stress (compression test) or the value of the major principal stress (extension test). Thus the intermediate principal stress parameter, $b=\left(\sigma_{2}^{\prime}-\sigma_{3}^{\prime}\right) /\left(\sigma_{1}^{\prime}-\sigma_{3}^{\prime}\right)$, is either zero or one. This deficiency can even influence the friction angle (Uthayakumar and Vaid, 1998). 
(a)
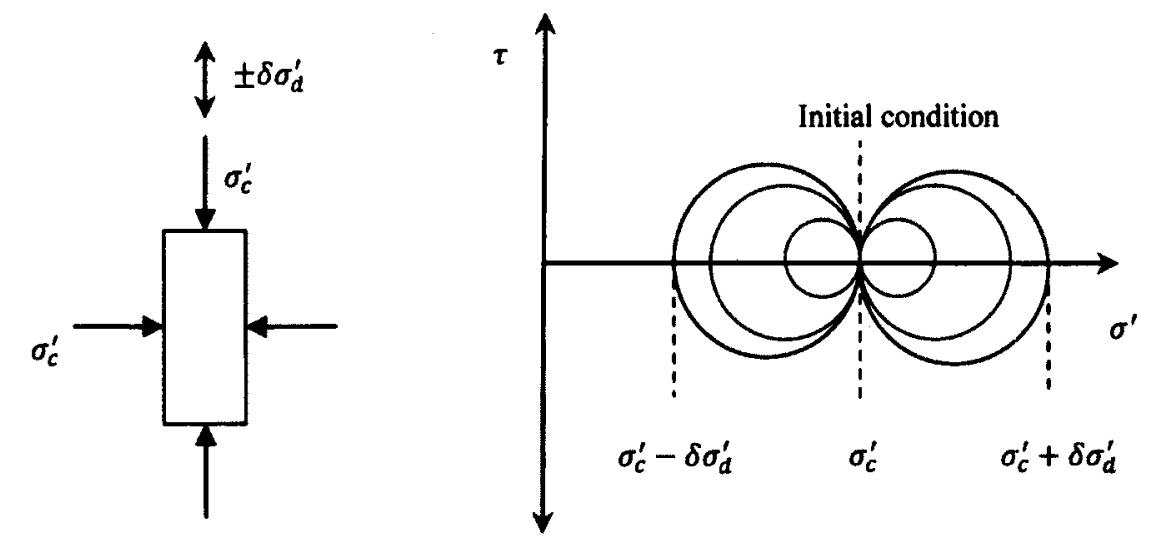

(b)
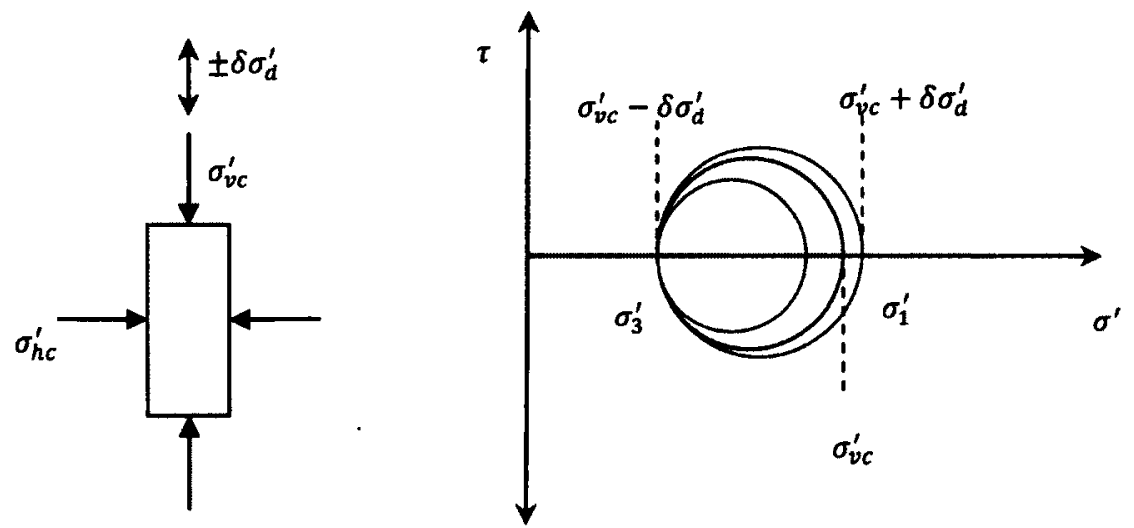

Figure 2.19 Stress conditions and Mohr's circle of triaxial test (a) Isotropically consolidated (b) Anisotropically consolidated 


\section{CHAPTER 3}

\section{EXPERIMENTAL WORK}

Details of the experimental work carried out in pursuit of the research objectives mentioned in chapter 1 are provided in this chapter. Tested material, the apparatus, sample preparation method, and possible errors and steps taken to minimize them are discussed. In addition, the repeatability of tests is demonstrated by showing typical results of the experiments at identical initial states.

\subsection{MATERIAL TESTED}

Tests have been performed on Fraser River sand which has been obtained from the Fraser Delta in British Columbia, Canada. The main reason behind the selection of this sand is that it underlies the highly populated Fraser Delta which is located in a region with high seismic activity and hence is highly susceptible to liquefaction. In order to remove the fine particles and obtain uniform specimens, the sand was wet sieved through a $0.075 \mathrm{~mm}$ sieve ( $\# 200$ sieve). Figure 3.1 shows the particle size distribution of the wet sieved materials. Average particle size $\left(D_{50}\right)$ is $0.28 \mathrm{~mm}$, uniformity coefficient $\left(C_{u}\right)$ is 2.29 and coefficient of curvature $\left(C_{c}\right)$ is 1.27 . The specific gravity of Fraser River sand is 2.72. Maximum void ratio, measured according to ASTM D4252, is 0.806 and minimum void ratio, according to ASTM D4253, is 0.509 . The initial void ratios used in the experimental work are maintained at three states yielding loose $(0.756 \pm 0.005)$, medium dense $(0.696 \pm 0.005)$ and dense $(0.614 \pm 0.005)$ samples. 


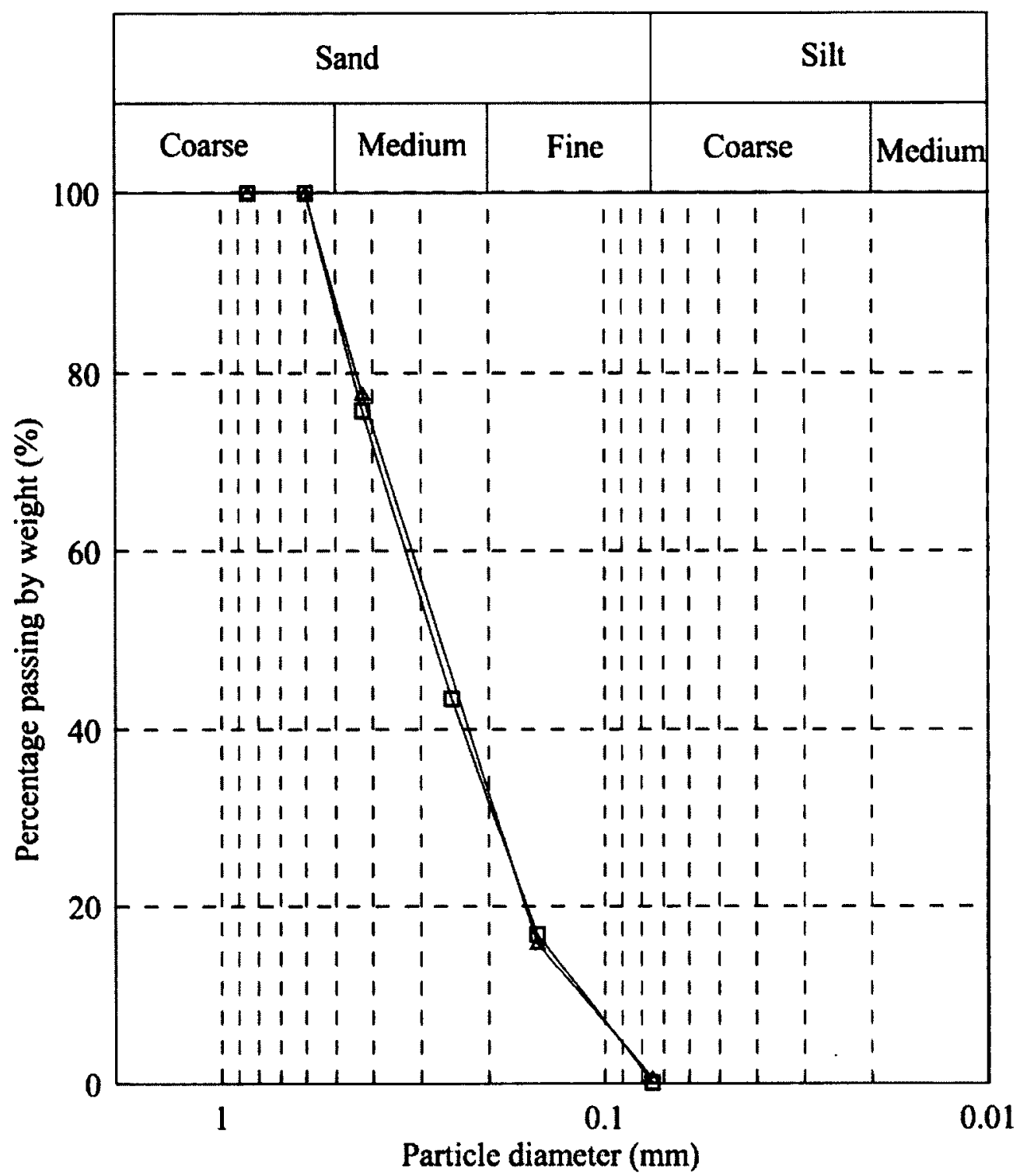

Figure 3.1 Particle size distribution of Fraser River sand

\subsection{TESTING APPARATUS}

All tests were performed using triaxial loading conditions. The triaxial apparatus used in this study is capable of performing strain controlled monotonic loading under extension and compression loading modes and stress controlled cyclic loadings. Figure 3.2 shows a schematic diagram of the testing apparatus. Triaxial specimens of approximately $130 \mathrm{~mm}$ height and $63 \mathrm{~mm}$ diameter were used in this study. End restraint 
was minimized by using polished top cap and pedestal with $21 \mathrm{~mm}$ diameter drainage stones at the center.

An "S"-Beam load cell with a precision of better than $0.01 \mathrm{~kg}$ and capacity of 450 kg was used to measure the applied vertical load. Axial strain was measured by a Linear Variable Displacement Transducer (LVDT) with a range of $25 \mathrm{~mm}$ and a precision better than $0.01 \mathrm{~mm}$. Volumetric deformation was measured using a Differential Pressure Transducer (DPT). The DPT is capable of measuring differential pressures at ultra low levels so that it yields a precision of $0.05 \%$ of volumetric strain for the samples in this study. This differential pressure transducer has a measuring range of $\pm 3 \mathrm{kPa}$ differential. Pore water pressure and cell pressure are measured using high performance millivolt output pressure transducers with the precision of better than $0.1 \mathrm{kPa}$, and range of 700 $\mathrm{kPa}$.

A standard triaxial cell was used in this study and a low friction seal used to prevent air bleeding from the connection of the cell with the loading ram and the base. In order to be able to accurately measure the axial load outside the cell, the friction was reduced to a negligible amount by balancing the cell pressure against an equal pressure in the clearance between the ram and the bushing.

Stress controlled loading is applied through the double acting, low- friction air piston. This piston is connected in series to the constant speed drive which applies the strain controlled loading. This series connection provide a smooth transition from stress controlled loading (cyclic) to stress controlled (monotonic) loading without undue disturbance to the specimen. Also, during anisotropic consolidation, the desired deviator stress is applied using the piston. 


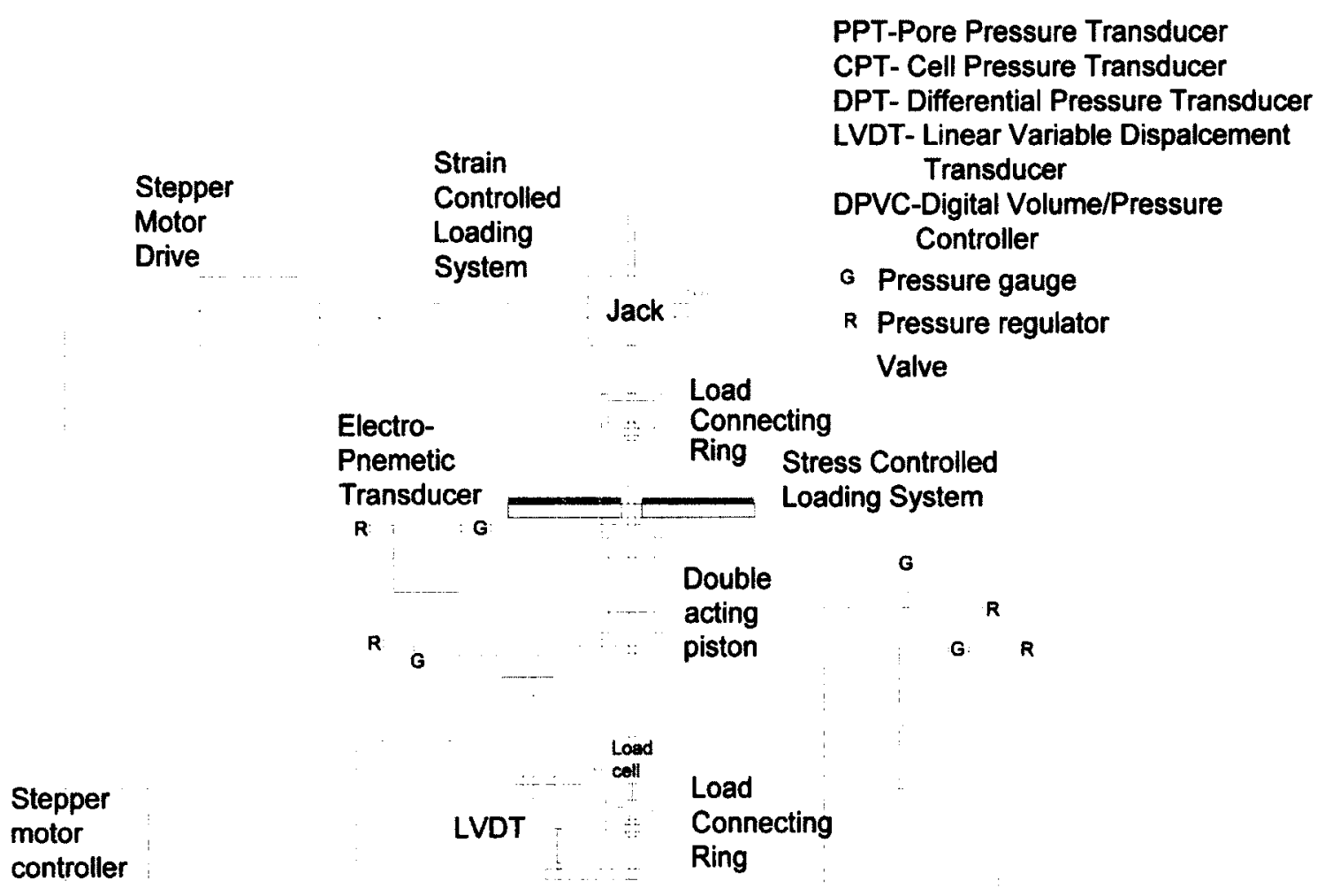

Data acquisition system

DPT

Computer

PPT

CPT

DPVC

Deaired

water

Figure 3.2(a) Schematic diagram of the triaxial device in this study (After Logeswaran, 2005) 


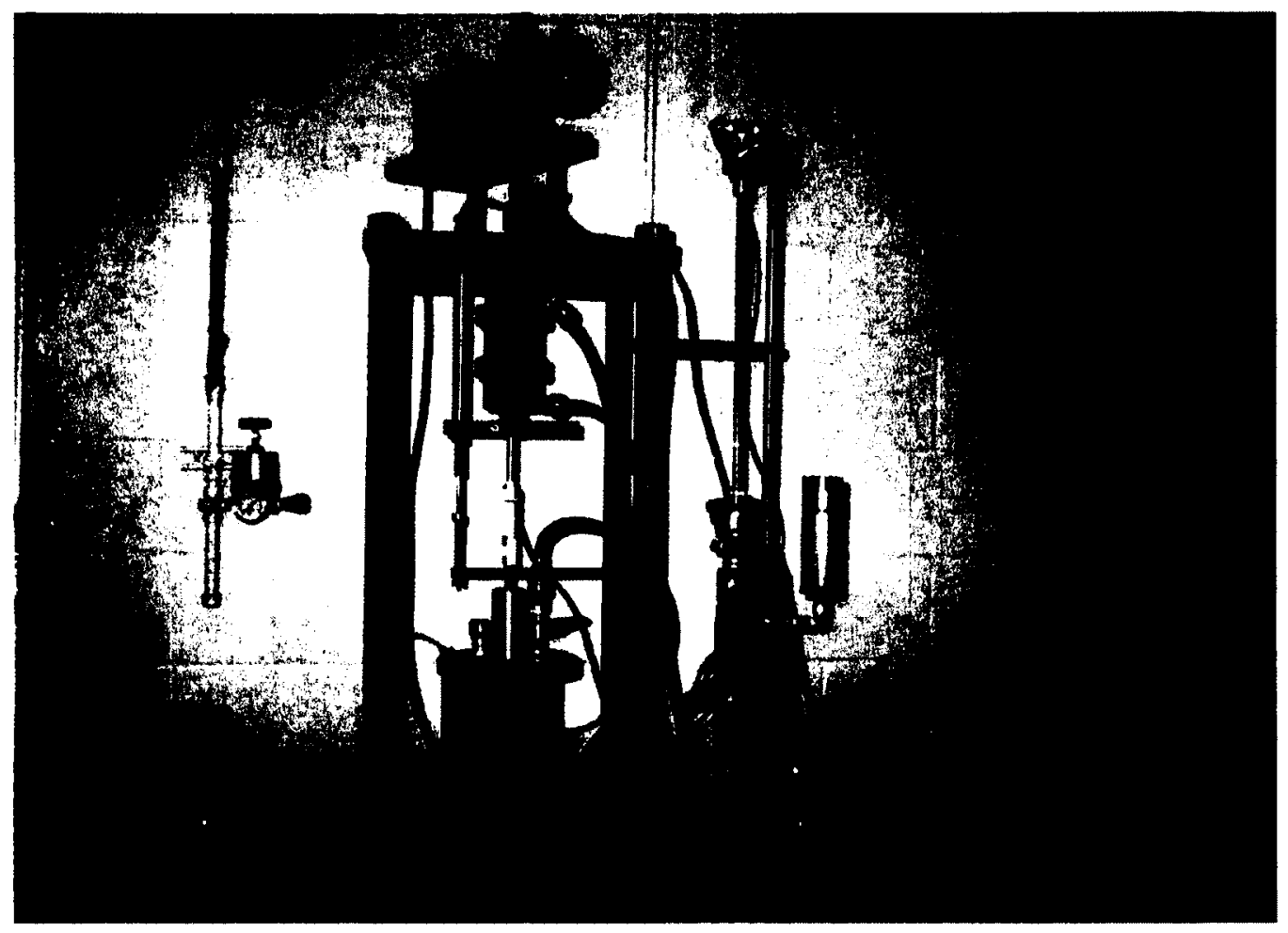

Figure 3.2(b) Triaxial device at the advanced geotechnical laboratory at Carleton University

\subsection{TEST SPECIMEN}

\subsubsection{Preparation Method}

Although undisturbed samples yield a more representative behaviour of the soil in-situ and should be preferred in laboratory testing, obtaining these samples in sandy deposits is difficult. The only reliable method of getting undisturbed sand samples is insitu ground freezing which is extremely expensive (Yoshimi et al. 1989). Moreover, identical samples are essential for a systematic study of soil behaviour which cannot be obtained by using undisturbed samples. Therefore, reconstituted specimens are usually used in laboratory to study the fundamental behaviour of granular materials. 
The water pluviation technique was used to prepare samples in this study. This method has been described by Vaid and Negussey (1988) and has proven to yield repeatable uniform specimens. This method produces samples which provide similar fabric as natural alluvial sands and hydraulic fills (Oda, 1972). Water pluviation technique also ensures full saturation of the specimen since during the deposition of the sand particles there is no contact between air and sand particles. To achieve a consistent loosest state void ratio, extra precautions must be taken to eliminate vibration during sample preparation. However, lower void ratios can be obtained by applying vertical vibration by tapping the base after the deposition of the sand. The main disadvantage of this method of sample preparation is that it will lead to particle segregation in well graded soils. However, the sand used in this study is poorly graded and hence this method would yield homogenous repeatable specimens.

To remove the trapped air between particles, the sand was boiled and then cooled down at room temperature without any contact with air. This sand was then pluviated through de-aired water in the membrane lined mould. Sand was deposited in the mould by slowly moving the flask in a circular or spiral path so that the flask tip was always submerged into the water. This process allows making of homogeneous samples with a consistent relative density. Top of the sample was then levelled by siphoning the excess sand and water. Then the top cap was placed on the sample with extra care to avoid any unwanted disturbance. To obtain higher relative densities, an external vertical vibration was applied by tapping beside the base using a soft hammer. After reaching the desired void ratio, the membrane was carefully rolled up onto the cap and an O-ring was placed around the cap to completely seal the sample. To prevent the collapse of the sample after 
the removal of the mould, a $25 \mathrm{kPa}$ suction was applied to the bottom of the sample prior to removing the mould. During suction, the drainage valve was kept open and the volume of expelled water was measured by collecting it in a graduated burette. The initial volume of the sample is calculated using the mould cavity area and sample height. Knowing the expelled water volume and sample height after applying the vacuum, the specimen void ratio can be determined very accurately. Vaid and Sivathayalan (1996) have shown that this method reduces the potential error in measuring the circumference of the sample and subsequently minimizes the errors in void ratio calculations.

\subsubsection{Saturation}

After the sample was prepared, the degree of saturation was checked by measuring the Skempton's B-value. B-value has been defined as the ratio of the pore pressure increase, $\Delta u$ to the change in all-around pressure, $\Delta \sigma_{3}$ (Skempton, 1954). In a fully saturated sample, any increment of $\Delta \sigma_{3}$ will be equal to the increment of pore pressure and will yield a B-value of 1.00 . By carrying this test, essentially complete saturation of all specimens in this study was confirmed by obtaining a minimum B-value of 0.99 .

\subsubsection{Consolidation}

After ensuring a high B-value, the sample was consolidated to the target confining stress state (hydrostatic or anisotropic). The consolidation processes was done by following the below noted steps:

- Setting the back pressure to the same value as the sample pore pressure at the end of saturation. 
- Open the drainage valve.

- Decrease the back pressure to obtain the target effective stress stresses. Alternatively, the all around cell pressure could have been increased to reach the desired effective stress.

The samples in this study are both isotropically and anisotropically consolidated. To achieve a specific mean effective confining stress $\left(\sigma_{n c}^{\prime}\right)$, the horizontal stress is increased manually by altering the cell pressure and then the vertical stress is adjusted automatically so that the desired $K_{c}$ value was always maintained during the consolidation process (Figure 3.3). To obtain overconsolidation, the samples were loaded up to a higher mean effective confining stress of $\sigma_{n o c}^{\prime}$ along the same $K_{c}$ line and then unloaded to the final value of mean effective confining stress $\left(\sigma_{n c}^{\prime}\right)$ and finally the overconsolidation ratio (OCR) was defined as in equation (3.1).

$$
O C R=\frac{\sigma_{n o c}^{\prime}}{\sigma_{n c}^{\prime}}
$$

During the consolidation process the pressure was applied in several steps so that the ratio of the stress increment to the previous stress was constant. The load was increased when the sample volume reached a constant value. Drainage was permitted to continue for a fixed amount of time (about 20 minutes) at the last load increment. This was done to assure that the sample will not have further volume change and also to minimize the time dependence effect.

Loading and unloading characteristic of isotropically consolidated samples of Fraser River sand at different initial relative densities prior to consolidation is demonstrated in Figure 3.4 in $e-\log \left(\sigma_{n c}^{\prime}\right)$ space. The compressibility index $\left(C_{c}\right)$ is 
0.024 in loose sand $\left(D_{r i}=16 \%\right)$ and decreases to 0.016 as the level of relative density increases. However, no measurable difference was noted between medium dense and dense samples due to the relatively smaller range of stress levels used in the study. However, the rebound index $\left(C_{r}\right)$ measured is constant and does not depend on the initial void ratio and has a constant value of 0.010 . The ratio of $C_{c} / C_{r}$ reflects the contribution of recoverable deformation in total deformation. A ratio of 1.00 implies a fully elastic response. This ratio changes from 2.4 in loose samples to 1.6 in medium dense and dense specimens. A ratio of 2.4 in Fraser River sand indicates that a large portion of volumetric deformation is non-recoverable. This can be related to the fact that this sand is consisted of semi-angular particles which make the recovery of deformation after slippage hard when the packing is loose.

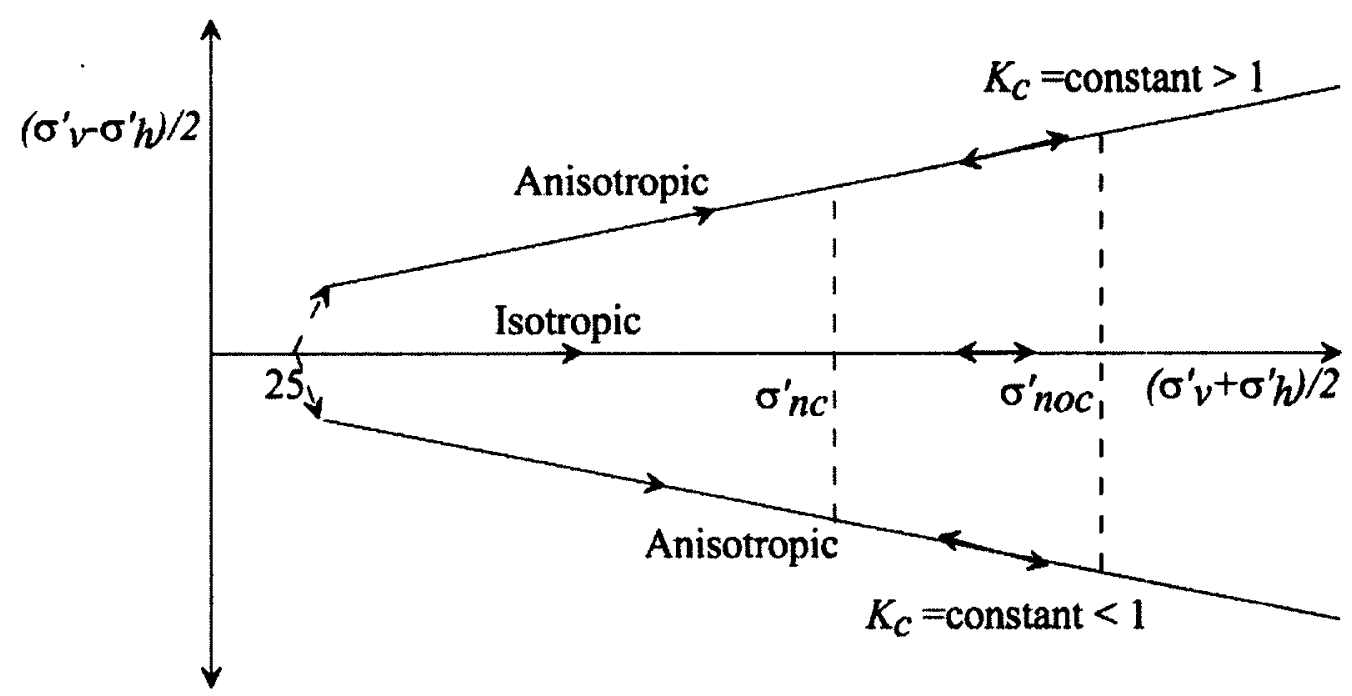

Figure 3.3 Isotropic and anisotropic consolidation stress path 


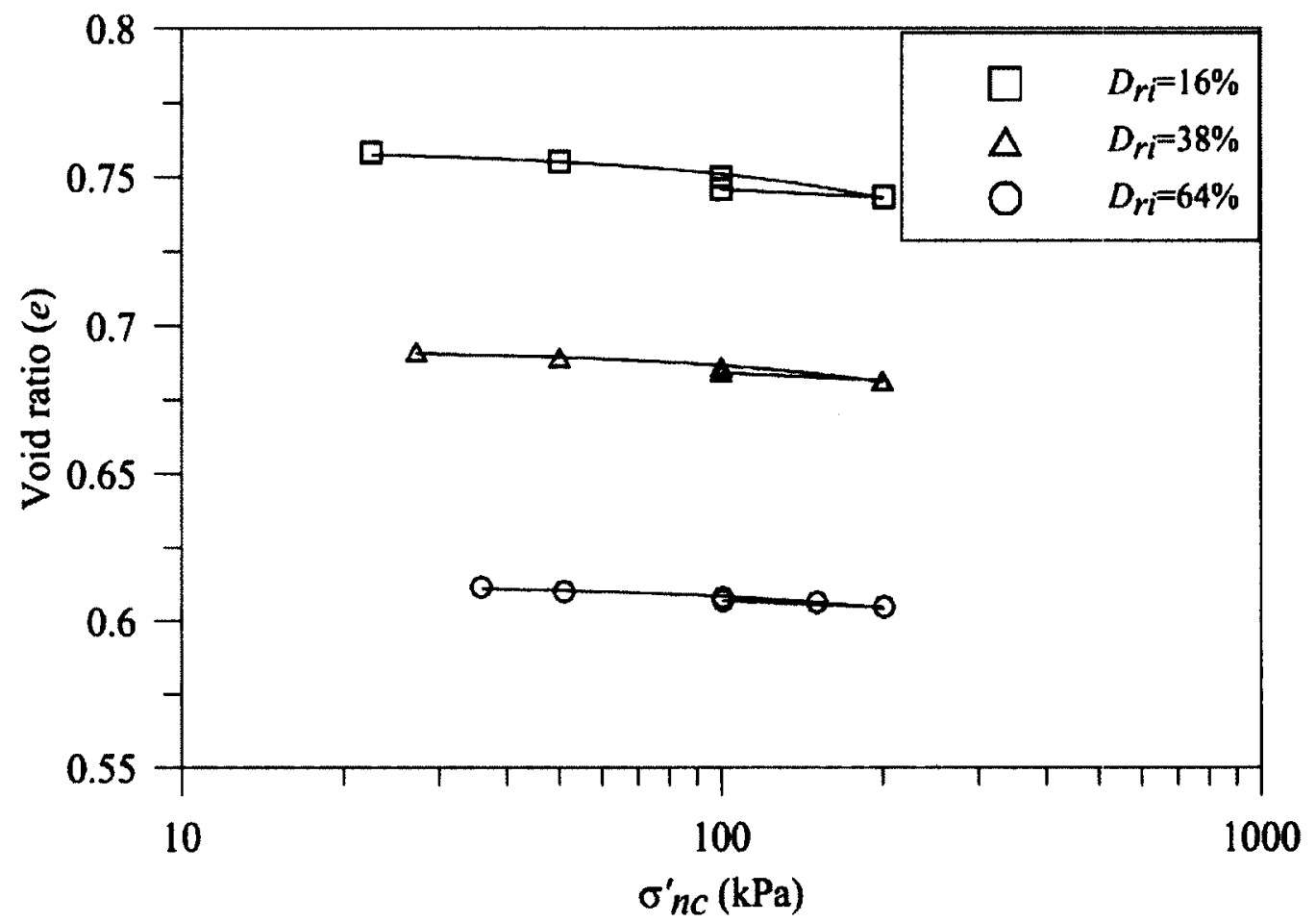

Figure 3.4 Isotropic loading and unloading characteristics of Fraser River sand at different initial void ratios

Figure 3.5 shows the change in void ratio with mean effective confining stress during consolidation under different $K_{c}$ values. Roy et al. (1996) have shown that the $e-\log \left(\sigma_{n c}^{\prime}\right)$ relation is highly affected by the induced anisotropy of effective stresses $\left(K_{c} \neq 1\right)$ during consolidation. It has been shown that beyond a mean effective confining stress level of $300 \mathrm{kPa}$, the normal consolidation line for samples with $K_{c}$ values of 1.50 and 2.00 would fall below the normal consolidation line of isotropically consolidated samples (Roy et al., 1996). The difference in the consolidation lines increases with increase in mean effective confining stress level. However, the effect of $K_{c}$ ratios of less than 1.00 on normal consolidation is not well studied. As shown in Figure 3.5, at low stress levels (less than $200 \mathrm{kPa}$ ), the $e-\log \left(\sigma^{\prime}{ }_{n c}\right)$ is not affected by the anisotropic 
consolidation ratio, or the effect is not detectable given the measurement resolution. Therefore, the average normal consolidation line has been used to represent the state of the sand prior to loading regardless of the $K_{c}$ value. On the other hand, the unloading characteristics of all samples were observed to be identical with a rebound index of 0.01 for all samples regardless of their $K_{c}$ value or initial void ratio.

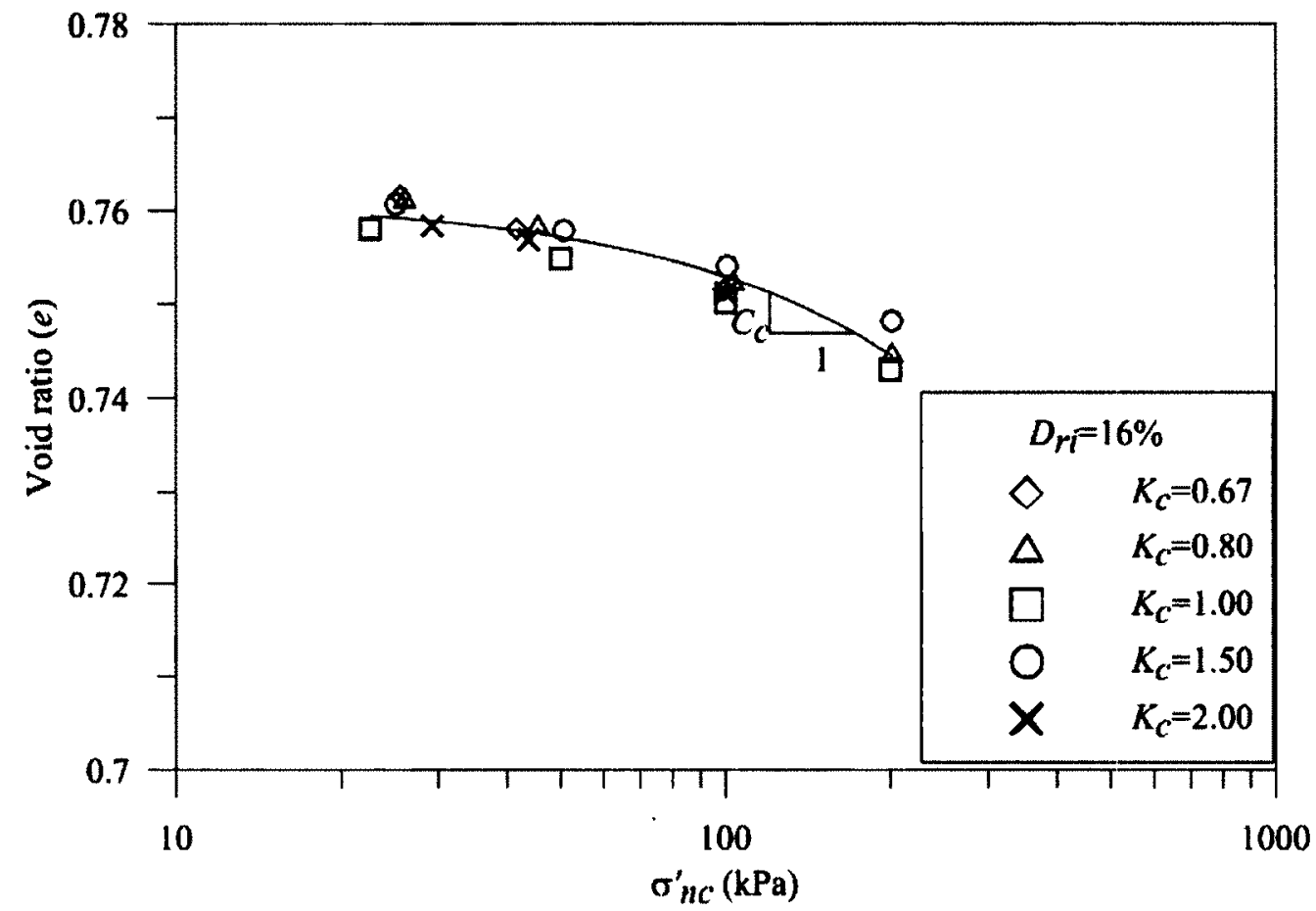

Figure 3.5 Effect of anisotropic consolidation on compressibility of Fraser River sand The strain paths during consolidation with different $K_{c}$ values are shown in Figure 3.6. The radial strain to axial strain ratio is about 2 in isotropically consolidated samples. This ratio is a reflection of the inherent anisotropy in water pluviated samples of Fraser River sand. On the other hand, the induced anisotropy affects the strain path and causes the strain path to deviate from the isotropic consolidation line. Since the horizontal stress is higher than the vertical stress, samples consolidated with $K_{c}=0.80$ have a higher radial strain than the axial strain. Therefore, the strain path tends towards the vertical axis. On 
the other hand, a $K_{c}$ value of greater than one would cause more axial strain than radial and therefore the strain path moves towards the horizontal axis. The unloading strain paths of three $K_{c}$ values are also shown in Figure 3.6. The radial to axial strain ratio is constant in unloading regardless of the $K_{c}$ value (either above or below one). This ratio is identical to the isotropic loading strain path slope.

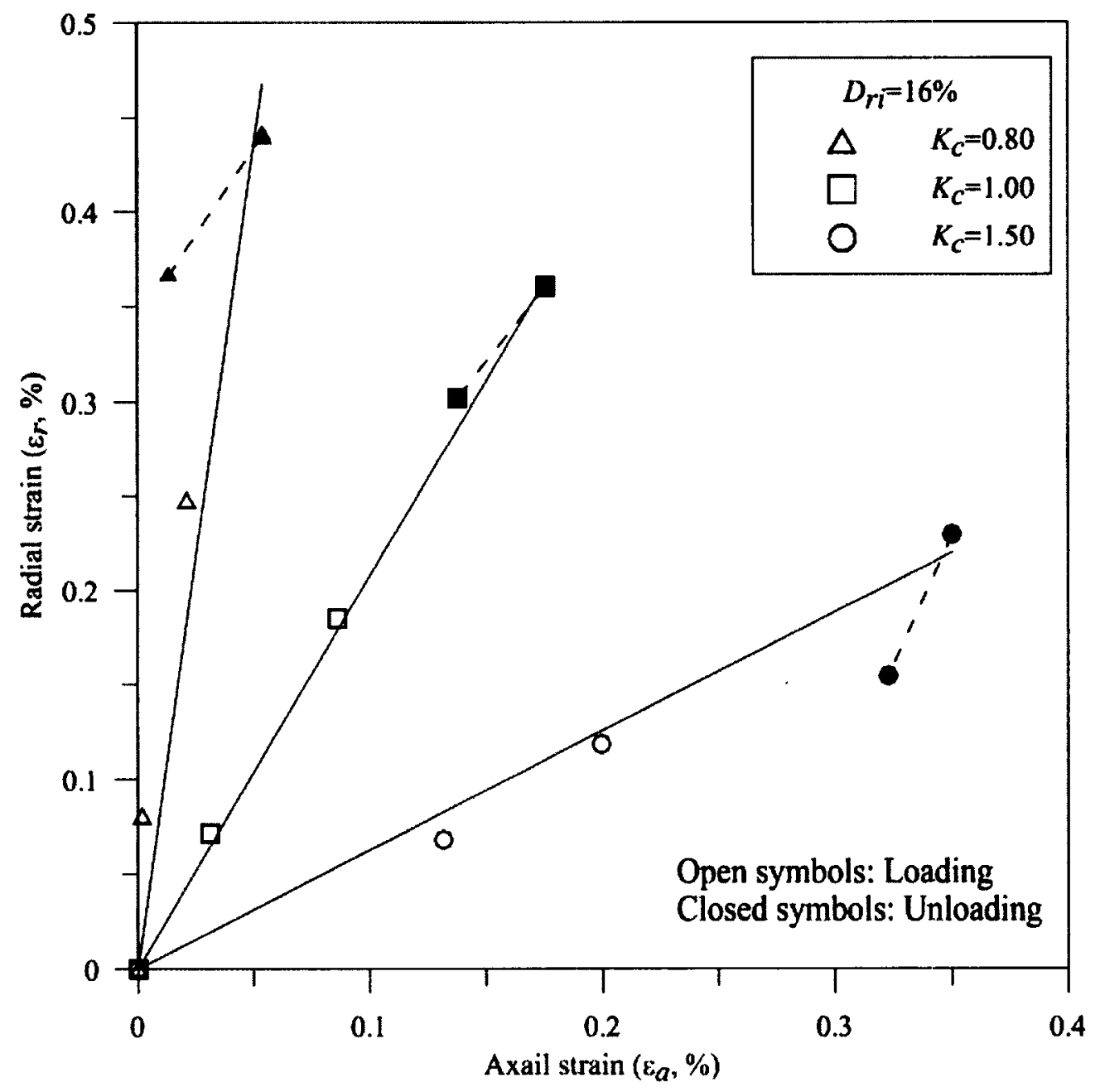

Figure 3.6 Loading and unloading strain path during isotropic and anisotropic consolidation of Fraser River sand 


\subsubsection{Monotonic Loading}

To understand the static behaviour of the sand and thus establish the link between cyclic and monotonic response, a series of static tests have been conducted. Following consolidation, the samples were sheared monotonically under strain controlled loading in extension or compression over a range of initial void ratios, overconsolidation ratios and static shear values. Tests were conducted at an axial strain rate of $12 \%$ per hour.

\subsubsection{Cyclic Loading}

Cyclic axial stress was applied by changing the pressure in the top chamber of the double acting piston shown in Figure $3.2(a, b)$. The piston is freely floating when the pressure on both sides is equal. The top chamber pressure is controlled by an electro pneumatic transducer. The signal voltage supplied by the signal conditioner to the electro pneumatic transducer controls the deviator stress. The output cyclic stress was determined based on the geometry of the vertical piston, the sample area and targeted cyclic stress amplitude. The transducer was calibrated for the cyclic stresses by using a dummy solid bar in place of the sample. An electronic sinusoidal signal wave with the frequency of $0.1 \mathrm{~Hz}$ was sent to the electro pneumatic transducer to apply the cyclic load. The cyclic load was so that the first quarter pulse of the load was in the compression mode. This applied cyclic stress was superimposed on top of the vertical stress already applied to either overcome the hydrostatic ram lift or the vertical stress needed to achieve the anisotropic consolidation. Although the anticipated frequency of most earthquakes is higher than $0.1 \mathrm{~Hz}$, this low value gives a better degree of resolution from the instruments. And, since undrained boundary conditions were enforced the relatively 
lower loading rate will not influence the measured response. The data was recorded at a rate of about 90 points per cycle.

\subsubsection{Post Cyclic Loading}

Following the cyclic loading the strain-controlled drive was lowered and connected to the top of the double acting piston. This ensures no disturbance to the stressstrain condition of the sample at the end of the cyclic loading. Sample was then subjected to either monotonic compression or extension loadings. The strain controlled static loads were applied at strain rate of $60 \%$ per hour.

\subsection{TEST REPEATABILITY}

Test repeatability is key in conducting reliable experimental research on the fundamentals of the sand behaviour. The repeatability of the test is dependent upon the ability to reproduce identical specimens (relative density, replication of the structure), measurement accuracy, and exact duplication of the test routine. The fines content of the Fraser Delta sand used in this study is $1.0-1.5 \%$. This low amount of fines ensured uniform, repeatable samples using water pluviation.

On the other hand, due to limited supply of sands and large number of tests required to complete this study, the sand used in one test was reused in other tests, too. Soil response is affected by particle distribution and soil texture. Figure 3.7 shows the particle size distribution of used and virgin Fraser River sand. No significant difference can be seen in gradation curves between used and virgin sand. This indicates that particle crushing due to monotonic loading at low confining pressures is negligible. Undrained response of used and virgin sand under monotonic and compression loading mode are 
shown in Figures 3.8 and 3.9 respectively. There is no detectable difference between the responses of the two sands. This shows that the sand used in the test with low confining pressure can be reused.

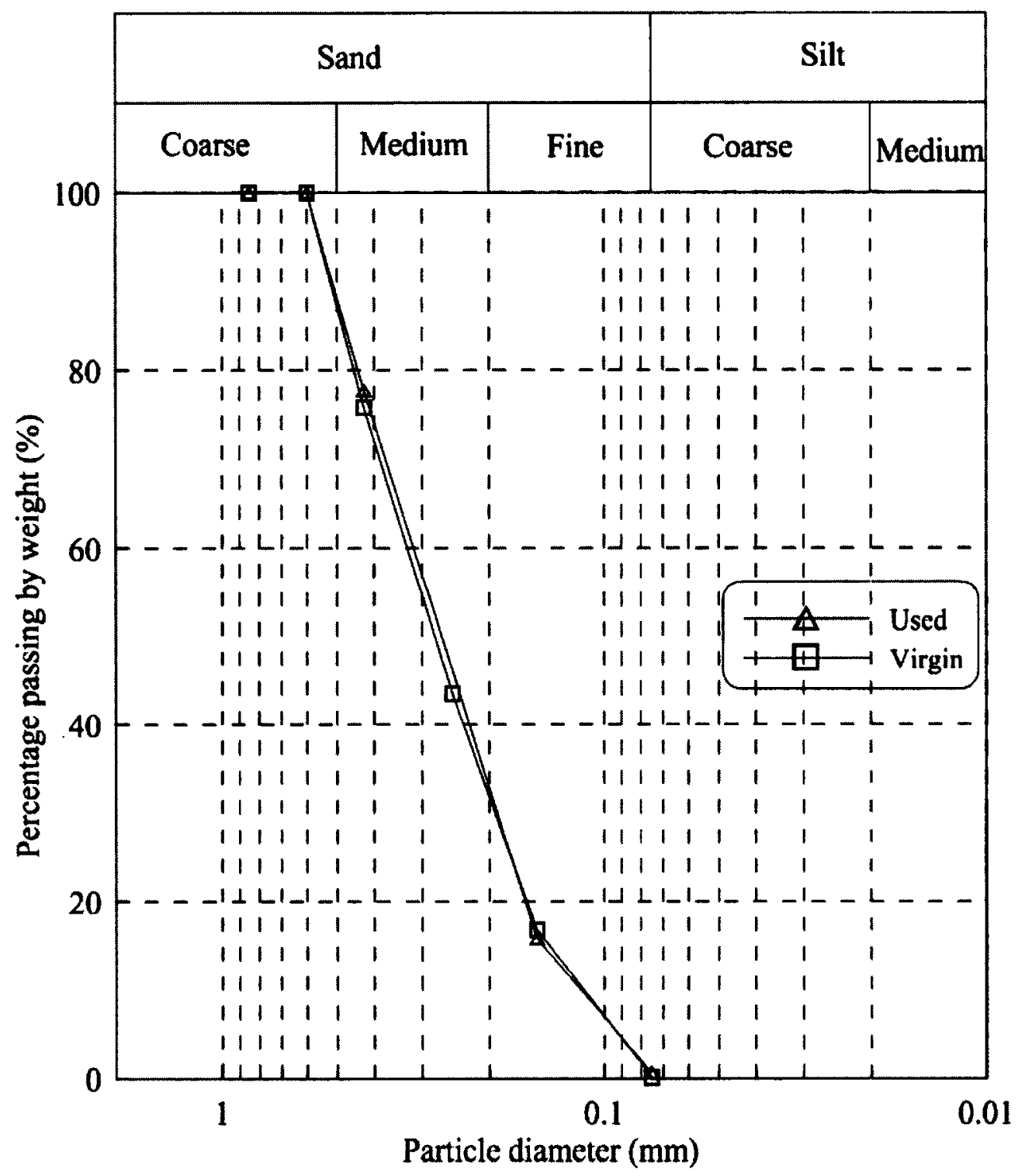

Figure 3.7 Particle size distribution of virgin and used Fraser River sand 

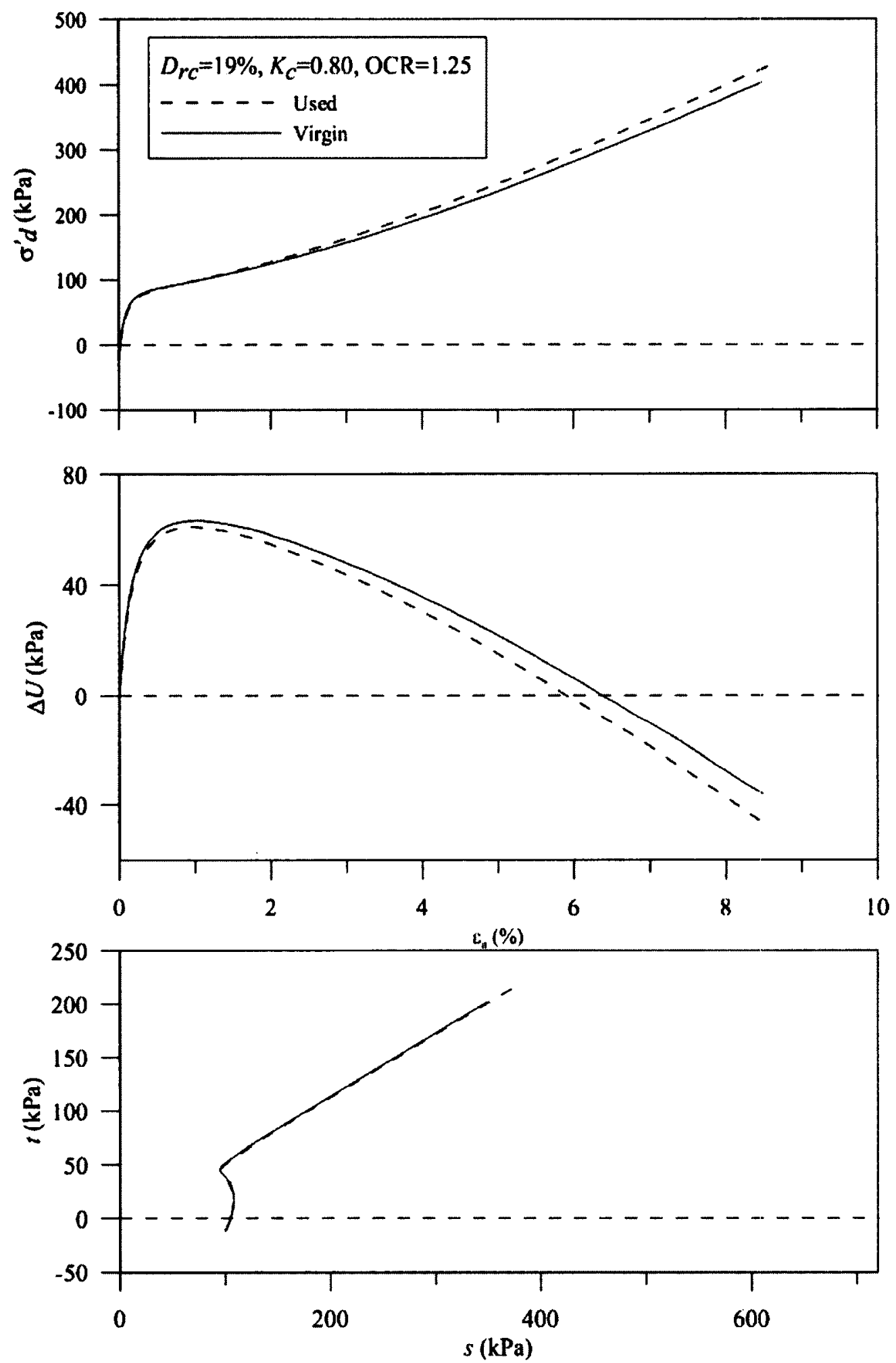

Figure 3.8 Monotonic response of used and virgin sand under triaxial compression loading mode 

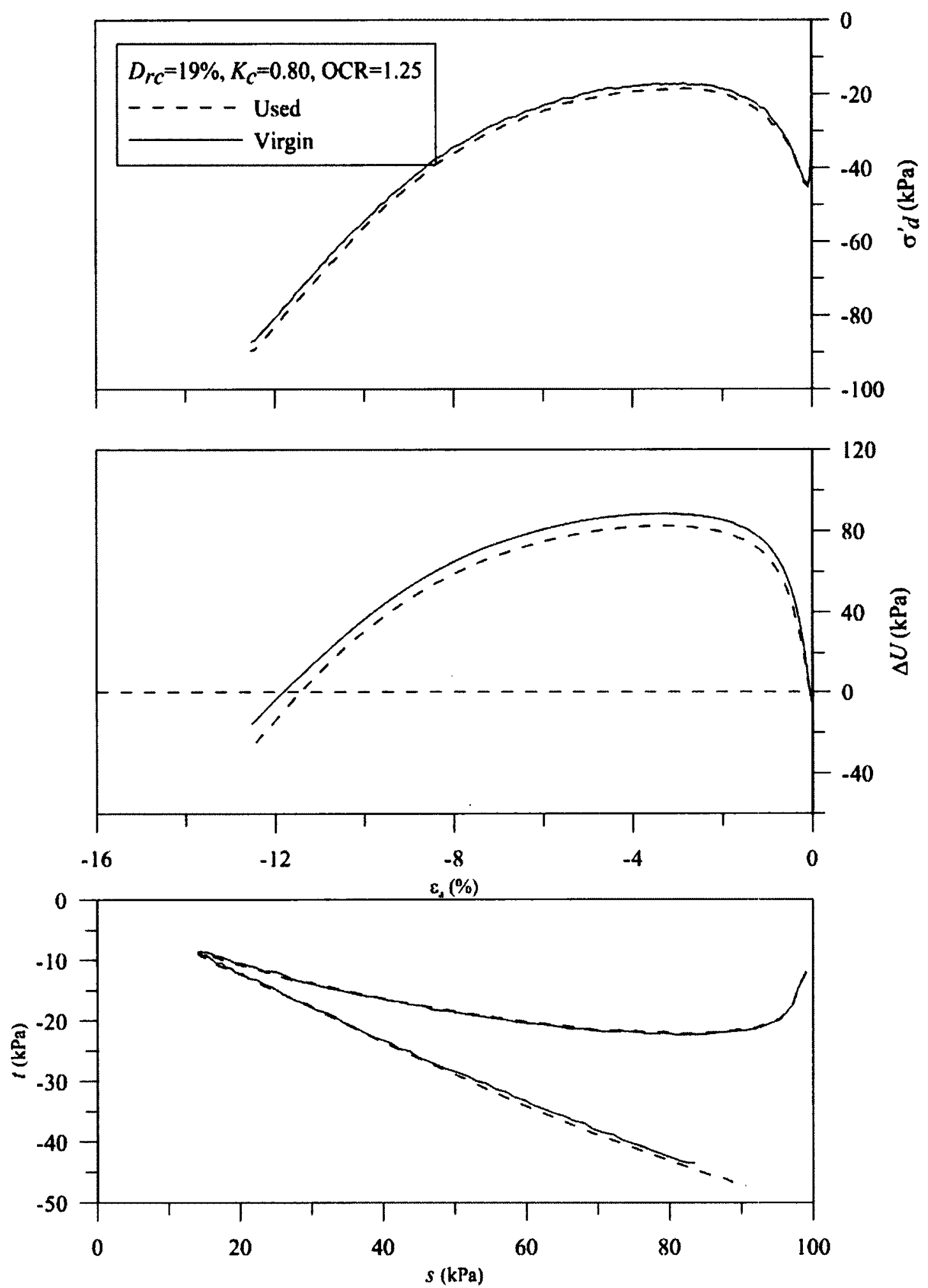

Figure 3.9 Monotonic response of used and virgin sand under triaxial extension loading mode 


\subsection{MEMBRANE PENETRATION}

Membrane penetration alters the measurement of volume change of granular materials when tested under triaxial loading. The change in confining pressure causes the membrane to either indent or rebound which will change the peripheral configuration of the sample. Therefore, the volume change would not be only as a result of the soil skeleton deformation but also on account of the membrane penetration or withdrawal into or out of the interstices of the granular soil specimen. Membrane penetration affects the volume change in drained tests and the pore pressure change in undrained tests. Therefore, not considering the membrane penetration effect in triaxial test results, would lead to erroneous assessment of the sand behaviour and liquefaction potential.

The total volume change due to the change in confining pressure is equal to the sum of volume change by membrane penetration and the soil deformation and is shown in equation (3.2).

$$
\Delta V_{T}=\Delta V_{m}+\Delta V_{s}
$$

where $\Delta V_{m}$ is the volume change due to membrane penetration is, $\Delta V_{s}$ is the soil skeleton deformation and the total volume change is shown by $\Delta V_{T}$. Equation (3.2) can also be written in term of membrane penetration per unit membrane surface area $\left(\varepsilon_{m}\right)$ and soil volumetric strain $\left(\varepsilon_{v}\right)$.

$$
\Delta V_{T}=\varepsilon_{m} A_{m}+\varepsilon_{v} V_{s o}
$$

where $V_{s o}$ is the initial volume of the sample. 
Different researchers have proposed various methods to estimate the membrane penetration effect (Newland and Alley, 1959; Roscoe et al., 1963; Frydman et al., 1973; Raju and Sadasivan, 1974; Vaid and Negussey, 1988; Sivathayalan and Vaid, 1998).

The method suggested by Vaid and Negussey (1988) is used in this study to calculate the unit membrane penetration. This method is based on the results from hydrostatic compression in ordinary triaxial tests. In this method the soil deformation is assumed to be isotropic during hydrostatic unloading. Therefore, the actual volumetric strain would be equal three times of the axial strain.

$$
\varepsilon_{v u}=3 \varepsilon_{a u}
$$

Substituting equation (3.3) into equation (3.2) yields:

$$
\frac{\Delta V_{T u}}{A_{s}}=\varepsilon_{m}+\frac{3 \varepsilon_{a u}}{4} D
$$

where "u" refers to unloading.

Membrane induced volume change and effective confining stress has a linear relationship when plotted on the semi logarithmic scale. Slope of unit membrane penetration vs. logarithm of normalized effective minor stress $\left(\sigma_{3}^{\prime}\right)$ is referred as normalized penetration $(m)$. This parameter $(m)$ can be defined by using equation (3.6):

$$
\varepsilon_{m}=m \log \left(\frac{\sigma_{c}^{\prime}}{\sigma_{c i}^{\prime}}\right)
$$


Figure 3.10 shows the unit membrane penetration $\left(\varepsilon_{m}\right)$ against radial effective stress $\left(\sigma_{r}^{\prime}\right)$. These values of the unit membrane penetration are consistent with the values reported for sands with similar $\mathrm{D}_{\mathbf{s 0}}$.

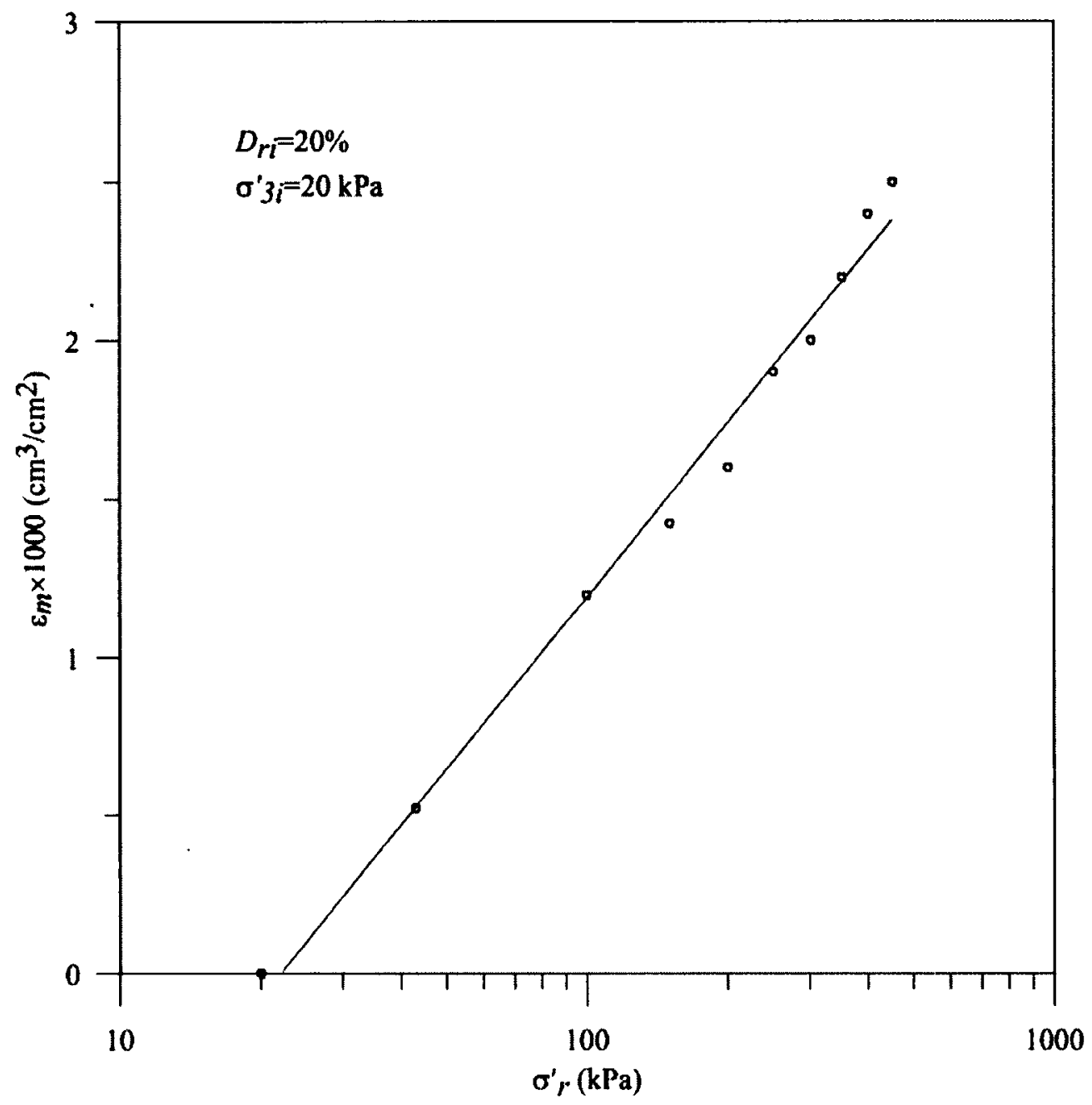

Figure 3.10 Unit membrane penetration $\left(\varepsilon_{m}\right)$ vs. radial effective stress $\left(\sigma_{r}^{\prime}\right)$ for loose Fraser River sand (After Logeswaran, 2005) 


\subsection{TESTING PROGRAM}

\subsubsection{Monotonic response}

Monotonic triaxial compression and extension tests were conducted over a range of initial conditions. To study the effect of major principal stress rotation and the direction of initial static shear stress, monotonic tests were performed on samples consolidated anisotropically with $K_{c}$ values of 0.80 and 1.50 with the definition of $K_{c}$ as the ratio of vertical stress over horizontal stress. On the other hand, the effect of overconsolidation on monotonic response of Fraser River sand is studied by performing tests on samples consolidated with overconsolidation ratios (OCR) of 1.25, 1.50, and 2.00. The results are then compared with the tests performed on normally consolidated (NC) sand. All the tests on overconsolidated samples are conducted on both isotropically and anisotropically consolidated samples to study the combined effect of induced anisotropy and OCR on monotonic response of sand. Monotonic tests were performed on a wide range of relative density $(19 \%, 40 \%$, and $65 \%)$. Rather than studying the effect of initial conditions on monotonic response, these tests provided a basis to understand the linkage between cyclic and monotonic loading responses. The mean effective confining stress $\sigma_{n c}^{\prime}$ at the beginning of monotonic loading was $100 \mathrm{kPa}$.

\subsubsection{Cyclic response}

Cyclic tests were performed on both isotropically and anisotropically consolidated samples. Samples were prepared at the same levels of relative density as in monotonic tests. Anisotropically consolidated samples are consolidated with two different $K_{c}$ values of 0.80 and 1.50. These two values were selected to study the effect of both the 
magnitude and the direction of initial static shear on cyclic resistance of Fraser River sand. Effect of OCR level is also studied by consolidating sample under three different overconsolidation ratios of $1.25,1.50$, and 2.00 both isotropically and anisotropically. In all tests the mean effective confining stress $\left(\sigma_{n c}^{\prime}\right)$ is $100 \mathrm{kPa}$ at the end of consolidation.

Sample at each initial condition (i.e. fixed $D_{r c}, K_{c}$, and OCR) are subjected to three to five different levels of cyclic stress ratio (CSR) so that the number of cycles to liquefaction varied between about 1 and 100 . This was intended to increase the confidence in the interpolated CSR value corresponding to liquefaction 10 cycles. The tests results permitted the construction of a series of curves for each set of initial conditions showing number of cycles to liquefaction $\left(\mathrm{N}_{c}\right)$ as a function of CSR. The cyclic resistance ratio (CRR) was then determined by interpolating between the points as the CSR causing liquefaction at a fixed number of cycles.

These experimental data were used to construct a set of $K_{\alpha}$ versus $\alpha$ relationship and study the effect of the direction of initial static shear stress on $K_{\alpha}$. The effect of OCR on CRR and combined effect of OCR and $\alpha$ are also studied at each level of relative density.

\subsubsection{Post-liquefaction response}

Following the undrained cyclic loading all samples were subjected to monotonic undrained loading. Samples were subjected to both compression and extension loading modes. These tests were aimed to assess the effect of relative density $\left(D_{r c}\right), \mathrm{OCR}$, initial static shear stress, and residual stress at the end of cyclic loading on post liquefaction monotonic response of Fraser River sand. 


\section{CHAPTER 4}

\section{EFFECT OF STRESS HISTORY AND INITIAL STRESS CONDITIONS ON LIQUEFACTION POTENTIAL}

\subsection{INTRODUCTION}

The undrained behaviour of Fraser River sand (FRS) under cyclic, monotonic and post-cyclic loading is presented and discussed in this chapter. The behaviour was studied by conducting triaxial tests at different initial conditions representing various static shear levels, void ratios, and overconsolidation ratios. Static tests were performed under both compression and extension loading modes at three different relative density levels $(19 \%$, $40 \%$, and $65 \%$ ) on specimens consolidated to different initial states. Monotonic tests were performed to: 1) study the effect of the direction and magnitude of the initial static shear, and 2) provide a baseline to understand the cyclic and post-cyclic response. As discussed in chapter two, only a limited number of studies have been undertaken on the effect of overconsolidation ratio on both static and cyclic behaviour of sands. Therefore this study tries to address this gap by conducting cyclic and monotonic triaxial tests that would cover a range of overconsolidation ratios.

Water pluviated samples were prepared in the loosest state so that a void ratio near the maximum void ratio according to ASTM-D4254 would be attained. Relatively denser samples were achieved by tapping using a small rubber mallet. After densification a confining stress of about $20 \mathrm{kPa}$ was applied to the specimen. The void ratio at this initial stage is referred to as $e_{i}$. On the other hand, the void ratio after consolidation is 
then termed $e_{i}$. The change in relative densities of different samples consolidated to the same mean normal effective stress level is shown to be negligible as the confining stress at the end of consolidation is the same in all tests and the static shear has negligible effect on $\mathrm{e}_{\mathrm{c}}$ in the range of stresses considered.

Comparison between static and cyclic behaviour was made. The effect of relative density and the overconsolidation ratio on the cyclic resistance of the sand was studied. Moreover, the effect of OCR on $K_{\alpha}$ correction factor is also investigated. It must be mentioned that $K_{\alpha}$ is calculated for an earthquake of $\mathrm{M}=6.75$ (equivalent of 10 cycles) by considering the ratio of the cyclic resistance at different initial static shear levels to the cyclic resistance ratio at zero static shear prior to the cyclic loading. The relationship between pre and post-liquefaction response is also presented in this chapter.

In conventional triaxial testing, the major principal stress is either vertical (as in compression test) or horizontal (as in extension test). In order to distinguish between the extension and compression tests the deviator stress is calculated as " $\sigma_{v}^{\prime}-\sigma_{h}^{\prime \prime}$. Thus negative deviator stress corresponds to the extension test while positive values indicate compression test. The same approach is used to express $\alpha$ (static shear stress ratio) so that a positive value means positive static shear and a negative value stands for a negative shear stress prior to loading. $K_{c}$ is defined as $\sigma_{v c}^{\prime} / \sigma_{h c}^{\prime}$ and thus $K_{c}$ larger than one means that the static shear prior to loading is due to a compression load and hence applying further compression loading causes shearing in the same direction. On the other hand a $K_{c}$ less than one implies a static shear due to extension loading prior to the shearing. Therefore, there would be a jump rotation of $90^{\circ}$ in the major principal stress direction when the compression load is applied to a sample consolidate anisotropically with $K_{c}<1$. 
A similar phenomenon would happen to a sample consolidated under a $K_{c}>1$ and sheared in extension loading mode.

\subsection{UNDRAINED MONOTONIC BEHAVIOUR}

Tests on samples at different void ratios and OCR values with different levels of static shear prior to loading have been performed. These tests provide a better understanding of the dependency of sand behaviour on OCR, static shear, and relative density along with a basis for assessing the cyclic behaviour.

\subsubsection{Effect of static shear level}

To isolate the effect of overconsolidation and static bias, static behaviour is studied at a fixed level of OCR. Figure 4.1 shows the behaviour of normally consolidated loosest deposited $\left(D_{r c}=19 \%\right)$ samples at different $K_{c}$ values of $0.50,0.67,0.80,1.00$, 1.50 , and 2.00 . It must be noted that although only a few data points are shown on the graphs, the test results consist of more than 200 data points in each test, and the limited number of points are plotted in the interest of clarity. As shown in Figure 4.1, the response is of dilative type regardless of the $K_{c}$ level and the direction of initial static shear stress. Sample with a $K_{c}$ value of 0.50 has the maximum peak excesses pore pressure and the peak excesses pore water pressure decreases as $K_{c}$ changes from 0.50 to 2.00. Excesses pore pressure decreases at a higher rate during post phase transformation loading in tests with $K_{c}<1.00$ compared to those with $K_{c}>1.00$. The rate of reduction increases as $K_{c}$ decreases from 0.80 to 0.50 and is almost constant in tests with $K_{c}>1.00$. This change in the rate of pore pressure change with axial strain implies that a $90^{\circ}$ rotation of the direction of major principal stress from $0^{\circ}$ to $90^{\circ}$ causes a more dilative re- 

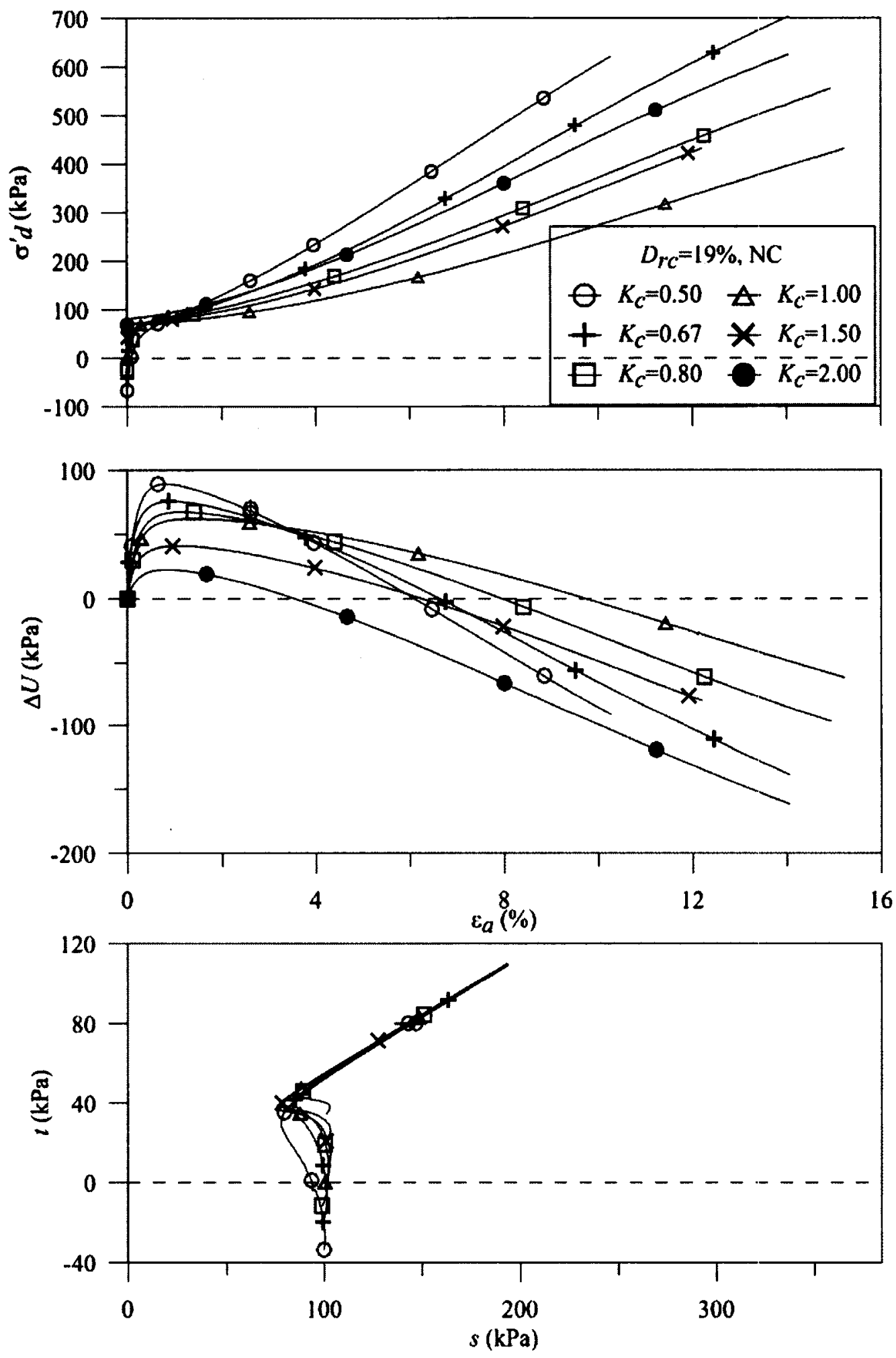

Figure 4.1 Behaviour of loosest deposited normally consolidated sand at different $K_{c}$ values 
sponse in spite of equal initial static shear stress levels. On the other hand, the dilation rate increases as the level of initial static shear stress increases in the opposite direction of applied shear stress under triaxial compression loading. The same response is shown in Figure 4.2 through Figure 4.4 but at different OCR values. It can be inferred from the graphs that the same behaviour and tendency for the dilative response exists in all OCR values with the change of $K_{c}$ from 0.80 to 1.50 .

It has been shown that under identical initial conditions, the sand response is dilative in triaxial compression and contractive under triaxial extension. The difference in behaviour of sand between triaxial compression and extension loading mode is related to the inherent anisotropy of granular materials (Arthur and Menzies, 1972). Therefore, response of sand to external loads is dependent on the direction of the major principal stress to the vertical direction $\left(\alpha_{\sigma}\right)$. In the triaxial compression loading mode $\alpha_{\sigma}$ is zero but in the extension loading mode this angle is $90^{\circ}$. In this study, there is a $90^{\circ}$ jump rotation of principal stress direction in triaxial compression tests on samples with $K_{c}<1$. To show the direction of the initial static shear, $K_{c}$ was calculated as the ratio of the vertical effective stress to the horizontal effective stress. For example, if principal stresses were used, $K_{c}$ of 0.50 would be equal to 2.00 and it was not possible to capture the effect of the direction of the initial static shear stress. It can be inferred from Figure 4.1 that if the incremental shear stress is in the opposite direction of the initial static shear, the behaviour would be more dilative as shear strength mobilizes at a faster rate compared to tests where the shear stress is applied in the same direction of initial static shear stress. This dependency of the behaviour on the direction of the initial static shear can be related to the change of sand behaviour with the jump rotation of principal stresses direction. 
Figures 4.5 to 4.8 show the response of isotropically and anisotropically consolidated samples under extension loading mode at different OCR levels. Although the Fraser Delta sand shows a dilative response under compression loading (even at the loosest states) the response is of true liquefaction or limited liquefaction type over a wide range of void ratios and OCRs under extension loading mode. Inherent anisotropy in pluviated sand has been considered to be responsible for this difference between extension and compression loading (Bishop and Wesley 1975; Miura and Toki, 1982; Chern, 1985; Kuerbis, 1989, Thomas, 1992).

To show the strain softening characteristics of soils Bishop (1971) defined the brittleness index $\left(I_{B}\right)$ as:

$$
I_{B}=\frac{S_{\text {peak }}-S_{\text {min }}}{S_{\text {peak }}}
$$

However, the effect of initial static on the flow potential of soil was not reflected in the original $I_{B}$ equation. To consider the effect of $K_{C}$, a modified form of brittleness index $\left(I_{\bar{B}}\right)$ defined has been used in the literature (Sivathayalan and Vaid, 2002):

$$
I_{\bar{B}}=\frac{S_{\text {peak }}-S_{\text {min }}}{S_{\text {peak }}-S_{\text {static }}}
$$

$I_{\bar{B}}=0$ refers to no strain softening and $I_{\bar{B}}=1.00$ corresponds to the state of a flow failure at which the minimum undrained strength equals the initial static shear as per this revised definition. $I_{\bar{B}}>1$ implies a higher initial static shear than the undrained shear strength. 

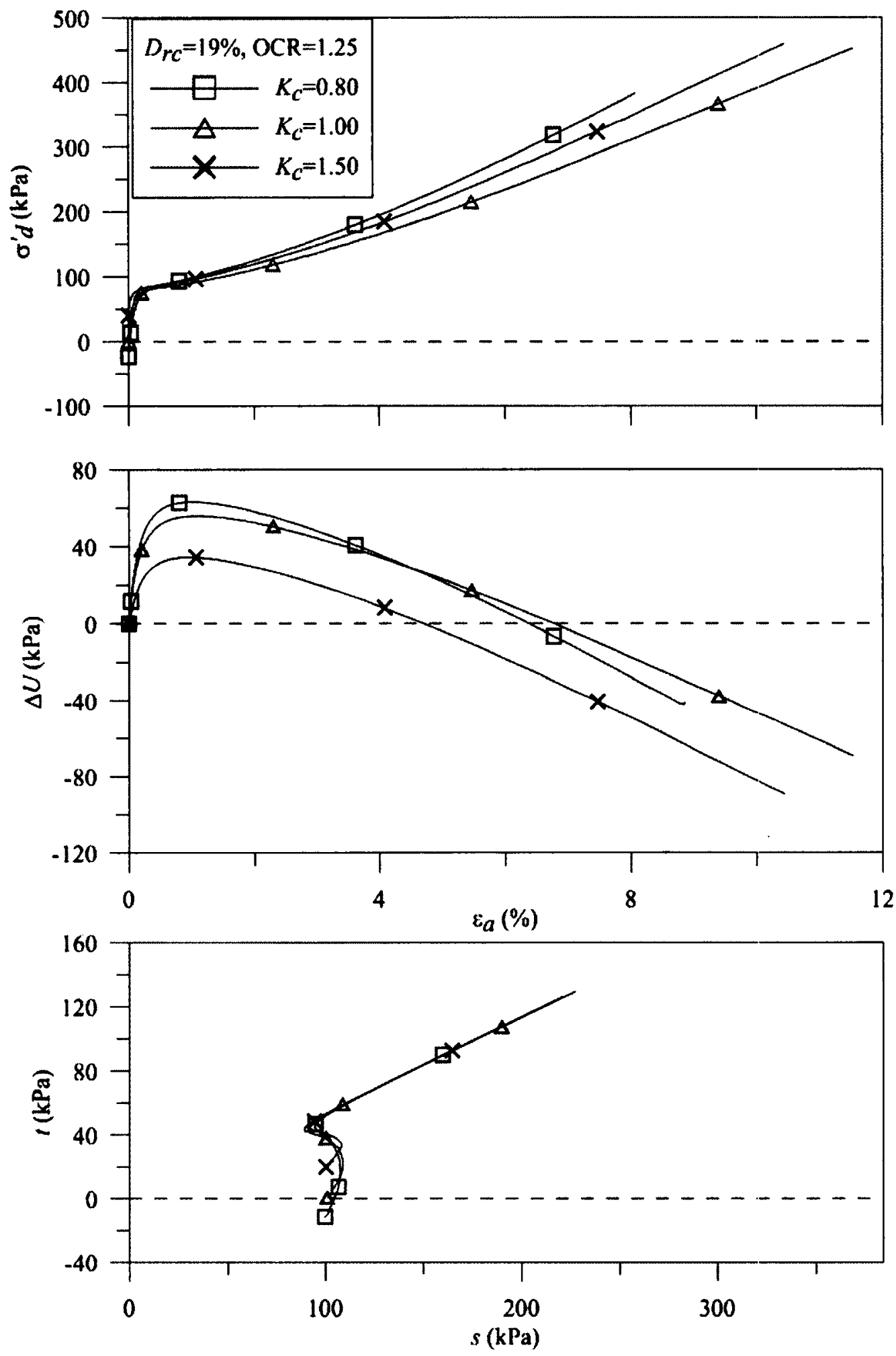

Figure 4.2 Behaviour of loosest deposited sand at $\mathrm{OCR}=1.25$ 

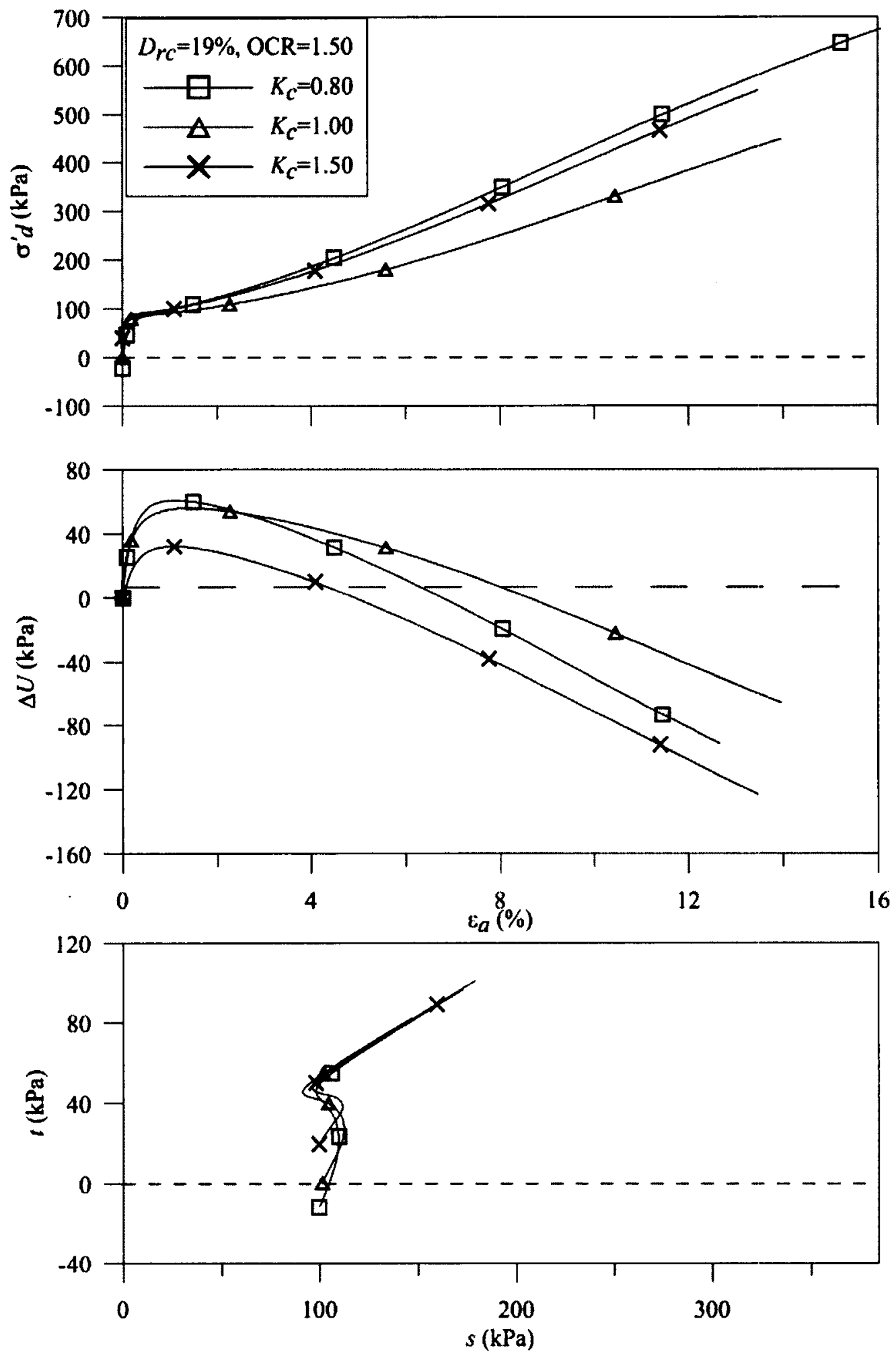

Figure 4.3 Behaviour of loosest deposited sand at $\mathrm{OCR}=1.50$ 

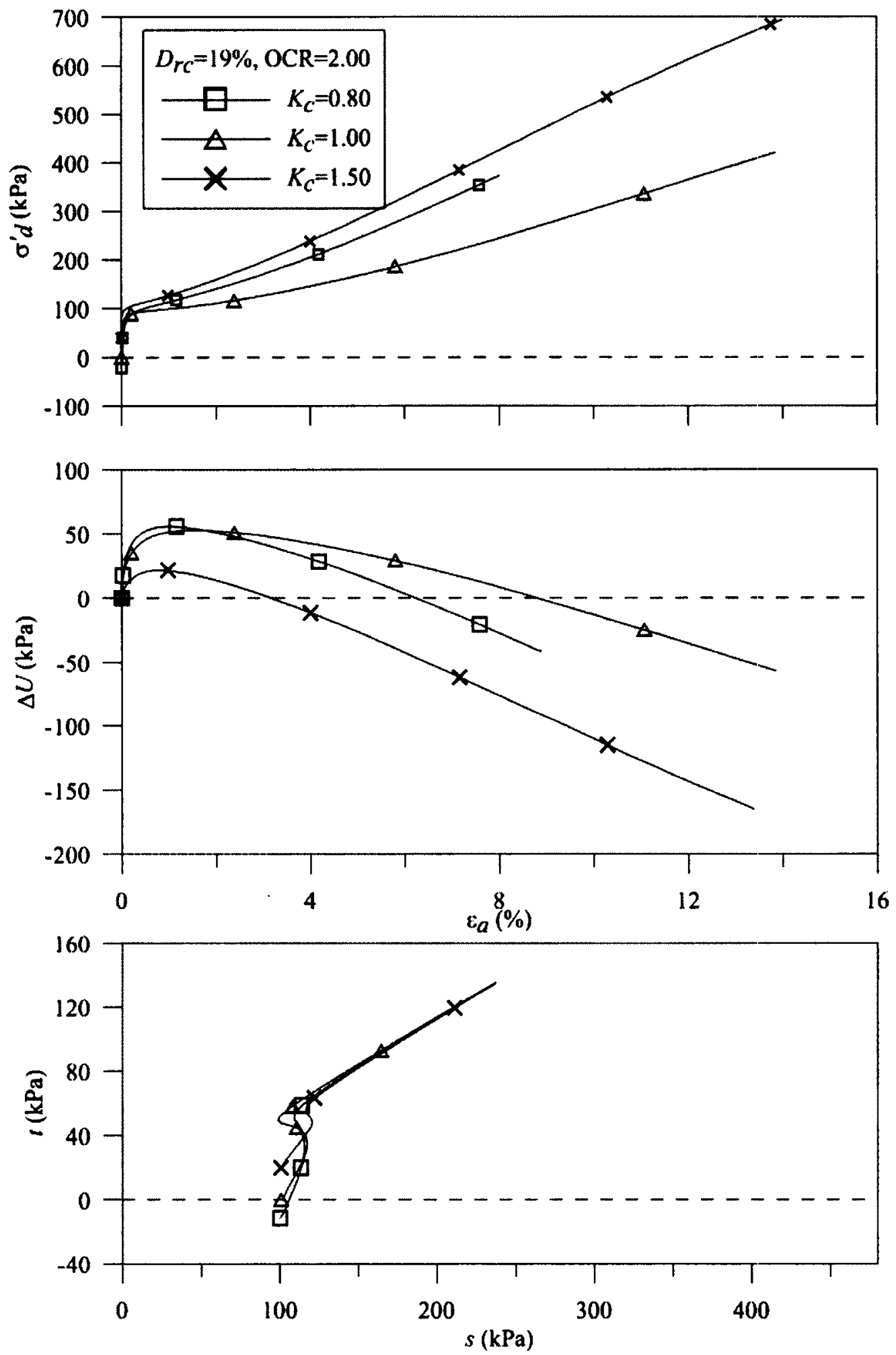

Figure 4.4 Behaviour of loosest deposited sand at $\mathrm{OCR}=2.00$ 

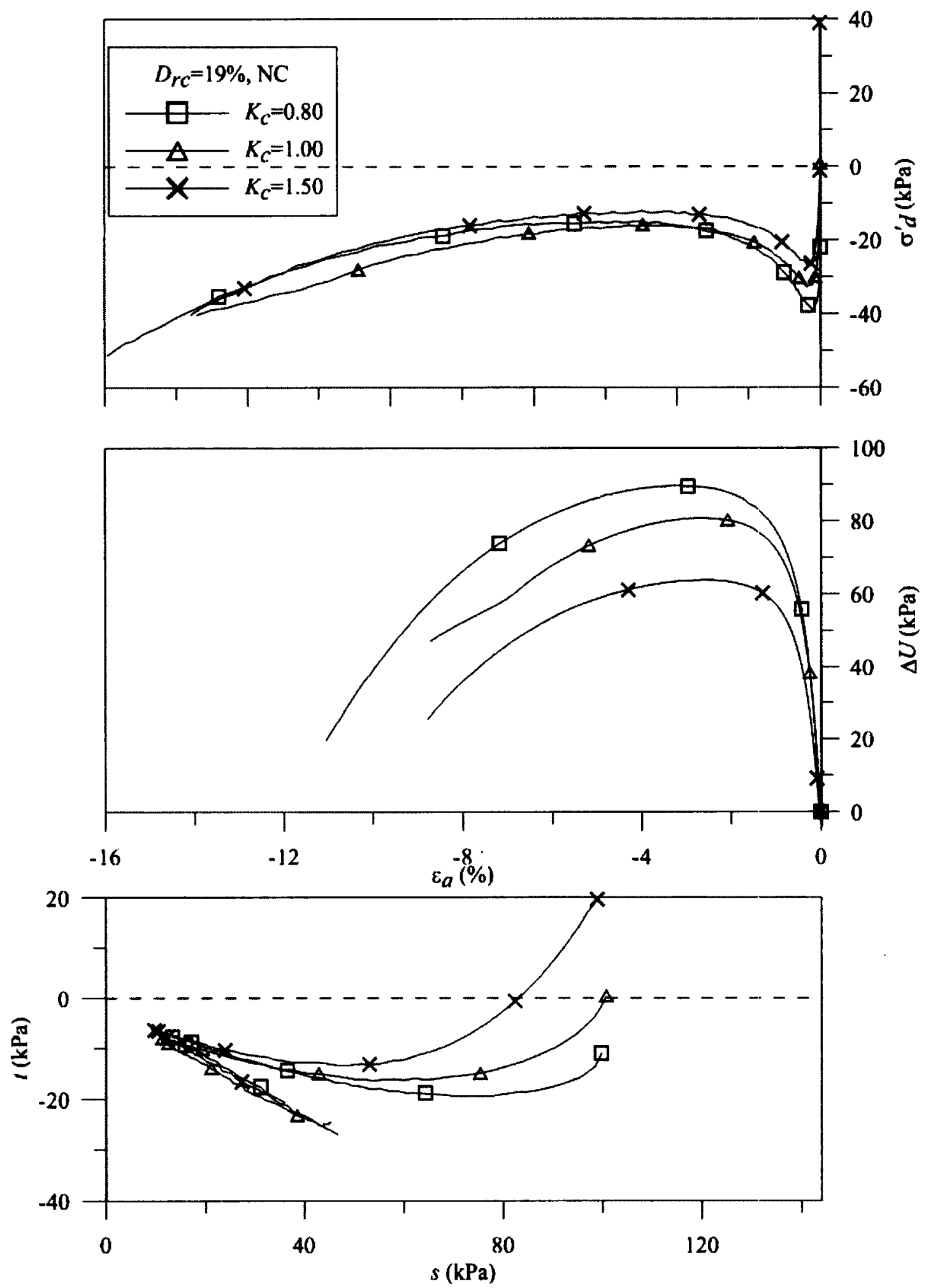

Figure 4.5 Behaviour of normally consolidated loosest deposited sand under extension loading mode 

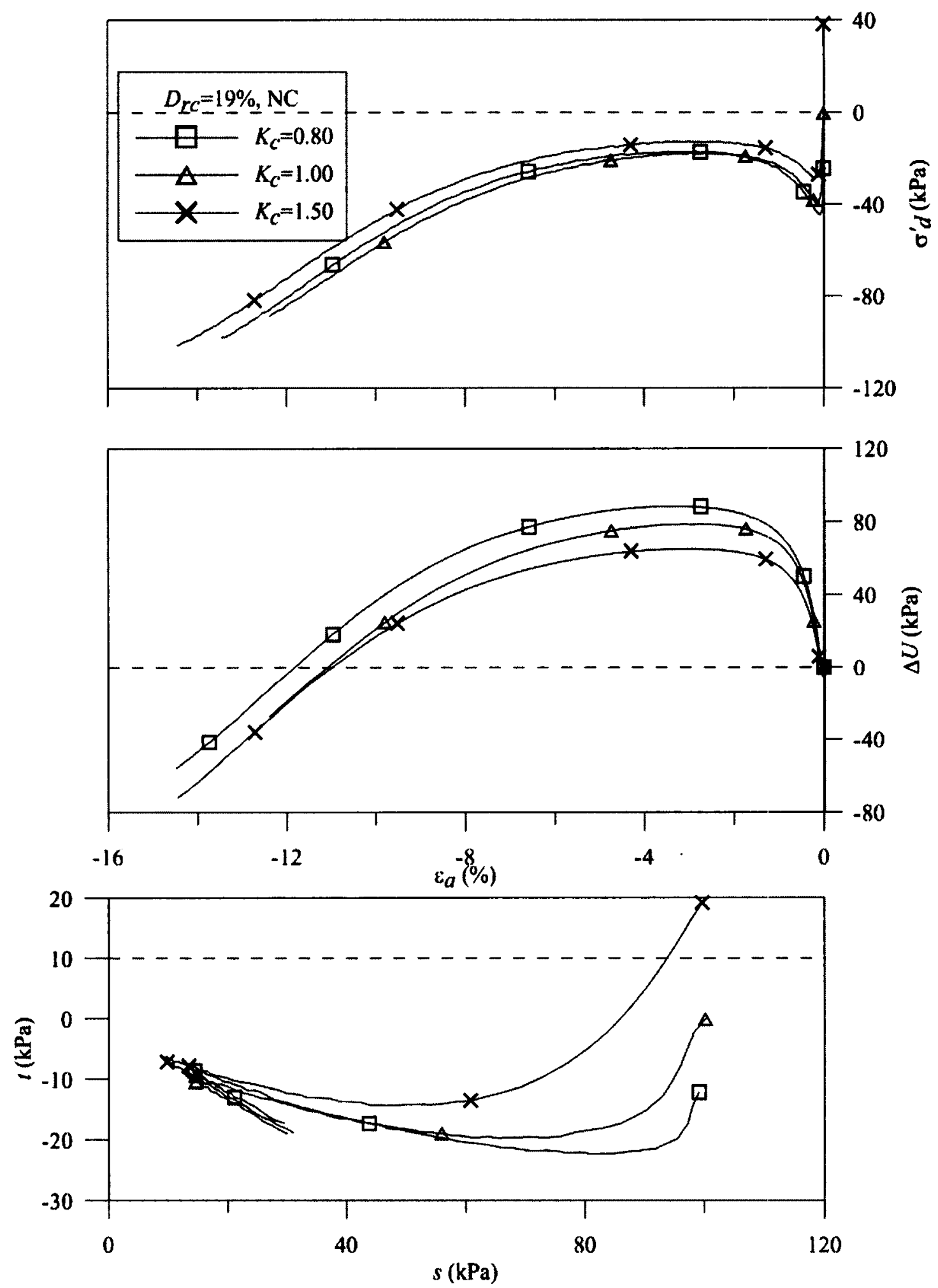

Figure 4.6 Behaviour of loosest deposited sand at $\mathrm{OCR}=1.25$ under extension loading mode 

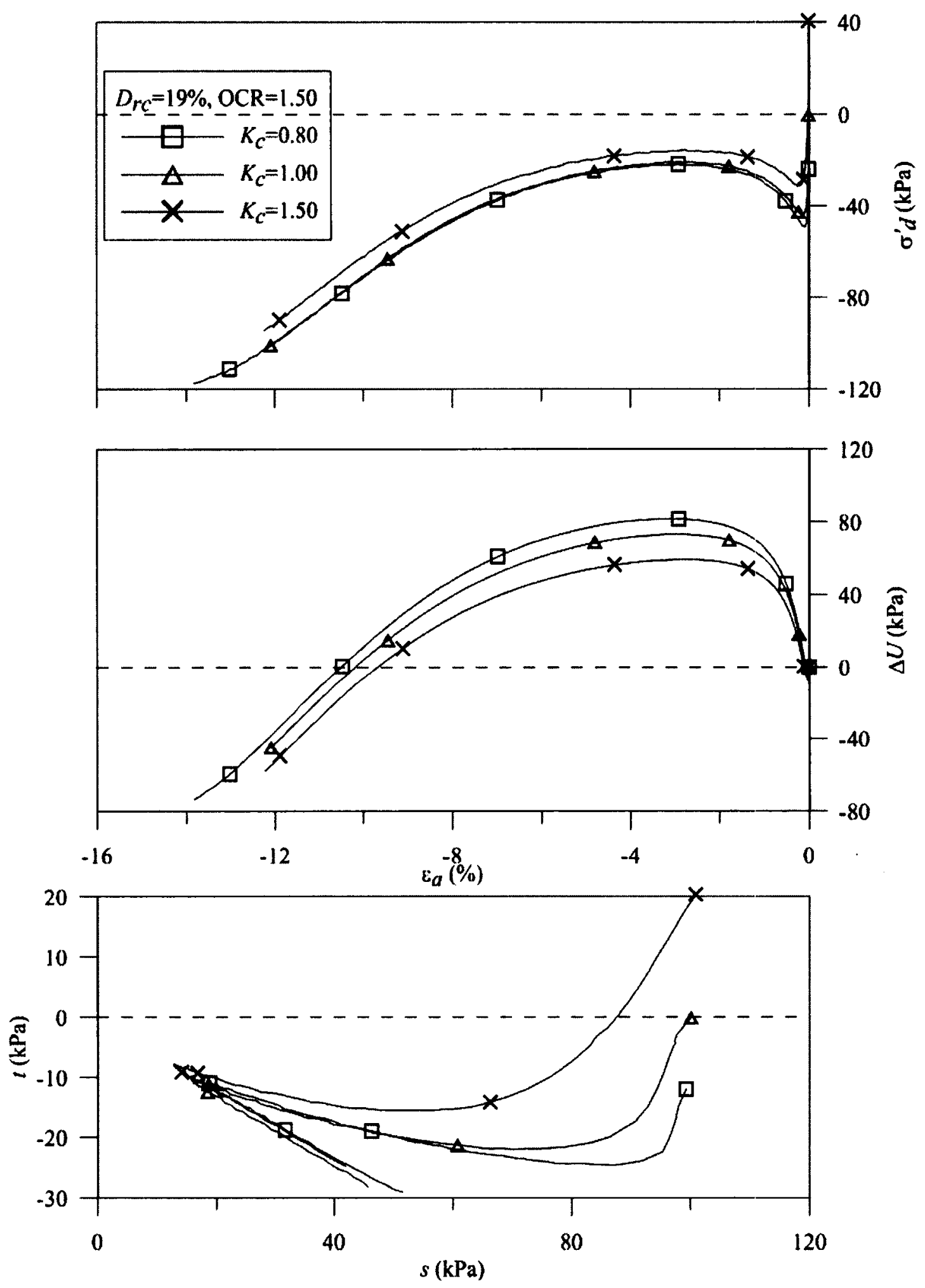

Figure 4.7 Behaviour of loosest deposited sand at $\mathrm{OCR}=1.50$ under extension loading mode 

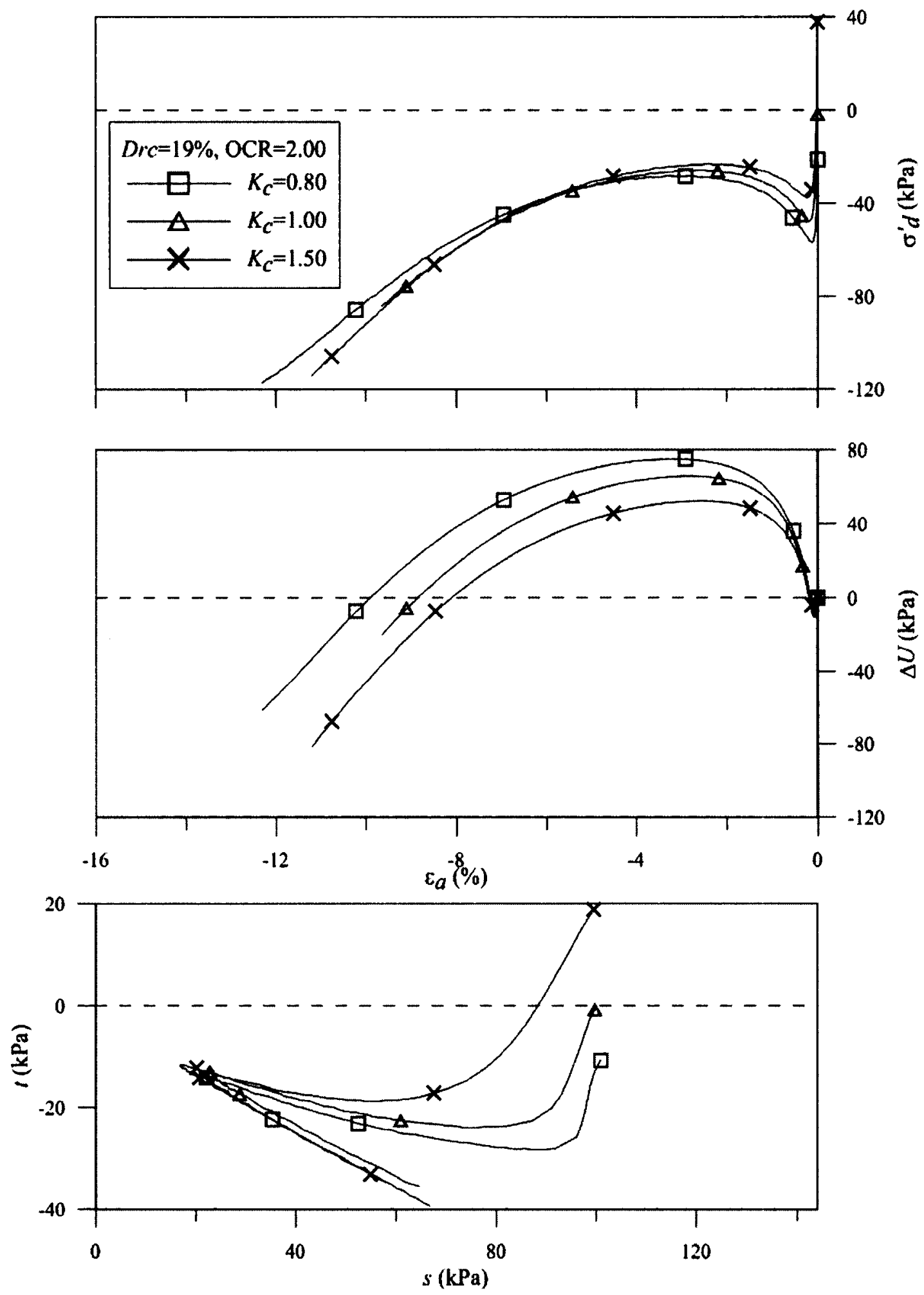

Figure 4.8 Behaviour of loosest deposited sand at $\mathrm{OCR}=2.00$ under extension loading mode 
No strain softening and hence no peak and minimum strength are observed under compression loading mode at all $K_{c}$ and OCR values. This observation implies that modified brittleness index in triaxial compression tests is undefined for the sand tested in this study. Variation of modified brittleness index of triaxial extension tests with initial static shear stress ratio in normally consolidated samples is shown in Figure 4.9. As depicted in Figure $4.9, I_{\bar{B}}$ increases as $K_{c}$ changes from 1.50 to 0.67 . Therefore, the sample with $K_{C}$ of 0.67 has the most contractive response while the sample with $K_{c}$ of 1.50 has the least contractive response with an $I_{\bar{B}}$ value of 0.22 . Although previous studies suggest that increasing static shear would increase the degree of contractiveness, the reverse is true in this case. The main difference between the previous studies and the current one refers to the direction of shear loading. The loading direction was aligned with the direction of principal stresses in the studies reported in the literature (Sivathayalan and Vaid, 2002) but the loading had caused a jump rotation in the tests reported herein.

\subsubsection{Effect of overconsolidation}

The effect of overconsolidation on the monotonic response of Fraser River sand has been studied under both compression and extension loading modes. Tests have been performed on normally consolidated (NC) samples and samples with three different levels of OCR $(1.25,1.50$, and 2.00). All samples were sheared undrained with an initial effective mean normal stress $\left(\sigma_{n c}^{\prime}\right)$ of $100 \mathrm{kPa}$ with different initial static shear stress levels. 


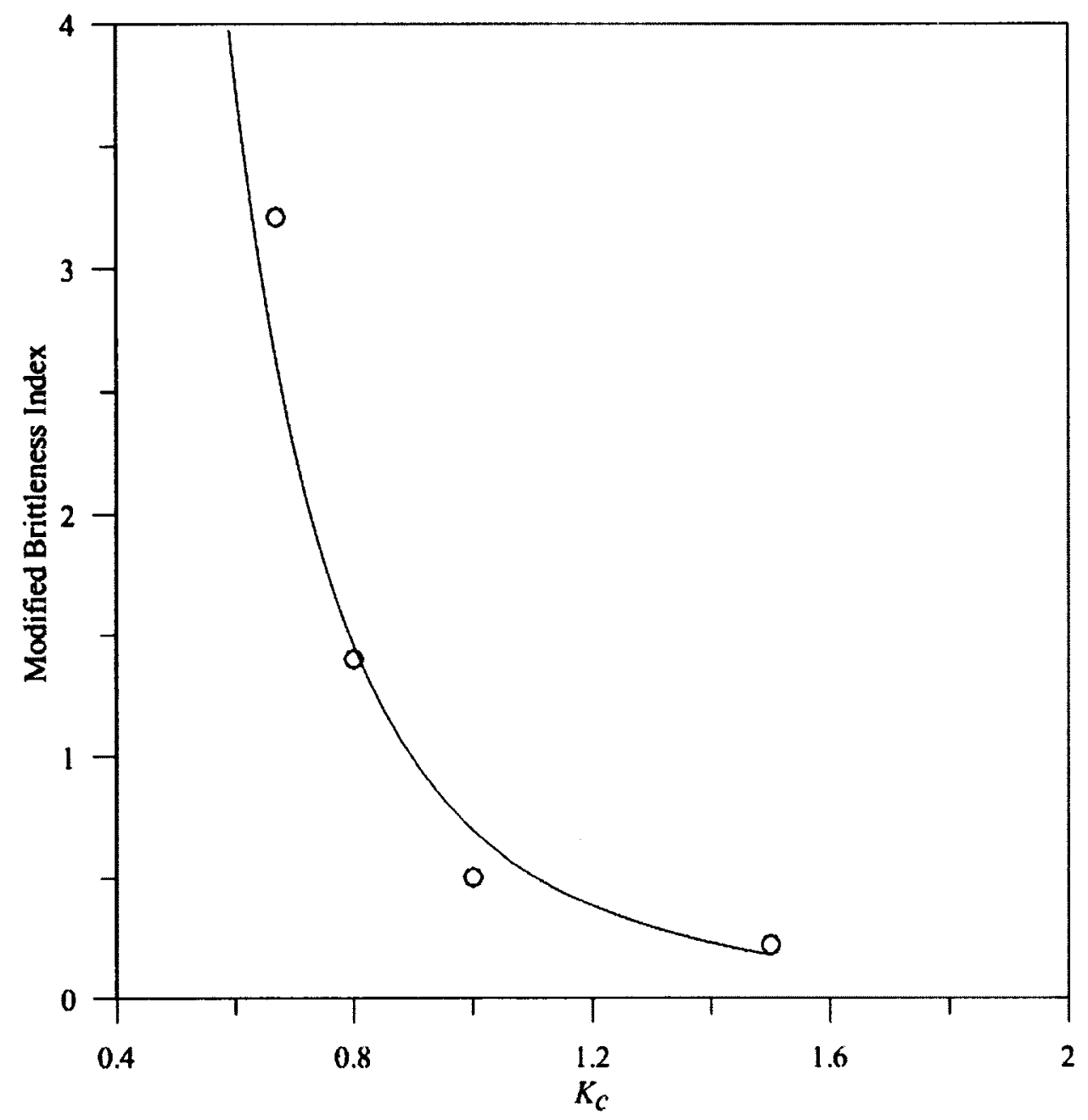

Figure 4.9 Variation of modified brittleness index with initial static shear stress ratio

Figure 4.10 shows the dependence of the monotonic behaviour of loose sand with $\alpha=-0.11$ on the level of overconsolidation. Increasing overconsolidation ratio promotes relatively more dilative behaviour under both compression and extension loading. (Notwithstanding the minor discrepancies noted in the data for corresponding to the test with $\mathrm{OCR}=1.25$ in compression. The minor difference (less than $5 \%$ ) in the relative density of the sands in each test is responsible for this discrepancy). The response under extension loading mode remains of the limited liquefaction type even at the highest level of overconsolidation used in this study. Therefore, the levels of overcon- 

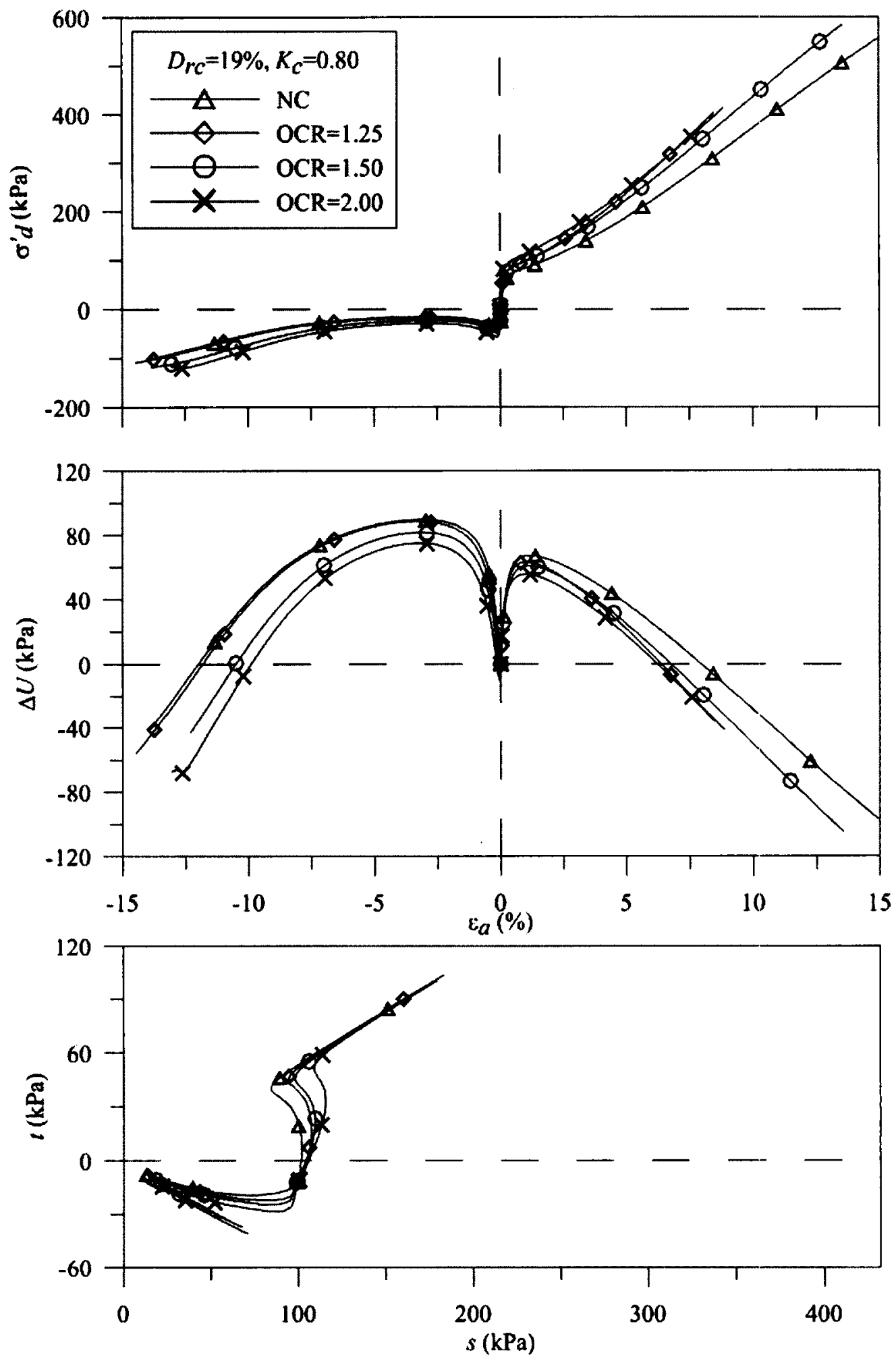

Figure 4.10 Monotonic response of loose sand with $K_{c}=0.80$ at different OCR 
solidation considered in this study do not alter the tendency towards contractive response under extension loading mode. Compared with compression loading mode, the effect of overconsolidation on the type of response is less evident in extension tests. Figures 4.11 and 4.12 depict the same trends at different values of initial static shear stress.

Figure 4.13 depicts the variation of modified brittleness index with OCR at three $K_{c}$ levels. As mentioned earlier, due to the dilative response of triaxial compression tests at all $K_{c}$, OCR, and relative density values and extension tests on medium dense and dense sand, it was not possible to define the modified brittleness index. Therefore, the data points in Figure 4.13 represent just the tests on loose samples under undrained triaxial extension tests. As shown in Figure 4.13, the degree of strain softening decreases dramatically as OCR increases in tests on samples with $K_{c}=0.80$. However, $I_{\bar{B}}$ is almost constant in tests on samples with $K_{c}$ values of 1.00 and 1.50 . On the other hand, as shown in Figure 4.9, sample with $K_{c}=0.80$ has the most contractive tendency based on $I_{\bar{B}}$ values. Therefore, it can be inferred that in cases of a flow failure or limited liquefaction type of response that leads to an $I_{\bar{B}}$ value of equal or greater than 1.00 , i.e. $S_{s t a t i c} \geq S_{\min }$, increasing OCR would lead to a more dilative response. However, OCR does not alter the degree of contractiveness of sands that has a modified brittleness index of less than one. 

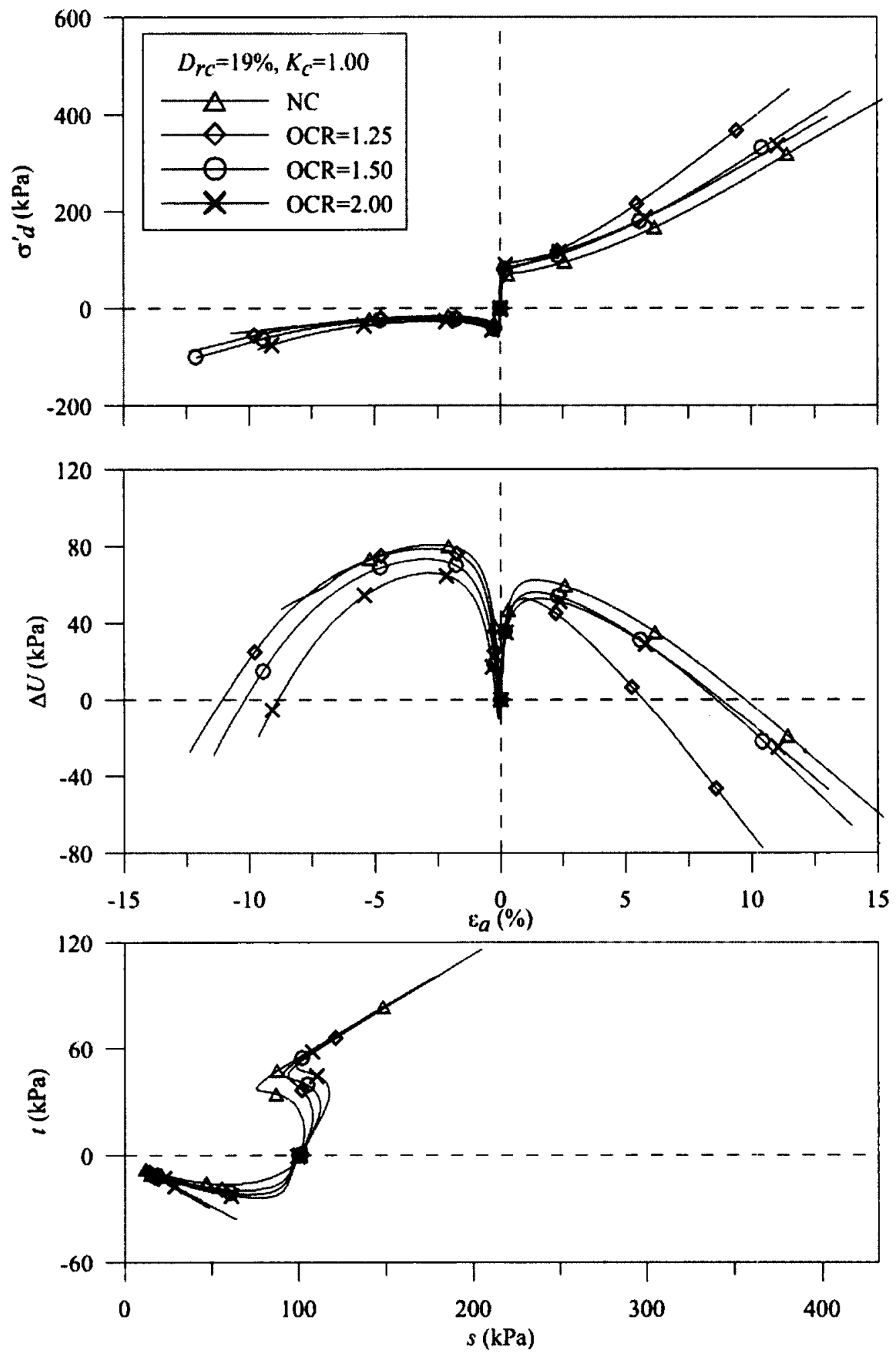

Figure 4.11 Monotonic response of loose sand with $K_{c}=1.00$ at different $\mathrm{OCR}$ 

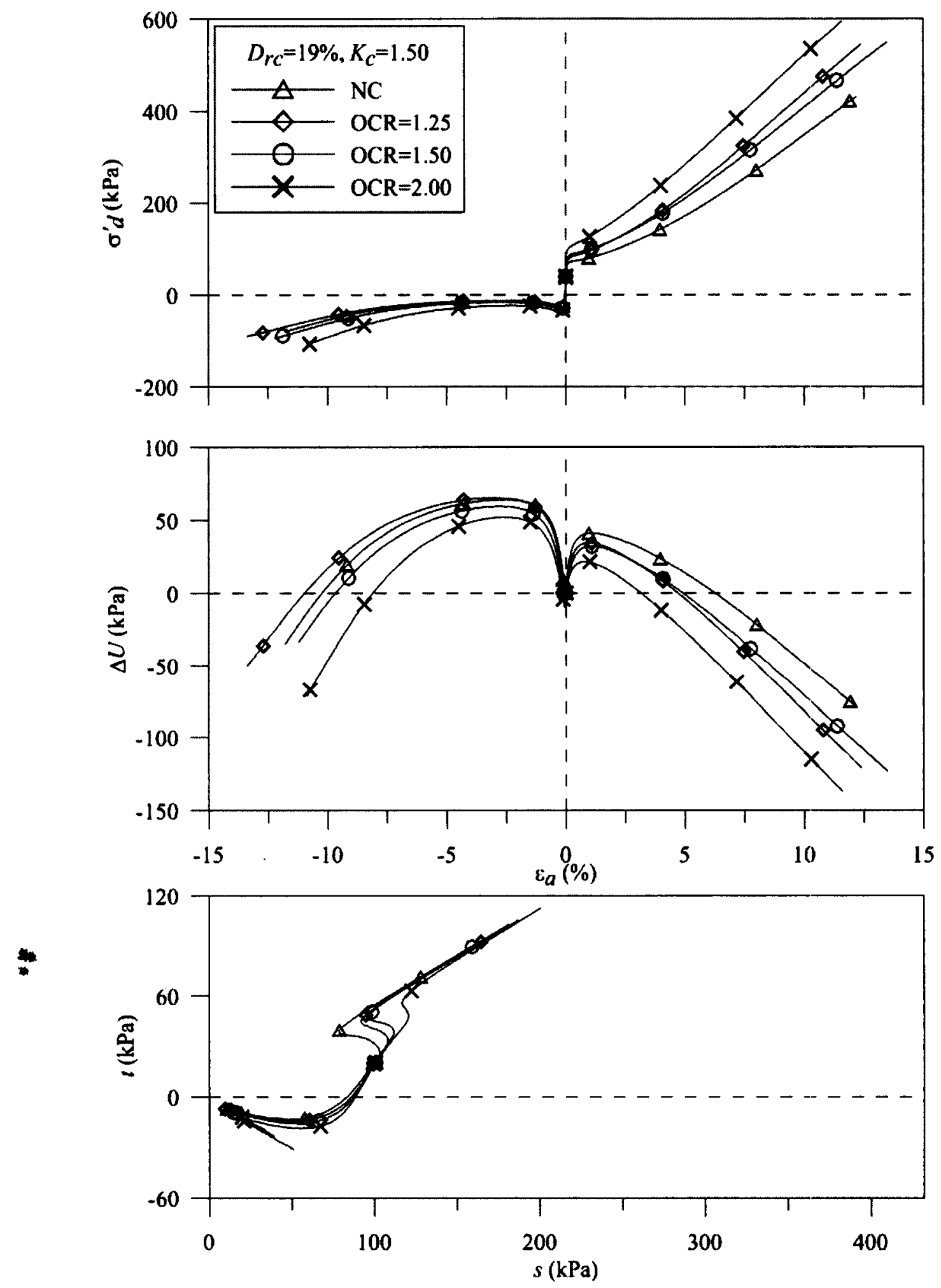

Figure 4.12 Monotonic response of loose sand with $K_{c}=1.50$ at different $\mathrm{OCR}$ 


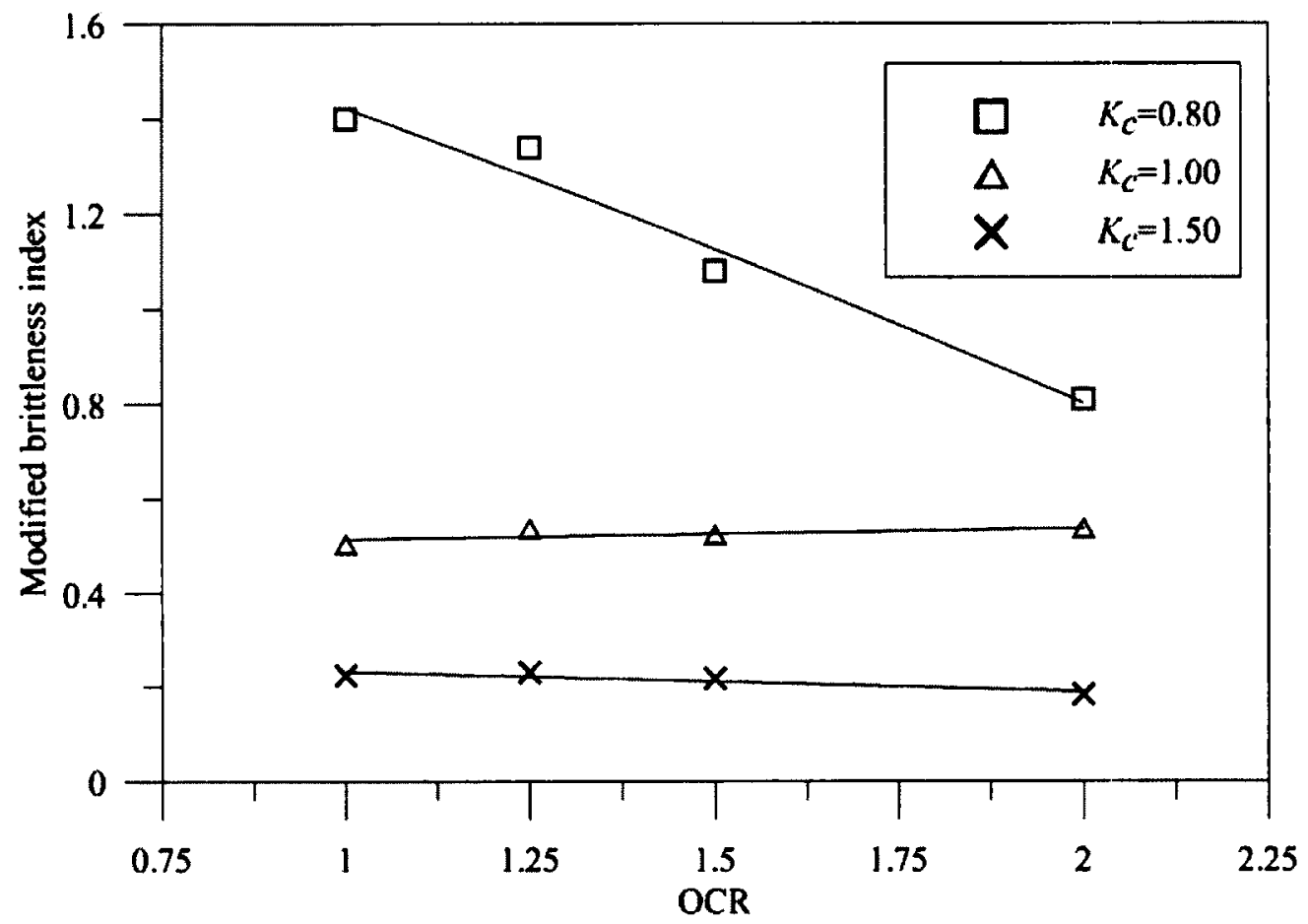

Figure 4.13 Variation of modified brittleness index with $K_{c}$ and OCR

\subsubsection{Triggering of contractive deformation}

The locus of points at the beginning of contractive response is shown in Figure 4.14 in $(t-s)$ space. No strain softening was observed in extension tests at higher relative densities and compression tests even at the loosest state. Therefore, just the stress ratios related to extension tests at different values of static shear and OCR levels have been shown in Figure 4.14. It is evident from the figure that all the points lie on a straight line passing through the origin. This constant line implies that the contractive response initiates at a constant value of stress ratio (CSR) regardless of the stress history and initial stresses prior to shearing. The friction angle at this stress ratio is referred to as $\varphi_{C S R}$. This friction angle is about $16^{\circ}$ in all samples. 


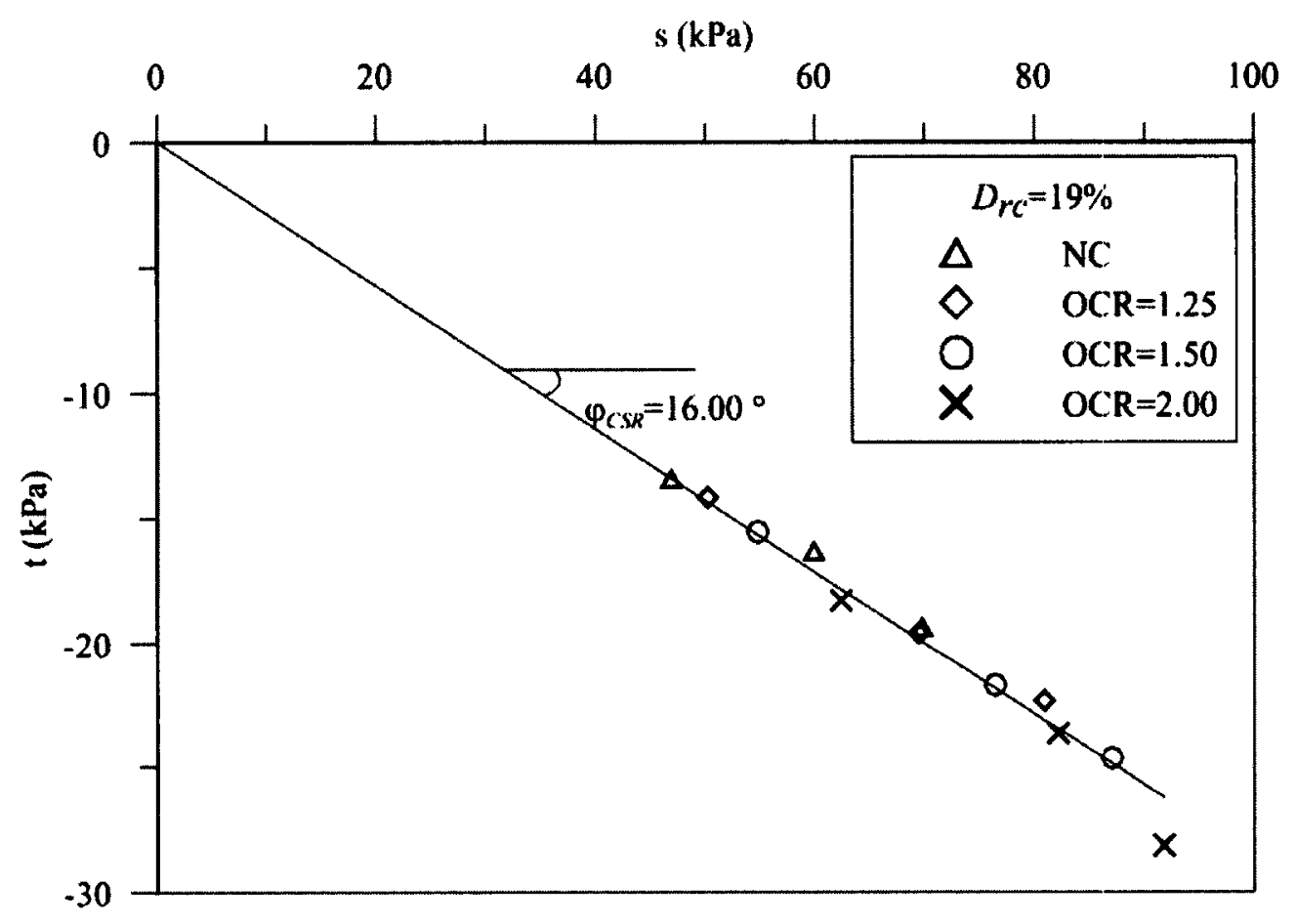

Figure 4.14 Effective stress state at the triggering of strain softening under extension loading mode at different OCR and $K_{c}$ levels

Figure 4.15 shows the peak shear strength $\left(S_{\text {peak }}\right)$ change with OCR in the loose samples. The absolute value of $S_{\text {peak }}$ increases as the OCR increases. On the other hand, the peak shear strength increases to some extent with the decrease in $K_{c}$. It has been shown that peak shear strength can be normalized either by $\sigma_{1 c}^{\prime}$ or $\sigma_{3 c}^{\prime}$ (Chern, 1985, and Thomas, 1992).

Chern (1985) suggested the use of $\sigma_{1 c}^{\prime}$ in contractive compression tests while Thomas (1992) shown that in extension tests $\sigma_{3 c}^{\prime}$ is preferred as it would result in almost constant ratio at a fixed relative density in normally consolidated sand. In this study, the mean normal stress at the end of consolidation is kept constant for all tests. Therefore, depending on $K_{c}$ value, there would be different major and minor principal stresses. Peak shear strengths of samples at different OCR and $K_{c}$ values are first normalized by using 
$\sigma_{1 c}^{\prime}$. As shown in Figure 4.16, the peak stress ratio of tests at $K_{c}=0.80$ are much closer to isotropically consolidated samples than those with $K_{c}=1.50$ all OCR level. On the other hand, if $\sigma_{3 c}^{\prime}$ is used to normalize the peak shear strength, as shown in Figure 4.17, isotropically consolidated samples and those with $K_{c}=1.50$ have almost the same stress ratio regardless of the $K_{c}$ level at all OCR levels. It must be noted that in tests with $K_{c}<1.00$, the major principal stress during consolidation is acting on the horizontal plane while it is acting on the vertical plane in tests with $K_{c}>1.00$. Therefore, to lessen the scatter in the peak shear strengths in tests at different $K_{c}$ values and fixed OCR level, as shown in Figure 4.18, the horizontal stress at the end of consolidation is used to normalize the peak shear strengths. It can also be noted from Figure 4.18 that the peak stress ratio has the least scatter with $K_{C}$ in normally consolidated test.

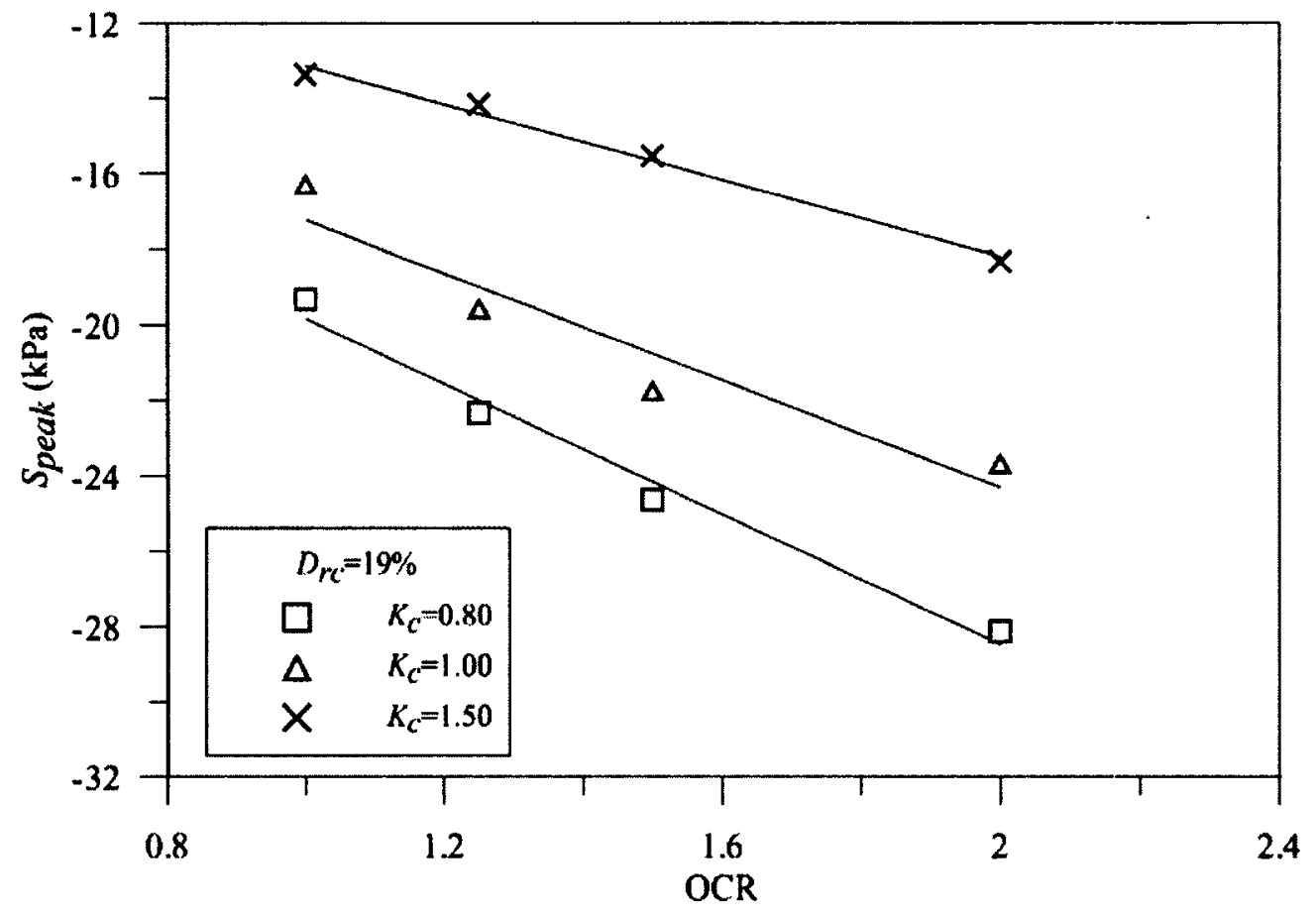

Figure 4.15 Variation of peak shear strength with OCR and $K_{c}$ in extension loading 


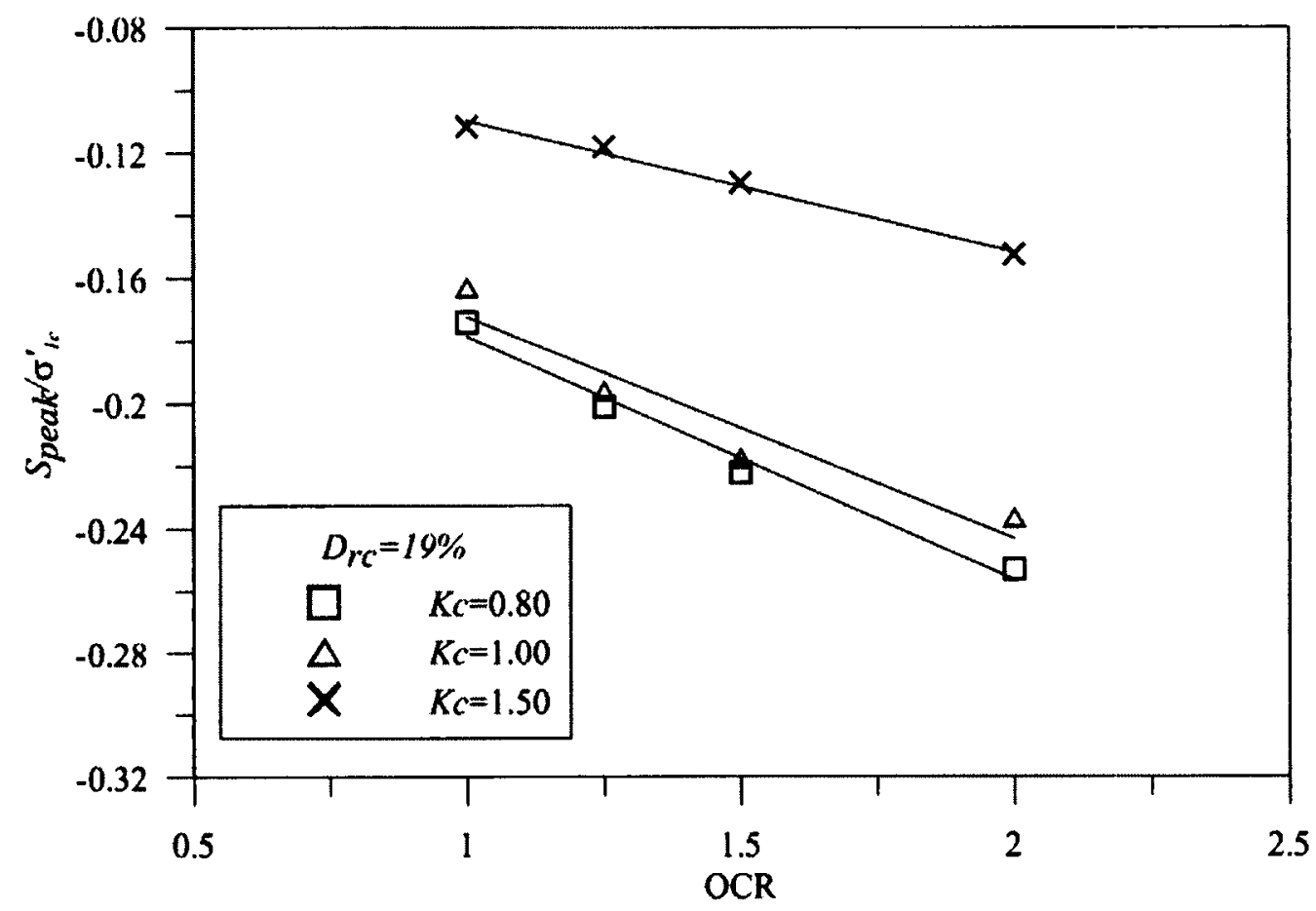

Figure 4.16 Peak shear strength normalised with respect to $\sigma_{1 c}^{\prime}$ at different OCR and $K_{c}$ levels

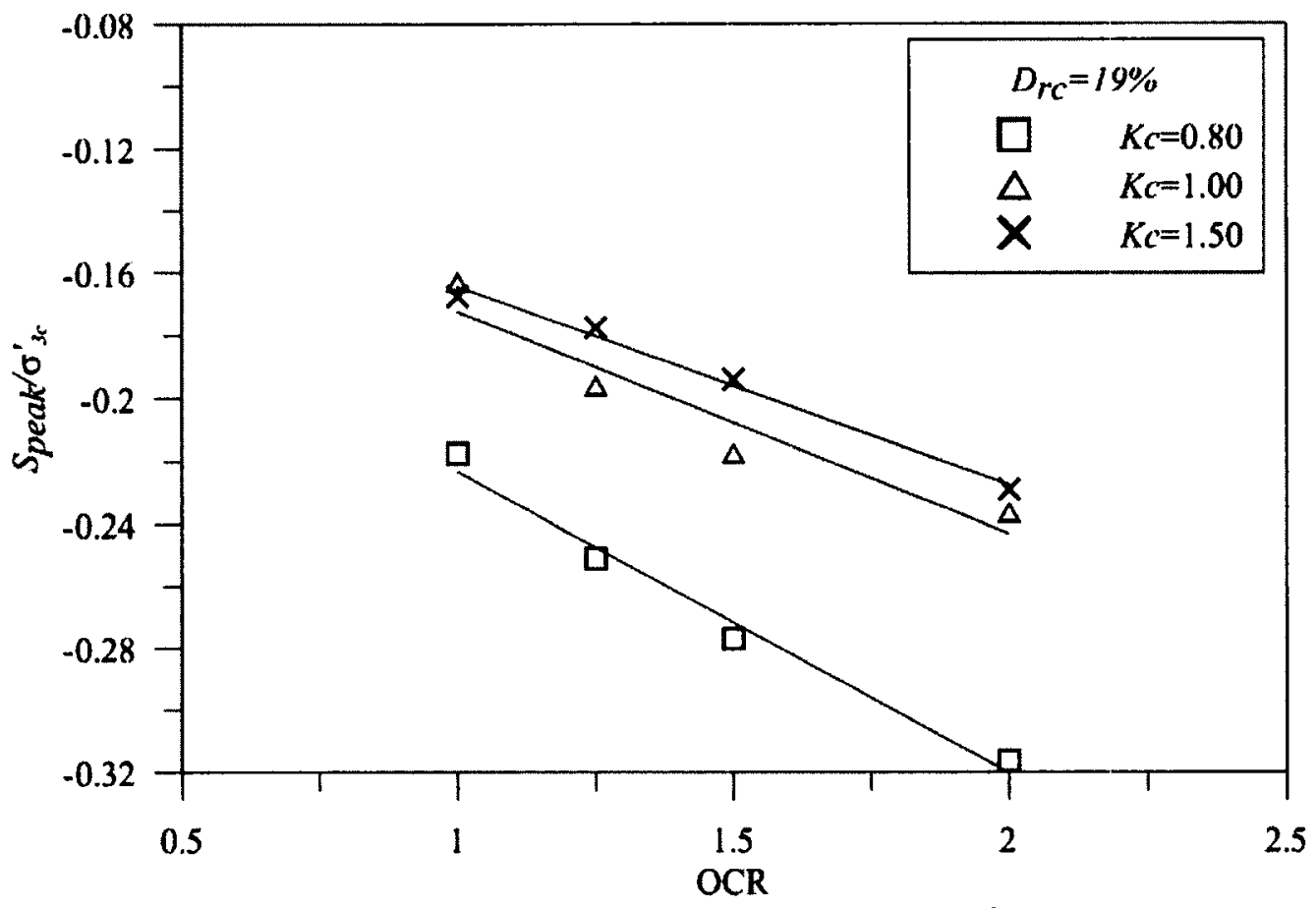

Figure 4.17 Peak shear strength normalised with respect to $\sigma_{3 c}^{\prime}$ at different OCR and $K_{c}$ levels 


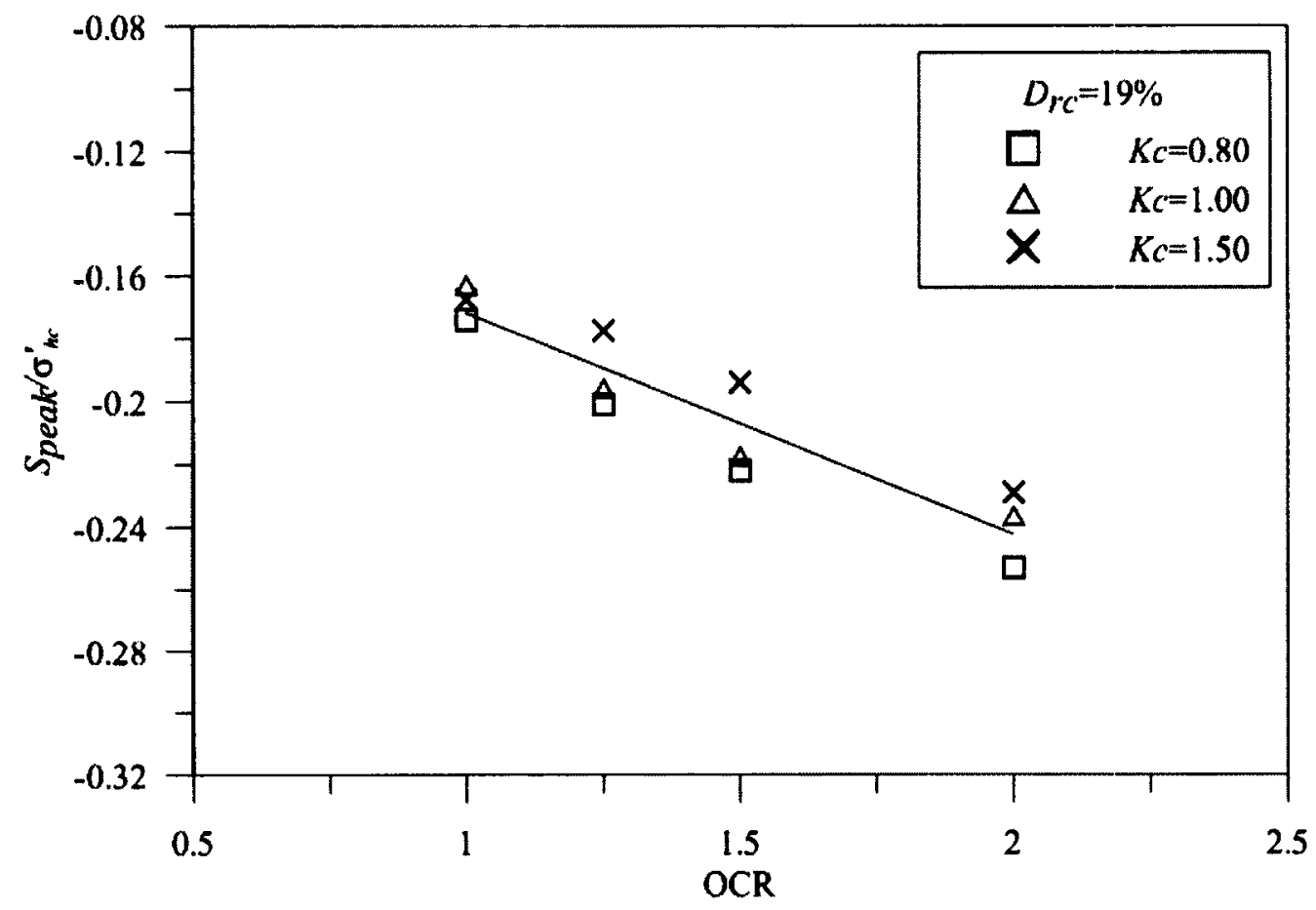

Figure 4.18 Peak shear strength normalised with respect to $\sigma_{h c}^{\prime}$ at different OCR and $K_{c}$ levels

\subsubsection{Phase transformation and steady state}

The effective stresses state at phase transformation is shown in Figure 4.19. Regardless of the initial stress state, the consolidation history (OCR), and loading mode, all the stress states lie on a straight line passing through the origin. The friction angle $\varphi_{P T}$ mobilized at these stress states is about $32^{\circ}$ and is identical in both compression and extension loading modes. This uniqueness of friction angle has been previously reported by several researchers (Vaid and Thomas, 1995; Stedman, 1997). In this study, it has been shown that in addition to confining stress level, static shear stress level, and void ratio, overconsolidation also has no effect on $\varphi_{P T}$. 


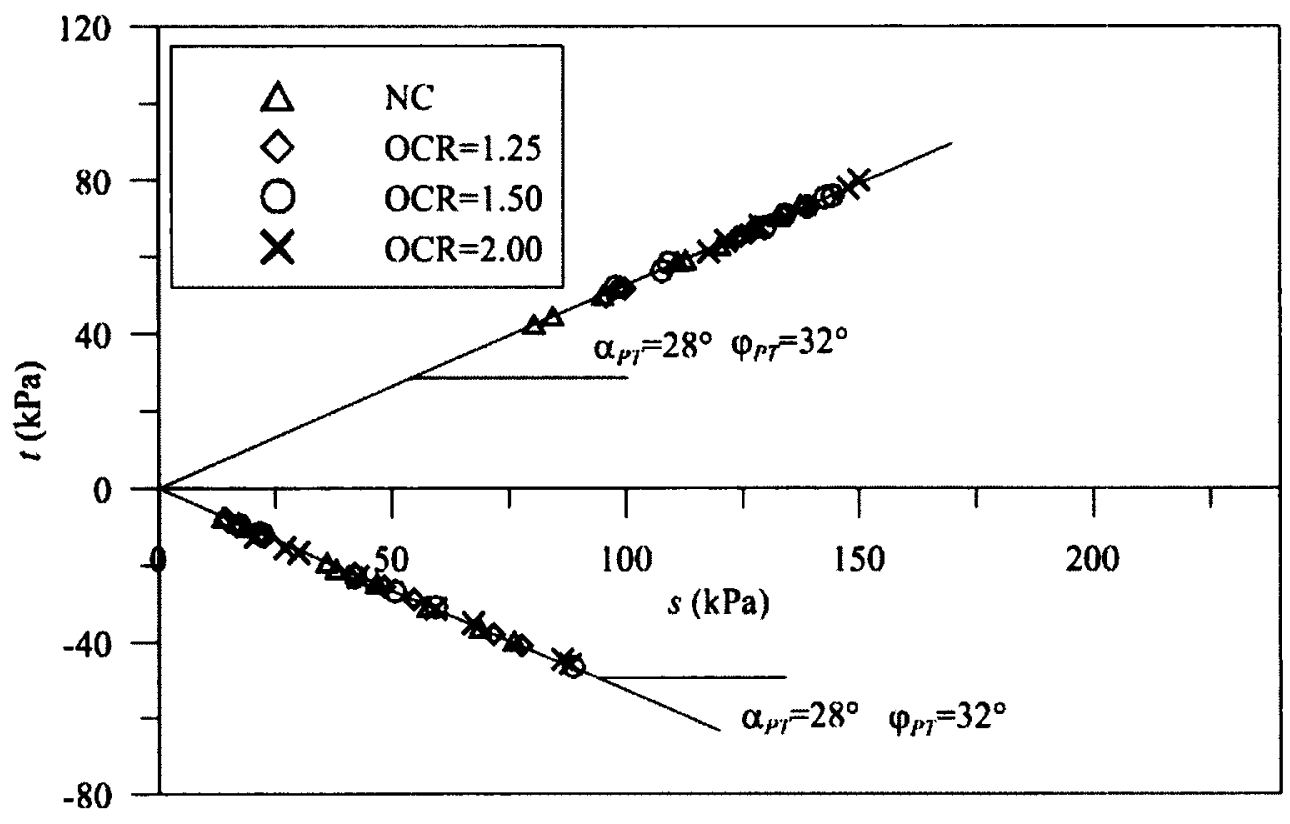

Figure 4. 19 Effective stress states at phase transformation in compression and extension loading modes

\subsection{CYCLIC RESPONSE}

Cyclic triaxial tests were performed on isotropically and anisotropically consolidated samples over a range of overconsolidation ratios and void ratios. These tests were performed to assess the effects of OCR, static bias, and void ratio on the cyclic response of Fraser River sand and to establish the dependence of $K_{\alpha}$ correction factor on overconsolidation. Tests were performed at different cyclic stress ratio (CSR) values while the static shear and OCR level were kept constant. Due to practical relevance, OCR levels of 1 (normally consolidated), $1.25,1.50$, and 2.00 were studied. On the other hand, to study the effect of the direction of major principal stress on the cyclic response, $K_{c}$ value of 0.80 was used. Other consolidation stress ratios that were used in this study are 1.00 and 1.50 . Also, three relative density levels of $19 \%, 40 \%$, and $65 \%$ were studied. 
As mentioned in chapter 2, liquefaction in triaxial undrained loading is defined as the development of axial strain in excess of $2.5 \%$ single amplitude regardless of the responsible mechanism. During cyclic loading the strain development can be due to either contractive flow deformation or cyclic mobility depending on stress level, applied cyclic stress, OCR, and void ratio. To better understand the effect of overconsolidation, the Fraser River sand response with no static shear is presented and discussed first, followed by the response of FRS with different levels of static shear.

\subsubsection{Behaviour dependency on Overconsolidation}

Figures 4.20(a) and (b) compare the cyclic response of samples consolidated with $K_{c}=0.80(\alpha=-0.11)$ at the loosest density with different consolidation stress histories. Specimens were consolidated under effective mean confining stresses of 125,150 , and $200 \mathrm{kPa}$ prior to unloading to the final confining pressure of $100 \mathrm{kPa}$ to yield overconsolidation ratios of $1.25,1.50$, and 2.00 , respectively. After consolidation, all the specimens where subjected to a cyclic shear stress of $10 \mathrm{kPa}$ (yielding a CSR of 0.10 ).

Figures 4.20(a) and (b) show a great dependency of cyclic resistance on OCR. The number of cycles to liquefaction based on a strain criteria increased from 1 for normally consolidated specimen to 150 in the specimen with OCR of 2.00 . At a fixed CSR the mechanism leading to liquefaction is also affected by overconsolidation. As shown in Figure 4.21 the response in all samples regardless of the OCR level was of true liquefaction type. As seen in Figures 4.20(a) and (b), there is some noise during the last cycle. These perturbations from the desired target stress were due to the loss of control during the large deformations that occurs in a very short time when flow failure (or limited liquefaction) occurs. As depicted in Figure 4.20, the rate of pore pressure 
generation decreases with increasing OCR due to the increasing dilative tendencies in the soil. After 28 cycles of loading the sample with $\mathrm{OCR}=1.25$, generated $100 \%$ of the peak excess pore pressure, but only $20 \%$ and $10 \%$ of the peak excess pore pressure were generated in sands with OCR values of 1.50 and 2.00 respectively. As noted in Figures 4.20(a) and (b), negative pore pressure has been developed in early stages of loading in overconsolidated samples. This negative excess pore pressure generation is responsible for the increase in cyclic resistance of overconsolidated sands. Similar OCR dependency of the cyclic behaviour was observed in all samples with different initial conditions and CSR levels. These findings are discussed and summarized in the following sections.

\subsubsection{Number of cycles to liquefaction}

The variation of the number of cycles to liquefaction as a function of OCR at a fixed relative density $\left(D_{r c}=19 \%\right)$ and different levels of static shear and CSR is shown in Figure 4.22. Regardless of CSR and $K_{c}$ the number of cycles to liquefaction increases as OCR increases. Data similar to those presented in Figure 4.22 allow the quantification of the levels of additional load cycles that can be sustained by an overconsolidated soil at a given $K_{c}, D_{r c}$, and CSR. This quantification is important since in practice, cyclic stress ratio is related to the peak ground acceleration and therefore the cyclic resistance increase due to overconsolidation can be estimated for a specific site condition. However, due to higher practical importance, the focus of this study was on obtaining cyclic resistance ratio (CRR) than studying the effect of OCR on the number of cycles to liquefaction at a specific CSR. Therefore, due to lack of data it is not possible to propose a proper relationship between OCR and number of cycles to liquefaction. 

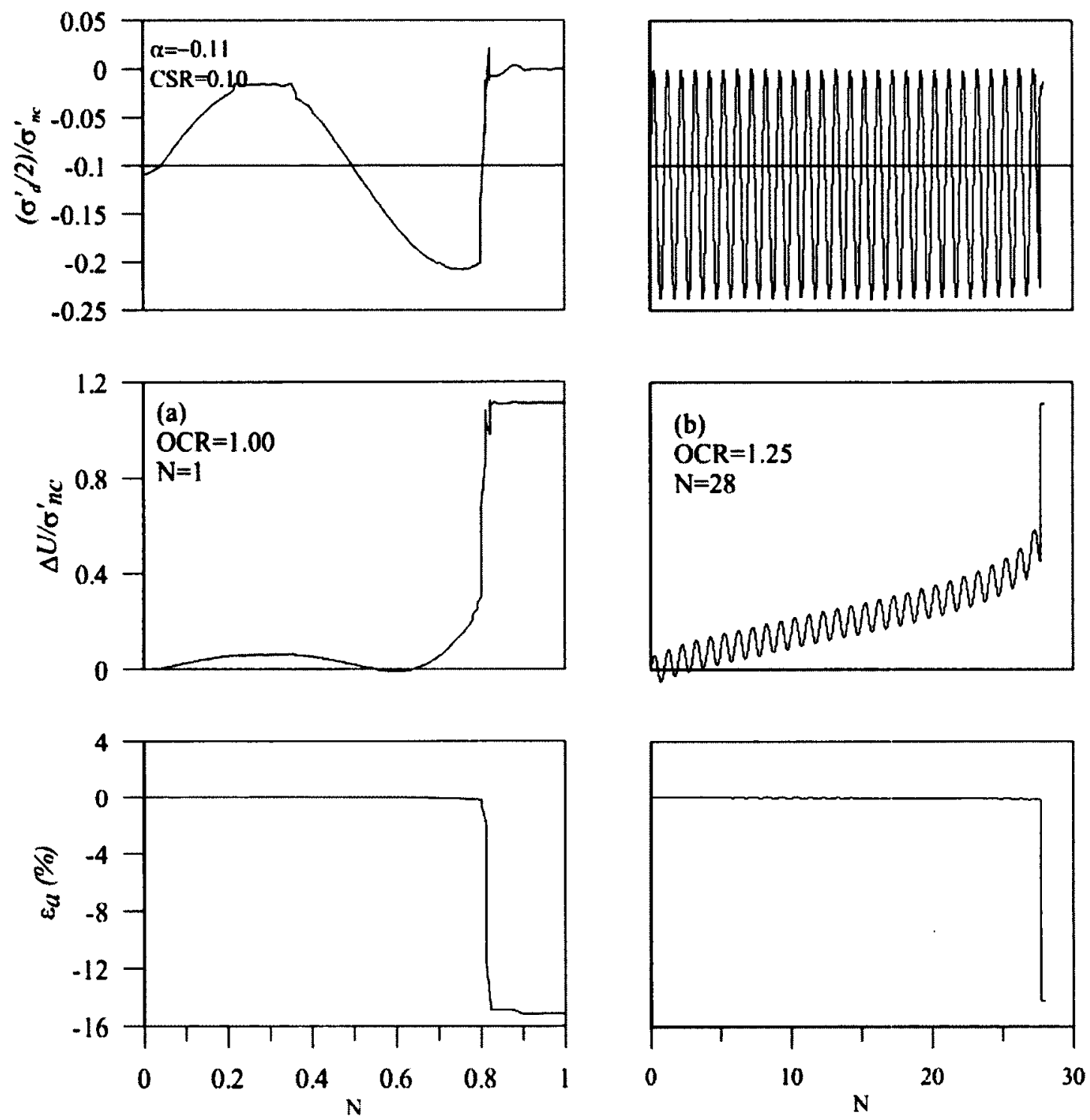

Figure 4.20(a) Cyclic test results of loose samples at $\alpha=-0.11$ (a) normally consolidated, (b) at $\mathrm{OCR}=1.25$ with $\mathrm{CSR}=0.10$ 

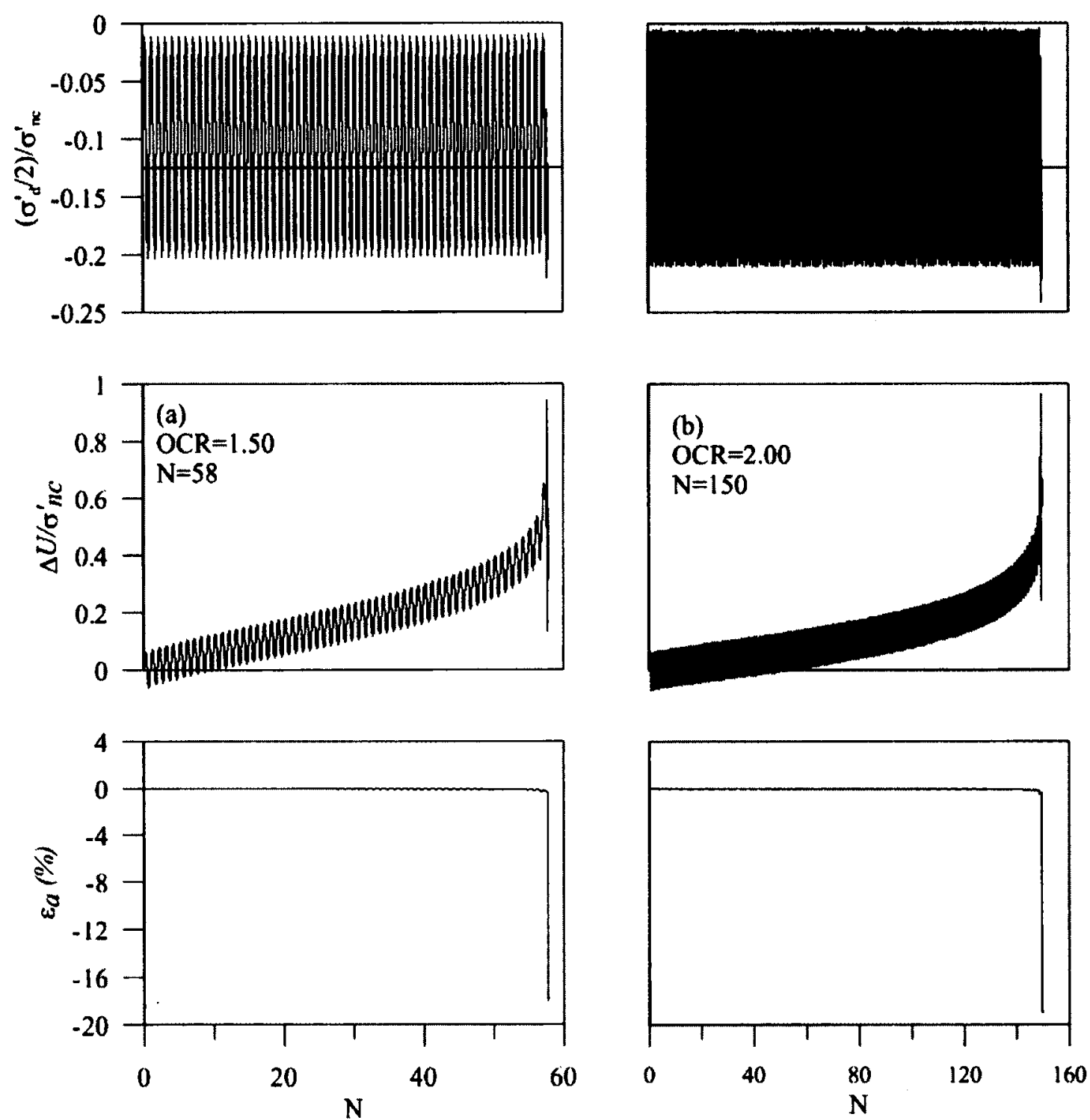

Figure 4.20(b) Cyclic test results of loose samples at $\alpha=-0.11$ (a) OCR=1.50, (b) at $\mathrm{OCR}=2.00$ with $\mathrm{CSR}=0.10$ 

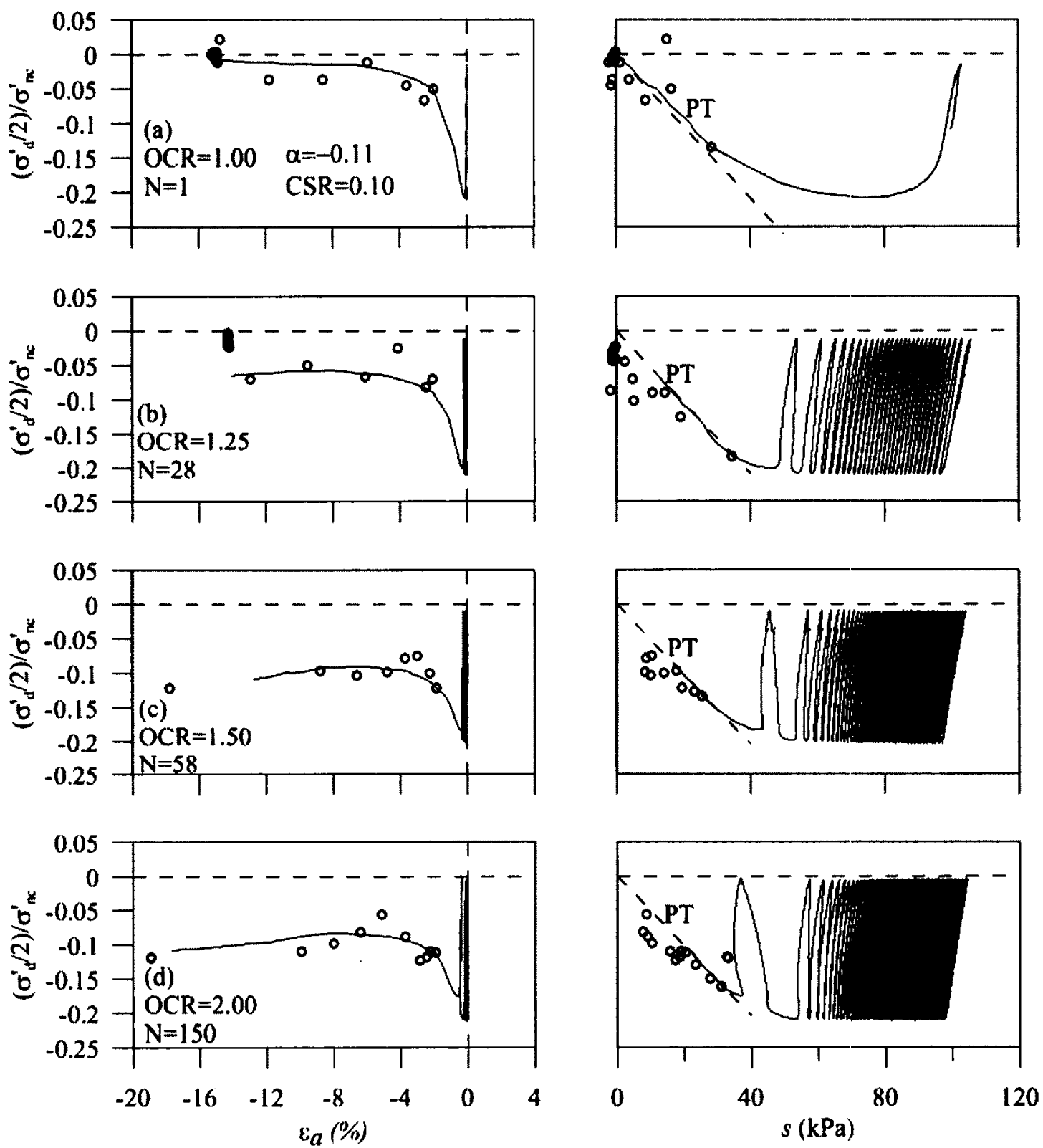

Figure 4.21 Stress-strain and stress path response of isotropically consolidated sand at different $\mathrm{OCR}$ values with $\mathrm{CSR}=0.10$ 


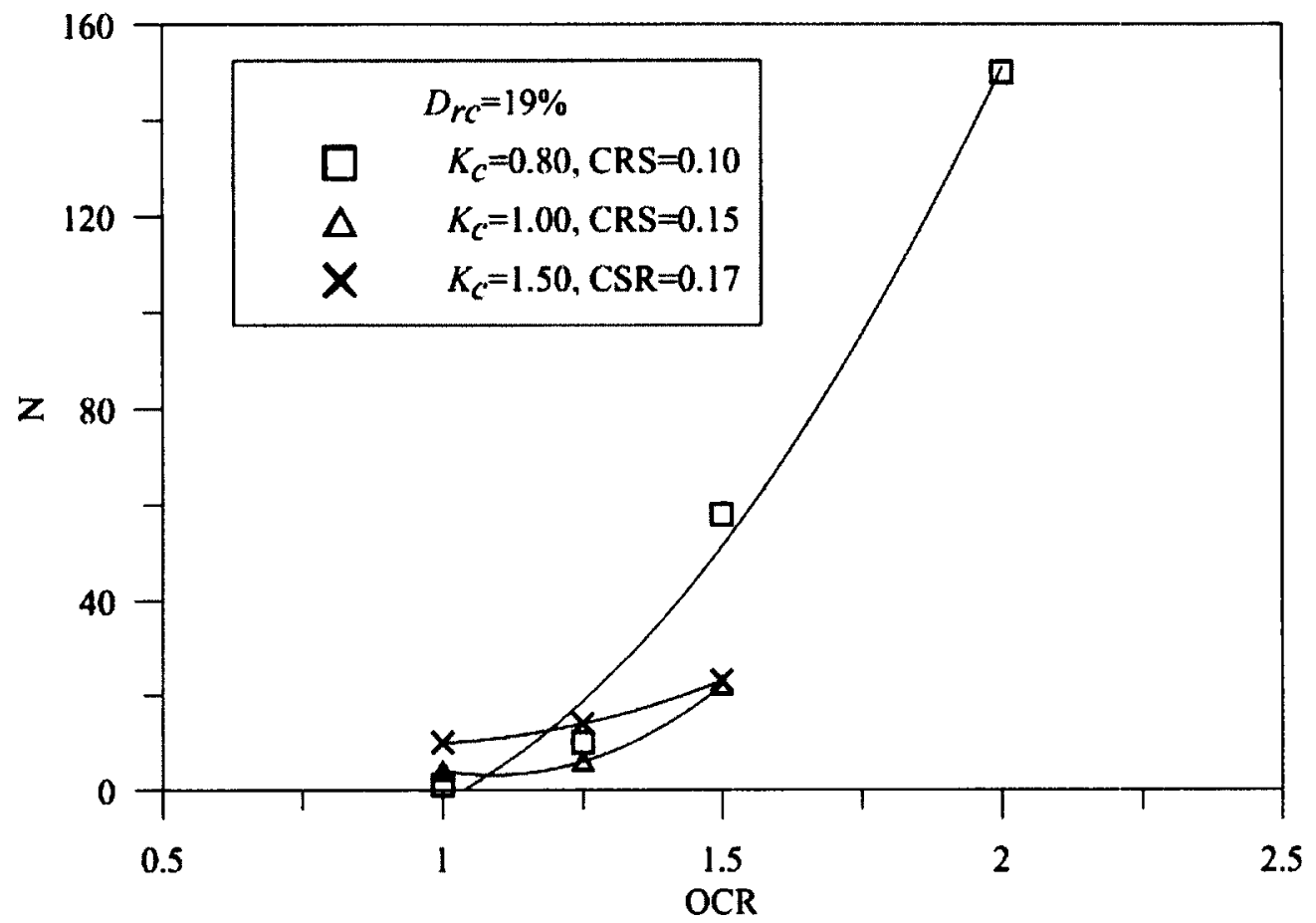

Figure 4.22 Variation of the number of cycles to liquefaction with OCR

\subsubsection{Cyclic resistance ratio, $C R R$}

As mentioned in chapter 2 , in this study, the cyclic resistance ratio (CRR) is considered to be the stress ratio that causes liquefaction in 10 cycles. This number of cycles is characteristic of an M 6.75 earthquake. The CRR values have been obtained by interpolation from the $\mathrm{N}$ vs. CSR graphs for specific initial conditions (Figure 4.23). Figure 4.24 shows the variation of CRR with relative density at different OCR levels on isotropically consolidated samples.

Figure 4.24 clearly shows that the cyclic resistance of sand increases with increasing relative density and OCR. The relationship between CRR and $D_{r c}$ at a specific OCR level can be defined as: 


$$
C R R_{O C R, D_{r c}}=a * e^{b * D_{r c}}
$$

where $D_{r c}$ is in decimal format. Based on the data presented in Figure 4.24, the parameter "b" in equation (4.3) is independent of OCR level and found to have a mean value of $(2 \pm 0.1)$. However, parameter " $a$ " is dependent on OCR value at a fixed $K_{c}$ level and increases linearly with OCR. Equation (4.4) shows the relationship between " $a$ " and OCR in isotropically consolidated samples.

$$
a=0.0277 *(O C R)+0.06
$$

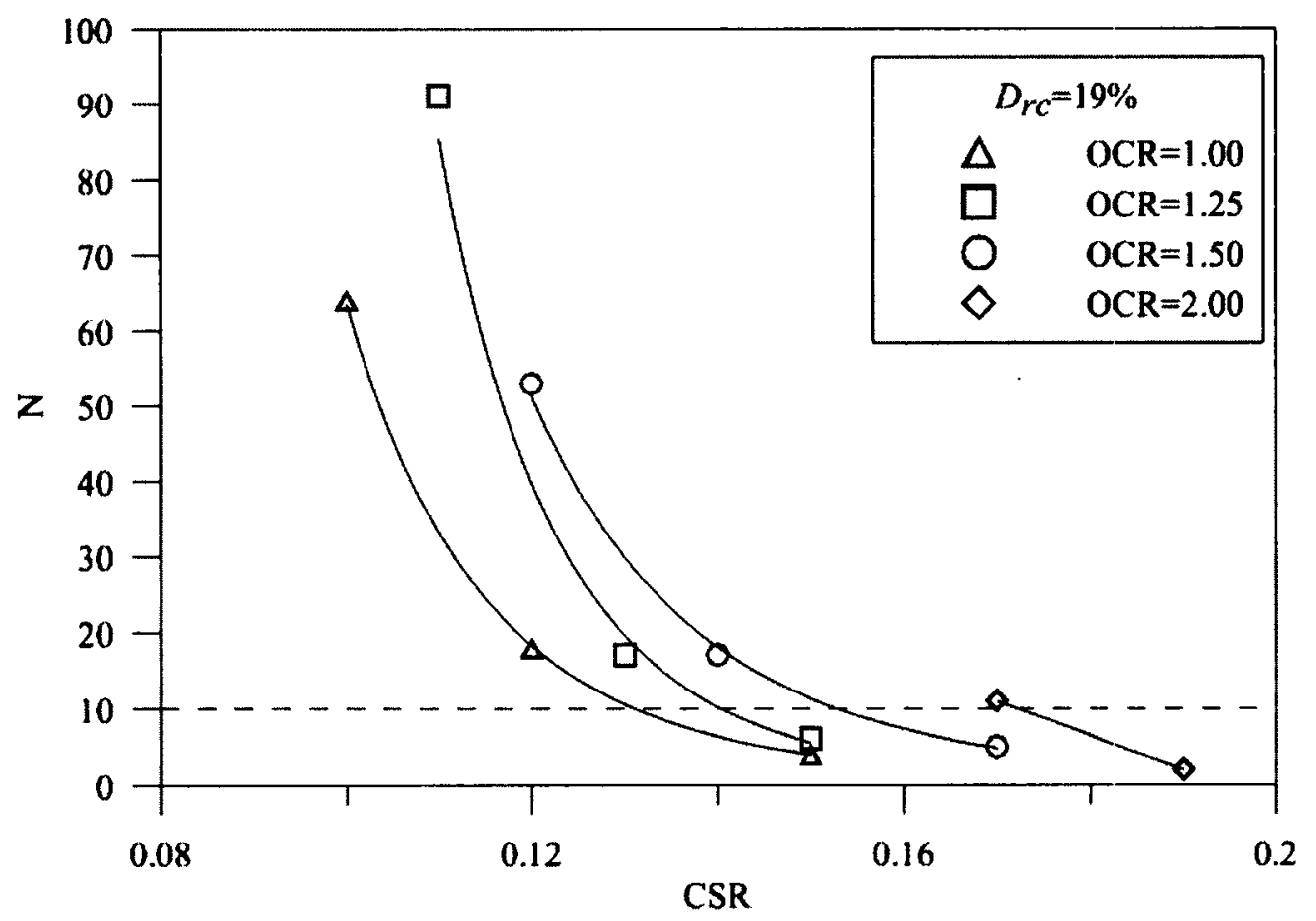

Figure 4.23 Variation of number of cycles to liquefaction with CSR 


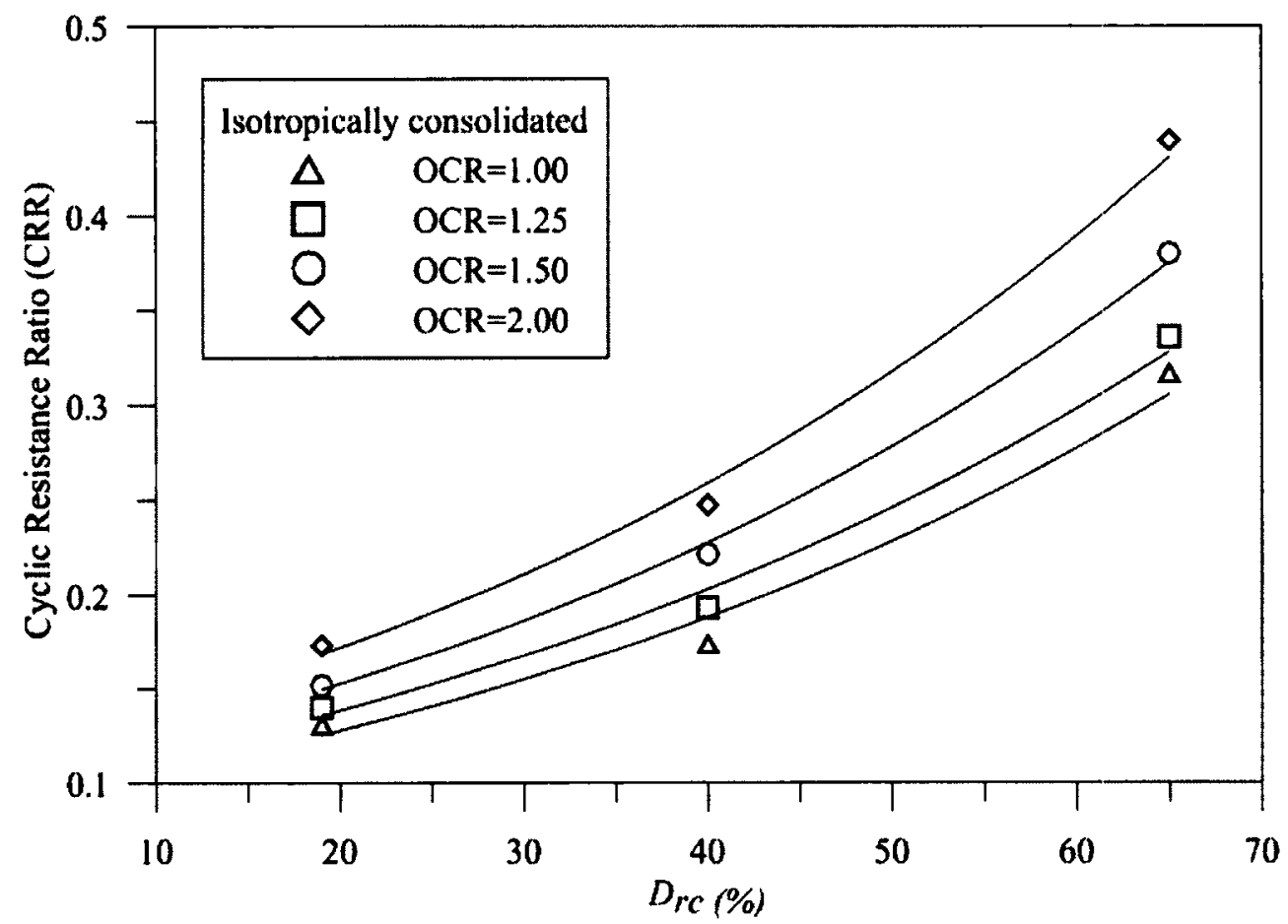

Figure 4.24 Variation of the cyclic resistance ratio (CRR) of sand with relative density $\left(D_{r c}\right)$ and $\mathrm{OCR}$

In current engineering practice, the cyclic resistance of a site is established by using a reference CRR, and then correcting it using $K_{\alpha}$ and $K_{\sigma}$ correction factors for static shear and confining stress effects, respectively. However, the effect of overconsolidation is ignored in current design method and the reference is measured at the normally consolidated state. To consider the effect of overconsolidation, Manmatharajan (2011) has introduced a new correction factor, $K_{O C R}$, based on cyclic simple shear test results. However, most of the research on $K_{\alpha}$ and $K_{\sigma}$ have been done by performing cyclic triaxial tests on saturated samples. Therefore, an OCR correction factor based on cyclic triaxial tests would be a more appropriate complement to the previous research work. $K_{O C R}$ is defined as the ratio of the cyclic resistance of overconsolidated 
soil to that of normally consolidated soil, at a given relative density and stress state as shown in equation (4.5).

$$
K_{O C R}=\frac{C R R_{O C R}, D_{r}, \sigma_{n}^{\prime} n}{C R R_{N C,} D_{r}, \sigma^{\prime} n}
$$

Figure 4.25 shows the variation of the $K_{O C R}$ values with OCR over a range of void ratios but at fixed mean confining stress of $100 \mathrm{kPa}$. At shown in the graph, there is some scatter in data according to the relative density. The same kind of scatter was reported by Manmatharajan (2011) on simple shear results at two OCR levels of 1.50 and 2.00. However, the effect of relative density on $K_{O C R}$ is found to be minimal compared to OCR. The cyclic resistance of the soil consolidated with OCR of 1.50 is increased by $10 \%$ as the relative density changes from $19 \%$ to $40 \%$. However, at all relative densities, the cyclic resistance is increased $40 \%$ as the OCR increased from 1 to 2.00 . Therefore, based on the information provided in Figure 4.25, a linear trend line can be fitted on all the test data regardless of the relative density. The equation of the trend line is given as:

$$
K_{O C R}=0.38 *(O C R-1)+1
$$

Equation (4.6) is in an excellent agreement with the previous relationship as $K_{O C R}=0.3 *(O C R-1)+1$ proposed by Manmatharajan (2011) based on simple shear tests on the same sand. Therefore, it can be inferred that loading mode does not have a significant effect on the effect of OCR on the cyclic resistance of Fraser River sand and $K_{O C R}$ would be just a function of OCR irrespective of the loading mode and relative density. Ishihara and Takatsu (1979), based on cyclic torsional shear tests on medium dense samples of Fuji River sand, have also proposed an equation for the correction 
factor $K_{O C R}$. As shown in Figure 4.25, Ishihara and Takatsu's relationship for $K_{O C R}$ is in a very good agreement with the medium dense sand tests results. $K_{O C R}$ values for overconsolidated loose and dense sands appear to be somewhat lower than that of medium dense sands, but the differences are relatively minor. The reasons for this are not understood at this time, and additional tests are required to ascertain whether this is a systematic variation. Proposed linear equation has been based on data obtained from tests with OCR values of up to 2 only, and thus the use the proposed equation is not recommended for higher OCR levels unless additional tests have been conducted to verify the relationship.

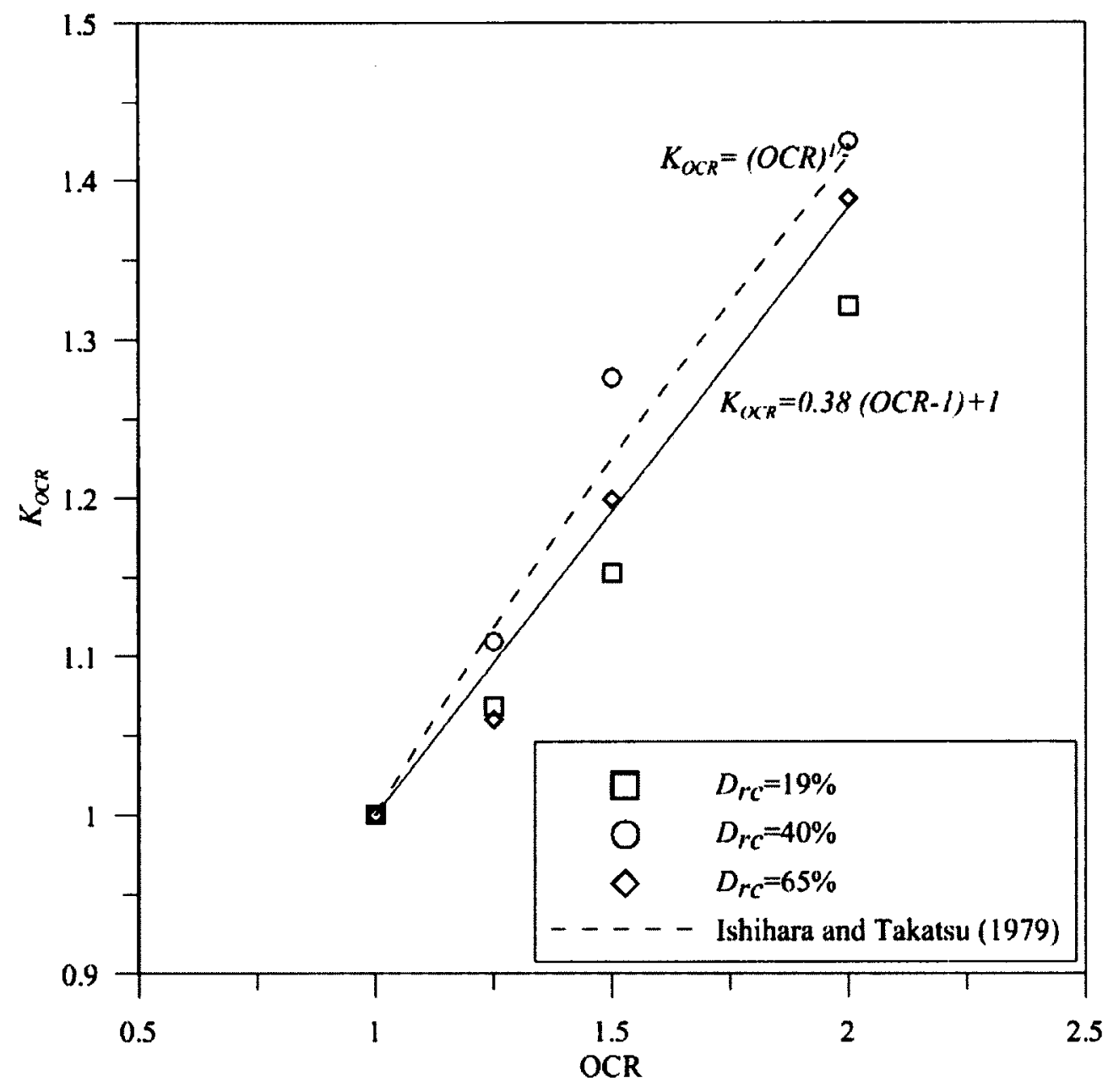

Figure 4.25 Dependency of $K_{O C R}$ on relative density 
By comparing Figures 4.21 and 4.24 or 4.25 , it can be inferred that the effect of OCR on the number of cycles to liquefaction at a fixed CSR is much more than its influence on cyclic resistance or $K_{O C R}$. However, the current design codes are more concerned about the consequences of a design earthquake of a given magnitude, and thus the interest is on CRR rather than number of cycles at a given CSR. Number of significant load cycles is related to the magnitude of the earthquake and is considered fixed once a design earthquake is selected.

\subsubsection{Effect of initial static shear stress level}

As mentioned in chapter 2, due to anisotropic nature of granular materials, the cyclic resistance of these soils is highly affected by the presence of static shear prior to undrained cyclic shearing. In addition, the presence of static shear can change the deformation mechanism of sand during cyclic loading. Depending on whether or not the magnitude of the cyclic shear stress is greater than the static shear during consolidation, stress reversal may or may not take place. Figure 4.26 shows two tests at different $\alpha$ and CSR. Strain and excess pore pressure development mechanisms are different as one (Figure 4.26(a)) undergoes stress reversal and thus transient states of zero effective stress $\left(\sigma_{n c}^{\prime}=0\right)$ and no stress reversal is observed in the other test (Figure $\left.4.26(\mathrm{~b})\right)$. The majority of previous studies on the effect of static shear stress on cyclic resistance of sand have been done with static shear stresses due to major principal stress in the vertical direction. However, the sand response is highly dependent on the loading mode and the response under compression loading is different from the extension one. 

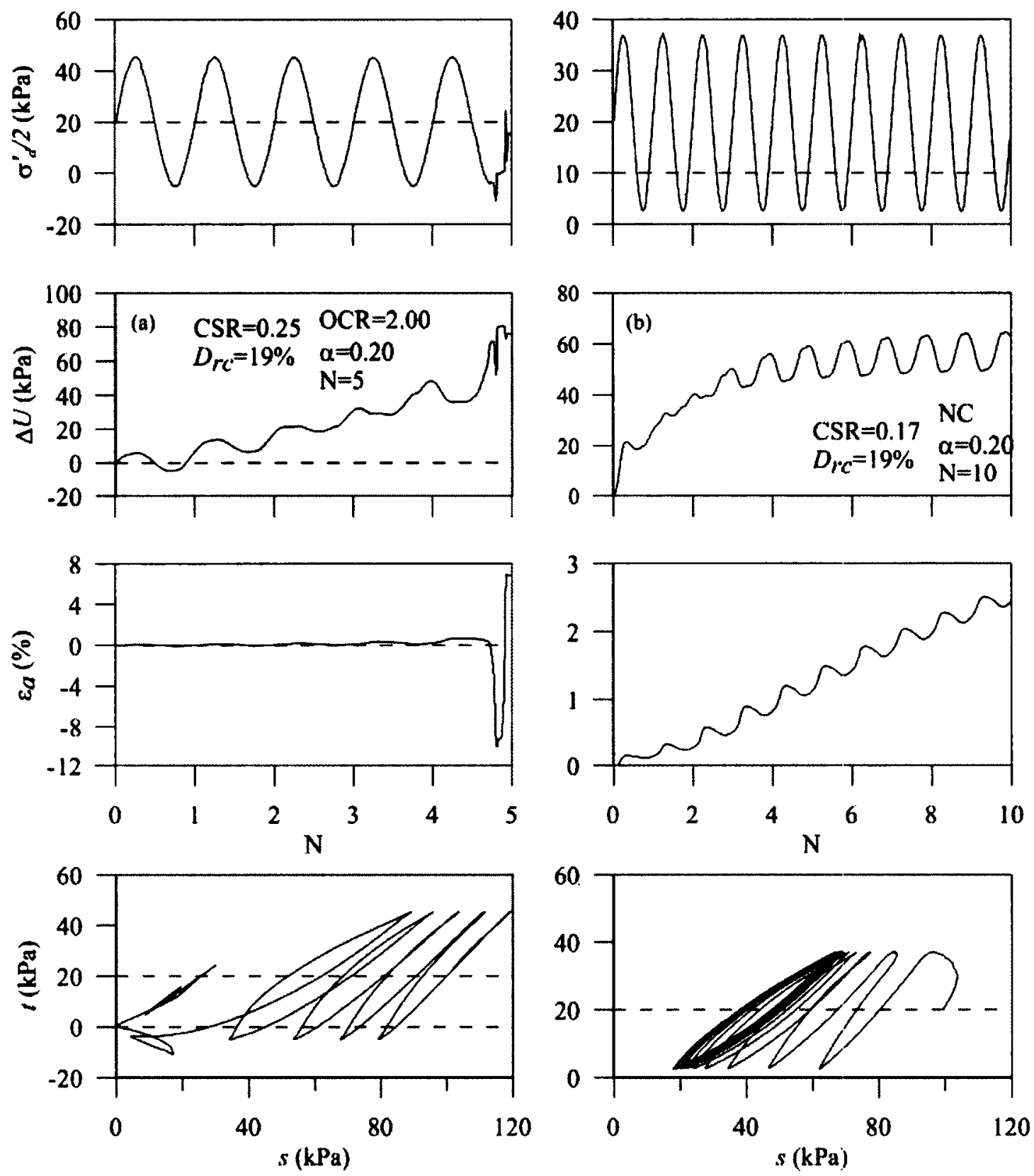

Figure 4.26 Cyclic tests (a) with stress reversal (b) without stress reversal 
Therefore, it is necessary to understand the effect of initial static shear stress direction on the cyclic resistance. To do that, a series of cyclic triaxial tests on samples consolidated with $K_{c}=0.80,1.00$, and 1.50 have been performed. As Vaid et al. (2001) have pointed out, the effect of initial static shear can be affected by the level of relative density. Therefore, tests have been performed over a range of relative density values $(19 \%, 40 \%$, and $65 \%)$.

On the other hand, just a few researchers (e.g. Ishihara and Takatsu, 1979) have studied the effect of overconsolidation on the cyclic resistance of anisotropically consolidated sand specimens. Also, to the knowledge of the writer, all the previous studies on the effect of overconsolidation on $K_{\alpha}$ have been done on samples at just one level of relative density and the effect of relative density has not been studied. Therefore, cyclic triaxial tests have been performed on normally consolidated specimens and specimens with $\mathrm{OCR}=1.25,1.50$, and 2.00 at a variety of relative density levels. These tests results are presented and discussed in this section.

\subsubsection{Effect of static shear level on cyclic resistance ratio (CRR)}

The cyclic resistance ratio of Fraser River sand subjected to initial static shear at fixed overconsolidation level but at different relative densities is compared in Figures 4.27(a) and 4.27(b). Regardless of the OCR level, at a given relative density, in the range of initial static shear stress ratios used in this study, the cyclic resistance increases with an increase in the level of static shear during consolidation. The maximum initial static shear stress used in this study is 0.20 and the effect of OCR on CRR at higher $\alpha$ values has not been studied. On the other hand, this study has covered a wide range of OCR at a specific 

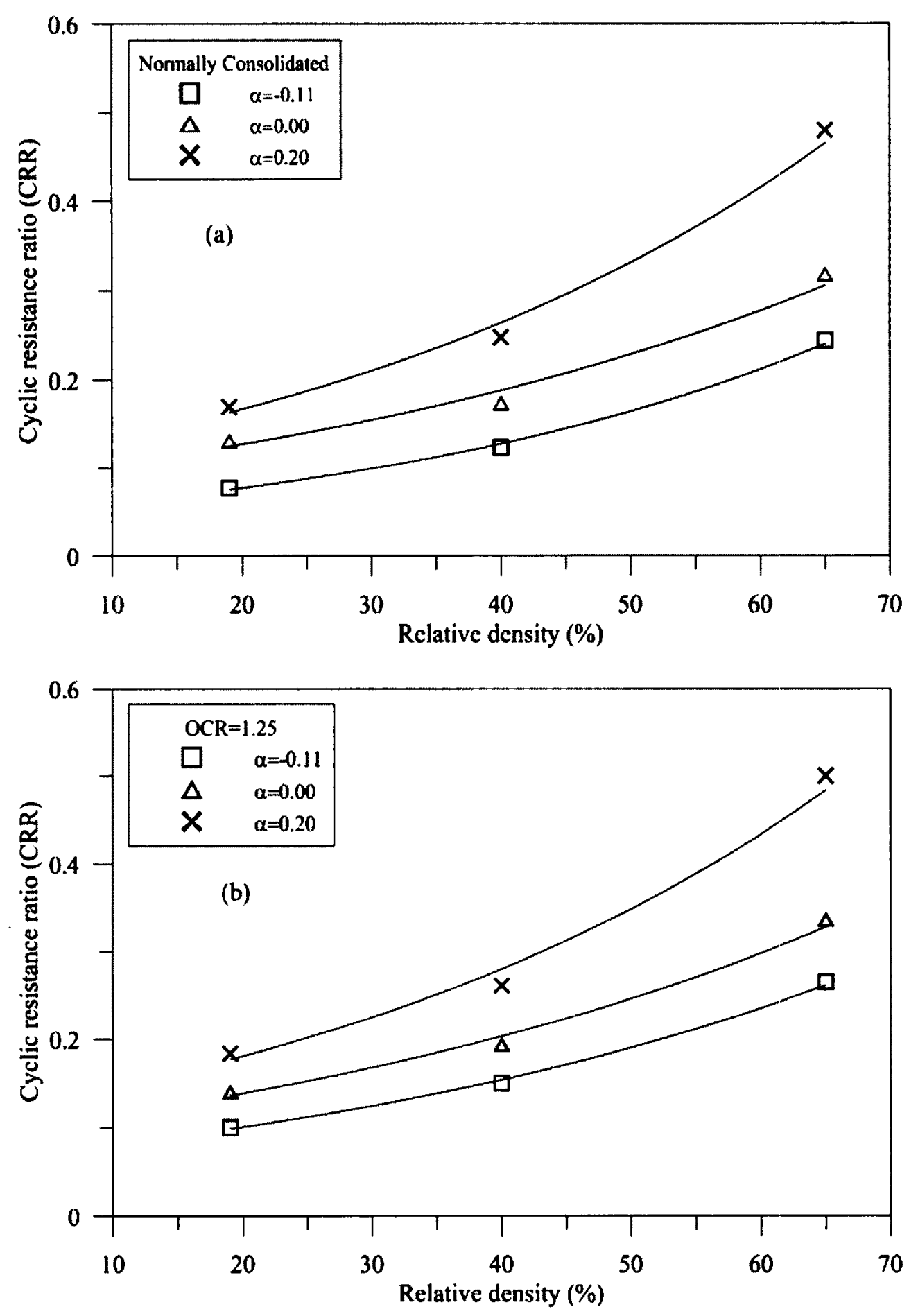

Figure 4.27(a) Variation of cyclic resistance ratio (CRR) of Fraser River sand with initial static shear stress ratio $(\alpha)$ at (a) $\mathrm{OCR}=1.00$, (b) $\mathrm{OCR}=1.25$ 

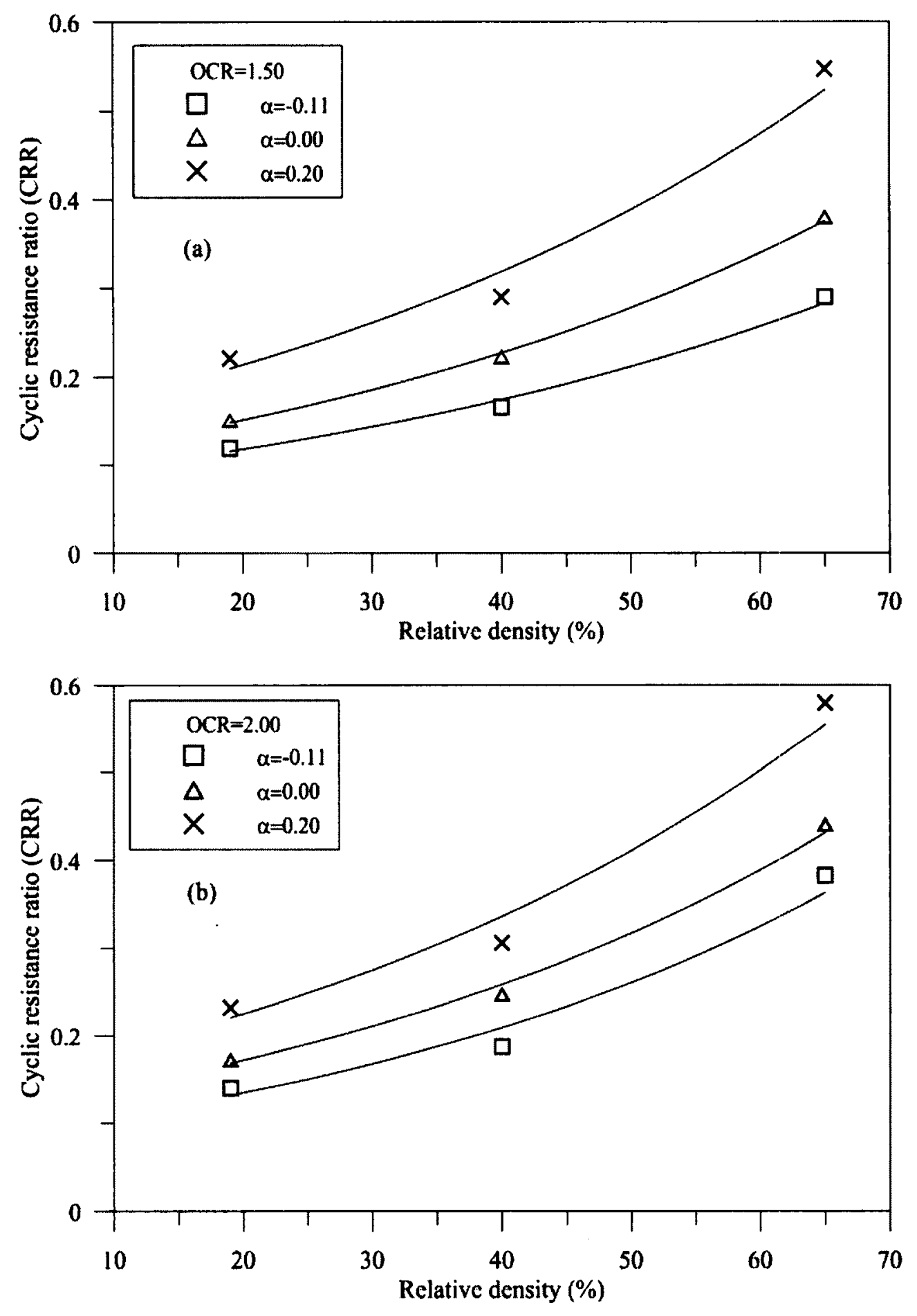

Figure 4.27(b) Variation of cyclic resistance ratio (CRR) of Fraser River sand with initial static shear stress ratio $(\alpha)$ at (a) $\mathrm{OCR}=1.50,(\mathrm{~b}) \mathrm{OCR}=2.00$ 
$\alpha$ value to obtain a better insight into the effects of overconsolidation on cyclic resistance.

Manmatharajan (2011) reported a completely different trend in the CRR change with initial static shear stress ratio in overconsolidated samples of the same sand testes under simple shear device. Samples overconsolidated to OCR levels of 1.50 and 2.00 showed a reduction in cyclic resistance as the static shear stress level increased (Manmatharajan, 2011).

This discrepancy in the test data on the same sand can only be related to the differences in the mechanisms of the two devices (simple shear and triaxial).The sample is under $K_{o}$ condition in simple shear device and the static shear can be applied on the horizontal plane without disturbing the at rest earth pressure coefficient $\left(K_{o}\right)$. On the other hand, $K_{o}$ is a function of the OCR level and changes as the OCR changes. Therefore, in simple shear loading, as the OCR increases the $K_{o}$ and thus the normal stress on the horizontal plane increases with increasing OCR. Hence, at a fixed $\alpha$ and $\sigma_{v c}^{\prime}$ the normal stress on the horizontal plane will be different at different OCR levels. This difference in stresses would lead to different principal stresses at different OCR values while $\alpha$ and vertical effective stress are the same at the end of consolidation. However, in the triaxial loading mode, horizontal normal stress is controlled externally and consolidation stress state does not correspond to the $K_{o}$ condition. In-situ stress state is closely captured by the simple shear device in most cases than the triaxial device.

Further, the static shear is applied on the horizontal plane in simple shear, but at a plane inclined at $45^{\circ}$ to horizontal in triaxial tests through the difference in the horizontal and vertical stresses as they are the principal stresses. Overconsolidation is also applied 
by changing the vertical and horizontal stresses so that a fixed OCR is applied in both planes in triaxial test.

Figures 4.28(a) and (b) show the variation of CRR as a function of $\alpha$ at different OCR levels at fixed relative densities. The cyclic resistance increases with increase in OCR; however, as mentioned previous, the change in CRR due to OCR is not very significant compared to its dependency on $\alpha$.

As shown in Figures 4.28(a) and 4.28(b), samples consolidated with $K_{c}$ of 0.80 ( $\alpha=$ -0.11 ) show the weakest response and have the lowest CRR regardless of the OCR. The monotonic response is weaker in triaxial extension and as shown in Figures 4.1 to 4.8 at all OCR levels the sand response was of dilative in compression and of limited liquefaction type in extension tests. While no peak shear strength in stress-strain curves was observed under triaxial compression loading, a peak shear stress could be seen in all triaxial extension tests on loose samples. Upon reaching this peak state (and associated $\left.\varphi_{C S R}\right)$ the sand would strain soften rapidly and reach the phase transformation state. The critical stress ratio and thus $\varphi_{C S R}$ are smaller in extension compared to compression and therefore, during cyclic loading the sand can reach the critical stress ratio in extension faster than that in compression. As a result, the failure due to cyclic loading occurs in extension side of the loading while there is a possibility of stress rotation during the loading. When $K_{c}$ is less than one, the initial stress condition is already on the extension side of the loading and as result the stress ratio can reach the critical ratio faster and hence a weaker response to cyclic loads. This finding shows the importance of the direction of the initial static shear during consolidation. Therefore, it is better to calculate the $K_{c}$ based on the overburden and lateral stresses instead of principal 

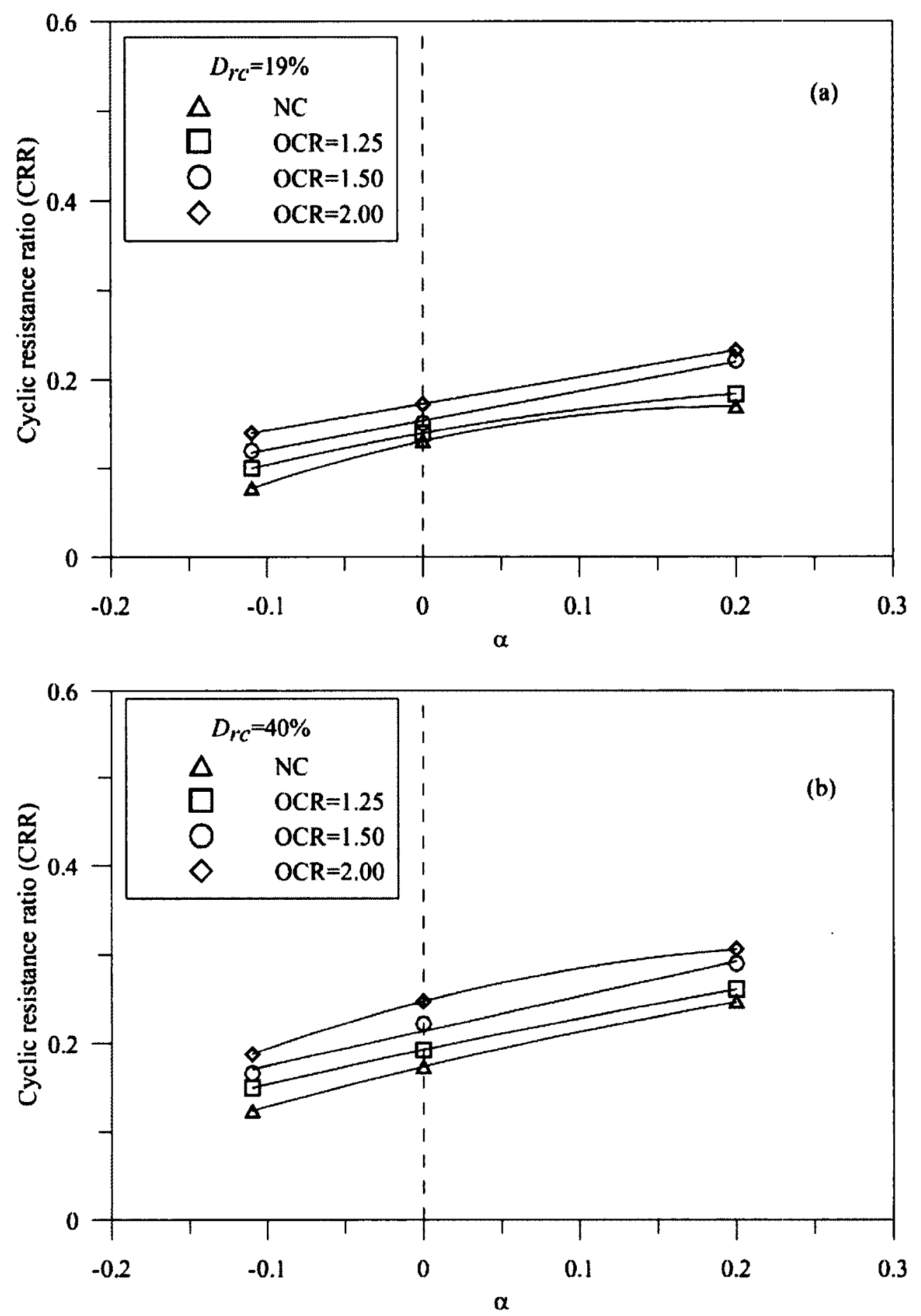

Figure 4.28(a) Variation of cyclic resistance with OCR and $\alpha$ at (a) $D_{r c}=19 \%$ (b)

$$
D_{r c}=40 \%
$$




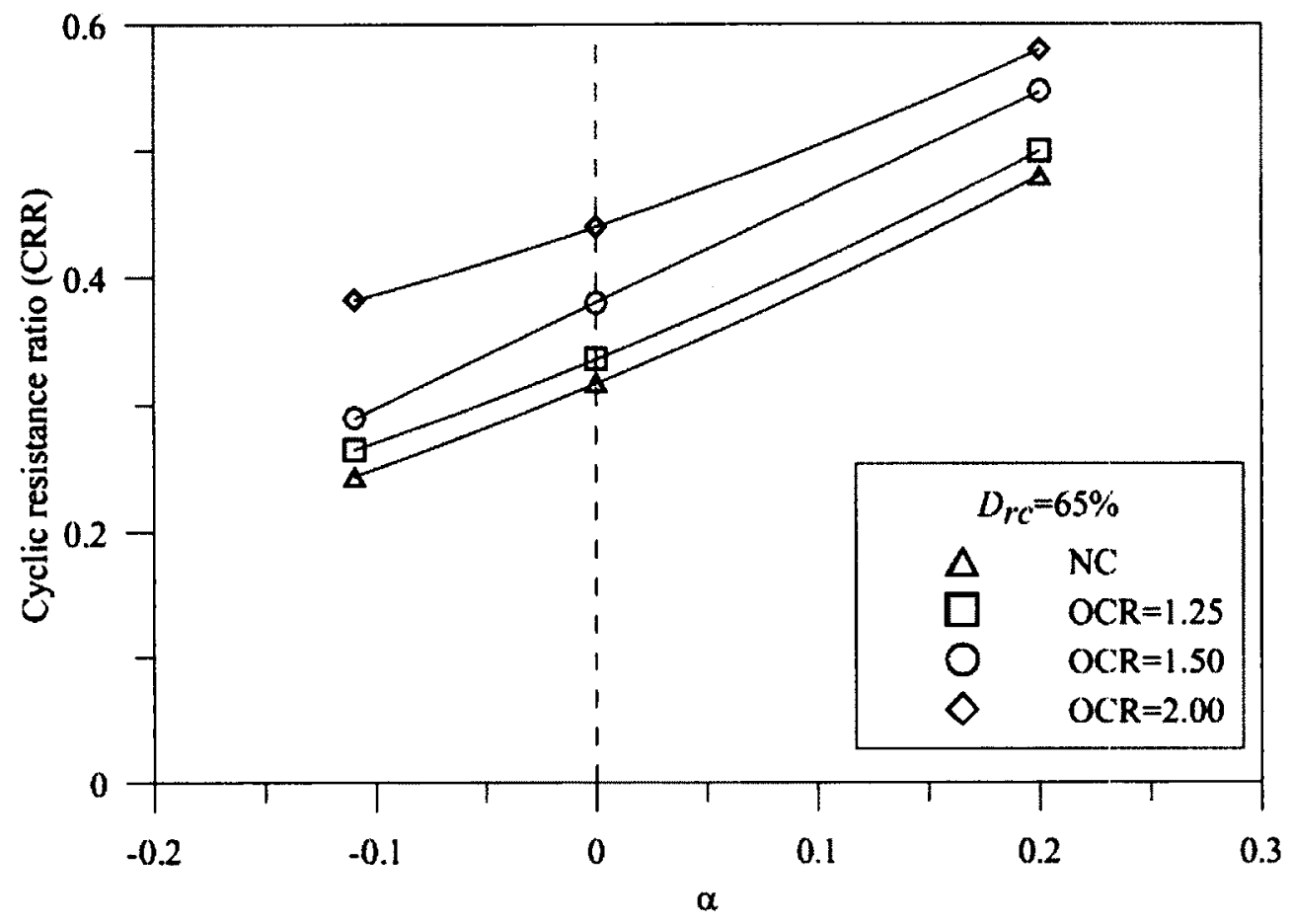

Figure 4.28(b) Variation of cyclic resistance with OCR and $\alpha$ at $D_{r c}=65 \%$

stresses since the definition based on the vertical and horizontal stresses would also show the direction of the initial static shear. Previous studies (Stedman, 1997; Vaid et al., 2001; $\mathrm{Ha}, 2003$ ) show that under triaxial loading, samples consolidated with $K_{c}=1.25$ show a stronger response than the samples consolidated anisotropically under identical confining pressure and with the same relative densities. On the other hand, if principal stresses are used to calculate $K_{c}$, a $K_{c}$ value of 0.80 would be calculated as 1.25 and would lead to an unreliable design.

\subsubsection{2 $K_{\alpha}$ correction factor}

Seed (1983) proposed the use of $K_{\alpha}$ correction factor to obtain the cyclic resistance of the soil subjected to initial static shear. As mentioned in chapter $2, K_{\alpha}$ values are generally calculated from tests on normally consolidated specimens and the effect of overconsolidation has not been studied in detail. 
Figure 4.29 shows the variation of $K_{\alpha}$ with $\alpha$ for the loose samples at different values of OCR. At $\alpha=0.20, K_{\alpha}$ does not necessarily increase with OCR. It increases somewhat as OCR increase from 1.0 to 1.5 , but decreases with further increase in OCR (to two). However, the changes in $K_{\alpha}$ with OCR are fairly small and the maximum difference is about of $10 \%$. Therefore, due to irregular and relatively small changes in $K_{\alpha}$ with OCR at $\alpha=0.20$ and considering that the normally consolidated specimen had the lowest $K_{\alpha}$, the effect of OCR on cyclic resistance of loose sand subjected to an initial static shear stress ratio of 0.20 can be ignored.

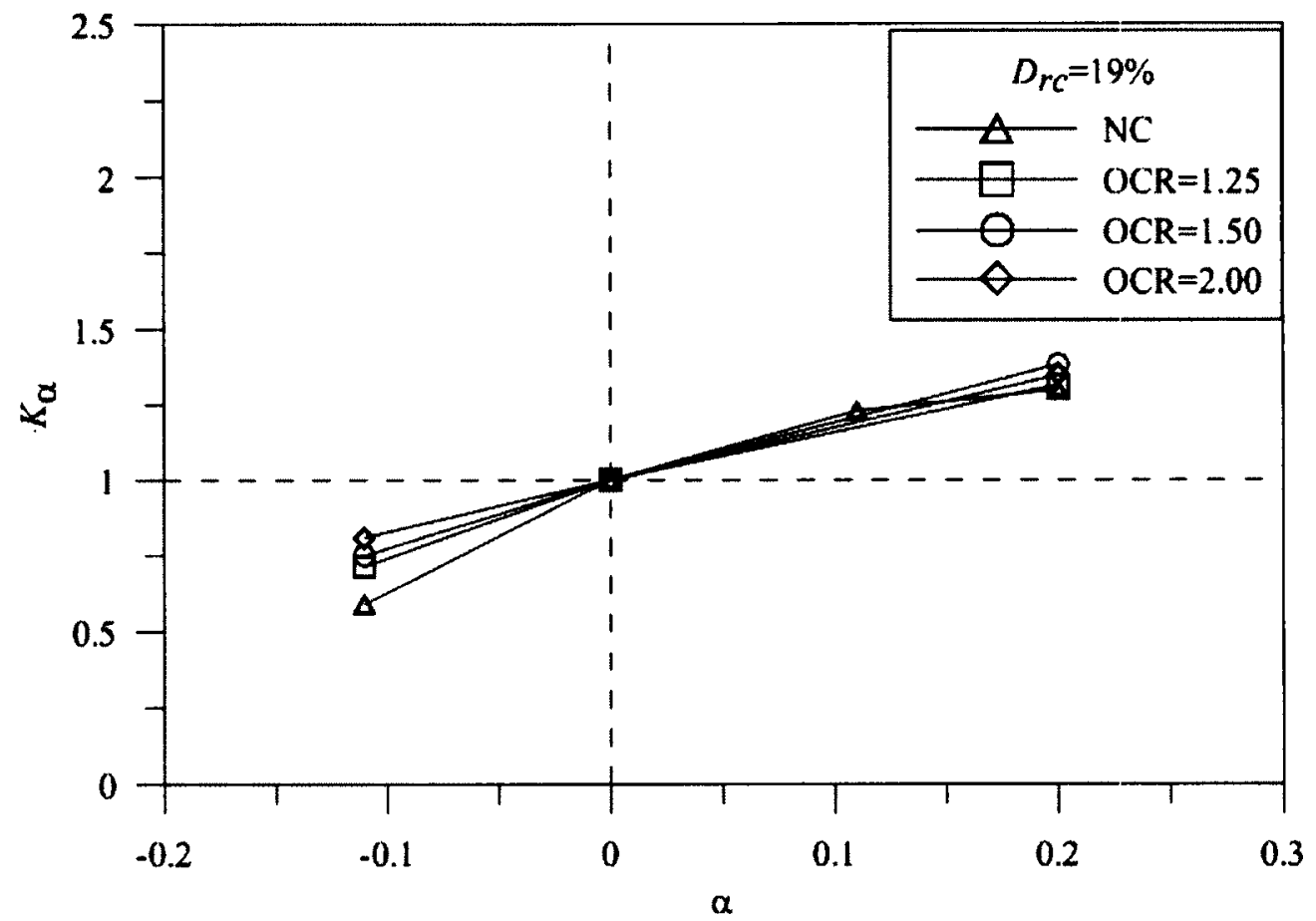

Figure 4.29 Variation of $K_{\alpha}$ with $\alpha$ at different levels of OCR and $D_{r c}=19 \%$

On the other hand, at negative value of $\alpha$ (i.e., $\alpha=-0.11$ ), the effect of OCR on $K_{\alpha}$ is much more significant. At $\alpha=-0.11, K_{\alpha}$ increases from about 0.6 to 0.9 as OCR increases from 1.00 to 2.00 . About a $50 \%$ variation depending on OCR at negative $\alpha$ compared to about $10 \%$ at positive $\alpha$ clearly highlights the importance of the direction of 
principal stresses on the subsequent cyclic resistance. In addition, regardless of the OCR level, the $K_{\alpha}$ value is less than one when $\alpha=-0.11$. These low values of $K_{\alpha}$ in overconsolidated sand at $\alpha=-0.11$ imply that the effect of the direction of initial static shear stress would be more prominent than overconsolidation on cyclic resistance of loose sand. Therefore, the direction of initial static shear has a great effect on the cyclic resistance of saturated sand and needs to be considered in the design, even in overconsolidated sand, to avoid unsafe designs.

Variation of $K_{\alpha}$ with OCR and $\alpha$ for medium dense $\left(D_{r c}=40 \%\right)$ samples is shown in Figure 4.30. $K_{\alpha}$ decreases as OCR increases from 1.00 to 2.00 in medium dense sand consolidated anisotropically with a positive value of $K_{c}$. On the other hand, samples consolidated under a $K_{c}$ value of 0.80 does not show a considerable change in $K_{\alpha}$ with OCR change.

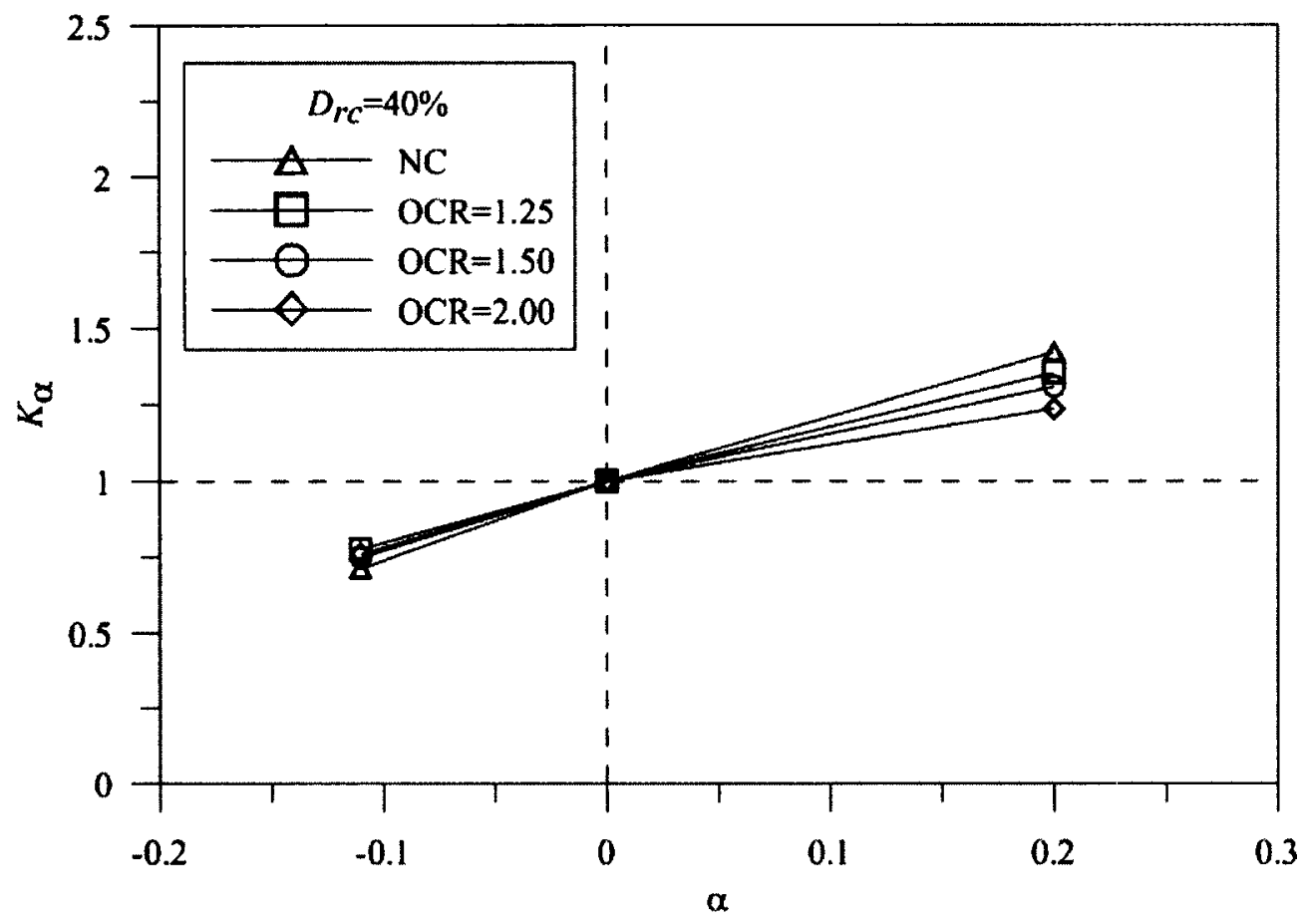

Figure 4.30 Variation of $K_{\alpha}$ with $\alpha$ at different levels of OCR and $D_{r c}=40 \%$ 
Figure 4.31 shows the variation of $K_{\alpha}$ with OCR and $\alpha$ in dense sand $\left(D_{r c}=65 \%\right)$. As shown in Figure 4.30, at $\alpha=0.20, K_{\alpha}$ decreases as OCR increases to 2.00 . On the other hand, at $\alpha=-0.11$, there is a scatter in the data and $K_{\alpha}$ does not change regularly with OCR. The highest value of $K_{\alpha}$ is observed at $\mathrm{OCR}=2.00$ while the lowest value is at $\mathrm{OCR}=1.50$. On the other hand, the $K_{\alpha}$ values are still less than 1.00 even though the samples were deposited at high relative densities and overconsolidated. Therefore, the direction of the initial static bias must be considered in the engineering designs dealing with dense sands. Also, due to the irregular variation of $K_{\alpha}$ with OCR at $\alpha=-0.11$, extra care must be taken in overconsolidated sand if the change is systematic and representative of actual material behaviour. However, it is suspected that the response could be a reflection of experimental errors, and additional test data is needed to draw reliable conclusions.

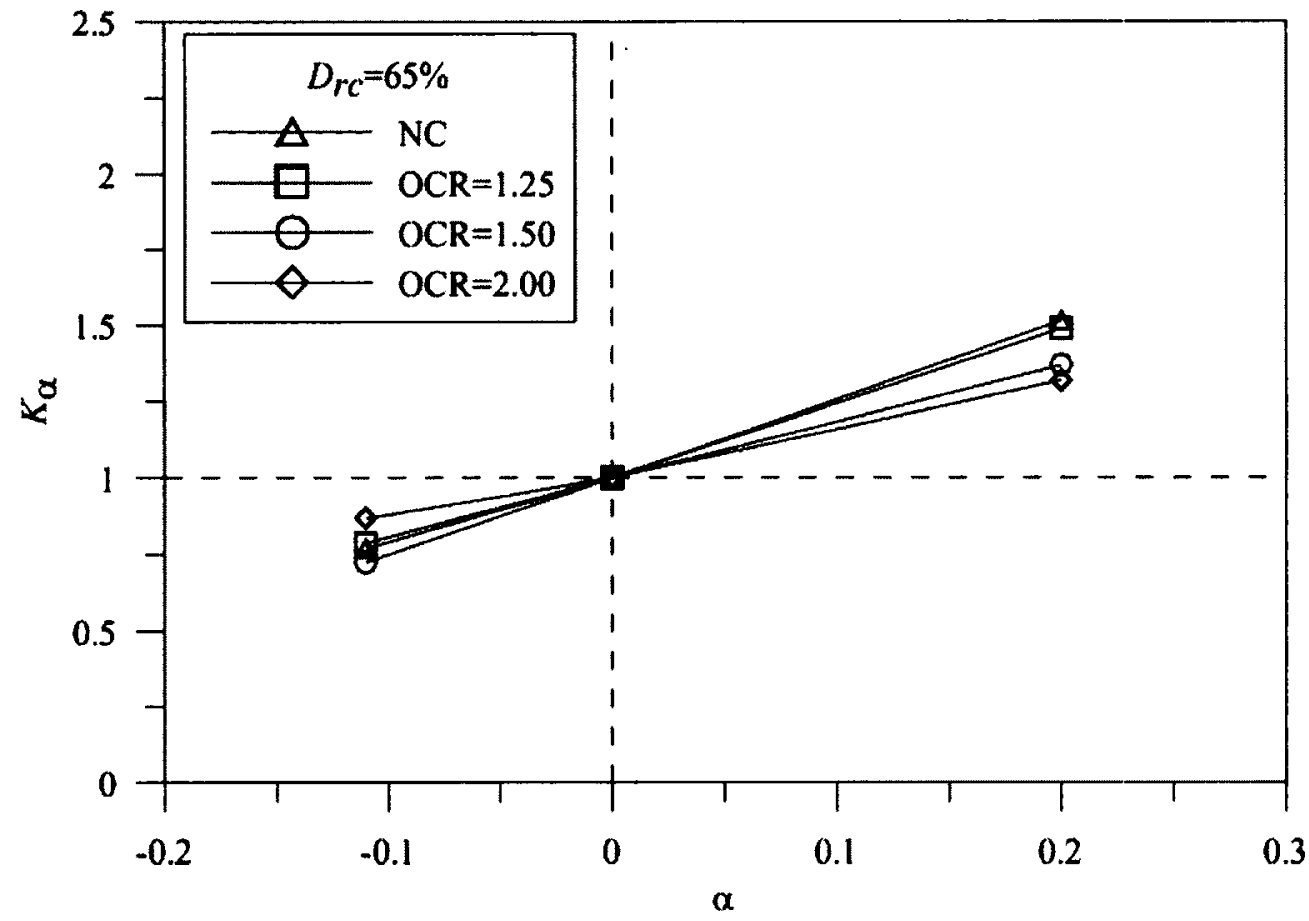

Figure 4.31 Variation of $K_{\alpha}$ with $\alpha$ at different levels of OCR and $D_{r c}=65 \%$ 
Variation of $K_{\alpha}$ in normally consolidated sand to that of overconsolidated to $\mathrm{OCR}=2.00$ at different relative density states is compared in Figure 4.32 . The correction factor $K_{\alpha}$ increases as the relative density increases in normally consolidated sand. However, as the level of OCR increases to 2.00 , the change in $K_{\alpha}$ with relative density becomes less considerable. Therefore, although dense sand has a higher cyclic resistance at all $\alpha$ and OCR values, the variation of $K_{\alpha}$ with relative density is smaller in overconsolidated samples compared to normally consolidated ones. Also, in overconsolidated samples, $K_{\alpha}$ does not increase with relative density and its relationship with $D_{r c}$ is dependent on $\alpha$. Therefore, additional tests at other $\alpha$ values (both positive and negative) are needed to be able to make any conclusions about the relationship between $D_{r c}, K_{\alpha}$, and $\alpha$.

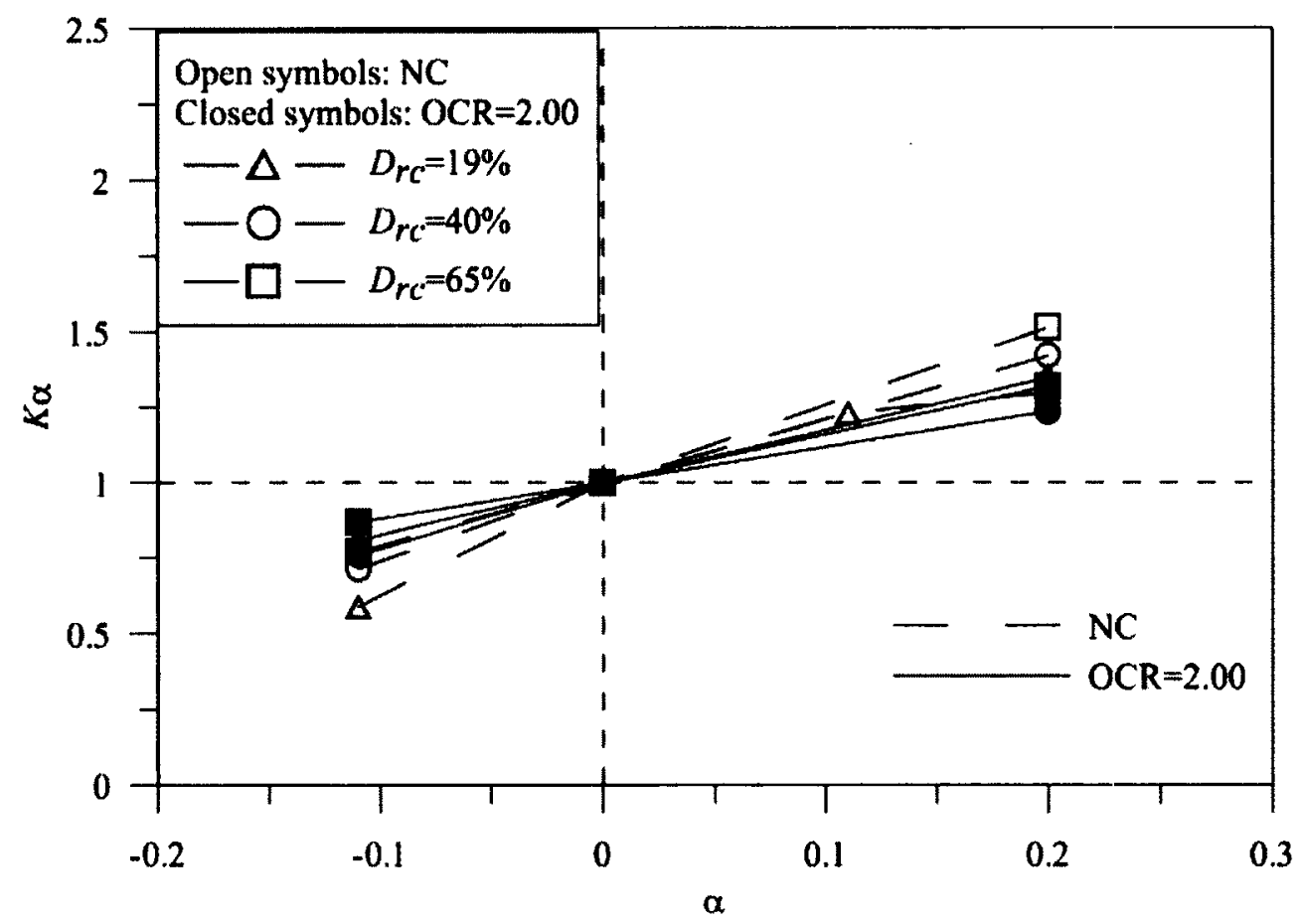

Figure 4.32 Variation of $K_{\alpha}$ with $\alpha$ at different levels of relative density at $\mathrm{OCR}=1.00$ and 2.00 
The samples consolidated anisotropically with $K_{c}=0.80(\alpha=-0.11)$ show a different response with OCR. As OCR increases $K_{\alpha}$ also increases but it is still quite small compared with those at $\alpha=0.20$. This finding shows the importance of the direction of initial static shear; as even at high relative density of $65 \%, K_{\alpha}$ is still less than one (about 0.85 ) in samples consolidated with $\mathrm{OCR}=2.00$ and $\alpha=-0.11$ compared to about 1.25 at $\alpha=0.20$.

In engineering design the site specific liquefaction potential is assessed by calculating the CRR by applying appropriate correction factors to the reference cyclic resistance at confining pressure of $100 \mathrm{kPa}$ and zero initial static shear stress. However, the role of overconsolidation in cyclic resistance is ignored, and the CRR of normally consolidated sand is always used in practice in the Seed's (1983) simplified method. Manmatharajan (2011) proposed a modification to this practice by introducing a correction factor based on OCR to yield:

$$
C R R_{\sigma, \alpha, O C R}=K_{\sigma} * K_{\alpha} * K_{O C R} * C R R_{\sigma=100, \alpha=0.00, N C}
$$

As shown in Figure $4.25, K_{O C R}$ is always greater than 1.00 and indicates higher cyclic resistance at higher OCR values. On the other hand, as $\alpha$ increases in the positive direction, the cyclic resistance increases in all OCR values (for the range of $\alpha$ considered in this study), but, the rate of increase becomes lower as OCR increases at a fixed positive $\alpha$ value. Therefore, if overconsolidation is going to be considered in the design to reduce the expenses, it is vital to use appropriate $K_{\alpha}$. Using $K_{O C R}$ will lead to a higher CRR, however, if $\alpha$ is greater than zero, using the static shear correction factor of normally consolidated sand would yield an unsafe design as the cyclic resistance of 
overconsolidated soil does not increase as high as normally consolidated soil with positive values of $\alpha$. On the other hand, the direction of the initial static shear plays an important role in the cyclic resistance and ignoring this parameter would cause unsafe designs and failures. However, OCR does not have a significant influence on $K_{\alpha}$ at $\alpha=-0.11$ and can be ignored in the design.

\subsection{POST-LIQUEFACTION RESPONSE}

Many failures such as those occurred in Lower San Fernando Dam (1971) have been due to undrained deformations following the earthquake. It has been shown that post-liquefaction failures occur due to void redistribution that happens after liquefaction (Boulanger and Truman, 1996; Boulanger, 1999). These failures indicate that deformations may exceed the ultimate and/or serviceability limit not only during the ground shaking but also after its cessation. Therefore, the stability of soil and liquefaction induced deformations should be assessed both during and following an earthquake to prevent catastrophic events. On the other hand, preventing soil liquefaction is not always possible and sometimes will impose high costs to the projects. Therefore, the alternative design approach would be dealing with the consequences of liquefaction.

To assess the post liquefaction response of Fraser River sand, samples have been subjected to undrained monotonic loading following the cyclic loading. Both compression and extension loading modes have been applied. During post-liquefaction loading under triaxial compression the effective confining stress would be increased beyond $800 \mathrm{kPa}$ in medium dense and dense sands. Therefore, there was a high chance of sand particles breakage. To be able to reuse the sand, post-liquefaction tests on medium 
dense and dense sands have been performed under triaxial extension loading mode. On the other hand, under triaxial extension loading mode sand shows a weaker response and the lower bound of soil strength at fixed initial states can be studied. Effects of relative density, overconsolidation, and initial static shear have been studied and the results are presented in this section.

\subsubsection{Post liquefaction stress-strain response}

Figure 4.33 shows the response of Fraser River sand under cyclic and post cyclic monotonic loading. Since the liquefaction occurred due to flow failure, the same kind of noise due to loss of control over sample deformation is observed in Figure 4.33. Therefore, the noisy data points are shown as dots in the graph and a smooth line is fitted trough them to represent the real soil response. Axial strains in post cyclic response are calculated based on sample configuration at the end of consolidation. It is evident from the figure that deformations during cyclic loading have been due to flow failure on the extension side of loading and $12 \%$ of axial strain was developed. Unloading of the shear stress to zero (initial state) has brought the sand to the condition of $\sigma_{n c}^{\prime}=0 \mathrm{kPa}$ which has become the initial stress condition for post cyclic loading. During post cyclic loading, deformations occurred with zero stiffness in sand over a large range of axial strain (about $17 \%)$. However, further loading caused negative excess pore pressure generation and lead to an increase in shear modulus. These deformations are similar to those occur under monotonic loading after the phase transformation and progress along the maximum obliquity line in stress space. 

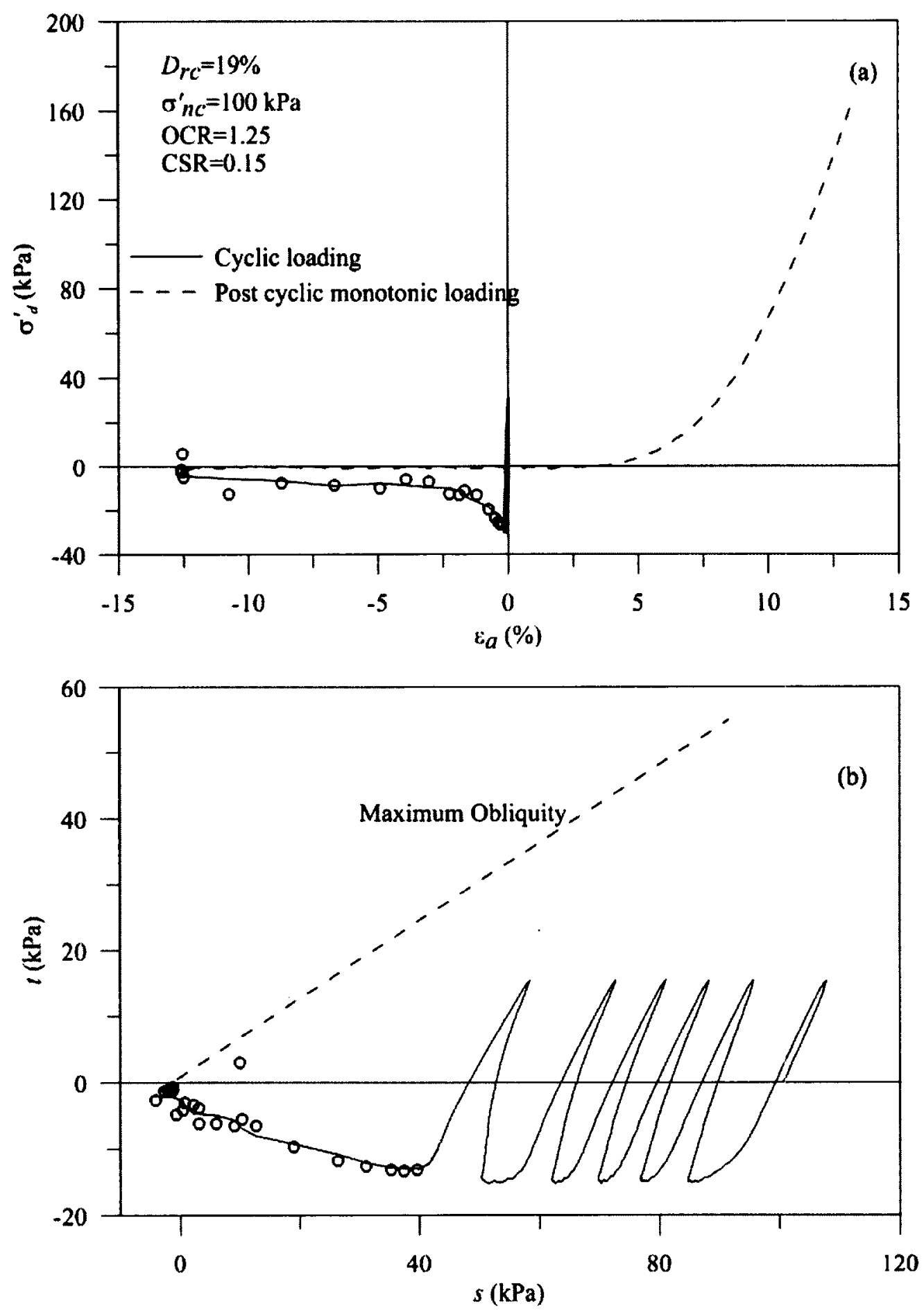

Figure 4.33 Cyclic and post cyclic response of Fraser River sand (a) stress-strain (b) stress path 
Three distinct zones of deformation that were originally noted by Vaid and Thomas (1995) are observed in the post cyclic stress-strain curve (Figure 4.33). During the first stage of loading, deformations occur without mobilizing any shear stress at essentially zero shear stiffness until an axial strain of about $4 \%$ has been reached. Following this phase, soil stiffness begins to increase with further deformations at a high rate until an axial strain of $10 \%$. Beyond $10 \%$ of axial strain, the shear modulus does not change significantly and the stiffness of the material remains constant during this stage of loading. During all these three phases of deformation, negative pore pressure is generated in the sand. Such dilative response is consistent with the fact that during the cyclic loading, $100 \%$ pore pressure has been generated and further generation of positive excess pore pressure is not possible. As shown in Figure 4.33 (b), with zero residual effective stress at the end of cyclic loading, the stresses in the stress space follow the maximum obliquity that has previously observed in monotonic loading.

\subsubsection{Dependence on relative density}

Post liquefaction responses of normally consolidated samples of Fraser River sand with zero residual effective stress at the end of cyclic loading but at two different relative density levels under extension loading mode are shown in Figure 4.34. To facilitate the comparison, the medium dense sand has been taken as the reference and stress-strain curve at denser relative density level has been shifted horizontally so as to match the $\sigma_{d}=5 \mathrm{kPa}$ point on each curve. The maximum axial strain during cyclic loading was $3.63 \%$ in the sample with the relative density of $40 \%$ and $-2.50 \%$ in the one with $65 \%$ relative density. Both samples showed the same kind of response and relative density did not affect the type of response. However, the deviator stress built up at a higher rate as 

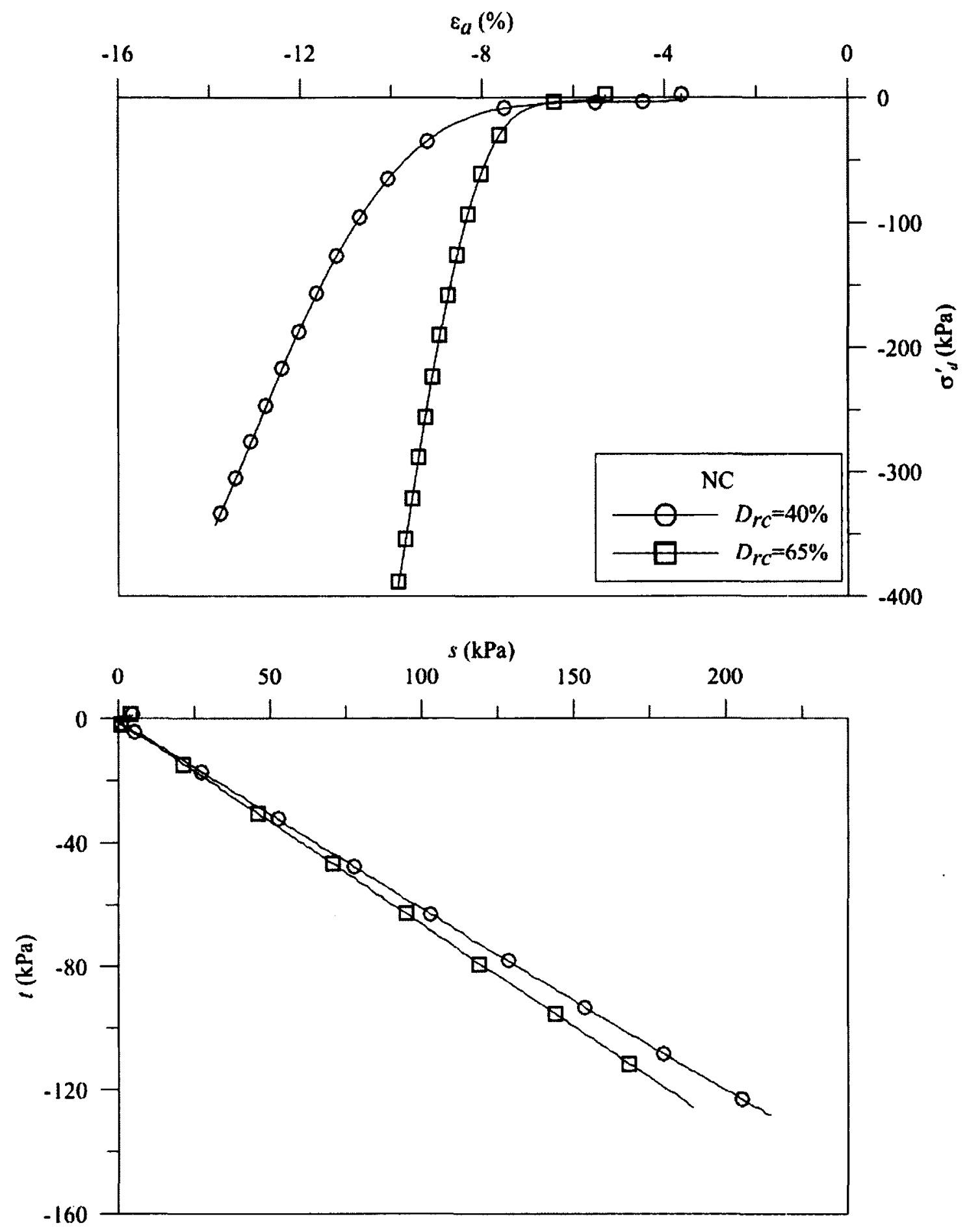

Figure 4.34 Effect of relative density post liquefaction response of normally consolidated Fraser River sand 
the relative density increased and the axial strain at which the curves become linear (third phase of deformation) became smaller. For instance, the medium dense sand has mobilized about $12 \mathrm{kPa}$ of deviator stress at $8 \%$ axial strain while the dense sand shows a deviator stress of about $66 \mathrm{kPa}$ at the same axial strain level. On the other hand, the dense sand recovers from the state of zero shear stiffness faster than the medium dense one. In

stress space both samples deformed along the line of maximum obliquity that was observed under monotonic loading. The same void ratio dependency of post-liquefaction response have also been reported by Vaid and Thomas (1995) and Sivathayalan and Yazdi (2004).

\subsubsection{Effect of overconsolidation ratio}

The post liquefaction behaviour of sand under compression and extension loading mode at different relative density and OCR levels is illustrated in Figure 4.35. To facilitate the comparison, the normally consolidated sand has been taken as the reference and stressstrain curve at other OCR levels have been shifted horizontally so as to match the $\sigma_{d}=5$ $\mathrm{kPa}$ point on each curve. As shown in the graph, the shear modulus increases at the same rate in all samples regardless of the OCR level. On the other hand, the shear modulus during the third phase of deformation is a constant value and is independent of OCR level at a fixed relative density level. As depicted in Figure 4.35, at a fixed level of axial strain, the normally consolidated sand has lower mobilized shear strength than the overconsolidated sands. However, the mobilized shear strength at a specific axial strain is independent of the OCR level in overconsolidated sand at all three relative density levels. For instance, at $10 \%$ of axial strain from the $\sigma_{d}=5 \mathrm{kPa}$ point, the loose soil $\left(D_{r c}=19 \%\right)$ shows a deviator stress of $239 \mathrm{kPa}$ in $\mathrm{NC}$ sand and $283 \mathrm{kPa}$, in samples with OCR values 

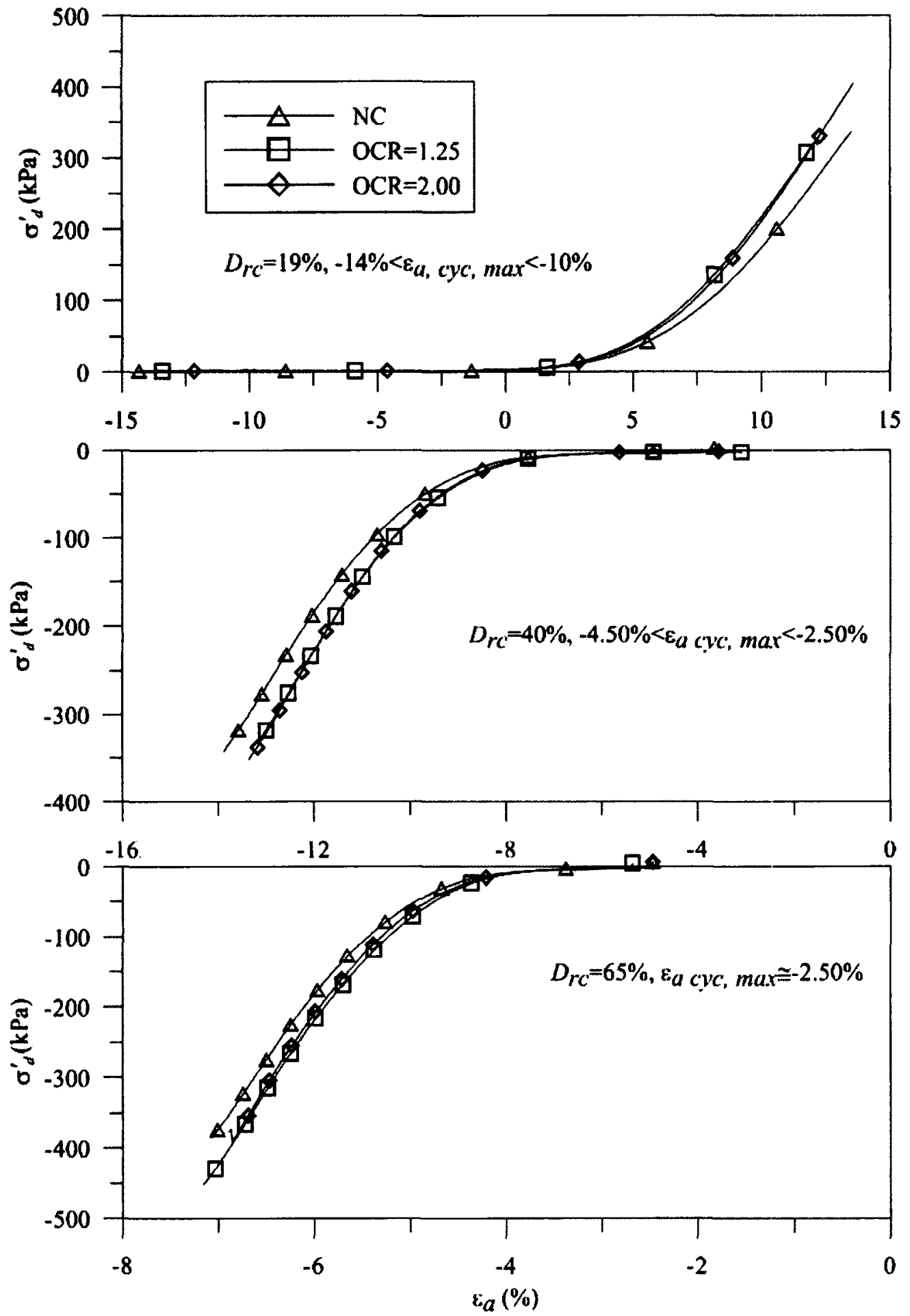

Figure 4.35 Effect of OCR on post-liquefaction response of Fraser River sand at different levels of relative density 
of 1.25 , and 2. This indicates that overconsolidation effect on post liquefaction shear strength is not so significant in comparison with relative density effect. On the other hand, as the relative density increases and soil becomes stiffer the effect of OCR becomes less significant.

Vaid and Thomas (1995) showed that the range of strain over which deformation occurs at essentially zero shear stiffness depends solely on the maximum strain during cyclic loading. They assumed that a deviator stress of $5 \mathrm{kPa}$ would correspond to the end of this phase. However, Sivathayalan and Yazdi (2004) showed that this strain range also depends on the level of confining stress and relative density. Therefore, to reduce the scatter in the data, they proposed the use of a normalized shear stress ratio of 0.02 as the end of the first stage of post cyclic loading. However, all the previous studies have been done on normally consolidated samples and the effect of OCR on this postulate is not recognized yet. Figure 4.36 shows the range of strain required to mobilize a deviator stress ratio of 0.02 as a function of maximum axial strain during cyclic loading at different $\mathrm{OCR}$ and relative density levels. The maximum axial strains of above $10 \%$, about $4 \%$, and $2.5 \%$ correspond to tests at relative densities of $19 \%, 40 \%$, and $65 \%$ respectively. The same kind of scatter that was seen in Vaid and Thomas (1995) and Sivathayalan and Yazdi (2004) is observed in the data shown in the graph. Regardless of the scatter, this type of data can be used as an approximate means of predicting post liquefaction deformations. The data in Figure 4.36 suggests that OCR does not affect the range of strain over which deformation occurs at nearly zero stiffness and this strain range only depends on the maximum axial strain at the end of cyclic loading. The ratio of the axial strain range during the first stage of deformation to the maximum axial strain 
during cyclic loading is found to be constant at fixed level of relative density and maximum cyclic stress regardless of OCR level. This ratio is about 0.98 in loose sand with about $18 \%$ maximum axial strain during cyclic loading. It decreases to about $0.60 \sim 0.80$ in medium dense samples with $3.5<\left|\varepsilon_{\max , c y c}\right|<5.5$ and reaches a value of 0.45 in dense sand that has experienced an absolute maximum axial strain of $2.5 \%$ during cyclic loading.

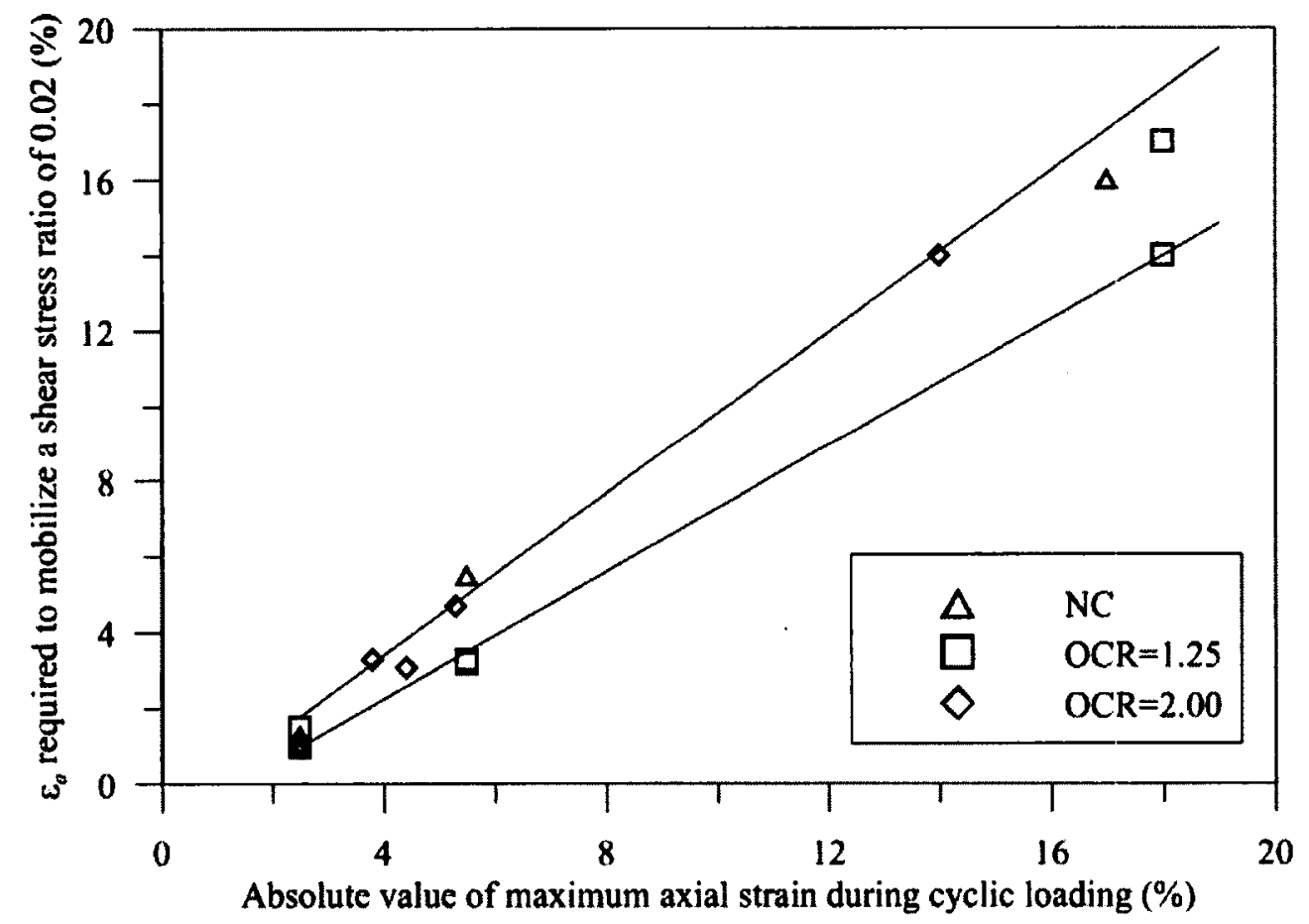

Figure 4.36 The range of deformation at zero stiffness

One of the main objectives of laboratory tests is to determine the undrained shear strength of soil, which is a key parameter in deformation evaluation. However, due to the dilative post liquefaction response of sand at all states, it was not possible to define a residual strength. Therefore, Sivathayalan and Yazdi (2004) proposed that the use of the shear strength at a specific level of shear strain could be an alternate indicator of post liquefaction soil strength. Since deformation during the first phase is independent of 
relative density, while the second and third phases of deformation are functions of relative density, Sivathayalan and Yazdi (2004), suggested that the shear strain measured from the end of the first stage of loading would be a proper measurement of deformation during post cyclic loading. Therefore, the mobilized shear stress at $10 \%$ shear strain (about $6.5 \%$ axial strain) from the end of first phase of deformation was considered to be an indicative of soil shear strength during post cyclic monotonic undrained loading.

The previous studies on the mobilized shear strength in post liquefaction loading have been done on normally consolidated sand. However, overconsolidation increases the soil strength and therefore, having a knowledge of the effect of OCR on post liquefaction strength would improve the engineering design. On the other hand, due to the necking of dense samples at axial strains of at above $6 \%$ axial strain from the end of first phase, the mobilized strength at a shear strain of $6 \%$ is calculated. It must be noted that, post cyclic tests on loose samples have been performed under compression loading mode, while medium dense and dense samples have been tested under triaxial extension loading mode. Variation of the mobilized shear strength during phase 2 with OCR and relative density is shown in Figure 4.37. The shear strength increases with OCR at a fixed level of relative density, however, it remains constant at different levels of OCR. On the other hand, this shear strength also increases with relative density under identical loading condition. Although this shear stress is not the ultimate strength of the soil, it can be regarded as an indicator of soil post liquefaction strength and its variation with OCR and $D_{r c}$ has practical implications. 


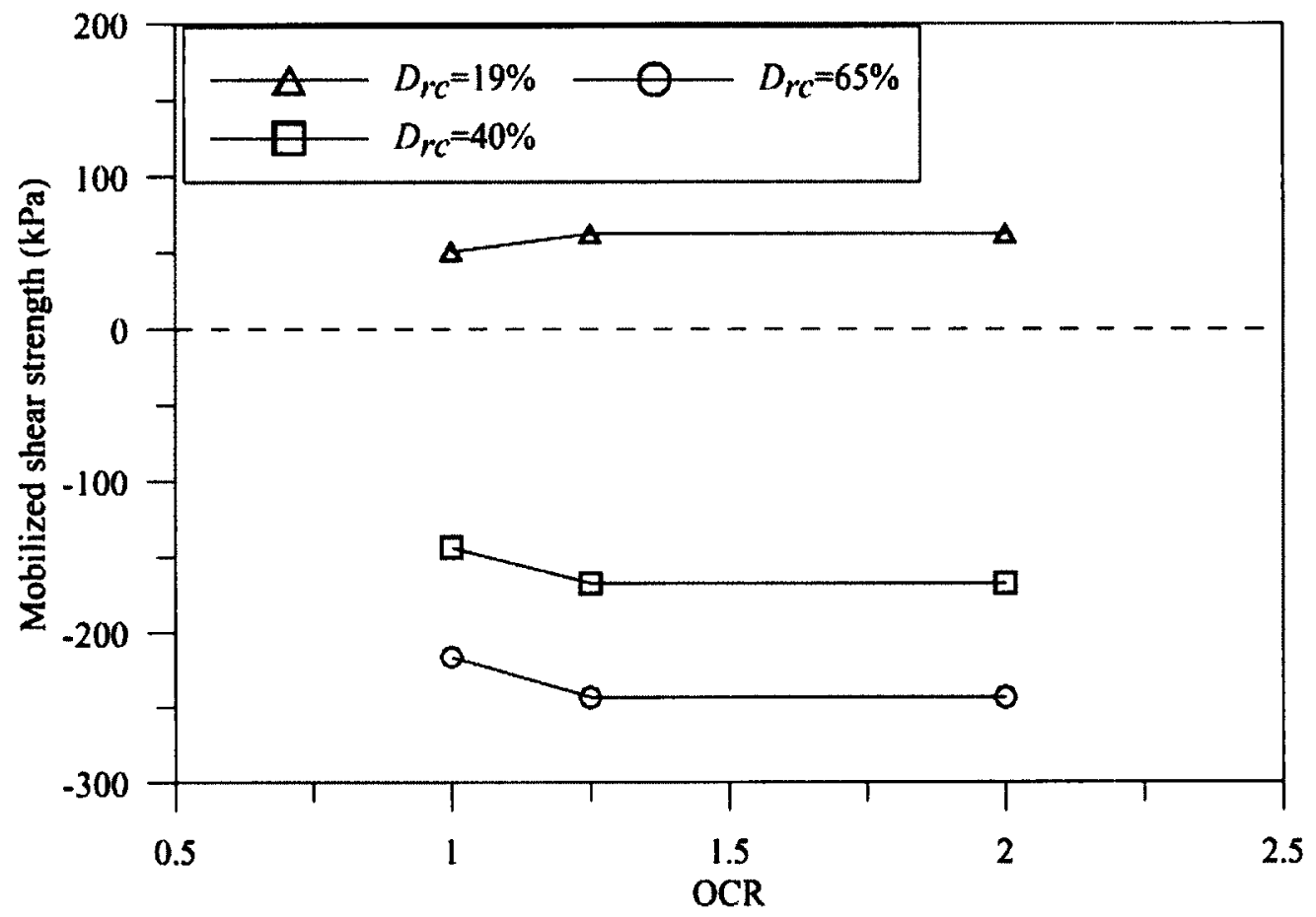

Figure 4.37 Mobilized shear strength from the end of phase one

\subsubsection{Effect of initial static shear stress}

Monotonic undrained tests, following liquefaction, on both isotropically and anisotropically consolidated samples of Fraser River sand have been performed. In all tests sand retained its initial static shear value at the end of cyclic loading and hence, post-liquefaction tests on anisotropically samples started with a non-zero value of shear stress. However, under natural conditions the sand may or may not have an initial static shear stress at the end of the cyclic loading. Therefore, in compression tests the last cycle data have been added to the post-liquefaction test data to represent a state of zero shear strength following the liquefaction. On the other hand, in the extension tests, the deformation section with positive shear stress is ignored in the analysis as it does not represent the field situation at the end of cyclic liquefaction. 
Figure 4.38 shows the response of two sands consolidated under $K_{c}$ values of 1.00 and 1.50 to $100 \mathrm{kPa}$ on mean normal stress under triaxial compression loading mode. As mentioned previously the samples consolidated anisotropically with a stress ratio of 1.50 showed a greater cyclic resistance and the cyclic mobility was the responsible mechanism for liquefaction. Pore water pressure started to decrease immediately after applying the load. It was noted that the range of the first phase of deformation as mentioned by Vaid and Thomas (1995) was almost zero and the sand response suddenly started from the second phase on account of the initial stress state. On the other hand, compared to the isotropically consolidated sample, the sample with initial static shear showed greater shear strength at a fixed level of axial strain. However, the shear modulus remained the same regardless of the initial static shear stress.

The post liquefaction response of medium dense sand under triaxial extension loading mode is shown in Figure 4.39. To make a better comparison of the stress-strain response, the $K_{c}=1.50$ graph has been shifted horizontally to match the $\sigma_{d}^{\prime}=5 \mathrm{kPa}$ point on the $K_{c}=1.00$ graph. The differences in the stress-strain response are small. The shear modulus during the third phase of deformation varies about $20 \%$ between the two samples. On the other hand, shear strength at the end of deformations differ by $50 \mathrm{kPa}$.. The differences could be attributed to the fact that the maximum axial strain at the end of cyclic loading was about $-5 \%$ in isotropically consolidated sand and $2.5 \%$ in the anisotropically sample. 

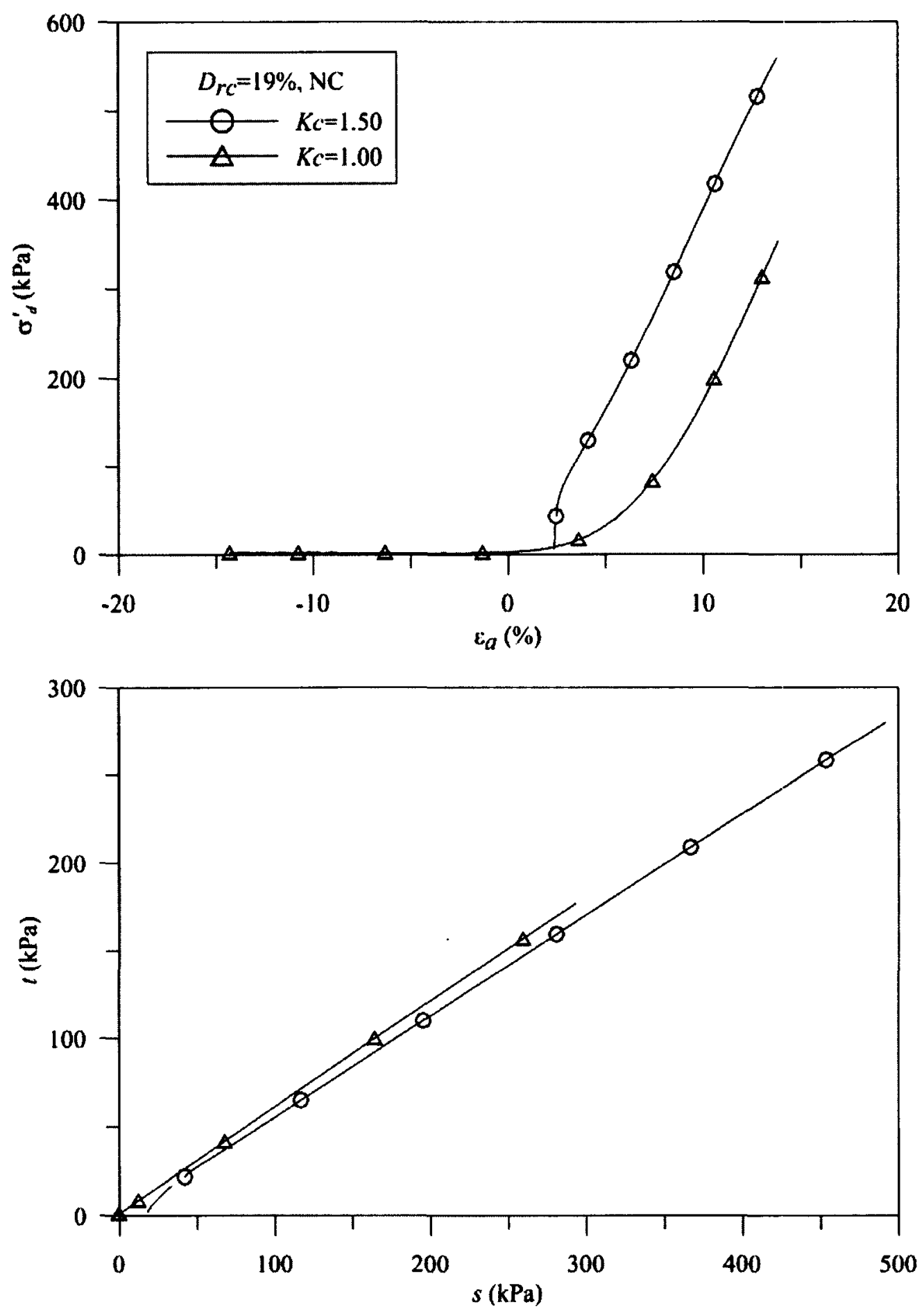

Figure 4.38 Post liquefaction response of isotropically and anisotropically consolidated sand under triaxial compression loading mode 

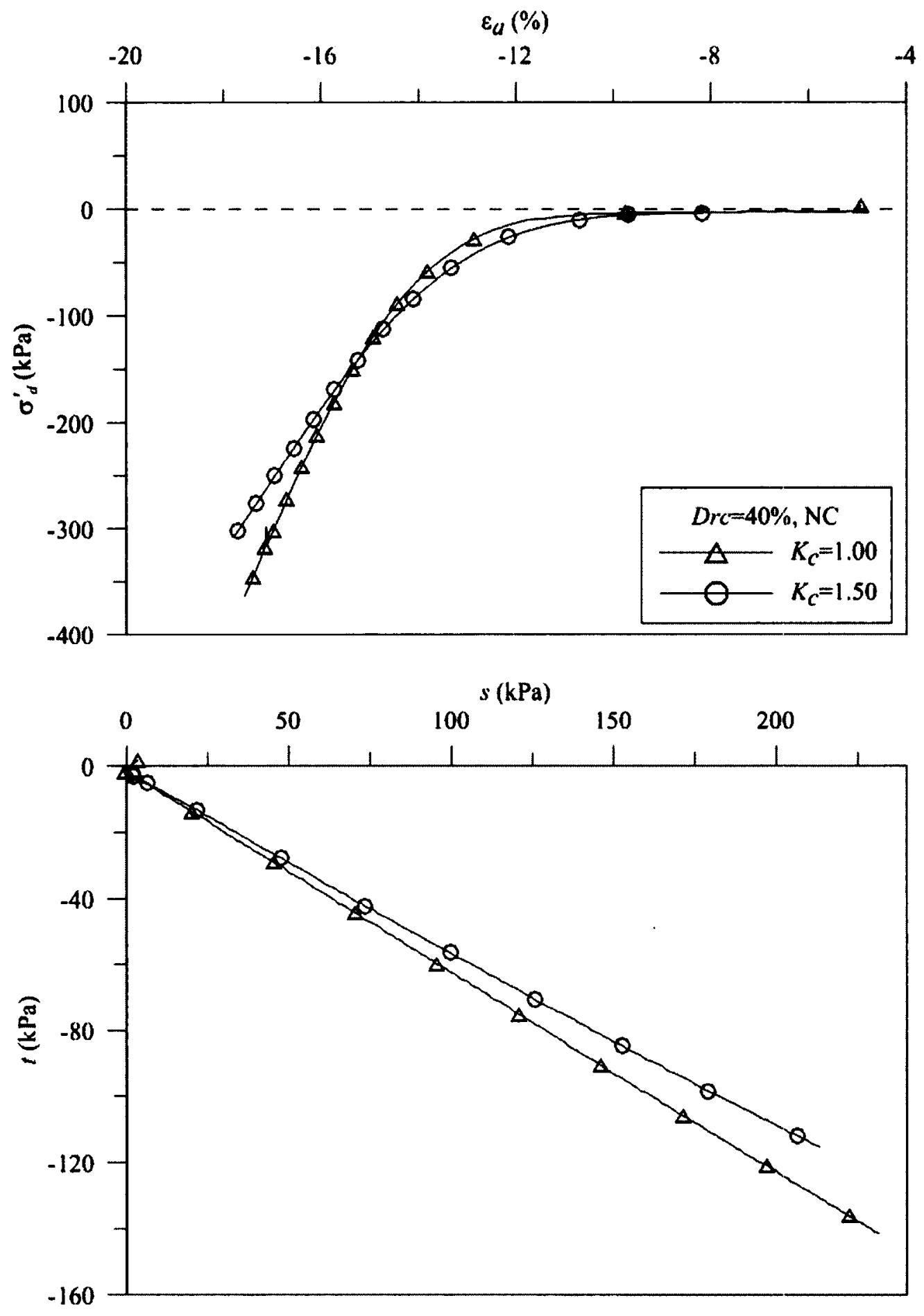

Figure 4.39 Post liquefaction response of isotropically and anisotropically consolidated sand under triaxial extension loading mode 


\section{CHAPTER 5}

\section{CONCLUSIONS}

Several factors, such as the initial static shear, confining stress level, relative density, and overconsolidation affect the liquefaction potential of sands under both monotonic and cyclic loading. Undrained monotonic, cyclic, and post-cyclic triaxial tests on Fraser River sand under both compression and extension loading mode over a variety of relative densities, initial static shear stress, and overconsolidation ratio were conducted. All samples were prepared using the water pluviation technique to yield a fabric as similar as possible to in-situ soils deposited in an alluvial/hydraulic environmental. Test results are used to study the effect of overconsolidation and the direction and magnitude of initial static on $K_{\alpha}$ correction factor. A summary these findings, and conclusions drawn from the research is presented in this chapter.

\subsection{MONOTONIC TRIAXIAL TESTS}

- Triaxial compression response of Fraser River sand is dilative over all relative density levels attainable by water pluviation regardless of the OCR level. Increasing initial static shear due to increasing major principal stress in the vertical direction (i.e., parallel to the deposition direction) induced relatively lesser dilative response under compression loading mode.

- Initial static shear that was due to extensional consolidation (horizontal major principal stress) increased the dilatancy of the sand under 
compression loading. It leads to a stronger response under compression loading mode compared to tests with the same magnitude of the static shear but due to compressional consolidation.

- Rotation of major principal stress direction from horizontal to vertical during compression loading leads to more dilative response in comparison to the cases without any rotation of the major principal stress direction.

- Monotonic undrained response is contractive under extension loading mode at low relative densities (i.e. $D_{r c}=19 \%$ ) and it changes to dilative as the level of relative density increased.

- Rotation of the direction of major principal stress direction from vertical to horizontal leads to a less dilative response in static extension tests.

- In addition to the magnitude of initial static shear, its direction also influences the monotonic undrained response of sand.

- Overconsolidation increases the dilative tendencies of sand at a given level of relative density.

- The phase transformation state is unique in the stress space, and the corresponding friction angle is a constant in sand. They do not depend on relative density, OCR, presence of initial static shear or the loading mode (compression or extension). 


\subsection{CYCLIC RESPONSE}

- Increasing relative density increases the cyclic resistance of sand at a fixed level of OCR and $\alpha$.

- Overconsolidation increases the number of cycles to liquefaction. The increase in the number of cycles is not significant at $\alpha$ values of 0.00 and 0.2. However, even a small increase in OCR at a given relative density at $\alpha=-0.11$ increases the number of cycles to liquefaction quiet significantly.

- Cyclic resistance ratio (CRR) is highly affected by OCR. Following the previous studies using torsional shear by Ishihara and Takatsu (1979) and simple shear by Manmatharajan (2011), a correction factor of $K_{O C R}$ as the ratio of the cyclic resistance ratio of (isotropically) overconsolidated sand to that of normally consolidated sand is defined based on triaxial test results. This correction factor has a linear relationship with OCR and has little dependency on relative density level and loading mode. The relationship is fairly similar regardless of the loading mode (cyclic simple shear, triaxial and torsional shear).

- At a given level of relative density, the cyclic resistance increases with an increase in $\alpha$ regardless of the level of OCR. On the other hand, as the level of relative density increases the correction factor increases at a higher rate in normally consolidated sand. However, in overconsolidated sand, $K_{\alpha}$ does not necessarily increase with relative density at a given $\alpha$ value. 
- In addition to the magnitude of initial static shear stress, its direction has a strong influence on cyclic resistance of sands. Samples consolidated with major principal stress acting parallel to the bedding plane, show a significantly lower cyclic resistance compared to the ones with same level of initial static shear stress acting in the opposite direction.

- $K_{\alpha}$ value is highly affected by the direction of initial static shear. The correction factor is lower than unity in negative $\alpha$ values (representing major principal stress in the horizontal direction).

- The change in $K_{\alpha}$ with OCR is highly influenced by the level of relative density and the direction of initial static shear stress. $K_{\alpha}$ does not change significantly with OCR at positive values of $\alpha$ in loose sand. However, at a negative values of $\alpha, K_{\alpha}$ increases with OCR. On the other hand, in medium dense and dense samples, $K_{\alpha}$ does not change significantly with OCR at $\alpha$ less than zero, but, decreases with OCR at $\alpha$ greater than zero. This implies that using $K_{\alpha}$ of normally consolidated sand when the sand is overconsolidated would lead to an unsafe design even after considering the increase in CRR by using $K_{O C R}$.

\subsection{POST LIQUEFACTION BEHAVIOUR}

- During post liquefaction loading, the sand developed negative pore pressure and deformations occurred on account of dilation. Three distinct phases of deformations that were previously reported by Vaid and Thomas (1995) have been confirmed in this study. Sand response in stress 
space followed the maximum obliquity line obtained during pre cyclic monotonic response.

- The rate of dilation during post liquefaction monotonic undrained loading increases with an increase in relative density level, regardless of OCR, initial static shear stress and maximum axial strain during cyclic loading.

- The stress-strain response of the overconsolidated samples were the same regardless of their OCR. At a fixed level of axial strain, the overconsolidated samples showed a higher shear strength than the normally consolidated ones at all relative density levels. However, the increase is not as significant as the one due to relative density change. The dilative tendency in post liquefaction response is not affected by the variation of OCR in overconsolidated sand. However, the overconsolidated sand shows a more dilative post-liquefaction response than the normally consolidated sand. On the other hand, the final shear modulus would not be affected by overconsolidation and deformations during the third phase of post liquefaction loading occurred at a constant rate at all OCR values but fixed level of relative density.

- The range of axial strain over which deformations occur at essentially zero shear strength is not affected by OCR and is only a function of the maximum axial strain during cyclic loading. 


\subsection{SUGGESTIONS FOR FUTURE RESEARCH}

- The effect of $90^{\circ}$ jump rotation of major principal stress direction was studied on a type of sand that shows a dilative response under compression loading mode even at the loosest relative density. However, the effect of this parameter on contractive sand is unknown and needs to be understood to be able to make more general conclusions and design recommendations.

- Vaid et al. (2001) have shown that $K_{\alpha}$ reduces as $\alpha$ increases in loose sand. In this study the range of $\alpha$ was from -0.11 to 0.2 . Therefore, the effect of OCR on $K_{\alpha}$ at other values of a both positive and negative needs more investigation.

- The effect of OCR on $K_{\alpha}$ correction factor under triaxial cyclic loading has been studied on a dilative sand. Although Manmatharajan (2011) has shown that $K_{\alpha}$ reduces with OCR in a contractive sand, his conclusions are based on cyclic simple shear tests and the effect of OCR on $K_{\alpha}$ of a contractive sand under triaxial cyclic loading is needed to be investigated.

- Manmatharajan (2011) studied the effect of OCR on $K_{\sigma}$ correction factor by performing cyclic simple shear tests. However, the variation of $K_{\sigma}$ with OCR under triaxial cyclic loading is not well known and further research would improve the future geotechnical designs. 


\section{REFERENCES}

Adalier, K., and Elgamal, A., (2005), "Liquefaction of over-consolidated sand: a centrifuge investigation", Journal of Earthquake Engineering, Imperial College Press, 9(1): 127150.

Arthur, J.R.F., and Menzies, B.K., (1972), "Inherent Anisotropy in Sand", Geotechnique, 22 (1):115-128.

ASTM, 2001a, "Standard Test Methods for Maximum Index Density and Unit Weight of Soils Using a Vibratory Table (D-4253-00)", Annual Book of ASTM Standards, American Society for Testing and Materials, Philadelphia, PA, 4(8).

ASTM, 2001b, "Standard Test Methods for Minimum Index Density and Unit Weight of Soils and Calculation of Relative Density (D-4254-00)", Annual Book of ASTM Standards, American Society for Testing and Materials, Philadelphia, PA, 4(8).

Barden, L., Khayatt A.J., (1966), "Incremental Strain Rate Ratio and Strength of Sand in the Triaxial Test", Geotechnique, 16(4), 338-357.

Been, K., Jefferies, M.G., and Hachey, J., (1991), "The Critical State of Sands", Geotechnique, Vol. 4(3), 365-381.

Bishop, A.W., (1971), "Shear Strength Parameters for Undisturbed and Remolded Soil Specimens", Proceedings of Roscoe Memorial Symposium on Stress-Strain Behaviour of Soils, Cambridge University, pp. 3-58.

Bishop, A.W., and Green, G.E., (1965), "The Influence of End Restraint on the Compression Strength of a Cohesionless Soil", Geotechnique, 15(3):243-266.

Bishop, A. W., and Wesley, L. D., (1975), "A Hydraulic Triaxial Apparatus for Controlled Stress Path Testing”, Geotechnique, Vol. 25(4), 657-670.

Boulanger, R.W., (1999), "Void Redistribution in Sand Following Earthquake Loading", Physics and Mechanics of Soil Liquefaction, Edited by Lade, P.V., and Yamamuro J.A., Balkema, Roterdam, 261-268.

Boulanger, R.W., Idriss, I.M., (2004), "State Normalization of Penetration Resistance and the Effect of Overburden Stress on Liquefaction Resistance", Proceedings of $11^{\text {th }}$ International Conference on Soil Dynamics and Earthquake Engineering and $3^{\text {rd }}$ International Conference on Earthquake Geotechnical Engineering, University of California, Berkeley, Stallion Press, 484-491.

Boulanger, R.W., and Truman, S.P., (1996), Void Redistribution in Sand under Post-Earthquake Loading", Canadian Geotechnical Journal, 33, 829-833. 
Casagrande, A. (1965). "Second Terzaghi Lecture: the role of "calculated risk" in earthwork and foundation engineering" Journal of the Soil Mechanics and Foundations Division, ASCE, 91(SM4), $1-40$.

Casagrande, A., (1975), "Liquefaction and Cyclic Deformation of Sands: a Critical Review", Proceedings of $5^{\text {th }}$ Pan-American Conference on Soil Mechanics and Foundation Engineering, 79-133.

Castro, G., (1969), "Liquefaction of Sands", PhD Thesis, Harvard University, Cambridge, Massachusetts, 231p.

Castro, G., and Poulos, S.J., (1977), "Factors Affecting Liquefaction and Cyclic Mobility", Journal of Geotechnical Engineering Division, ASCE, 103(6):501-516.

Castro, G., Poulos, S.J., France, J.W., and Enos, J.L., (1982), "Liquefaction Induced by cyclic Loading", Report submitted to the National Science Foundation, March 1982.

Chern, J.C., (1985), "Undrained Response of Sands with Emphasis on Liquefaction and Cyclic Mobility", PhD Thesis, University of British Columbia, Vancouver, Canada, 213p.

Finn, W.D.L., Pickering, J., and Bransby, P.L., (1971), "Sand Liquefaction in Triaxial and Simple Shear Test", Journal of Soil Mechanics and Foundations Division, ASCE, 97(4):839-851.

Fourie, A.B., Blight, G.E., and Papageorgiou, G., (2001), "Static Liquefaction as a Possible Explanation for the Merriespruit Tailings Dam Failure", Canadian Geotechnical Journal, 38(4): 707-719.

Frydman, S., Zeitlen, J.G., and Alpan, 1., (1973), "The Membrane Effect in Triaxial Testing of Granular Soils", Journal of Testing and Evaluation, Vol. 1(1), 37-41.

Ha, D., (2003), "Effect of Initial Stress State on the Undrained Cyclic Behaviour of Sands", M.A.Sc. Thesis, Carleton University, Ottawa, Canada $157 \mathrm{p}$.

Harder, L.F., and Boulanger, R.W., (1997), "Application of $\mathrm{K}_{\sigma}$ and $\mathrm{K}_{\alpha}$ Correction Factors ", Rep. No. NCEER-97-0022, NCEER, Buffalo, NY.

Haynes, ME, and Olsen, RS (1998), "Influence of confining stress on liquefaction resistance", In Proceedings of the International Workshop on the Physics and Mechanics of Liquefaction, Editors Lade, P.V., and Yamamuro, J.A., Baltimore, Maryland, USA, Sept 10-11.

Hazen, A., (1918), "A Study of the Slip in the Calaveras Dam", Engineering News Record, 81(26):1158-1164

Hight, D.W., Gens, A., and Symes, M.J., (1983), "The Development of a New Hollow Cylinder Apparatus for Investigating the Effects of Principal Stress Rotation in Soils", Geotechnique, 33(4):355-383. 
Ishihara, K., and Okada, S., (1978), "Yielding of Over consolidated Sand and Liquefaction Model under Cyclic Stresses", Soils and Foundations, 18(1):57-71.

Ishihara, K., Sadekawa, M., Tanaka, Y., (1978), "Effects of Overconsolidation on Liquefaction Characteristics of Sands Containing Fines", Dynamic Geotechnical Testing, ASTM, STP 654, 246-264.

Ishihara, K., and Takatsu, H., (1979), "Effects of Overconsolidation and $K_{o}$ conditions on the Liquefaction Characteristics of Sand", Soils and Foundations, 19(4):59-68.

Ishihara, K., Tatsuoka, F., and Yasuda, S., (1975), "Undrained Deformation and Liquefaction of Sands under Cyclic Stresses", Soils and Foundations, 15(1):29-44.

Kuerbis, R.H., (1989), "Effects of Gradation and Fine Content on the Undrained Response of Sand", M.A.Sc. Thesis, The University of British Columbia, Vancouver, Canada.

Ladd, C.C., Foot, R., Ishihara, K., Schlosser, F., and Poulos, H.G., (1977), "Stress-Deformation and Strength Characteristics", Proceedings of $9^{\text {th }}$ International Conference on Soil Mechanics and Foundation Engineering, 421-494.

Lade, P.V., (1982), "Localization Effects in Triaxial Tests on Sand", Proceedings, IUTAM Symposium on Deformation and Failure of Granular Materials, Editors: P.A. Vermeer and H.J. Luger, Balkema, Rotterdam, 461-471.

Lee, K.L., and Seed, H.B., (1967), "Cyclic Stress Conditions Causing Liquefaction of Sand", Journal of Geotechnical Engineering Division, ASCE, 93(5), 47-70.

Lee, K.L., Seed, H.B., Idriss, I.M., and Makdisi, F.I., (1975), "Properties of Soils in the San Fernando Hydraulic Fill Dams", Journal of Geotechnical Engineering Division, ASCE, Vol. 101(8), 801-821.

Logeswaran, P., (2005), "Behaviour of Sands under Simultaneous Changes of Volume and Pore Pressure", M.A.Sc. Thesis, Carleton University, Ottawa, Canada, 177p.

Logeswaran, P., (2010), "Behaviour of Sands under Generalized Loading and Drainage Conditions", Ph.D. Thesis, Carleton University, Ottawa, Canada, 273p.

Manmatharajan, V., (2011), "Initial Stress State and Stress History Effects on Liquefaction Susceptibility of Sands", M.A.Sc. Thesis, Carleton University, Ottawa, Canada, 162p.

Miura, S., and Toki, S., (1982), "A Sample Preparation Method and Its Effect on Static and Cyclic Deformation - Strength Properties of Sand", Soils and Foundations, 22(1):61-77.

Mulilis, J.P., Seed, H.B., Chan, C.K., Mitchell, J.K., and Arulanandan, K., (1977), "Effects of Sample Preparation on Sand Liquefaction", Journal of the Geotechnical Engineering Division, ASCE, 103(2):91-108.

National Research Council (NRC), (1985), "Liquefaction of Soils during Earthquakes", National Academy Press, Washington, D.C. 
Negussey, D., Wijewickreme, W.K.D., and Vaid, Y.P., (1988), "Constant Volume Friction Angle of Granular Materials", Canadian Geotechnical Journal, 25:50-55.

Newland, P.L., and Allely, B.H., (1959), "Volume Changes During Undrained Triaxial Tests on Saturated Dilatant Granular Materials", Geotechnique, Vol. 9(4), 174-182.

Oda, M., (1972), "The Mechanism Fabric Changes during Compressional Deformation of Sand", Soils and Foundations, 12(2):1-18.

Olson, S.M. and Stark, T.D. (2003). "Yield strength ratio and liquefaction analysis of slopes and embankments" Journal of Geotechnical and Geoenvironmental Engineering, ASCE, 129(8), 727-737.

Raju, V.S., and Sadasvian, S.K., (1974), "Membrane Penetration in Triaxial Tests on Sand", Journal of Geotechnical Engineering Division, ASCE, Vol. 100(4), 482-489.

Roscoe, K.H., (1953), "An Apparatus for Application of Simple Shear to Soil Samples", Proceedings of $3^{\text {rd }}$ International Conference on Soil Mechanics and Foundation Engineering, 186-191.

Rowe, P.W., and Barden, L., (1964), "The Importance of Free Ends in the Triaxial Test", Journal of Soil Mechanics and Foundation Engineering Division, ASCE, 90(1):1-27.

Roy, D., Campanella, G., Hughes, J., (1996), Discussion on "State Parameter from Self-Boring Pressuremeter Tests in Sand", Journal Geotechnical Engineering Division, ASCE, 122(5):413-414.

Sarsby, R.W., Kalteziotis, N., and Haddad, E.H., (1980), "Bedding Error in Triaxial Tests on Granular Media", Geotechnique, Vol. 30(3), 302-309.

Seed, H.B., (1979), "Soil Liquefaction and Cyclic Mobility Evaluation for Level Ground during Earthquakes", Journal of Geotechnical Engineering Division, ASCE, 105(2):201-225.

Seed, H.B., (1983), "Earthquake Resistance Design of Earth Dams", Symposium on Seismic Design of Embankments and Caverns, Philadelphia, PA, ASCE, 41-64.

Seed, H.B., and Idriss, I.M., (1971), "Simplified Procedure for Evaluating Soil Liquefaction Potential", Journal of the Soil Mechanics and Foundations Division, ASCE, 97(SM9), 1249-1273.

Seed, H.B., and Peacock, W.H., (1971), "Test Procedure for Measuring Soil Liquefaction Characteristics", Journal of the Soil Mechanics and Foundation Division, ASCE, Vol. 97(8), 1099-1119.

Seed, H.B., Tokimatsu, K., Harder, L.F., and Chung, R.M., (1985), "Influence of SPT Procedure in Soil Liquefaction Resistance Evaluation", Journal of Geotechnical Engineering, ASCE, 112(11), 1016-1032. 
Seed, R.B., and Harder, L.F., (1990), "SPT- Based Analysis of Cyclic Pore Pressure Generation and Undrained Residual Strength", Seed Memorial Symposium, BiTech Publications, Vancouver, Canada, 351-376.

Shamoto, Y., Zhang, J.M., and Goto, S., (1997), "Mechanism of large post-liquefaction deformation in saturated sand" Soils and Foundations, 37(2), 71-80.

Shibuya, S., and Hight, D.W., (1988), "A Bounding Surface for Granular Materials", Soils and Foundations, 27(4):123-136.

Sivathayalan, S., Ha, D., (2004), "Effect of initial stress state on the cyclic simple shear behaviour of sands", Proceedings of the International Workshop on Cyclic Behaviour of Soils and Liquefaction Phenomena. Edited by T. Triantafyllidis, Taylor \& Francis Group, London, 207-214.

Sivathayalan, S., Ha, D., (2011), "Effect of static shear stress on the cyclic resistance of sands in simple shear loading", Canadian Geotechnical Journal, 48(10), 1461-1470.

Sivathayalan, S., and Vaid, Y.P., (2002), "Influence of Generalized Initial State and Principal Stress Rotation on the Undrained Response of Sands", Canadian Geotechnical Journal, 39:63-76.

Sivathayalan, S., Yazdi, A.M., (2004), "Post Liquefaction Response of Initially Strain Softening Sand", Proceedings of the International Conference on Cyclic Behaviour of Soils and Liquefaction Phenomena, Bochum, Germany, 215-221.

Skempton, A.W., (1954), "The Pore Pressure Coefficients A and B", Geotechnique, Vol. 4,143147.

Sladen, J.A., D'Hollander, R.D., and Krahn, J., (1985), "The Liquefaction of Sands- A Collapse Surface Approach", Canadian Geotechnical Journal, 22 (4):564-578.

Stedman, D., (1997), "Effects of Confining Pressure and Static Shear on Liquefaction Resistance of Fraser River Sand", M.A.Sc. Thesis, University of British Columbia, Vancouver, Canada, 93p.

Symes, M.J., Gens, A. and Hight, D.W. (1984), "Undrained Anisotropy and Principal Stress Rotation in Saturated Sand", Geotechnique, 34(1):11-27.

Taylor, D.W., (1948), "Fundamental of Soils mechanics" John Wiley \& Sons, New York, 700p.

Thomas, J., (1992), "Static, Cyclic and Post Liquefaction Behaviour of Fraser River Sand", M.A.Sc. Thesis, University of British Columbia, Vancouver, Canada, $117 \mathrm{p}$.

Uthayakumar, M., (1995), "Liquefaction of Sands under Multi-axial Loading", Ph.D. Thesis, University of British Columbia, Vancouver, Canada, 185p. 
Uthayakumar, M., and Vaid, Y.P. (1998), "Static Liquefaction of Sands under Multiaxial Loading", Canadian Geotechnical Journal, 35(2):273-283.

Vaid, Y.P., and Chern, J.C., (1983), "Mechanism of Deformation during Undrained Loading of Saturated Sand", International Journal of Soil Dynamics and Earthquake Engineering, 2(3):171-177.

Vaid, Y.P., and Chern, J.C., (1985), "Cyclic and Monotonic Undrained Response of Sands", Proceedings of Advances in the Art of Testing Soils under Cyclic Loading Conditions, Detroit, 120-147.

Vaid, Y.P., Chung, E.K.F., and Kuerbis, R.H., (1989), "Preshearing and Undrained Response of sands", Soils and Foundations, 29(4):49-61.

Vaid, Y.P., Chung, E.K.F., and Kuerbis, R.H., (1990), "Stress Path and Steady State", Canadian Geotechnical Journal, 27(1):1-7.

Vaid, Y.P., and Negussey, D., (1988), "Preparation of Reconstituted Sand Specimens", Symposium on Advanced Triaxial Testing of Soil and Rock, ASTM, STP 977, 405-417.

Vaid, Y.P., and Sivathayalan, S., (1996), "Static and Cyclic Liquefaction Potential of Fraser Delta Sand in Simple Shear and Triaxial Tests", Canadian Geotechnical Journal, 33(2):281-289.

Vaid, Y.P., and Sivathayalan, S., (2000), "Fundamental Factors Affecting Liquefaction Susceptibility of Sands", Canadian Geotechnical Journal, 37:592-606.

Vaid, Y.P., Sivathayalan, S., and Stedman, D., (1999), "Influence of Specimen Reconstitution Method on Undrained Response of Sand", Geotechnical Testing Journal, ASTM, 22(3):187-195.

Vaid, Y.P., Stedman, J.D., and Sivathayalan, S. (2001), "Confining Stress and Static Shear Effects in Cyclic Liquefaction", Canadian Geotechnical Journal, 38(3):580-591.

Vaid, Y.P., and Thomas, J., (1994), "Post Liquefaction Behaviour of Sand", Proceedings of $13^{\text {th }}$ International Conference on Soil Mechanics and Foundation Engineering, New Delhi, India, pp. 1305-1310.

Vaid, Y.P., and Thomas, J., (1995), "Liquefaction and Post Liquefaction of Sand", Journal of Geotechnical Engineering Division, ASCE, 121(2):163-173.

Yazdi, A.M., (2004), "Post Liquefaction Deformation of Initially Strain Softening Sand", M.A.Sc. Thesis, Carleton University, Ottawa, Canada, 119p.

Yoshimi, Y., Tokimatsu, K., and Hosaka, Y., (1989), "Evaluation of Liquefaction Resistance of Clean Sands Based on High Quality Undisturbed Samples", Soils and Foundations, 29(1):93-104. 
Youd, TL, Idriss, IM, Andrus, RD, Arango, I., Castro, G., Christian, JT, Dobry, R, Finn, WDL, Harder, LF, Hynes, ME, Ishihara, K, Koester, JP, Liao, SC, Marcuson, WF, Martin, GR, Mitchell, JK, Moriwaki, Y, Power, MS, Robertson, PK, Seed, RB, and Stokoe, KH, 2001, Liquefaction Resistance of Soils: Summary Report from the 1996 NCEER and 1998 NCEER/NSF Workshops on Evaluation of Liquefaction Resistance of Soils, Journal of Geotechnical and Geoenvironmental Engineering, ASCE, 127(10): 817-833. 


\section{APPENDIX A}

(CYCLIC TESTS DATA) 


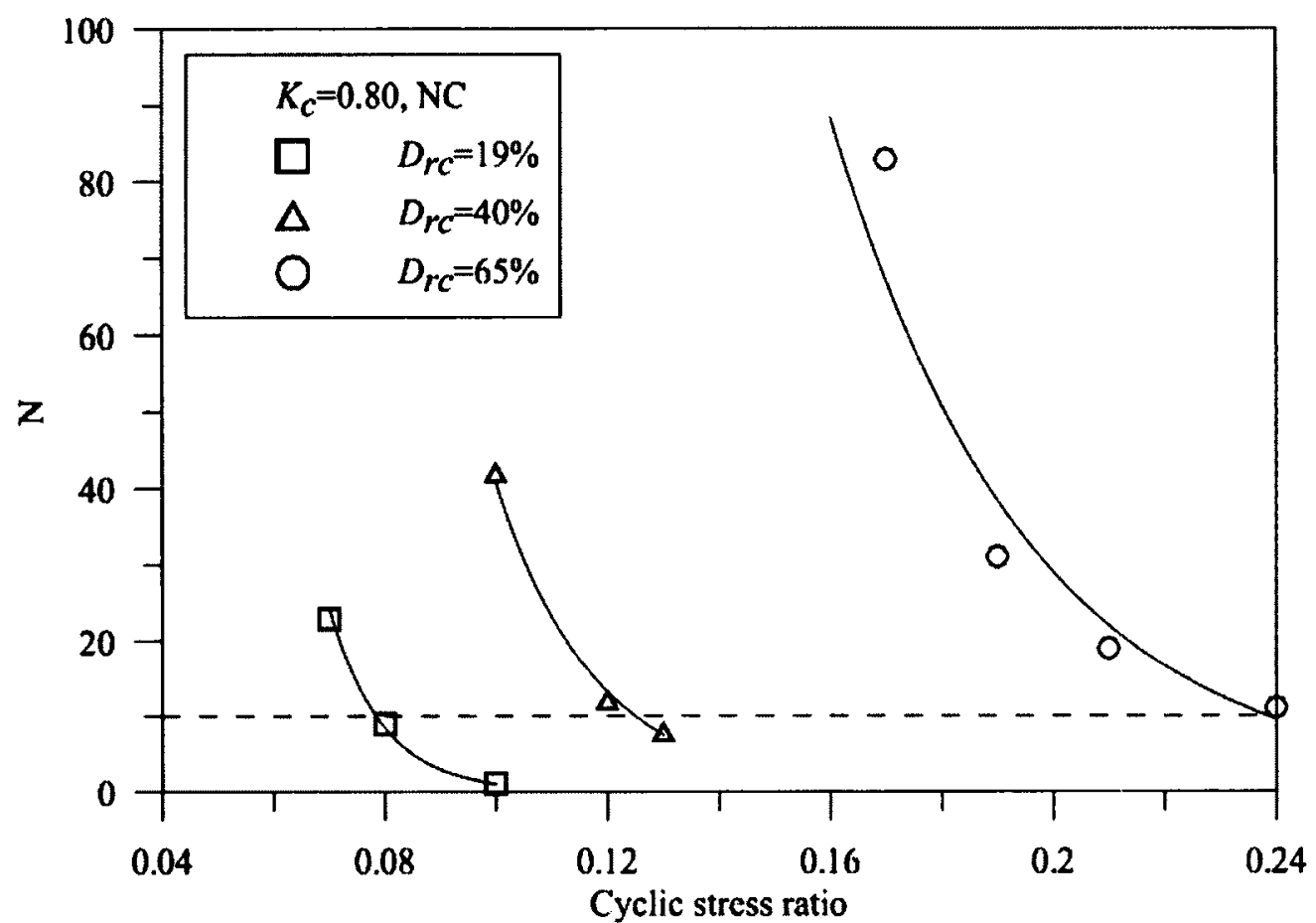

Figure A. 1 Variation of number of cycles to liquefaction at $K_{c}=0.80$ and $\mathrm{OCR}=1.00$

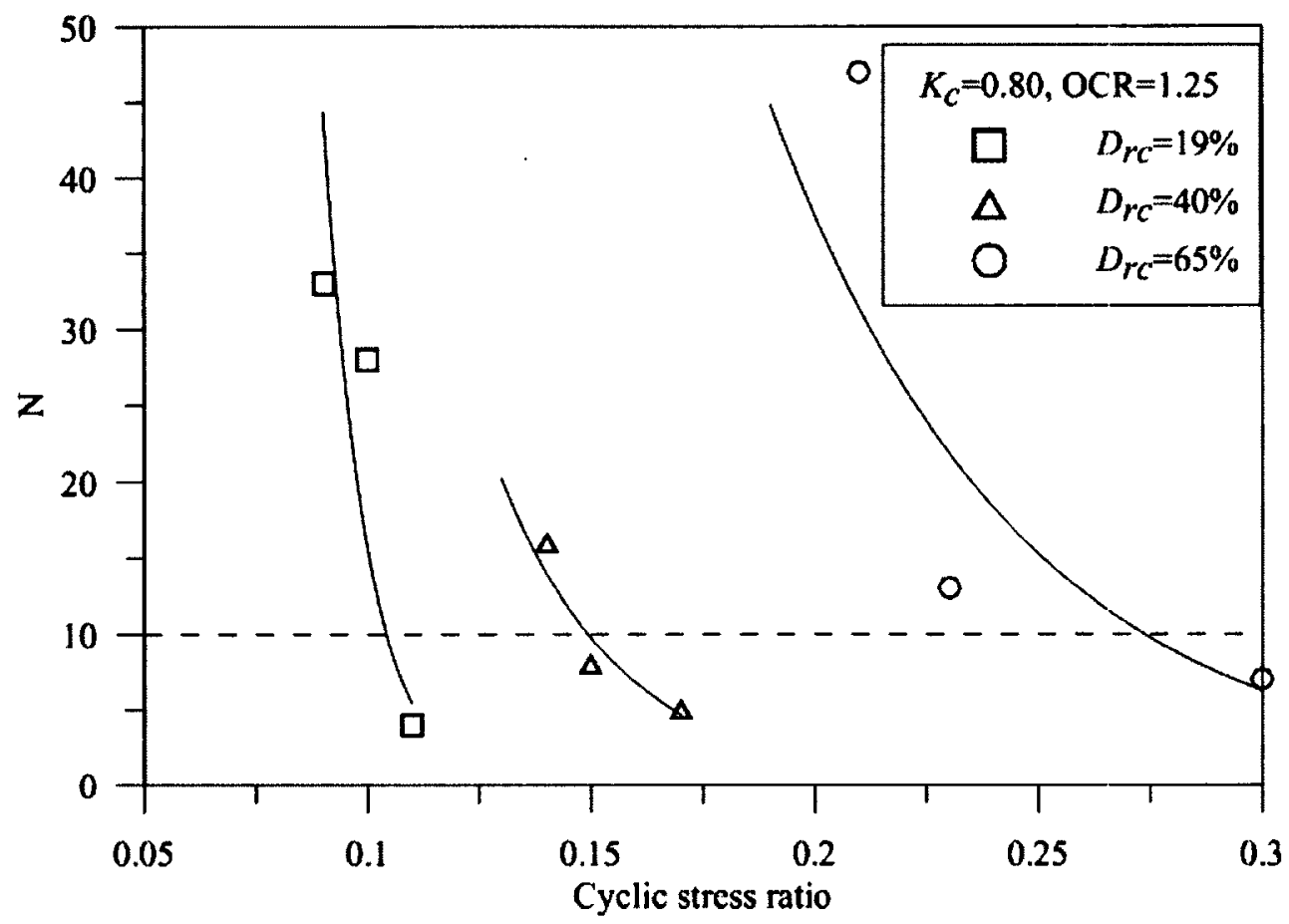

Figure A. 2 Variation of number of cycles to liquefaction at $K_{c}=0.80$ and $\mathrm{OCR}=1.25$ 


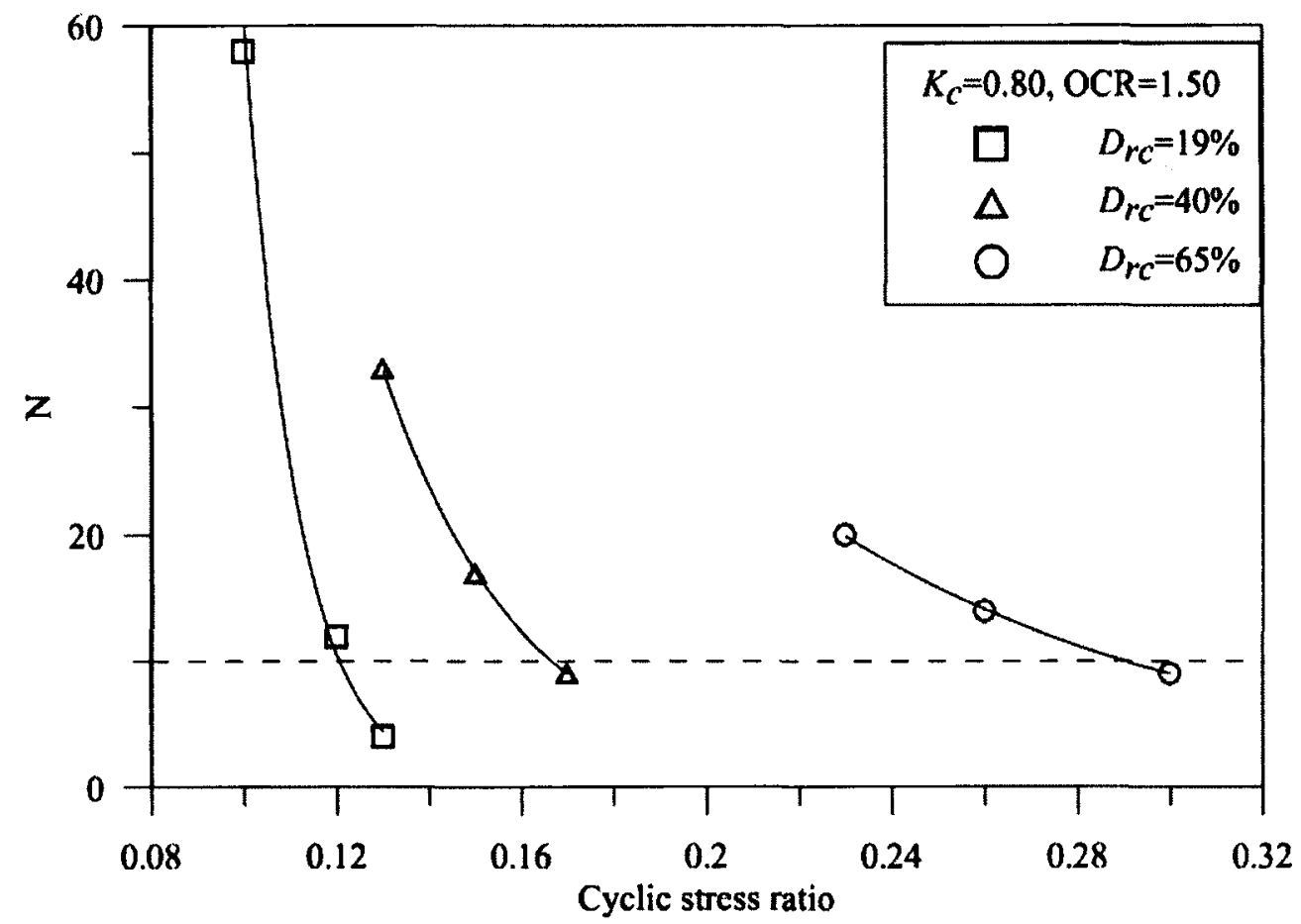

Figure A. 3 Variation of number of cycles to liquefaction at $K_{c}=0.80$ and $\mathrm{OCR}=1.50$

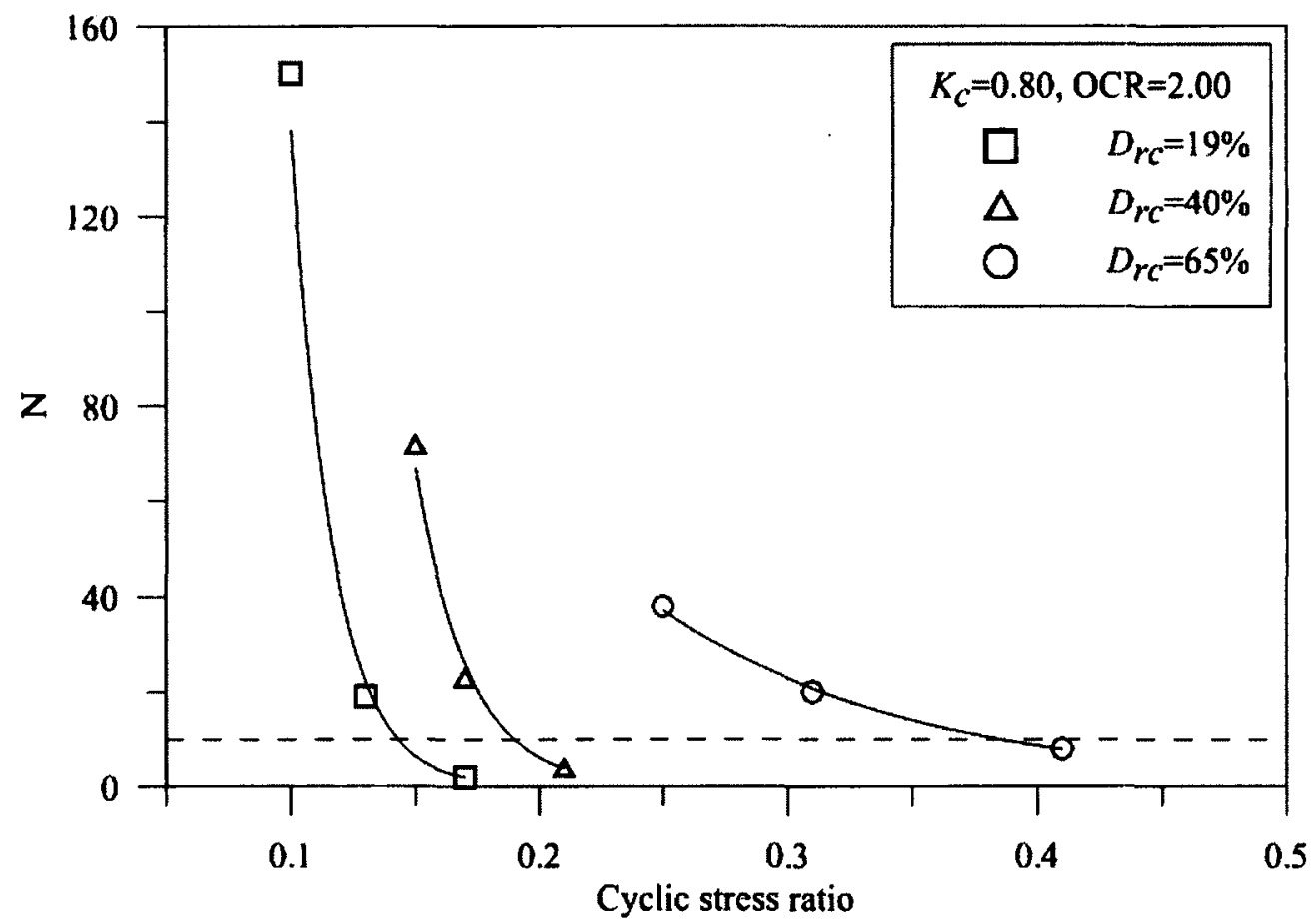

Figure A. 4 Variation of number of cycles to liquefaction at $K_{c}=0.80$ and $\mathrm{OCR}=1.50$ 


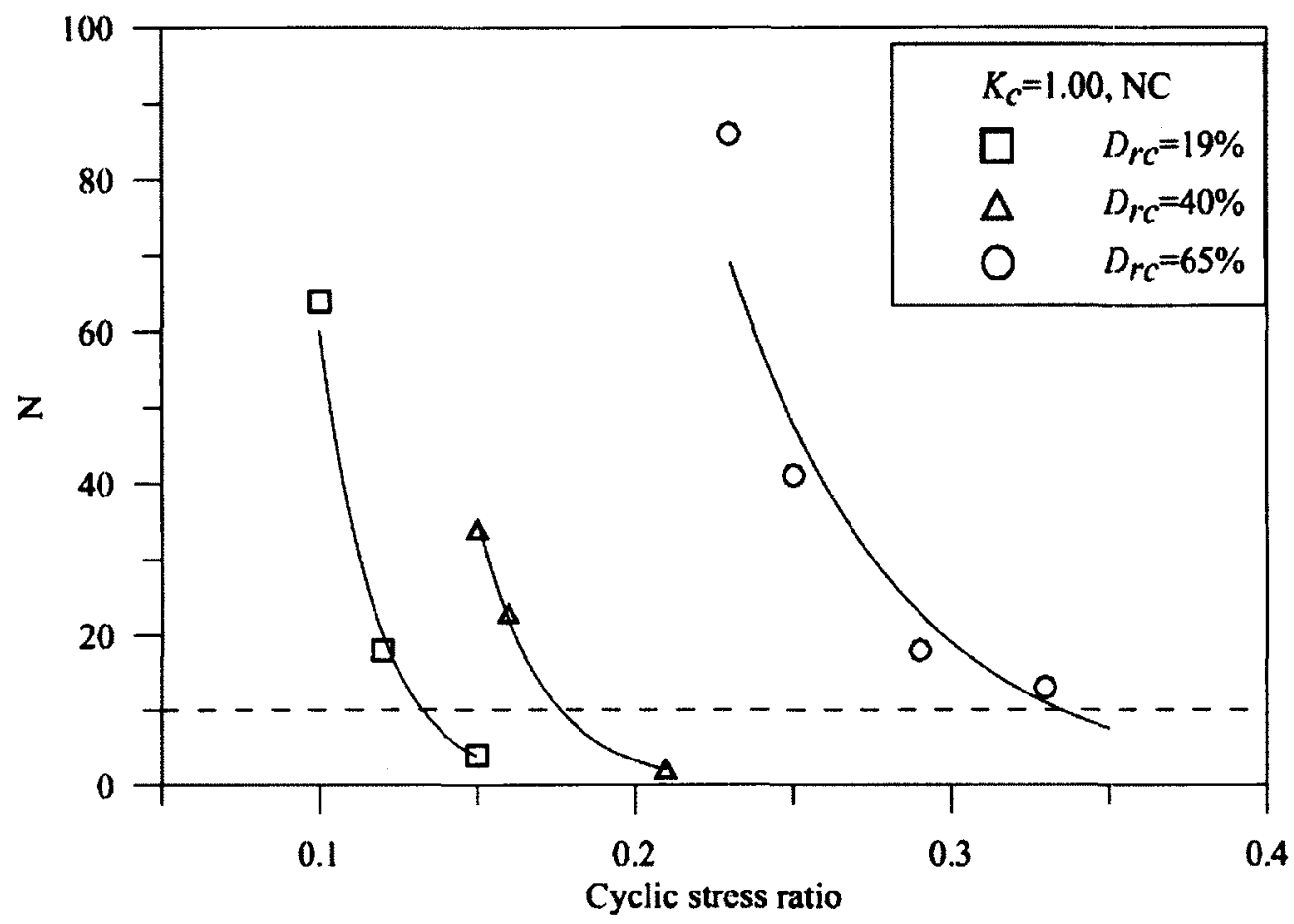

Figure A. 5 Variation of number of cycles to liquefaction at $K_{c}=1.00$ and $\mathrm{OCR}=1.00$

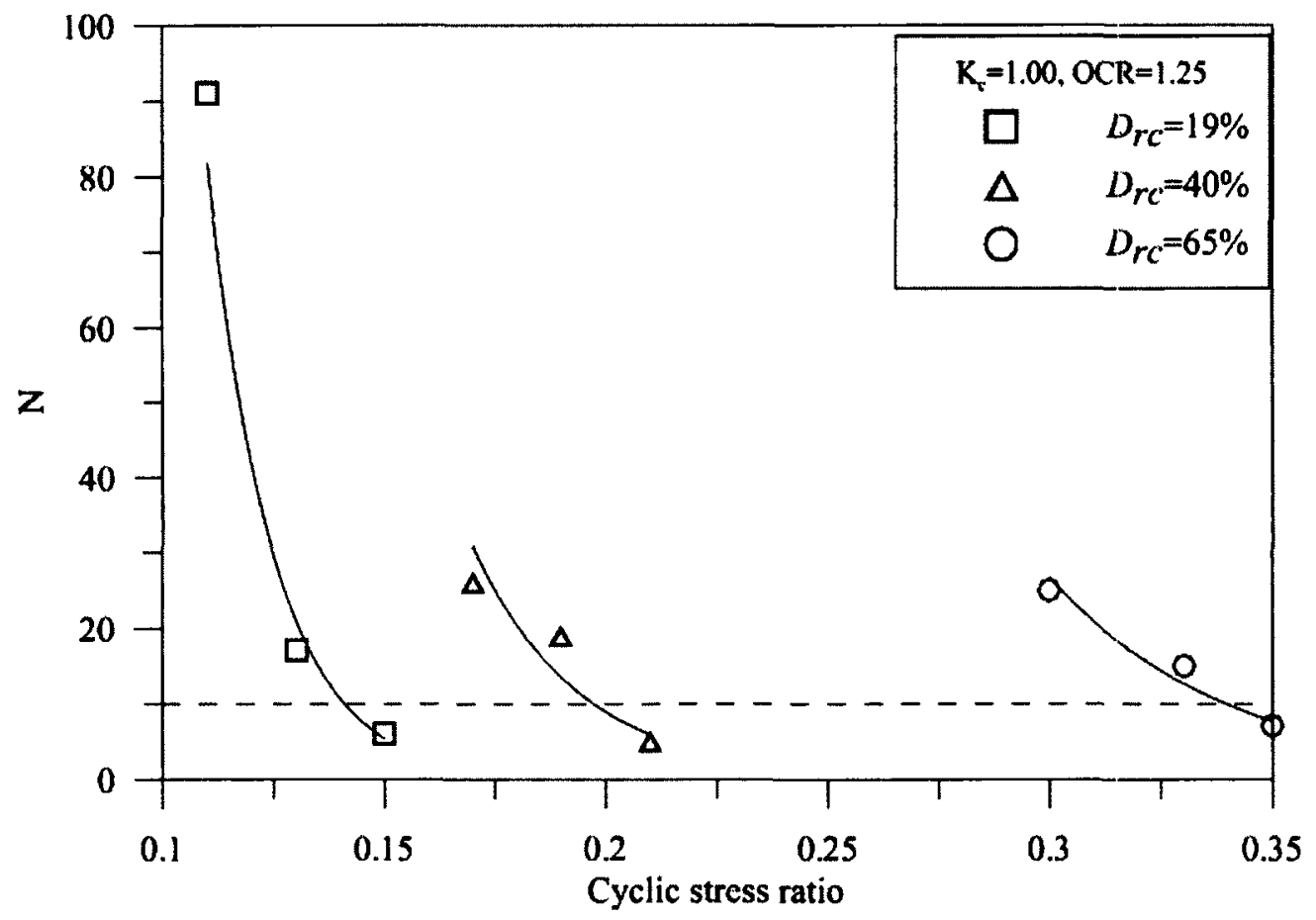

Figure A. 6 Variation of number of cycles to liquefaction at $K_{c}=1.00$ and $\mathrm{OCR}=1.25$ 


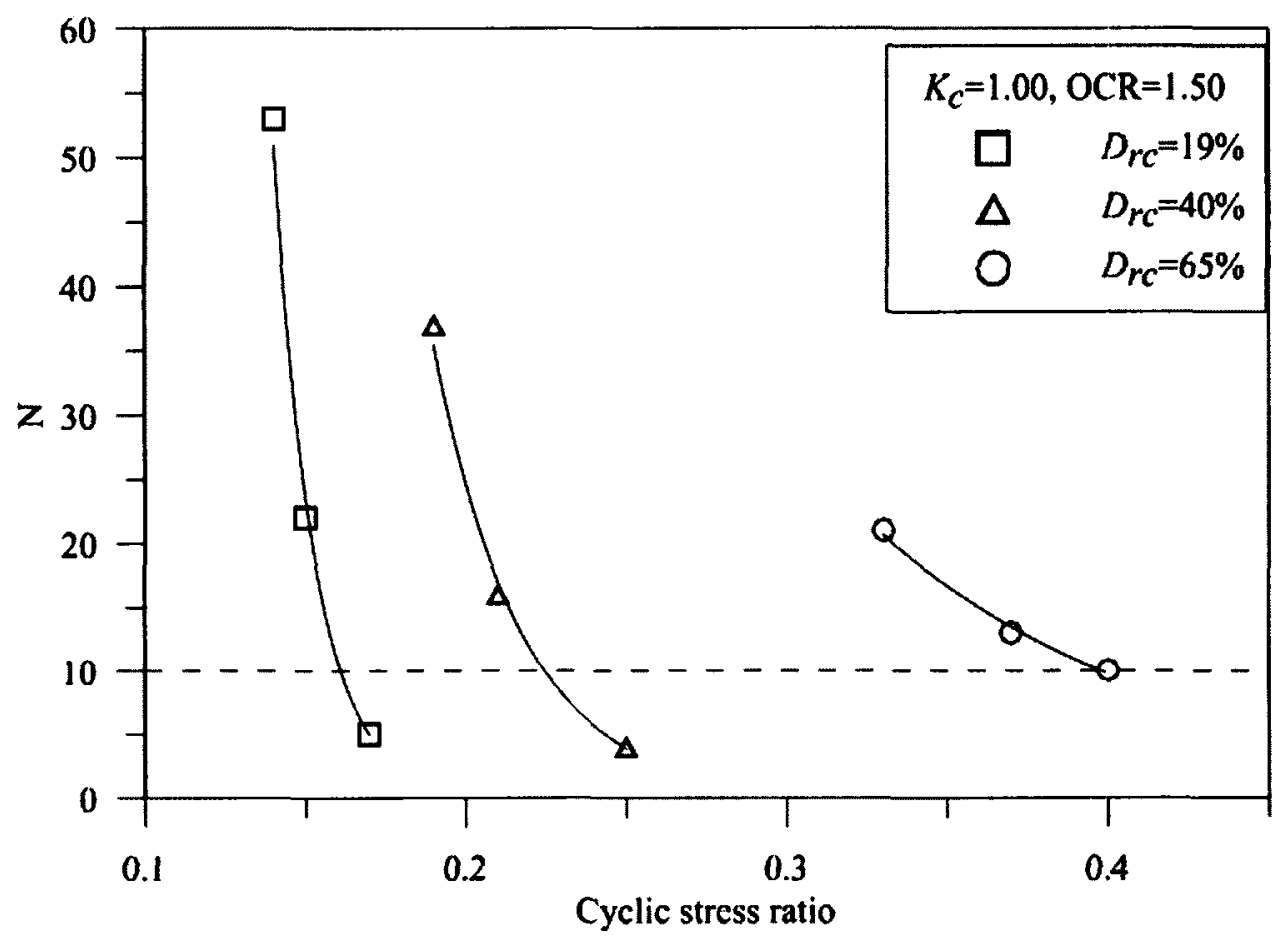

Figure A. 7 Variation of number of cycles to liquefaction at $K_{c}=1.00$ and $\mathrm{OCR}=1.50$

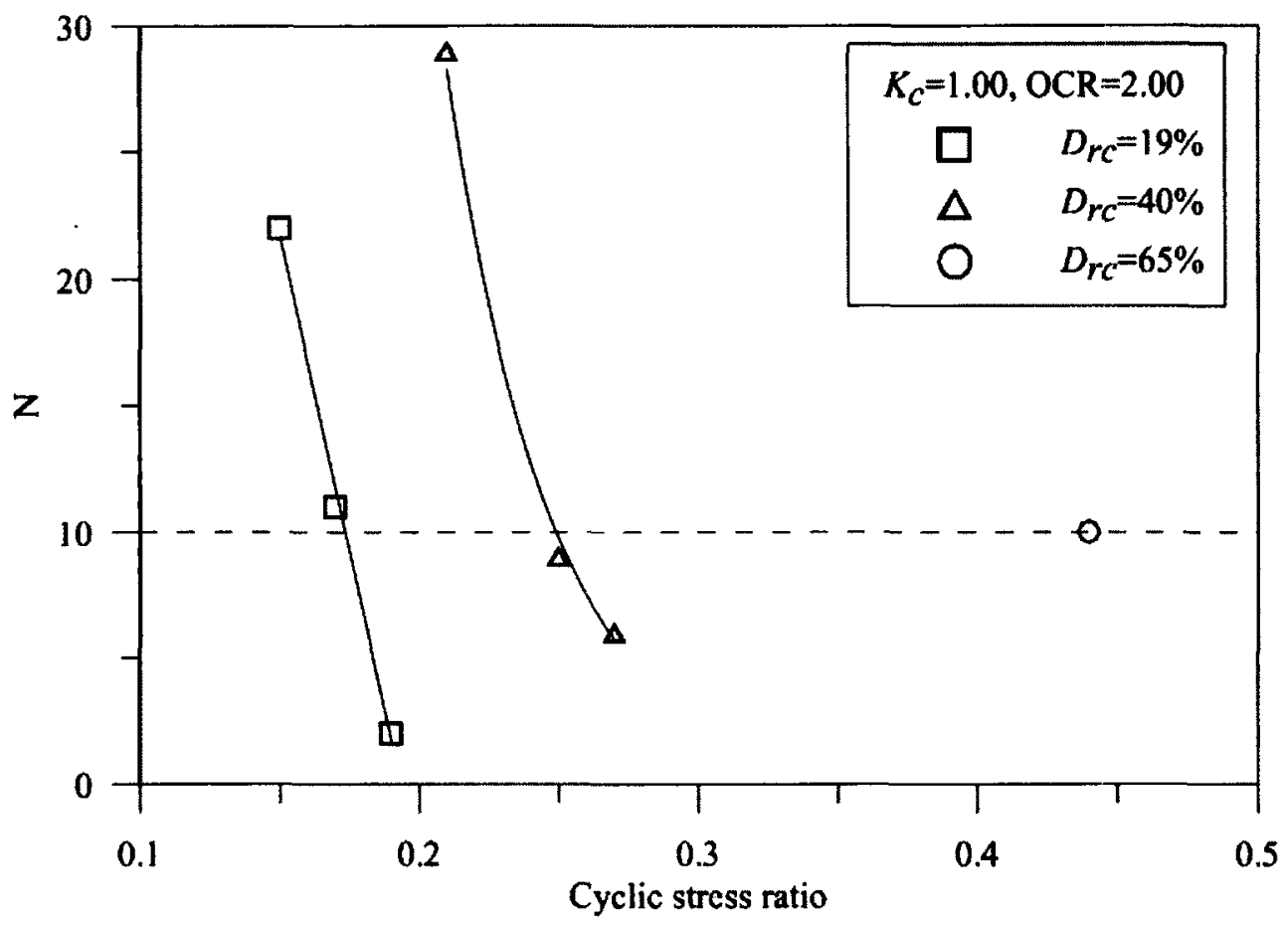

Figure A. 8 Variation of number of cycles to liquefaction at $K_{c}=1.00$ and $\mathrm{OCR}=2.00$ 


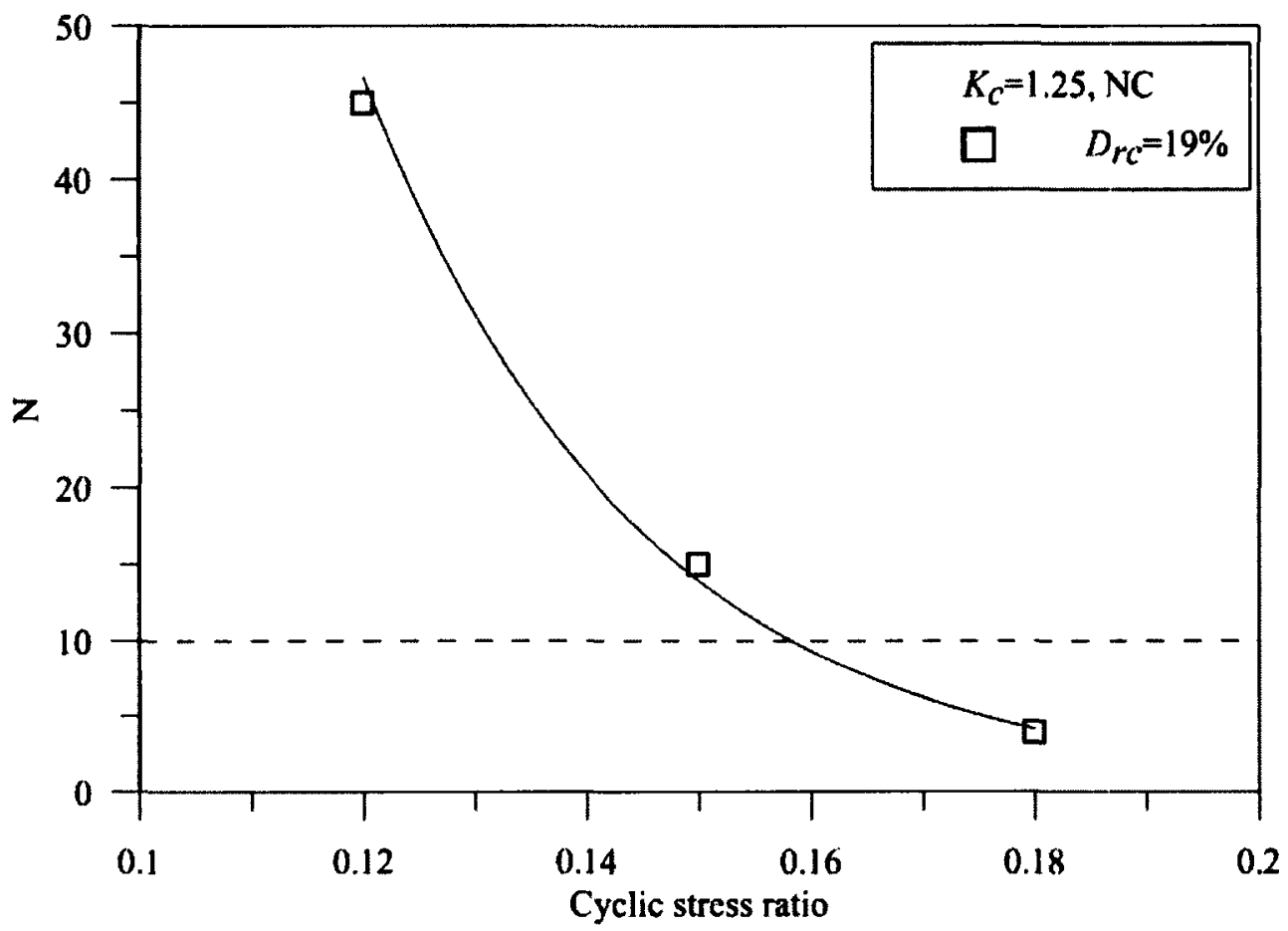

Figure A. 9 Variation of number of cycles to liquefaction at $K_{c}=1.25$ and $\mathrm{OCR}=1.00$

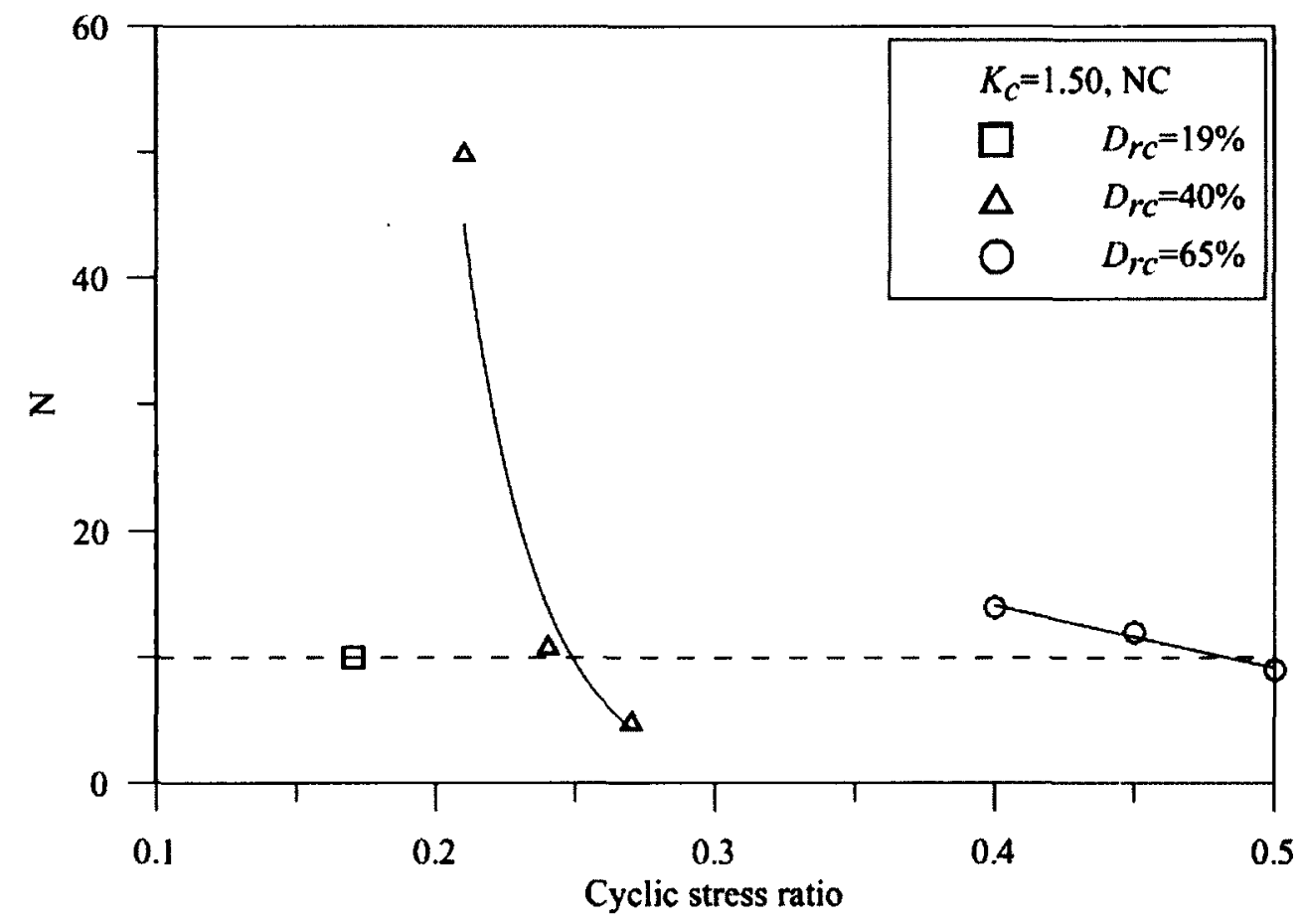

Figure A. 10 Variation of number of cycles to liquefaction at $K_{c}=1.50$ and $\mathrm{OCR}=1.00$ 


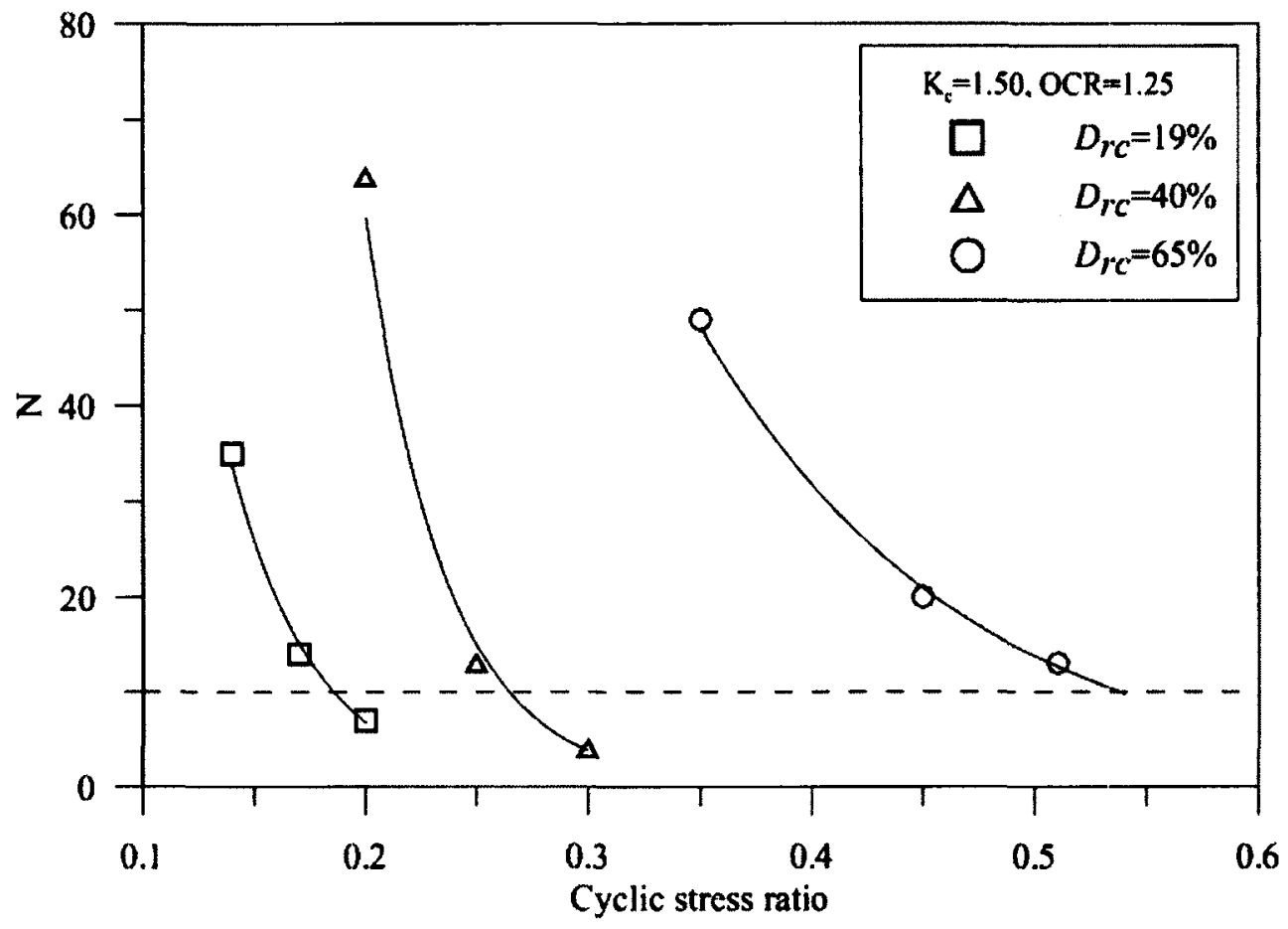

Figure A. 11 Variation of number of cycles to liquefaction at $K_{c}=1.50$ and $\mathrm{OCR}=1.25$

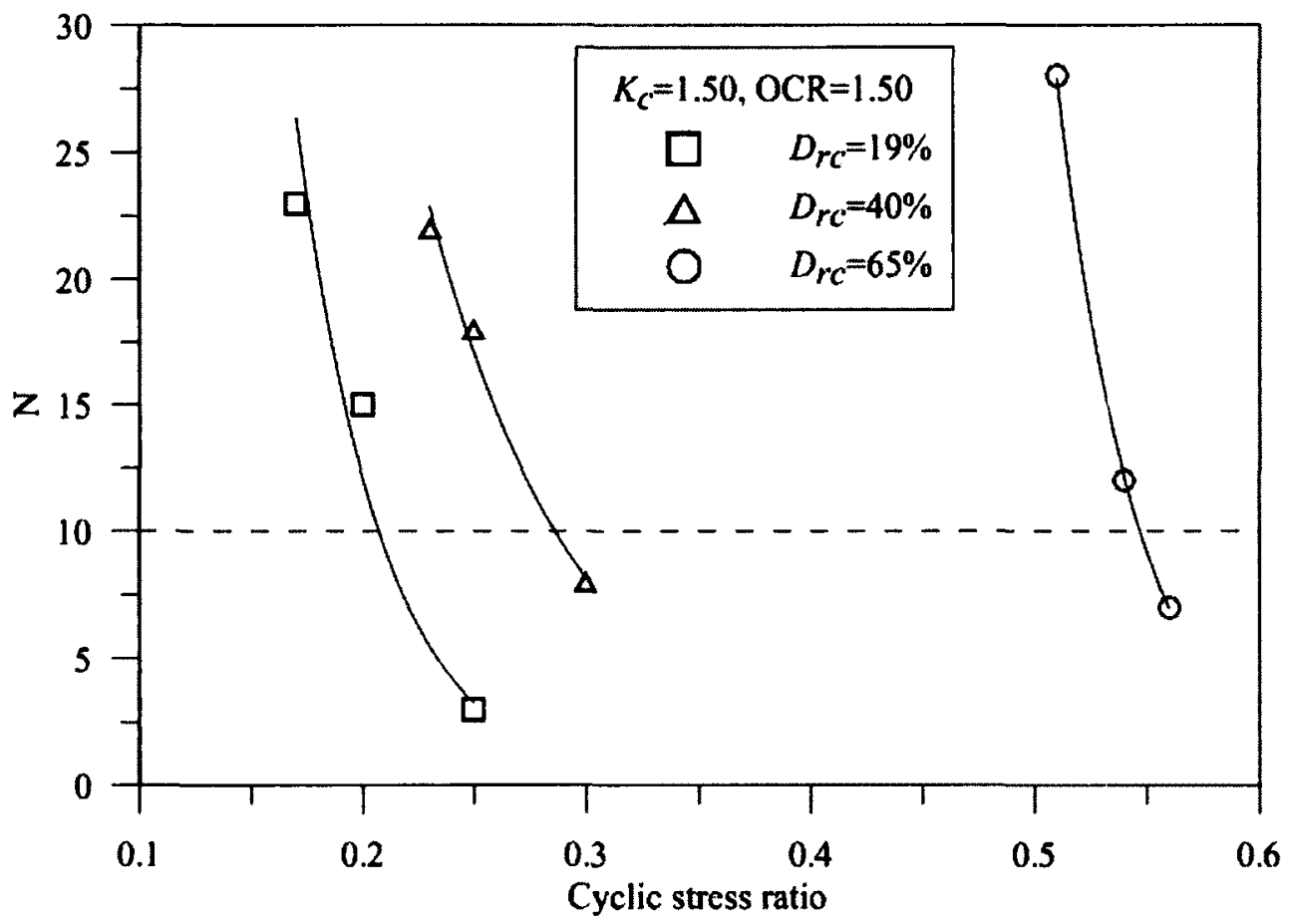

Figure A. 12 Variation of number of cycles to liquefaction at $K_{c}=1.50$ and $\mathrm{OCR}=1.50$ 


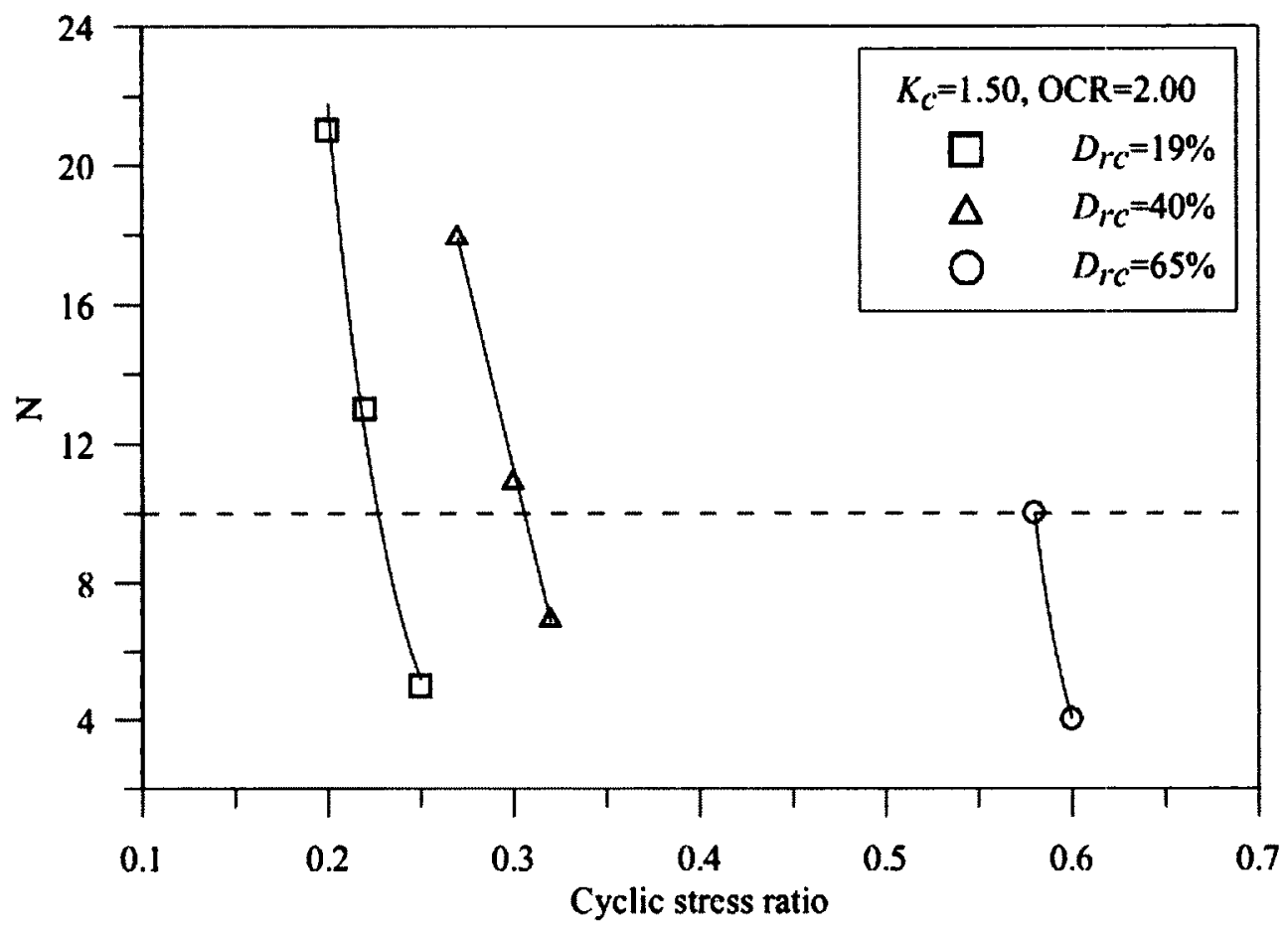

Figure A. 13 Variation of number of cycles to liquefaction at $K_{c}=1.50$ and $\mathrm{OCR}=2.00$ 


\section{APPENDIX B}

(TESTS PROGRAM) 
Table B.1 Monotonic tests on Fraser River sand

\begin{tabular}{|c|c|c|c|c|}
\hline Test No. & Loading mode & $D_{r c}(\%)$ & OCR & $\alpha$ \\
\hline M-1 & C & 19.00 & 1.00 & -0.33 \\
\hline M-2 & C & 19.00 & 1.00 & -0.20 \\
\hline M-3 & C & 19.00 & 1.00 & -0.11 \\
\hline M-4 & C & 19.00 & 1.00 & 0.00 \\
\hline M-5 & $\mathrm{C}$ & 19.00 & 1.00 & 0.20 \\
\hline M-6 & $\mathrm{C}$ & 19.00 & 1.00 & 0.33 \\
\hline M-7 & $\mathrm{C}$ & 19.00 & 1.25 & -0.11 \\
\hline M-8 & $\mathrm{C}$ & 19.00 & 1.25 & 0.00 \\
\hline $\mathrm{M}-9$ & $\mathrm{C}$ & 19.00 & 1.25 & 0.20 \\
\hline $\mathrm{M}-10$ & $\mathrm{C}$ & 19.00 & 1.50 & -0.11 \\
\hline $\mathrm{M}-11$ & $\mathrm{C}$ & 19.00 & 1.50 & 0.00 \\
\hline $\mathrm{M}-12$ & $\mathrm{C}$ & 19.00 & 1.50 & 0.20 \\
\hline $\mathrm{M}-13$ & $\mathrm{C}$ & 19.00 & 2.00 & -0.11 \\
\hline $\mathrm{M}-14$ & $\mathrm{C}$ & 19.00 & 2.00 & 0.00 \\
\hline $\mathrm{M}-15$ & $\mathrm{C}$ & 19.00 & 2.00 & 0.20 \\
\hline $\mathrm{M}-16$ & $\mathrm{C}$ & 40.00 & 1.00 & -0.11 \\
\hline $\mathrm{M}-17$ & $\mathrm{C}$ & 40.00 & 1.00 & 0.00 \\
\hline $\mathrm{M}-18$ & $\mathrm{C}$ & 40.00 & 1.00 & 0.20 \\
\hline $\mathrm{M}-19$ & $\mathrm{C}$ & 40.00 & 1.25 & -0.11 \\
\hline $\mathrm{M}-20$ & $\mathrm{C}$ & 40.00 & 1.25 & 0.00 \\
\hline $\mathrm{M}-21$ & $\mathrm{C}$ & 40.00 & 1.25 & 0.20 \\
\hline $\mathrm{M}-22$ & $\mathrm{C}$ & 40.00 & 1.50 & -0.11 \\
\hline $\mathrm{M}-23$ & $\mathrm{C}$ & 40.00 & 1.50 & 0.00 \\
\hline
\end{tabular}




\begin{tabular}{|c|c|c|c|c|}
\hline Test No. & Loading mode & $D_{r c}(\%)$ & OCR & $\alpha$ \\
\hline M-24 & C & 40.00 & 1.50 & 0.20 \\
\hline M-25 & C & 40.00 & 2.00 & 0.00 \\
\hline M-26 & C & 40.00 & 2.00 & 0.20 \\
\hline M-27 & C & 65.00 & 1.00 & -0.11 \\
\hline M-28 & C & 65.00 & 1.00 & 0.00 \\
\hline M-29 & C & 65.00 & 1.00 & 0.20 \\
\hline M-30 & C & 65.00 & 1.25 & -0.11 \\
\hline M-31 & C & 65.00 & 1.25 & 0.00 \\
\hline M-32 & C & 65.00 & 1.50 & -0.11 \\
\hline M-33 & C & 65.00 & 1.50 & 0.00 \\
\hline M-34 & E & 19.00 & 1.00 & -0.20 \\
\hline M-35 & E & 19.00 & 1.00 & -0.11 \\
\hline M-36 & E & 19.00 & 1.00 & 0.00 \\
\hline M-37 & E & 19.00 & 1.00 & 0.20 \\
\hline M-38 & E & 19.00 & 1.25 & -0.11 \\
\hline M-39 & E & 19.00 & 1.25 & 0.00 \\
\hline M-40 & E & 19.00 & 1.25 & 0.20 \\
\hline M-41 & E & 19.00 & 1.50 & -0.11 \\
\hline M-42 & E & 19.00 & 1.50 & 0.00 \\
\hline M-43 & E & 19.00 & 1.50 & 0.20 \\
\hline M-44 & E & 19.00 & 2.00 & -0.11 \\
\hline M-45 & E & 19.00 & 2.00 & 0.00 \\
\hline M-46 & E & 19.00 & 2.00 & 0.20 \\
\hline M-47 & E & 40.00 & 1.00 & -0.11 \\
\hline
\end{tabular}




\begin{tabular}{|c|c|c|c|c|}
\hline Test No. & Loading mode & $D_{r c}(\%)$ & OCR & $\alpha$ \\
\hline M-48 & $\mathrm{E}$ & 40.00 & 1.00 & 0.00 \\
\hline$M-49$ & $\mathrm{E}$ & 40.00 & 1.00 & 0.20 \\
\hline M-50 & E & 40.00 & 1.25 & -0.11 \\
\hline M-51 & E & 40.00 & 1.25 & 0.00 \\
\hline M-52 & $\mathrm{E}$ & 40.00 & 1.25 & 0.20 \\
\hline M-53 & $\mathrm{E}$ & 40.00 & 1.50 & -0.11 \\
\hline M-54 & $E$ & 40.00 & 1.50 & 0.00 \\
\hline M-55 & $\mathrm{E}$ & 40.00 & 1.50 & 0.20 \\
\hline M-56 & $\mathrm{E}$ & 40.00 & 2.00 & -0.11 \\
\hline M-57 & $\mathrm{E}$ & 40.00 & 2.00 & 0.00 \\
\hline M-58 & $\mathrm{E}$ & 40.00 & 2.00 & 0.20 \\
\hline M-59 & $\mathrm{E}$ & 65.00 & 1.00 & -0.11 \\
\hline$M-60$ & $\mathrm{E}$ & 65.00 & 1.00 & 0.00 \\
\hline M-61 & $\mathrm{E}$ & 65.00 & 1.00 & 0.20 \\
\hline M-62 & $\mathrm{E}$ & 65.00 & 1.25 & -0.11 \\
\hline$M-63$ & $\mathrm{E}$ & 65.00 & 1.25 & 0.00 \\
\hline M-64 & $\mathrm{E}$ & 65.00 & 1.50 & -0.11 \\
\hline M-65 & $\mathrm{E}$ & 65.00 & 2.00 & -0.11 \\
\hline M-66 & $\mathrm{E}$ & 65.00 & 2.00 & 0.00 \\
\hline
\end{tabular}


Table B.2 Cyclic tests on Fraser River sand

\begin{tabular}{|c|c|c|c|c|c|}
\hline Test No. & $\alpha$ & OCR & $D_{r c}(\%)$ & CSR & $\mathrm{N}$ \\
\hline CYC-1 & -0.11 & 1.00 & 19.00 & 0.07 & 23 \\
\hline CYC-2 & -0.11 & 1.00 & 19.00 & 0.08 & 9 \\
\hline CYC-3 & -0.11 & 1.00 & 19.00 & 0.10 & 1 \\
\hline CYC-4 & -0.11 & 1.00 & 40.00 & 0.10 & 42 \\
\hline CYC-5 & -0.11 & 1.00 & 40.00 & 0.12 & 12 \\
\hline CYC-6 & -0.11 & 1.00 & 40.00 & 0.13 & 8 \\
\hline CYC-7 & -0.11 & 1.00 & 65.00 & 0.19 & 31 \\
\hline CYC-8 & -0.11 & 1.00 & 65.00 & 0.21 & 19 \\
\hline CYC-9 & -0.11 & 1.00 & 65.00 & 0.24 & 28 \\
\hline CYC-10 & -0.11 & 1.25 & 19.00 & 0.09 & 33 \\
\hline CYC-11 & -0.11 & 1.25 & 19.00 & 0.10 & 10 \\
\hline CYC-12 & -0.11 & 1.25 & 19.00 & 0.11 & 4 \\
\hline CYC-13 & -0.11 & 1.25 & 40.00 & 0.14 & 16 \\
\hline CYC-14 & -0.11 & 1.25 & 40.00 & 0.15 & 8 \\
\hline CYC-15 & -0.11 & 1.25 & 40.00 & 0.17 & 5 \\
\hline CYC-16 & -0.11 & 1.25 & 65.00 & 0.21 & 47 \\
\hline CYC-17 & -0.11 & 1.25 & 65.00 & 0.23 & 13 \\
\hline CYC-18 & -0.11 & 1.25 & 65.00 & 0.30 & 7 \\
\hline CYC-19 & -0.11 & 1.50 & 19.00 & 0.10 & 58 \\
\hline CYC-20 & -0.11 & 1.50 & 19.00 & 0.12 & 12 \\
\hline CYC-21 & -0.11 & 1.50 & 19.00 & 0.13 & 4 \\
\hline CYC-22 & -0.11 & 1.50 & 40.00 & 0.13 & 33 \\
\hline CYC-23 & -0.11 & 1.50 & 40.00 & 0.15 & 17 \\
\hline
\end{tabular}




\begin{tabular}{|c|c|c|c|c|c|}
\hline Test No. & $\alpha$ & OCR & $D_{r c}(\%)$ & CSR & $\mathrm{N}$ \\
\hline CYC-24 & -0.11 & 1.50 & 40.00 & 0.17 & 9 \\
\hline CYC-25 & -0.11 & 1.50 & 65.00 & 0.23 & 20 \\
\hline CYC-26 & -0.11 & 1.50 & 65.00 & 0.26 & 14 \\
\hline CYC-27 & -0.11 & 1.50 & 65.00 & 0.30 & 9 \\
\hline CYC-28 & -0.11 & 2.00 & 19.00 & 0.17 & 2 \\
\hline CYC-29 & -0.11 & 2.00 & 19.00 & 0.13 & 19 \\
\hline CYC-30 & -0.11 & 2.00 & 19.00 & 0.10 & 150 \\
\hline CYC-31 & -0.11 & 2.00 & 40.00 & 0.15 & 72 \\
\hline CYC-32 & -0.11 & 2.00 & 40.00 & 0.17 & 23 \\
\hline CYC-33 & -0.11 & 2.00 & 40.00 & 0.21 & 4 \\
\hline CYC-34 & -0.11 & 2.00 & 65.00 & 0.25 & 38 \\
\hline CYC-35 & -0.11 & 2.00 & 65.00 & 0.31 & 20 \\
\hline CYC-36 & -0.11 & 2.00 & 65.00 & 0.41 & 8 \\
\hline CYC-37 & 0.00 & 1.00 & 19.00 & 0.10 & 64 \\
\hline CYC-38 & 0.00 & 1.00 & 19.00 & 0.12 & 18 \\
\hline CYC-39 & 0.00 & 1.00 & 19.00 & 0.15 & 4 \\
\hline CYC-40 & 0.00 & 1.00 & 40.00 & 0.15 & 34 \\
\hline CYC-41 & 0.00 & 1.00 & 40.00 & 0.16 & 23 \\
\hline CYC-42 & 0.00 & 1.00 & 40.00 & 0.21 & 2 \\
\hline CYC-43 & 0.00 & 1.00 & 65.00 & 0.23 & 86 \\
\hline CYC-44 & 0.00 & 1.00 & 65.00 & 0.25 & 41 \\
\hline CYC-45 & 0.00 & 1.00 & 65.00 & 0.29 & 18 \\
\hline CYC-46 & 0.00 & 1.00 & 65.00 & 0.33 & 13 \\
\hline CYC -47 & 0.00 & 1.25 & 19.00 & 0.15 & 6 \\
\hline
\end{tabular}




\begin{tabular}{|c|c|c|c|c|c|}
\hline Test No. & $\alpha$ & OCR & $D_{r c}(\%)$ & CSR & $\mathrm{N}$ \\
\hline CYC-48 & 0.00 & 1.25 & 19.00 & 0.13 & 17 \\
\hline CYC-49 & 0.00 & 1.25 & 19.00 & 0.11 & 91 \\
\hline CYC-50 & 0.00 & 1.25 & 40.00 & 0.17 & 26 \\
\hline CYC-51 & 0.00 & 1.25 & 40.00 & 0.19 & 19 \\
\hline CYC-52 & 0.00 & 1.25 & 40.00 & 0.21 & 5 \\
\hline CYC-53 & 0.00 & 1.25 & 65.00 & 0.32 & 15 \\
\hline CYC-54 & 0.00 & 1.25 & 65.00 & 0.30 & 25 \\
\hline CYC-55 & 0.00 & 1.25 & 65.00 & 0.35 & 8 \\
\hline CYC-56 & 0.00 & 1.50 & 19.00 & 0.17 & 5 \\
\hline CYC-57 & 0.00 & 1.50 & 19.00 & 0.15 & 22 \\
\hline CYC-58 & 0.00 & 1.50 & 19.00 & 0.14 & 53 \\
\hline CYC-59 & 0.00 & 1.50 & 40.00 & 0.25 & 4 \\
\hline CYC-60 & 0.00 & 1.50 & 40.00 & 0.21 & 16 \\
\hline CYC-61 & 0.00 & 1.50 & 40.00 & 0.19 & 37 \\
\hline CYC-62 & 0.00 & 1.50 & 65.00 & 0.33 & 21 \\
\hline CYC-63 & 0.00 & 1.50 & 65 & 0.37 & 13 \\
\hline CYC-64 & 0.00 & 1.50 & 65 & 0.40 & 10 \\
\hline CYC-65 & 0.00 & 2.00 & 19.00 & 0.19 & 2 \\
\hline CYC-66 & 0.00 & 2.00 & 19.00 & 0.17 & 11 \\
\hline CYC-67 & 0.00 & 2.00 & 19.00 & 0.15 & 22 \\
\hline CYC-68 & 0.00 & 2.00 & 19.00 & 0.15 & 22 \\
\hline CYC-69 & 0.00 & 2.00 & 40.00 & 0.27 & 6 \\
\hline CYC-70 & 0.00 & 2.00 & 40.00 & 0.25 & 9 \\
\hline CYC-71 & 0.00 & 2.00 & 40.00 & 0.21 & 29 \\
\hline
\end{tabular}




\begin{tabular}{|l|l|l|l|l|l|}
\hline Test No. & $\alpha$ & OCR & $D_{r c}(\%)$ & CSR & $\mathrm{N}$ \\
\hline CYC-72 & 0.00 & 2.00 & 65.00 & 0.44 & 10 \\
\hline CYC-73 & 0.11 & 1.00 & 19.00 & 0.18 & 4 \\
\hline CYC-74 & 0.11 & 1.00 & 19.00 & 0.15 & 15 \\
\hline CYC-75 & 0.11 & 1.00 & 19.00 & 0.12 & 45 \\
\hline CYC-76 & 0.20 & 1.00 & 19.00 & 0.17 & 10 \\
\hline CYC-77 & 0.20 & 1.00 & 40.00 & 0.27 & 5 \\
\hline CYC-78 & 0.20 & 1.00 & 40.00 & 0.24 & 11 \\
\hline CYC-79 & 0.20 & 1.00 & 40.00 & 0.21 & 50 \\
\hline CYC-80 & 0.20 & 1.00 & 65.00 & 0.50 & 9 \\
\hline CYC-81 & 0.20 & 1.00 & 65.00 & 0.45 & 12 \\
\hline CYC-82 & 0.20 & 1.00 & 65.00 & 0.40 & 14 \\
\hline CYC-83 & 0.20 & 1.25 & 19.00 & 0.20 & 7 \\
\hline CYC-84 & 0.20 & 1.25 & 19.00 & 0.17 & 14 \\
\hline CYC-85 & 0.20 & 1.25 & 19.00 & 0.14 & 35 \\
\hline CYC-86 & 0.20 & 1.25 & 40.00 & 0.30 & 2 \\
\hline CYC-87 & 0.20 & 1.25 & 40.00 & 0.25 & 13 \\
\hline CYC-88 & 0.20 & 1.25 & 40.00 & 0.20 & 64 \\
\hline CYC-89 & 0.20 & 1.25 & 65.00 & 0.35 & 49 \\
\hline CYC-90 & 0.20 & 1.25 & 65.00 & 0.45 & 14 \\
\hline CYC-91 & 0.20 & 1.25 & 65.00 & 0.51 & 10 \\
\hline CYC-92 & 0.20 & 1.50 & 19.00 & 0.25 & 3 \\
\hline CYC-93 & 0.20 & 1.50 & 19.00 & 0.20 & 15 \\
\hline CYC-94 & 0.20 & 1.50 & 19.00 & 0.17 & 23 \\
\hline CYC-95 & 0.20 & 1.50 & 40.00 & 0.30 & 8 \\
\hline
\end{tabular}




\begin{tabular}{|c|c|c|c|c|c|}
\hline Test No. & $\alpha$ & OCR & $D_{r c}(\%)$ & CSR & $\mathrm{N}$ \\
\hline CYC-96 & 0.20 & 1.50 & 40.00 & 0.25 & 18 \\
\hline CYC-97 & 0.20 & 1.50 & 40.00 & 0.23 & 22 \\
\hline CYC-98 & 0.20 & 1.50 & 65.00 & 0.51 & 28 \\
\hline CYC-99 & 0.20 & 1.50 & 65.00 & 0.54 & 12 \\
\hline CYC-100 & 0.20 & 1.50 & 65.00 & 0.56 & 7 \\
\hline CYC-101 & 0.20 & 2.00 & 19.00 & 0.25 & 5 \\
\hline CYC-102 & 0.20 & 2.00 & 19.00 & 0.22 & 13 \\
\hline CYC-103 & 0.20 & 2.00 & 19.00 & 0.20 & 21 \\
\hline CYC-104 & 0.20 & 2.00 & 40.00 & 0.32 & 7 \\
\hline CYC-105 & 0.20 & 2.00 & 40.00 & 0.30 & 11 \\
\hline CYC-106 & 0.20 & 2.00 & 40.00 & 0.27 & 18 \\
\hline CYC-107 & 0.20 & 2.00 & 65.00 & 0.29 & 485 \\
\hline CYC-108 & 0.20 & 2.00 & 65.00 & 0.58 & 10 \\
\hline CYC-109 & 0.20 & 2.00 & 65.00 & 0.60 & 4 \\
\hline
\end{tabular}

